\title{
Ciência e Tecnologia
}

\section{dos Alimentos}
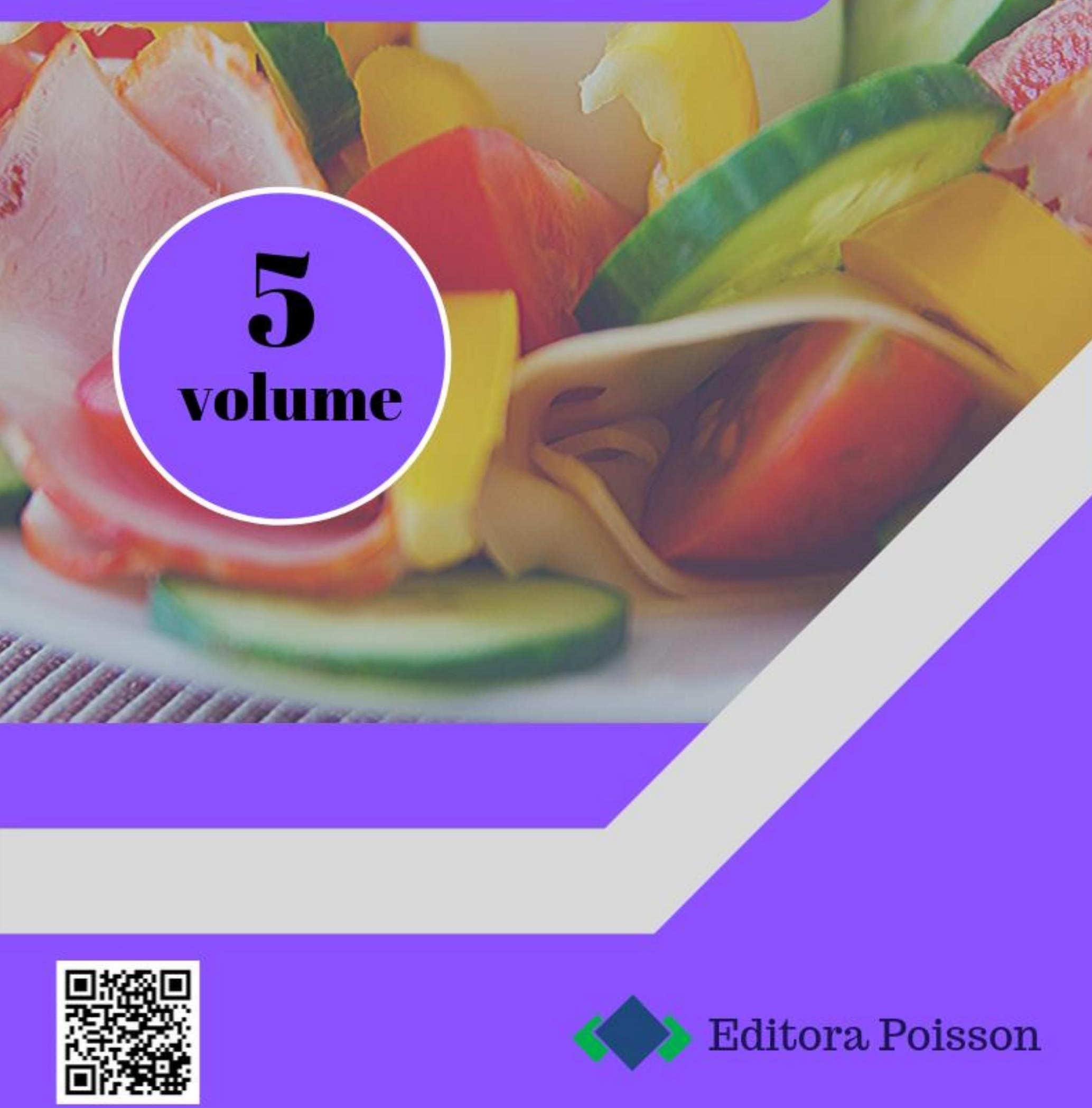

Editora Poisson 
Editora Poisson

\section{Ciência e Tecnologia dos Alimentos Volume 5}

1a Edição

Belo Horizonte

Poisson

2019 
Editor Chefe: Dr. Darly Fernando Andrade

\section{Conselho Editorial}

Dr. Antônio Artur de Souza - Universidade Federal de Minas Gerais Msc. Davilson Eduardo Andrade

Dra. Elizângela de Jesus Oliveira - Universidade Federal do Amazonas

Msc. Fabiane dos Santos

Dr. José Eduardo Ferreira Lopes - Universidade Federal de Uberlândia

Dr. Otaviano Francisco Neves - Pontifícia Universidade Católica de Minas Gerais

Dr. Luiz Cláudio de Lima - Universidade FUMEC

Dr. Nelson Ferreira Filho - Faculdades Kennedy

Msc. Valdiney Alves de Oliveira - Universidade Federal de Uberlândia

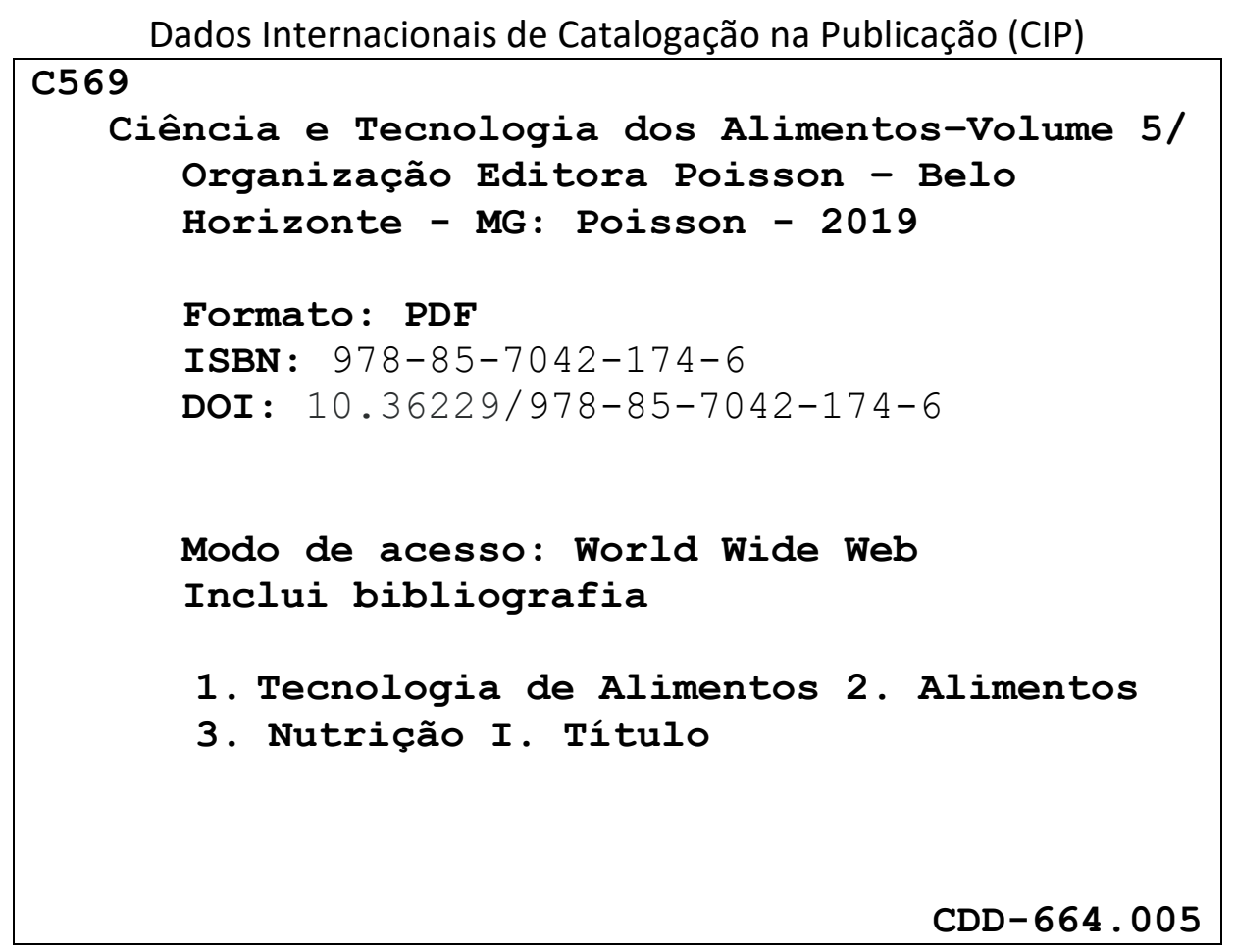

O conteúdo dos artigos e seus dados em sua forma correção e confiabilidade são de responsabilidade exclusiva dos seus respectivos autores.

www.poisson.com.br

contato@poisson.com.br 


\section{SUMÁRIO}

Capítulo 1: Tecnologia de processamento e qualidade microbiológica de patês elaborados com penacos.

Marina Corrêa da Costa Abreu, Geodriane Zatta Cassol, Tayza Ferreira Roseno, Jorge Antônio Ferreira de Lara, Edivaldo Sampaio de Almeida Filho, Luciana Kimie Savay-da-Silva

DOI: $10.36229 / 978-85-7042-174-6 . C A P .01$

Capítulo 2: Tecnologia de processamento e qualidade microbiológica de formatados elaborados com peixes de baixo valor comercial 16

Geodriane Zatta Cassol, Marina Corrêa da Costa Abreu, Joselaine de Souza Teixeira, Jorge Antônio Ferreira de Lara, Edivaldo Sampaio de Almeida Filho, Luciana Kimie Savay-da-Silva

DOI: $10.36229 / 978-85-7042-174-6 . C A P .02$

Capítulo 3: Avaliação higiênico-sanitária e nutricional de linguiça tipo frescal com adição de cerveja 26

Adna Quesia Costa de Oliveira, Dorival Pereira Borges da Costa, Cleytton Luiz Bezerra de Paula, Willian Pinheiro Soares, Danielli Matos Santiago

DOI: 10.36229/978-85-7042-174-6.CAP.03

Capítulo 4: Análise dos extratos brutos da Stryphnodendron adstringens (Barbatimão) e Poincianella pluviosa (Sibipiruna) quanto a ação antifúngica no fungo Botrytis cinerea

Ana Rita Zulim Leite, Amanda Correia Gardenal, Iasmim Pereira de Moraes, João Carlos Palazzo de Mello, Leila Larisa Medeiros Marques, Márcia Regina Ferreira Geraldo Perdoncini, Ana Carolina Guidi, Danielly Chierrito, Taísa Dalla Valle Rorig Ribeiro

DOI: $10.36229 / 978-85-7042-174-6 . C A P .04$

Capítulo 5: Utilização de biopolímeros comestíveis na conservação de feijão-caupi 37 Solange de Sousa, Gilmar Freire da Costa, Robson Rogério Pessoa Coelho

DOI: $10.36229 / 978-85-7042-174-6 . C A P .05$

Capítulo 6: Nanopartículas de ouro suportadas em filmes biopoliméricos eficientes na atividade antimicrobiana ...

Carla Weber Scheeren, Maicon Roldão Borges, Larissa Morgana Ferreira Scopel, Otávio Bugoni

DOI: $10.36229 / 978-85-7042-174-6 . C A P .06$

Capítulo 7: Avaliação da capacidade antioxidante de diferentes matrizes alimentares por voltametria* 


\section{SUMÁRIO}

Capítulo 8: High turbulence-assisted extraction of crude guarana seeds to recover polyphenols and alkaloids: A comparative study with conventional methods

Ádina Lima de Santana, Júlia Azevedo Zanini, Gabriela Alves Macedo

DOI: $10.36229 / 978-85-7042-174-6 . C A P .08$

Capítulo 9: Influência da luminosidade na conservação do Pinhão [Araucaria Angustifolia (Bertoloni) Otto kuntze]

Pérsia Barcellos Carrasco, Shanise Lisie Mello El Halal, Eliezer Avila Gandra, Carla Rosane Barboza Mendonça, Caroline Dellinghausen Borges

DOI: 10.36229/978-85-7042-174-6.CAP.09

Capítulo 10: Avaliação e caracterização de substâncias potencialmente tóxicas no chá de folha de cagaita pelo bioensaio da artemia salina e por espectrometria de massas com ionização electrospray

Rafael Resende Assis Silva, Amauri Geraldo de Souza, Júlio Onésio Ferreira Melo, Eric Marsalha Garcia, Hosane Aparecida Taroco

DOI: $10.36229 / 978-85-7042-174-6 . C A P .10$

Capítulo 11: Qualidade físico-química de néctares de caju comercializados na cidade de São Luís-MA. 83

Alexsandra Iarlen Cabral Cruz, Leidiana de Sousa Lima, Deydyane dos Santos Moreira, Nuberlene Ferreira Carvalho, Edna Maria Silva Santos, Valeria Sousa Mota, Rayanne Araújo Pessoa, Francisco José da Conceição Lima

DOI: 10.36229/978-85-7042-174-6.CAP.11

Capítulo 12: Análise da composição de pães industrializados dos tipos tradicional e light para comparação dos teores dos seus constituintes. 88

Ana Luiza Alves Faria, Paula André Borba, Roni Antonio Mendes, Maurielen Guterres Dalcin

DOI: 10.36229/978-85-7042-174-6.CAP.12

Capítulo 13: Teor de lactose em produtos destinados a alimentação infantil e estudo dos parâmetros estabelecidos pela nova legislação da ANVISA RDC 136/2017.

Alana de Almeida Oliveira, Suelen Pereira Ruiz Herrig, Juliana Scanavacca

DOI: 10.36229/978-85-7042-174-6.CAP.13

Capítulo 14: Elaboração de chocolate branco com adição de café 97

Jéssica Maria Ferreira de Almeida do Couto, Fabiana de Melo Caldereiro, Iolanda Cereza Zago, Gisele Cristina dos Santos Bazanella

DOI: 10.36229/978-85-7042-174-6.CAP.14 


\section{SUMÁRIO}

Capítulo 15: Elaboração de Cookies a base de quinoa e linhaça, para Celíacos. 102

Jordânia de Sousa Gomes, Karine Almeida Paula, Samuel de Oliveira Santos, Fábia Costa

DOI: 10.36229/978-85-7042-174-6.CAP.15

Capítulo 16: Produção de xarope de açúcar invertido por hidrólise ácida através do planejamento experimental

Camila Mika Sassai Sato, Pedro Bitencourt, Rita de Cássia Bergamasco, Gisele Cristina dos Santos Bazanella DoI: 10.36229/978-85-7042-174-6.CAP.16

Capítulo 17: Desenvolvimento de doce a base de arroz e feijão. 115

Bruna Demarchi, Liziane Dantas Lacerda

DOI: 10.36229/978-85-7042-174-6.CAP.17

Capítulo 18: Avaliação da rotulagem de bebidas não alcoólicas de uva comercializados em Imperatriz-MA.

Helen Costa Silva, Leonardo Hunaldo Santos, Andresa Sousa Carvalho, Victor Veríssimo Cardoso Lima, Lara Lima Seccádio, Vitória Virginia Soares Azevedo, Virlane Kelly Lima Hunaldo

DOI: 10.36229/978-85-7042-174-6.CAP.18

Capítulo 19: Sistemas de reuso do efluente proveniente do destilador do laboratório de engenharia de alimentos da Universidade Estadual de Maringá. 127

Danielle Cristine Silveira, Lais Cristina de Lima Silva, Gisele Cristina dos Santos Bazanella

DOI: $10.36229 / 978-85-7042-174-6 . C A P .19$

Capítulo 20: Composição química de sementes de Sorgo (Sorghum bicolor L. Moench)

Antonio Daniel Buriti de Macedo, Ana Paula Moises de Sousa, Aline Priscila de França Silva, Alison Silva Oliveira, Jaciara Dantas Costa, Ana Regina Nascimento Campos

DOI: 10.36229/978-85-7042-174-6.CAP.20

Capítulo 21: Tratamentos para superação da dormência em sementes de palmito Juçara

Bruno Vinicius Daquila, Marcia Regina Royer

DOI: 10.36229/978-85-7042-174-6.CAP.21

Autores: 


\section{Capítulo 1}

\section{Tecnologia de processamento e qualidade microbiológica de patês elaborados com penacos}

Marina Corrêa da Costa Abreu

Geodriane Zatta Cassol

Tayza Ferreira Roseno

Jorge Antônio Ferreira de Lara

Edivaldo Sampaio de Almeida Filho

Luciana Kimie Savay-da-Silva

Resumo: No Brasil, ainda há um baixo consumo de algumas espécies de pescado, mesmo que estas apresentem um elevado teor nutricional. Atualmente conhecidas como PENACOs (Peixes Não Convencionais) essas espécies têm conquistado espaço no mercado gourmet da alta gastronomia. Por isso, a elaboração de produtos de conveniência podem favorecer o consumo e agregar valor aos PENACOs, e um exemplo desse tipo de produto é o patê, que possui alto valor agregado e diversidade na forma de consumo. Entretanto, é importante que, além dos quesitos nutricionais e sensoriais, os produtos tenham excelente qualidade higiênica, garantindo a segurança do consumidor. 0 objetivo desse trabalho foi realizar uma avaliação e compilação de dados referentes a alguns trabalhos científicos, realizados em uma parceria entre a Empresa Brasileira de Pesquisa Agropecuária (Embrapa Pantanal) e a Universidade Federal de Mato Grosso (UFMT), que apresentaram resultados a respeito das condições microbiológicas de patês elaborados com duas espécies de PENACOs: curimbatá e barbado. Os patês foram produzidos artesanalmente, sendo posteriormente enviados ao Laboratório de Higiene e Tecnologia de Pescado da UFMT, campus Cuiabá, para realização das análises microbiológicas de: aeróbios mesófilos e psicrotróficos, coliformes à $35^{\circ} \mathrm{C}$ e $45^{\circ} \mathrm{C}$, Escherichia coli, Staphylococcus spp., Listéria spp., Shewanella spp., Aeromonas spp., fungos filamentosos e leveduras e Salmonella spp. De maneira geral, não houve contagens significativas para Escherichia coli, Staphylococcus spp., Listéria spp., Shewanella spp., Aeromonas spp., e Salmonella spp., quando comparado à literatura ou legislação vigente. Não foram encontradas contagens significativas para aeróbios psicrotróficos, coliformes a $35^{\circ} \mathrm{C}$ e a $45^{\circ} \mathrm{C}$ apenas para o patê de curimbatá. Contagens elevadas de mesófilos, porém dentro dos limites estabelecidos pela literatura, foram observadas para patês tanto de barbado como de curimbatá. Assim como contagens excessivas para fungos filamentosos e leveduras, todavia, estas estavam acima dos valores tolerados. Diante do exposto, é possível concluir que, principalmente os patês elaborados com a espécie barbado, encontravam-se em precárias condições higiênicas de produção e/ou armazenamento, provavelmente por falhas no que diz respeito as Boas Práticas de Fabricação desses produtos, assim como possíveis falhas higiênicas no processo de captura e manuseio dos animais.

Palavras-chave: patê de pescado, barbado, curimbatá, tecnologia de pescado, peixes não convencionais, qualidade higiênica 


\section{INTRODUÇÃO}

Desde a década de 60 , o aumento médio anual do consumo aparente mundial de pescado $(3,2 \%)$ tem sido maior que o crescimento da população $(1,6 \%)$ e superou o consumo médio de carne de todos os animais terrestres (2,8\%), assim como de cada classe separadamente (bovinos, ovinos, suínos e outros), exceto no que se refere ao consumo de carne de aves, cujo consumo médio foi de 4,9\% ao ano. Em termos per capita, o consumo de pescado aumentou de 9,0 Kg.hab ${ }^{-1}$.ano-1 em 1961 para 20,2 Kg.hab ${ }^{-1}$.ano ${ }^{-1}$ em 2015, a uma taxa média de aproximadamente $1,5 \%$ ao ano. 0 anos de 2016 e 2017 apontaram para um novo aumento, atingindo um consumo média per capita de 20,3 e 20,5 Kg.hab ${ }^{-1}$.ano-1 respectivamente, sendo previsto ainda que este consumo chegue a 21,5 Kg.hab ${ }^{-1}$.ano-1 em 2030 (FAO, 2018).

Dentre os benefícios já comprovados, verificam-se trabalhos na literatura que relatam a relação do consumo regular e permanente do pescado com a redução dos níveis de colesterol, de incidência de acidente vascular cerebral, doença cardíaca, obesidade e Alzheimer. Além disso, outros estudos também relatam efeitos significativos sobre os níveis de triglicerídeos no sangue, ajuda na manutenção da pressão sanguínea, na prevenção do câncer de mama, próstata e cólon e na redução da incidência de aterosclerose e, consequentemente, aumento na expectativa de vida. Estudos indicam ainda que o consumo de pescado pode aumentar a função cognitiva em adultos e impedir o nascimento de crianças com baixo peso e o parto pré-termo, assim como está associado a diminuição dos índices de depressão pós-parto (HIBBELN, 2002; SOUZA et al., 2003; BURGER, 2008; SARTORI; AMANCIO, 2012; TACON; METIAN, 2013).

Além disso, os consumidores têm apresentado mudanças em seus hábitos alimentares devido a maior atenção e importância a fatores como: facilidade, saúde, ética, variedade, custo, sustentabilidade e segurança. Nesse sentido o aumento do consumo de pescado se deve a globalização, a liberação do comércio entre os países, o despontamento de novos mercados e a um novo estilo de vida que preza pela saúde (FAO, 2016) e praticidade.

No geral, o músculo do pescado contém de 60 a $85 \%$ de umidade; aproximadamente $20 \%$ de proteína bruta, 1 a $2 \%$ de minerais e 0,6 a 36\% de lipídeos (OGAWA; MAIA, 1999). Sendo que a composição química da carne do pescado pode depender de muitas variáveis, entre as quais se destacam espécie, idade, estado fisiológico, época e região de captura. Em determinadas épocas, os peixes ficam mais magros e a carne apresenta conteúdo maior de água, enquanto conteúdo em proteínas e, sobretudo, em gordura é menor. Normalmente esse estado aparece após a desova, o que ocorre na primavera na maioria das espécies que vivem em águas temperadas ou árticas. Pode-se dizer, portanto, que, conforme as estações observam-se mudanças cíclicas na composição da carne da maioria, das espécies (ORDOÑEZ, 2005).

Destaca-se que, embora os benefícios do consumo de pescado sejam bem difundidos na população, muitas vezes essas vantagens ficam associadas apenas a algumas espécies específicas de peixes, geralmente aquelas com maior potencial comercial como, por exemplo, atum (Thunnus spp), salmão (Salmo salar), tilápia (Oreochromis niloticus) e merluza (Merluccius spp). Atualmente, entretanto, nota-se um maior destaque, principalmente na área da gastronomia gourmet, o uso de espécies de peixes de baixo valor comercial, ou peixes não convencionais, conhecidas como PENACOs,

Os PENACOs são espécies de baixo valor comercial e que geralmente não são muito utilizadas para consumo humano, seja pelo baixo rendimento de carne e alta quantidade de espinhas ou até mesmo pela rejeição do consumidor à primeira vista, devido a sua aparência ou mesmo por desconhecimento da espécie (LOPES, 2017)

Essas características podem também dificultar o processo de industrialização dessas espécies apenas na forma de filés. Sendo assim, uma alternativa seria a utilização dessas espécies para elaboração de produtos derivados, como por exemplo patês, que, além de apresentarem maior praticidade, versatilidade e conveniência de uso, também são produtos que podem apresentar boa aceitação entre consumidores.

Isso também já é recomendado por outros autores na literatura, os quais indicam que a forma ideal e mais vantajosa de utilização de várias espécies de baixo valor comercial seria através da carne mecanicamente separada, oferecendo um espaço promissor para o desenvolvimento de diversos produtos, como: fishburguer, nuggets, linguiças, salsichas, congelados e patês (NETO; GONÇALVES, 2011; AGH; JASOUR; NOORI, 2014).

No Brasil, o pescado de água doce é comercializado predominantemente in natura, fresco, eviscerado e muito pouco de forma processada. Entretanto, as perspectivas atuais apontam para um aumento na comercialização de pescado minimamente processado e industrializado, uma vez que atualmente a sociedade dispõe de pouco tempo para preparo de refeições e tem preferência por produtos de maior conveniência (VALENTI; PEREIRA, 2000; FERREIRA et al., 2002). 
Além disso, os peixes com baixa aceitação no mercado podem receber tratamento tecnológico de maneira a perder os constituintes desagradáveis de odor, sabor e textura, aumentando assim sua aceitabilidade e também vida de prateleira (FERREIRA et al., 2002). Dentre as várias tecnologias de fabricação, se destacam: congelamento, enlatamento, secagem, salga, defumação, fermentação, embutidos, formatados e patê (GONÇALVES, 2011).

Patê é um produto cozido com tradições gastronômicas importantes e com propriedades sensoriais bastante apreciadas. São conhecidas duas denominações para patês: patê cremoso e pastoso, sendo que o primeiro é produzido com parte da carne crua e outra cozida, enquanto que o segundo é processado com matéria prima cozida (MINOZZO, 2011).

Além disso, patês não são considerados emulsões, entretanto sua qualidade está associada a uma combinação de gordura, água e proteínas solúveis, as quais atuam como agentes emulsificantes. Para a confecção deste produto, é necessária a homogeneização dos ingredientes e posteriormente a massa pode ser embutida em envoltório natural ou artificial ou, ainda, ser acondicionada em frascos de vidros fechados hermeticamente, para posterior tratamento térmico (MACHADO, 2011).

Segundo o Regulamento de Inspeção Industrial de Produtos de Origem Animal (RIISPOA) em seu Artigo 343, patê ou pasta de pescado, seguido das especificações que couberem, é o produto industrializado obtido a partir do pescado transformado em pasta, com adição de ingredientes, submetido a processo tecnológico específico (BRASIL, 2017).

O Regulamento Técnico de Identidade e Qualidade geral de Patê preconiza as características físicoquímicas descritas na Tabela 1 para o produto destinado ao comércio nacional e/ou internacional (BRASIL, 2000):

Tabela 1: Características físico-químicas para patê destinado ao comércio nacional e/ou internacional.

\begin{tabular}{|c|c|}
\multicolumn{1}{|c|}{ Características } & $\begin{array}{c}\text { Valores em porcentagem } \\
(\%)\end{array}$ \\
\hline Amido* $^{*}$ & máximo de 10 \\
\hline Carboidratos totais* & máximo de 10 \\
\hline Umidade & máximo de 70 \\
\hline Gordura & máximo de 32 \\
\hline Proteína & mínimo de 8 \\
\hline
\end{tabular}

*A somatória de carboidratos totais máximos e amido máximo não deverá ser superior a 10\%.

Nesse sentido, o patê de pescado pode apresentar vantagens nutricionais e alternativas para o consumo de pescado. Além disso, esse alimento possui um alto valor agregado, podendo aumentar a renda do produtor, gerar empregos diretos e indiretos, sendo uma ótima alternativa para o incremento da produção nas indústrias, cooperativas e comunidade de pescadores (MINOZZO, 2011).

Todavia, não basta falar em praticidade e aceitabilidade, é preciso também garantir que o produto apresente segurança alimentar para o consumidor, principalmente no que se refere às contaminações microbiológicas.

Em se tratando disso, é preciso destacar que o pescado in natura é um alimento extremamente perecível, em razão de suas características naturais, como elevado $\mathrm{pH}$, altas concentrações de umidade e proteína e presença de ácidos graxos insaturados. Além disso, o pescado, como matéria prima, costuma ser submetido a condições inadequadas de manipulação e armazenamento, com destaque para sua exposição a temperaturas inadequadas, desde a etapa de captura até sua comercialização, o que contribui para a redução da sua vida de prateleira (SOARES, 1998).

Por isso, nas operações de processamento do pescado é importante saber que o grau de frescor é um parâmetro fundamental, uma vez que não se obtém um bom produto utilizando uma matéria prima de baixa qualidade (FERREIRA et al., 2002).

No que se refere a higiene e qualidade do patê, o Padrão de Identidade e Qualidade descrito na legislação brasileira vigente para esse produto estabelece as seguintes exigências (BRASIL, 2000):

1) 0 produto acima de $60 \%$ de umidade deve, obrigatoriamente, ser pasteurizado; 
2) 0 produto deverá ser embalado em materiais adequados para as condições de armazenamento e que lhe confiram uma proteção apropriada;

3) As práticas de higiene para a elaboração do produto estarão de acordo com o estabelecido no "Código Internacional Recomendado de Práticas de Higiene para os Produtos Cárneos Elaborados" (FAO/OMS, 1994);

4) O produto deve satisfazer os requisitos previstos na Portaria no 368, de 04/09/97 - Regulamento Técnico sobre as Condições Higiênico-Sanitárias e de Boas Práticas de Elaboração para Estabelecimentos Elaboradores/Industrializadores de Alimentos - Ministério da Agricultura, Pecuária e Abastecimento, Brasil (BRASIL, 1997);

5) 0 produto dever ter sido submetidos aos processos de inspeção prescritos no Regulamento de Inspeção Industrial e Sanitária de Produtos de Origem Animal;

6) As matérias primas e os produtos elaborados devem ser manipulados, armazenados e transportados em locais próprios de forma que não fiquem expostos à contaminação ou sofram adição de qualquer substância nociva para o consumo humano;

7) O produto não deverá conter materiais estranhos ao processo de industrialização;

8) Nos critérios microbiológicos, aplica-se a legislação vigente, ou seja, RDC no 12 de 02 de janeiro de 2001 (BRASIL, 2001).

Estas exigências e recomendações tem como principal objetivo a integridade do consumidor, de forma a evitar que o consumo de patês seja um possível veiculador de Doenças Transmitidas por Alimentos (DTAs).

Nesse contexto, o objetivo do presente estudo foi compilar informações sobre a forma de produção e qualidade microbiológica de patês elaborados com diferentes espécies de peixes não convencionais (PENACOs).

\section{MATERIAL E MÉTODOS}

Este trabalho trata-se de uma pesquisa qualitativa por meio de um compilado de resultados, parcialmente já publicados, de pesquisas realizadas pelos autores, através da parceria entre Universidade Federal de Mato Grosso (UFMT) e a Empresa Brasileira de Pesquisa Agropecuária (EMBRAPA).

Os patês foram elaborados por populações ribeirinhas, através do uso de peixes provenientes da pesca artesanal na região do Pantanal, rio Paraguai, em Corumbá-MS, com objetivo de incrementar a renda e agregar valor PENACOs, caracterizados como peixes de baixo valor comercial. As espécies utilizadas foram barbado (Pinirampus pirinampu) e curimbatá (Prochilodus lineatus). Na Tabela 2 consta a lista de ingredientes utilizados na elaboração dos patês e na Figura 1, o fluxograma de processamento deles:

Tabela 2. Ingredientes utilizados na formulação de patês elaborados com Peixes Não Convencionais (PENACOs) (valores em porcentagem ou grama por $100 \mathrm{~g}$ do produto).

\begin{tabular}{|l|c|}
\hline \multicolumn{1}{|c|}{ Ingredientes } & Porcentagem (\%) \\
\hline Carne de pescado triturada & 48,6 \\
\hline Proteína texturizada de soja & 1,5 \\
\hline Sal de cura & 0,15 \\
\hline Gordura vegetal hidrogenada & 5 \\
\hline Eritorbato de sódio - INS 316 & 0,2 \\
\hline Amido & 2 \\
\hline Gelo & 25 \\
\hline Cebola desidratada & 0,5 \\
\hline Salsa desidratada & 0,5 \\
\hline Orégano & 0,2 \\
\hline Cebola em pó & 0,3 \\
\hline Alho em pó & 0,2 \\
\hline Glutamato monossódico - INS 621 & 0,2 \\
\hline Cominho em pó & 0,2 \\
\hline Pimenta em pó & 0,2 \\
\hline Tripolifosfato de sódio - INS 451i & 2 \\
\hline
\end{tabular}

Fonte: CASSOL et al., 2015; CASSOL et al., 2016. 
Figura 1 - Fluxograma de processamento dos patês elaborados com Peixes Não Convencionais (PENACOs).

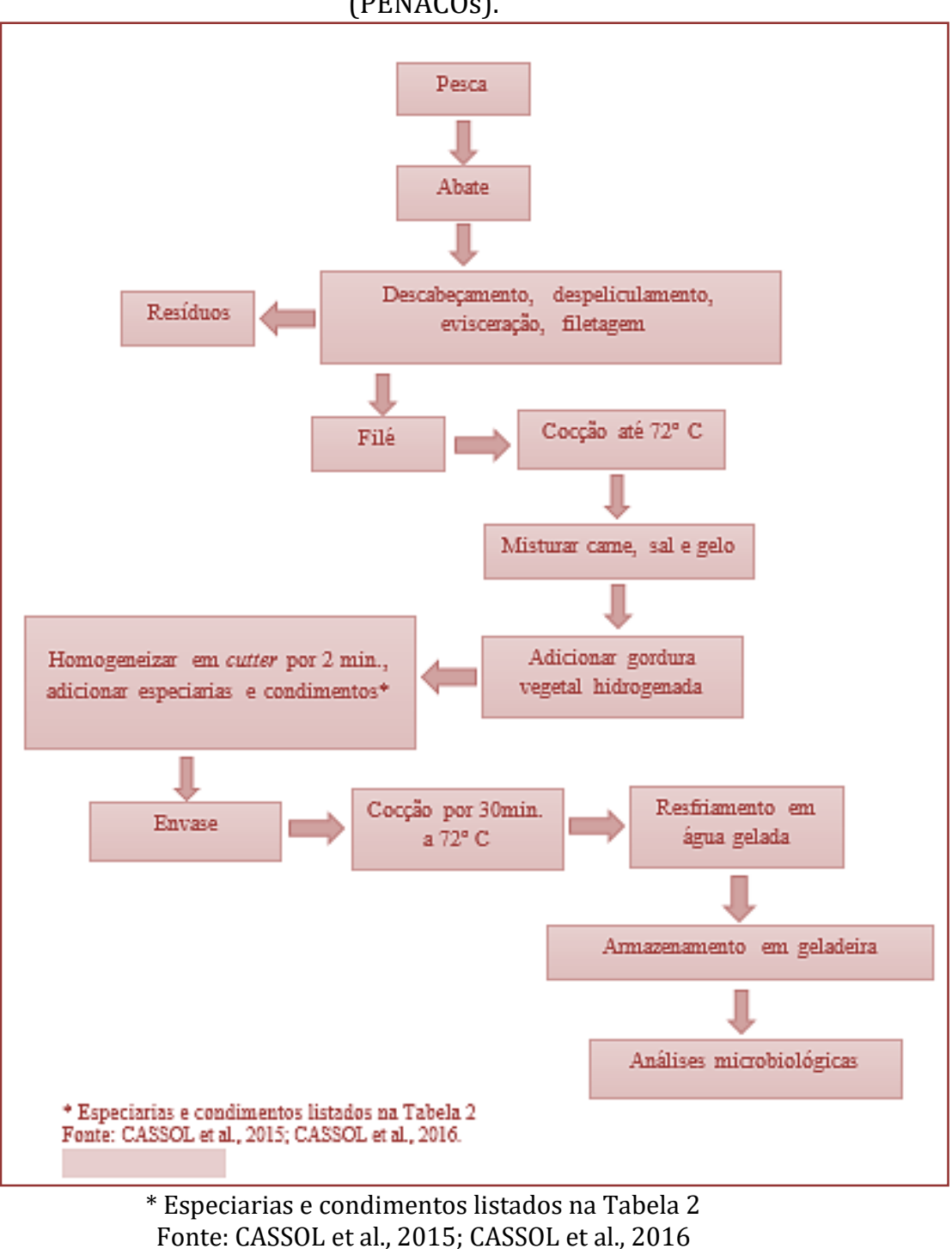

Após elaborados, três lotes desses produtos foram transportados (cerca de $3 \mathrm{Kg}$ de patê), em caixas de isopor com gelo, via transporte aéreo, até o Laboratório de Higiene e Tecnologia de Pescado da Universidade Federal de Mato Grosso, Cuiabá-MT. No laboratório, as amostras foram armazenadas sob refrigeração a $0^{0} \mathrm{C}$, até o momento de realização das análises.

Para todas as amostras foram realizadas análise de contagem total de micro-organismos aeróbios mesófilos, aeróbios psicrotróficos, coliformes à $35^{\circ} \mathrm{C}$ e $45^{\circ} \mathrm{C}$, Escherichia coli, Staphylococcus spp., Listéria spp., Shewanella spp., Aeromonas spp., fungos filamentosos e leveduras e testes de presença ou ausência para Salmonella spp. em $25 \mathrm{~g}$ de amostra. Todas as análises foram realizadas segundo Silva et al. (2010). Os resultados foram apresentados em forma de média dos três lotes avaliados.

Todo material obtido nas pesquisas foi analisado, resumido e discutido conforme a problemática e o tema central, com o propósito de um melhor embasamento teórico e compreensão acerca do assunto.

\section{RESULTADOS E DISCUSSÃO}

Observa-se que em várias etapas do fluxograma de produção dos patês (Figura 1) há a necessidade de implantação e monitoramento de Pontos Críticos de Controle (PCC), desde a captura do peixe até a estocagem do produto final, fato este preocupante quando se trata de elaboração do alimento por populações ribeirinhas, as quais, no geral, não possuem conhecimento técnico de Boas Práticas de Fabricação (BPF) e segurança alimentar. Isto pode ser comprovado com os resultados observados das 
análises microbiológicas realizadas, dispostos na Tabela 3, onde se observa elevada contaminação para alguns micro-organismos analisados.

Tabela 3 - Resultados microbiológicos observados em estudos realizados com patês elaborados com Peixes Não Convencionais (PENACOs).

\begin{tabular}{|c|c|c|c|}
\hline MICRO-ORGANISMO & $\begin{array}{l}\text { Barbado }(\text { Pininampus } \\
\text { pirinampu })^{*}\end{array}$ & $\begin{array}{l}\text { Curimbatá } \\
\text { (Prochilodus } \\
\text { lineatus)** }\end{array}$ & $\begin{array}{l}\text { Legislação } \\
\text { e Literatura }\end{array}$ \\
\hline Aeróbios Mesófilos (log UFC.g-1) & 5,45 & 6,47 & 7 a \\
\hline Aeróbios Psicrotróficos (log UFC.g-1) & 5,47 & $<3$ & $7 \mathrm{a}$ \\
\hline Coliformes à 35으 C (log NMP.g-1) & 4,04 & $<3$ & $3^{\mathrm{b}}$ \\
\hline Coliformes à 45으 $\mathrm{C}\left(\log \mathrm{NMP}^{\circ} \mathrm{g}^{-1}\right)$ & 4,04 & $<3$ & $3^{c}$ \\
\hline Escherichia coli (log NMP.g-1) & $<3$ & $<3$ & $3 \mathrm{~d}$ \\
\hline Staphylococcus spp. (log UFC.g-1) & $<1$ & $<1$ & $3^{c}$ \\
\hline Listeria spp. (log UFC.g-1) & $<3$ & $<3$ & $2^{\mathrm{e}}$ \\
\hline Shewanella spp. (log UFC.g-1) & $<3$ & $<3$ & $2^{\mathrm{f}}$ \\
\hline Aeromonas spp. $\left(\log\right.$ UFC.g-1 $\left.{ }^{-1}\right)$ & $<3$ & $<3$ & $2 g$ \\
\hline $\begin{array}{c}\text { Fungos filamentosos e leveduras (log UFC.g- } \\
1 \text { ) }\end{array}$ & 3,8 & 4 & $3^{\mathrm{h}}$ \\
\hline Salmonella spp. & ausente. $25 g^{-1}$ & ausente. $25 \mathrm{~g}^{-1}$ & $\begin{array}{l}\text { ausente. } 25 \\
\mathrm{~g}^{-1 \mathrm{c}}\end{array}$ \\
\hline
\end{tabular}

UFC= Unidades Formadoras de Colônia; NMP= Número Mais Provável; *CASSOL et al., 2016; **CASSOL et al., 2015; a ICMSF, 1986; b KOLAWOLE et al., 2011; c BRASIL, 2001; d MANDAL et al., 2009; e MELDRUM et al., 2010; f JORGENSEN; HUSS, 1989; g NEYTS et al., 2000; h RODRÍGUEZ et al., 2015.

Na Tabela 3, é possível observar que não houve contagens significativas para diversos micro-organismos analisados nas amostras de patês elaborados com PENACOs, como por exemplo para Staphylococcus spp., Salmonella spp., Shewanella spp., Aeromonas spp. e Listeria spp.

Na legislação brasileira atual, não há valores de referência com relação aos limites toleráveis de presença ou quantidade de micro-organismos para patês elaborados com pescado, todavia, a Resolução da Diretoria Colegiada (RDC) da Agência Nacional de Vigilância Sanitária (ANVISA) № 12 de 02 de janeiro de 2001 (BRASIL, 2001), em seu item referente a produtos à "base de pescado refrigerados ou congelados (hambúrgueres e similares)" prevê valores máximos toleráveis de $10^{3} \mathrm{UFC}_{\text {.g }}{ }^{-1}$ para Coliformes à $45^{\circ} \mathrm{C}$ e Staphylococcus coagulase positivo, e ausência de Salmonella spp. em $25 \mathrm{~g}$ de amostra analisada. Logo, os patês de PENACOs avaliados neste estudo estavam de acordo com o estabelecido na legislação brasileira vigente, exceto com relação as contagens apresentadas para coliformes à 45ํㅡ $\mathrm{C}$ para os patês da espécie barbado, que apresentaram uma média de contagem de 1 log acima do tolerável (Tabela 3). Ressalta-se que como não houve contagens significativas para o grupo Staphylococcus spp, infere-se que também não houve contagens para Staphylococcus coagulase positivo.

Mesmo não havendo legislações pertinentes aos demais micro-organismos analisados é importante que limites máximos sejam preconizados para se garantir uma segurança no consumo desses alimentos. Portanto, a literatura cita um limite máximo de 2 log UFC.g-1 para Listeria spp., Shewanella spp. e Aeromonas spp (JORGENSEN; HUSS, 1989; NEYTS et al., 2000; MELDRUM et al., 2010). Esses microorganismos são considerados importantes patógenos de origem alimentar (MELDRUM et al., 2010). Para Shewanella spp., a literatura alerta que em contagens a partir de 7 log UFC.g-1 ocorre produção de trimetilamina e detecção de off-flavor a partir de 8 log UFC.g-1 (JORGENSEN; HUSS, 1989). Já no acaso das Aeromonas spp., estudos indicam que contagens acima de 2 log UFC.g-1 podem indicar problemas de gastroenterite alimentar aos consumidores (NEYTS et al., 2000). No caso dos resultados apresentados na Tabela 3, verifica-se que todos apresentam-se em conformidade com esses padrões estabelecidos pela literatura.

Com relação as contagens verificadas para coliformes à 35으 $\mathrm{C}$, novamente observa-se que apenas as amostras de patês de barbado não apresentam-se de acordo com os limites máximos sugeridos pela literatura, que é de 3 log NMP.g-1 (KOLAWOLE et al., 2011). Valores acima deste podem indicar precariedade nas condições higiênico-sanitárias das etapas de processamento ou armazenamento da matéria prima ou produto final, sendo a higiene do manipulador um fator relevante para aumento dessas contagens. 
Embora tenha sido observada altas contagens para coliformes à $35^{\circ}$ e $45^{\circ} \mathrm{C}$ nas amostras de patês de barbado, em nenhuma das amostras analisadas foi observada contagens significativas para Escherichia coli, o que significa que provavelmente a alta contagem de coliformes termotolerantes não está ligada à contaminação de origem fecal.

Os resultados encontrados neste estudo (Tabela 3) podem ser comparados com os resultados de outros trabalhos feitos com patês de peixes de outras espécies. E conforme é possível observar na Tabela 4, o que se encontra na literatura são trabalhos que apresentaram melhores condições higiênicas e de segurança dos produtos avaliados (patês de tilápia e pescada-bicuda).

Tabela 4: Análises microbiológicas de patê de pescado

\begin{tabular}{|c|c|c|}
\hline Micro-organismo & $\begin{array}{c}\text { Tilápia } \\
{\text { (Oreochromis niloticus })^{1}}\end{array}$ & $\begin{array}{c}\text { Pescada-bicuda } \\
(\text { Sphyraena guachancho) }\end{array}$ \\
\hline Coliformes a $45^{\circ} \mathrm{C}\left(\log\right.$ NMP.g-1 $\left.{ }^{-1}\right)$ & $<3$ & $<3$ \\
\hline Estafilococos coagulase positiva (log UFC.g-1) & $<1$ & $<2$ \\
\hline Salmonella spp. & ausente.25g-1 & ausente.25g-1 \\
\hline
\end{tabular}

UFC= Unidades Formadoras de Colônia; NMP= Número Mais Provável; ${ }^{1}$ MINOZZO et al., 2008; ${ }^{2}$ ESTANECH (2018); *BRASIL, 2001

Além das questões de inocuidade do alimento, também foram realizadas algumas análises para avaliar as condições higiênicas gerais dos patês de barbado e curimbatá (Tabela 3). Com isso, foi possível observar que para os micro-organismos heterotróficos aeróbios mesófilos e psicrotróficos - os quais são os principais micro-organismos deteriorantes de pescado resfriado e seus produtos - as amostras apresentaram contagens elevadas, tanto para os patês de barbado como de curimbatá, com relação a mesófilos e para o patê de curimbatá no que se refere a contagem de psicrotróficos. Sendo esses valores próximos aos entendidos na literatura como máximos tolerados para consumo, que é de 7 log UFC.g-1 valores acima destes podem comprometer a qualidade microbiológica e sensorial do produto, além de diminuir a vida de prateleira dos alimentos (ICMSF, 1998).

Outros micro-organismos que são comumente relacionados à precariedade na higiene e grande variação de temperatura no local de manipulação e armazenamento são os fungos filamentosos e as leveduras. Esse perigo é eminente, uma vez que esses micro-organismos são capazes de produzir micotoxinas nos alimentos (NUNES et al., 2013). Dito isso, é possível observar a não conformidade nos valores obtidos para os patês de barbado e curimbatá, pois as amostras de ambos apresentaram resultados maiores que o sugerido pela literatura (3 log UFC.g-1) (RODRÍGUEZ et al., 2015).

Paradoxalmente a isso, apesar de não terem sido feitas análises de qualidade nutricional dos patês elaborados, encontram-se na literatura dados referentes a boa qualidade nutricional da carne das espécies utilizadas. Adames et al. (2014) afirmam que a composição centesimal da carne de peixes da espécie barbado sugere o seu potencial para emprego na fabricação de produtos elaborados de forma artesanal ou industrial, apesar de seu alto valor lipídico.

Nota-se que nos dias atuais, a população tem buscado cada vez mais consumir produtos nutritivos e ao mesmo tempo de conveniência, uma vez que a rotina está mais acelerada. Nesse sentido, o processamento do pescado vem ao encontro das exigências do consumidor. Todavia, é preciso zelar pela qualidade da matéria prima, assim como do produto final, uma vez que os consumidores exigem um alimento de qualidade sensorial e rápido preparo, mas também que seja seguro para seu consumo.

Nesse contexto, o processamento de patês elaborados com PENACO's apresenta-se de grande interesse para a população consumidora e também para os produtores deste tipo de alimento, já que traz um alimento sensorialmente agradável, de fácil preparo e também agrega valor a essas espécies, movimentando assim a economia de toda uma cadeia produtiva. No que tange a qualidade microbiológica observada nos trabalhos aqui relatados, entende-se que é necessário a promoção de cursos de capacitação à essa população ribeirinha, sobretudo a respeito de Boas Práticas de Fabricação, com foco em contaminações microbiológicas. 


\section{CONCLUSÃO}

Conclui-se que a elaboração de patês de PENACO'S pode ser uma ótima alternativa para agregar valor a essas espécies e ofertar aos consumidores produtos de conveniência com alta qualidade nutricional, podendo ainda, aumentar a renda de ribeirinhos que sobrevivem da pesca extrativa. Todavia, é preciso rigoroso controle higiênico durante a captura dos peixes, fabricação e armazenamento desse tipo de produto, para que o mesmo não se torne um risco à saúde dos consumidores. Sendo assim, observou-se que os patês elaborados com a espécie barbado foram os que apresentaram maiores teores de contaminação, provavelmente por não terem atendido a esses requisitos.

\section{REFERÊNCIAS}

[1] Adames, M. S., Krause, R. A., Damasceno, D. Z., Piana, P. A., de Oliveira, J. D. S., Bombardelli, R. A. Características morfométricas, rendimentos no processamento e composição centesimal da carne do barbado. Boletim do Instituto de Pesca, 40(2), 251-260.2018.

[2] Agh, N.; Jasour S.; Noori, F. Potential Development of Value-Added Fishery Products in Underutilized and Commercial Fish Species: Comparative Study of Lipid Quality Indicators. Journal of the American Oil Chemists' Society, v.91, n.7, p. 1171-1177, 2014.

[3] Brasil. Ministério da Agricultura, Pecuária e Abastecimento. Portaria no 368, de 4 de setembro de 1997. Regulamento técnico sobre as condições higiênico-sanitárias e de boaspráticas de elaboração para estabelecimentos elaboradores/industrializadores de alimentos. Disponível em:

<http://www.cidasc.sc.gov.br/inspecao/files/2012/08/Portaria-368.pdf>. Acesso em: 21 jul 2019.

[4] Brasil. Ministério da Agricultura. Departamento de Inspeção de Produtos de Origem Animal. Regulamento técnico de identidade e qualidade de patê. Disponível em:

<http://site.sindicarnessp.org.br/wp2/wpcontent/uploads/2016/11/PAT\%C3\%8A.pdf.> Acesso em: 21 jul. 2019

[5] Brasil. Ministério da Saúde. Anvisa. Resolução 7. - RDC no 12, de 02 de Janeiro de 2001. Padrão microbiológico para alimentos. Disponível em:

<http://portal.anvisa.gov.br/documents/33880/2568070/RDC_12_2001.pdf/15ffddf63767-4527-bfac-

$740 \mathrm{a} 0400829 \mathrm{~b}>$. Acesso em: 21 jul 2019.

[6] Brasil. Ministério da Agricultura, Pecuária e Abastecimento. Secretaria de Defesa Agropecuária. Decreto ${ }^{\circ}$ 9.013, de março de 2017. Regulamento da Inspeção Industrial e Sanitária de Produtos de Origem Animal. Diário Oficial da União, Brasília, DF, 30 mar. 2017. Disponível em:

<http://www.agricultura.gov.br/assuntos/inspecao/produtosanimal/empresario/arquivos/Perguntaserespostasriis poasei_21000.039574_2017_02.pdf>. Acesso em 21 jul 2019.

[7] Burger, J. Fishing, fish consumption, and awareness about warnings in a university community in central New Jersey in 2007, and comparisons with 2004. Environmental Research, v. 108(1), p. 107-116, 2008.

[8] Cassol, G. Z. ; Teixeira, J. S. ; Roseno, T. F. ; Savay-da-Silva, L. K. ; Lara, J. A. F. ; Almeida Filho, E. S. . Avaliação da qualidade microbiológica de patê de curimbatá (Prochilodus lineatus).XXV Congresso Brasileiro de Ciência e Tecnologia de Alimentos \& X CIGR Section IV International Technical Symposium. Anais eletrônicos. Gramado: Universidade Federal do Rio Grande do Sul , 2015. Disponível em: <http://www.ufrgs.br/sbctarseventos/xxvcbcta/anais/files/918.pdf>. Acesso em: 21 jul 2019.

[9] Cassol, G. Z. ; Roseno, T. F. ; Teixeira, J. S. ; Abreu, M. C. C. ; Savay-da-Silva, L. K. ; Lara, J. A. F. ; Almeida Filho, E. S. . Avaliação da Qualidade Microbiológica de Patê de Barbado (Pinirampus pinirampu). IV Workif. Anais de evento. Cuiabá: Instituto Federal de Mato Grosso,2016. Disponível em: <https://www.ifmtsvc.edu.br/workif/>. Acesso em: 21 jul 2019.

[10] Estanech, A.F.C. Desenvolvimento de patê da pescada bicuda (Sphyraena tome, Fowler, 1903) com propriedades funcionais para diversificação e agregação de valor. Dissertação de mestrado. Universidade Federal Rural do Rio de Janeiro. Programa de pós graduação em ciência e tecnologia de alimentos. 105f. Rio de Janeiro-RJ, 2018.

[11] Organización de las Naciones Unidas Para la Agricultura Y LA Alimentación- Fao. OMS Organización Mundial de la Salud Ginebra y Programa Conjunto Fao/OMS sobre Normas Alimentarias Roma Comisión del Codex Alimentarius. Codex alimentarius volumen 10: carne y productos cárnicos incluso los bouillons y consomés. 2a ed. Roma: FAO OMS, 1994. 241 p.

[12] Organização das Nações Unidas para Agricultura e Alimentação - FAO. The State of World Fisheries and Aquaculture: Contributing to food security and nutrition for all. Roma, 2016. 204p. Disponível em: <http://www.fao.org/3/a-i5555e.pdf>. Acesso em: 21 jul 2019 
[13] Organização das Nações Unidas para Agricultura e Alimentação - FAO. The State of World Fisheries and Aquaculture: meeting the sustainable development goals. Roma, 2018. Disponível em: <http://www.fao.org/3/i9540EN/i9540en.pdf>. Acesso em: 10 jun 2019.

[14] Ferreira, M. W., et al. Pescados processados: maior vida de prateleira e maior valor agregado. Universidade Federal de Lavras, Lavras-MG, 2002.

[15] Gonçalves, A.A. Tecnologia do pescado: ciência, tecnologia, inovação e legislação. São Paulo : Editora Atheneu, 2011.

[16] Hibbeln, Joseph R. Seafood consumption, the DHA content of mothers' milk and prevalence rates of postpartum depression: a cross-national, ecological analysis. Journal of affective disorders, v. 69, n. 1-3, p. 15-29, 2002.

[17] International Comission on Microbiological Specification for Foods (ICMSF), 1998. Pescados y productos derivados. In:___. Microorganismos de Los alimentos: ecología microbiana de los productos alimentarios. Zaragoza: Acribia. p. 121-166.

[18] Jorgensen, B. R.; Huss, H. H. Growth and activity of Shewanella putrefaciens isolated from spoiling fish. International Journal of Food Microbiology, 9: 51-62. 1989.

[19] Kolawole, O. M.; Ajayi, K. T.; Olayemi, A. B.; Okoh, A. I. Assessment of Water Quality in Asa River (Nigeria) and Its Indigenous Clarias gariepinus Fish. International Journal of Environmental Research and Public Health, 8: 4332$4352,2011$.

[20] Lopes, F. O mar está para Penacos. Site: Boa mesa, 2017. Disponível em: <http://atdigital.com.br/boamesa/2017/08/o-mar-esta-para-penacos/>. Acesso em: 24 jun 2019.

[21] Machado, T.M. Embutidos de pescado. In: Gonçalves, A.A. Tecnologia do pescado: ciência, tecnologia, inovação e legislação. São Paulo: Editora Atheneu, 2011. p.262-270.

[22] Mandal, S. C.; Hasan, M.; Rahman, M. S.; Manik, M. H.;Mahmud, Z. H.; Isla, S. Coliform Bacteria in Nile Tilapia, Oreochromis niloticus of Shrimp-Gher, Pond and Fish Market. World Journal of Fish and Marine Sciences 1 (3): 160 166, 2009.

[23] Meldrum, R. J.; Ellis, P. W.; Mannion, P. T.; Halstead, D.; Garside, J. Prevalence of Listeria monocytogenes in Ready-to-Eat Foods Sampled from the Point of Sale in Wales, United Kingdom. Journal of Food Protection, 73 (8): $1515-1518,2010$

[24] Minozzo, M. G.; Waszczynskyj, N.; Boscolo, W. R.; Utilização de carne mecanicamente separada de tilápia (Oreochromis niloticus) para a produção de patês cremoso e pastoso. Revista Cientifica Alimentos e Nutrição, v.19, n.3, p. 315-319, 2008.

[25] Neto, A. D. L.; Gonçalves, A. A. Formatados e reestruturados (hambúrguer, nuggets etc.) In: Gonçalves, A. A. Tecnologia do Pescado: Ciência, Tecnologia, Inovação e Legislação. São Paulo: Atheneu, cap.2, p.235-245. 2011.

[26] Neyts,K.; Huys, G.;Uyttendaele, M.; Swings,J.; Debevere,J. Incidence and identification of mesophilic Aeromonas spp. from retail foods. Letters in Applied Microbiology, 31: 359-363, 2000.

[27] Nunes, E. S. C. L.; Bittencourt, R. H. F. P. M.; Silva, M. C.; Mársico, E. T.; Franco, R. M. Avaliação da qualidade do camarão salgado seco (aviú) e da farinha de peixe (piracuí) comercializados em mercados varejistas da cidade de Belém, Pará. Revista Instituto Adolfo Lutz.72(2):147-54. 2013.

[28] Ogawa, M.; Maia, E. l. Manual de pesca: ciência e tecnologia do pescado. São Paulo: Varela, 1999. V.1, 430p.

[29] Ordonez, J.A, Tecnologia de alimentos: alimentos de origem animal. Porto Alegre: Artmed, 2005. vol.02. cap. 11. p. 219-229.

[30] Rodríguez, A.; Rodríguez, M.; Andrade, M. J.; Córdoba, J. J. Detection of filamentous fungi in foods. Current Opinion in Food Science, 5: 36-42. 2015.

[31] Silva, N.; Junqueira, V. F. A. S; Silveira, N. F. A.; Taniwaki, M. H.; Santos, R. F. S.; Gomes, R. A. R.; Okazaki, M. M. Manual De Métodos de Análise Microbiológica De Alimentos. Varela, 3ํㅡㄹ edição, São Paulo. 2010.

[32] Sartori, A. G. O.; Amancio, R. D. Pescado: importância nutricional e consumo no Brasil. Segurança alimentar e nutricional, v. 19, n. 2, p. 83-93, 2012.

[33] Soares, F. M. V et al. Teores de histamina e qualidade físico-química sensorial de filé de peixe congelado. Ciência e Tecnologia Alimentar. v. 18, n. 4, p.462-470, 1998.

[34] Souza, P.H.M.; Souza Neto, M.H.; Maia, G.A. Componentes funcionais nos alimentos. Boletim da Sociedade Brasileira de Ciência e Tecnologia de Alimentos, 37(2):127-135. 2003.

[35] Tacon, A.G.J.; Metian, M. Fish matters: importance of aquatic foods in human nutrition and global food suply. Reviews in fisheries Science. v 21 (1). p. 22-38, 2013. 


\title{
Capítulo 2
}

\section{Tecnologia de processamento e qualidade microbiológica de formatados elaborados com peixes de baixo valor comercial}

\author{
Geodriane Zatta Cassol \\ Marina Corrêa da Costa Abreu \\ Joselaine de Souza Teixeira \\ Jorge Antônio Ferreira de Lara \\ Edivaldo Sampaio de Almeida Filho \\ Luciana Kimie Savay-da-Silva
}

Resumo: 0 pescado é um alimento rico em nutrientes que oferecem diferentes ações benéficas ao organismo humano. Entretanto, no Brasil, seu consumo ainda é baixo sendo fatores como preço elevado, má qualidade dos produtos disponíveis e falta de diversidade e praticidade as principais justificativas para isso. Sendo assim, a elaboração de produtos de conveniência, a base de pescado, pode favorecer o aumento desse consumo e agregar valor à espécies de baixo valor comercial. 0 formatado de pescado, tipo quibe, é um produto que pode ser consumido após cocção ou até mesmo cru, sendo esse tipo de preparação, aliada à excessiva manipulação do pescado durante todo sua elaboração, um fator que pode contribuir para o desenvolvimento de micro-organismos indesejáveis, podendo acarretar em problemas de saúde pública. 0 objetivo desse trabalho foi realizar uma avaliação e compilação de dados referentes a trabalhos científicos, que apresentaram resultados a respeito das condições microbiológicas de quibes elaborados com espécies de peixe de baixo valor comercial. Os animais foram obtidos através da pesca extrativa no rio Paraguai, em Corumbá-MS, e os quibes foram produzidos de maneira artesanal, sendo posteriormente enviados a UFMT, onde permaneceram armazenados por 8 meses até a realização das análises. Foram realizadas análises para contagens totais de aeróbios mesófilos e psicrotróficos, coliformes a $35^{\circ} \mathrm{C}$ e $45^{\circ} \mathrm{C}$, Escherichia coli, Staphylococcus spp., Listéria spp., Shewanella spp., Aeromonas spp., fungos filamentosos e leveduras e presença de Salmonella spp. De maneira geral, não houve contagens representativas para Listeria spp., Shewanella spp., Aeromonas spp., Staphylococcus spp. e Salmonella spp., quando comparado à literatura ou legislação vigente. Apenas os quibes de peixe das espécies palmito e piavuçu não apresentaram contagens para fungos filamentosos e leveduras, porém obteve altas contagens para os elaborados com as espécies barbado e curimbatá. Altas contagens também foram verificadas, para todas as amostras, com relação a contagens de aeróbios mesófilos e psicrotróficos, coliformes a $35^{\circ} \mathrm{C}$ e a $45^{\circ} \mathrm{C}$, além de Escherichia coli, quando comparados à literatura ou legislação. Dessa maneira, é possível concluir que as amostras avaliadas apresentaram altas contagens de microorganismos deteriorantes e patogênicos, e que isso deve-se a falta de condições higiênico-sanitárias adequadas dos manipuladores, utensílios e da forma de armazenamento dos formatados. Portanto, sugere-se a melhoria nas boas práticas higiênicas desde a captura, manipulações, processamento e armazenamento, de forma que se possa garantir a elaboração de alimentos seguros ao consumidor.

Palavras-Chave: tecnologia de pescado, quibe, contaminação microbiológica, curimbatá, palmito, piavuçu, barbado 


\section{INTRODUÇÃO}

0 pescado encontra-se entre os primeiros alimentos consumidos pelo homem, sendo a proteína de origem animal mais consumida em muitos países, como por exemplo os do continente asiático, que juntos consumiram cerca de 106 milhões de toneladas de pescado (24 Kg.hab $\left.{ }^{-1} \cdot \mathrm{ano}^{-1}\right)$ no ano de 2016 (FAO, 2018).

Além de saborosa, a carne de pescado é muito nutritiva, possui elevados teores de proteínas de alto valor biológico e quantidades significativas de aminoácidos essenciais, como por exemplo a metionina e a lisina; vitaminas lipossolúveis $A$ e $D$, além das hidrossolúveis $B_{1}, B_{2}$ e $B_{12}$; minerais como sódio, potássio, fósforo, cálcio, selênio, magnésio, zinco e ferro; e ácidos graxos insaturados da família ômega 3 (DEAN, 1990; OGAWA, 1999; TACON; METIAN, 2013; FAO, 2016).

Devido ao seu alto valor nutricional, o consumo de pescado frequentemente tem sido associado a melhora na qualidade de vida e aumento da longevidade. Esses fatores estão intrinsicamente relacionados ao alto teor de EPA (ácido eicosapentaenoico) e DHA (ácido docosahexaenoico) presente na maioria das espécies de pescado (TACON; METIAN, 2013).

Estudos indicam que o consumo regular e permanente dessa matéria prima pode contribuir na prevenção de depressão pós parto (HIBBELN, 2002); reduzir a mortalidade por doenças coronarianas na população adulta (RUXTON, 2011; FAO, 2018), pois possui característica anti-inflamatória e antiaterogênica (BOUWENS et al., 2009); melhorar o desenvolvimento neurológico de fetos e bebês (FAO, 2018); beneficiar a função imunológica, cognitiva, saúde mental e saúde metabólica (RUXTON, 2011); e prevenir a sarcopenia em idosos (SMITH et al., 2015).

Todavia, embora o pescado apresente muitos pontos positivos em relação aos benefícios associados ao seu consumo, é também um dos alimentos mais suscetíveis à deterioração, justamente devido ao fato de possuir grande quantidade de nutrientes, principalmente proteína; além de ter um $\mathrm{pH}$ próximo à neutralidade e alto teor de umidade, o que facilita a atuação e crescimento de micro-organismos (GAVA, 2008).

Por isso, o pescado é uma matéria prima que requer inúmeros cuidados, desde o momento da sua captura até sua comercialização, sendo a cadeia do frio essencial em todas as etapas para manter sua qualidade microbiológica, físico-química e sensorial.

No Brasil, grande parte do pescado comercializado ainda é ofertado na forma in natura, inteiro ou inteiro e eviscerado, existindo poucos produtos de conveniência disponíveis no mercado, o que não estimula o seu consumo por certos grupos de consumidores.

Levando-se em consideração que o Brasil está entre os países da América Latina e Caribe, ele é classificado como um país de baixo consumo per capita de pescado, sendo registrado um consumo médio de cerca de 9,5 Kg.hab ${ }^{-1} \cdot$ ano $^{-1}$ (PERSPECTIVAS DE LA AGRICULTURA..., 2017), enquanto a média per capita anual mundial atinge valores de 20,2 Kg.hab ${ }^{-1} \cdot$ ano $^{-1}$ (FAO, 2018).

0 baixo consumo de pescado pelos brasileiros pode ser justificado pela má qualidade dos produtos disponíveis atualmente no mercado (BOMBARDELLI et al, 2005; FIGUEIRO et al., 2014; MACIEL et al., 2015; ARBEX et al., 2017); pouca diversidade, falta de conveniência e pouca praticidade oferecida pelos produtos comercializados (BOMBARDELLI et al, 2005; MACIEL et al., 2015;LOPES et al., 2016; RIBEIRO et al., 2018); elevado preço (FIGUEIRO et al., 2014; VITAL DE JESUS et al., 2014; MACIEL et al., 2015; SANTOS et al., 2015; LOPES et al., 2016; ARBEX et al., 2017) e indisponibilidade nos locais de compra (MACIEL et al, 2013; ARBEX et al., 2017).

Portanto, acredita-se que o desenvolvimento de produtos de pescado mais elaborados, de fácil preparo ou prontos para consumo, pode favorecer o aumento do consumo dessa matéria prima e agregar valor a espécies consideradas de baixo valor comercial, que são aquelas espécies que possuem valor de mercado abaixo do usual.

Dentre os possíveis produtos de conveniência a base de pescado que têm potencial para serem produzidos industrialmente destacam-se fishburguer (CAMPOS et al., 2019), nuggets (SILVA et al., 2015b), formatados (tipo quibes) (TEIXEIRA et al., 2015), patês (CASSOL et al., 2015), fiambre (PATRIARCA et al., 2015), salsicha (GONÇALVES et al., 2009), linguiça (SOUSA et al., 2016), entre outros.

Na literatura é possível observar trabalhos que testaram, com êxito, formulações para desenvolvimento desses tipos de produtos (Tabela 1). Além disso, esses trabalhos demonstram ser possível utilizar espécies de baixo valor comercial ou resíduos do processo de filetagem na elaboração desses produtos, sendo essa 
uma forma ideal para agregação de valor a essas espécies e esses resíduos, assim como diminuir a geração de descartes nas indústrias de beneficiamento de pescado e otimizar os lucros da empresa.

Tabela 1. Produtos de pescado elaborados com resíduos ou espécies de baixo valor comercial

\begin{tabular}{|l|l|l|l|}
\multicolumn{1}{|c|}{ Produto } & \multicolumn{1}{c|}{ Parte utilizada } & \multicolumn{1}{c|}{ Referência } \\
Fishburguer & $\begin{array}{l}\text { Tambatinga } \\
\text { (Colossoma macropomum X } \\
\text { Piaractus brachypomum) }\end{array}$ & aparas (espinhaço) & $\begin{array}{l}\text { CAMPOS et al. } \\
(2019)\end{array}$ \\
\hline Nuggets & $\begin{array}{l}\text { Surubim (Pseudoplatystoma } \\
\text { corruscans) }\end{array}$ & $\begin{array}{l}\text { resíduos do } \\
\text { processamento de postas }\end{array}$ & SILVA et al. (2015) \\
\hline Quibe & $\begin{array}{l}\text { Palmito } \\
\text { (Ageneiosus valenciennesi) }\end{array}$ & peixe inteiro & $\begin{array}{l}\text { TEIXEIRA et al. } \\
(2015)\end{array}$ \\
\hline Patê & $\begin{array}{l}\text { Curimbatá } \\
\text { (Prochilodus lineatus) })\end{array}$ & peixe inteiro & CASSOL et al. (2015) \\
\hline Salsicha & $\begin{array}{l}\text { Piramutaba (Brachyplatystoma } \\
\text { vaillantii) }\end{array}$ & descartes da filetagem & $\begin{array}{l}\text { GONÇALVES et al. } \\
(2009)\end{array}$ \\
\hline Linguiça & $\begin{array}{l}\text { Barbado } \\
\text { (Pinirampus pirinampu })\end{array}$ & peixe inteiro & $\begin{array}{l}\text { BARBOSA et al. } \\
(2015)\end{array}$ \\
\hline
\end{tabular}

Segundo a Instrução Normativa № 20 de 31 de julho de 2000 do Ministério da Agricultura, Pecuária e Abastecimento (MAPA) - Anexo V, que estabelece o Regulamento Técnico de Identidade e Qualidade de Quibe (BRASIL, 2000) e o Artigo 296 do Regulamento de Inspeção Industrial e Sanitária de Produtos de Origem Animal (RIISPOA) (BRASIL, 2017), quibe é o produto cárneo obtido de carne bovina ou ovina, moldado e acrescido de trigo integral e outros ingredientes. Entretanto, é possível a utilização de carnes de outras espécies animais desde que seja declarado no rótulo. Outras especificações para esse produto podem ser observadas na Tabela 2.

Tabela 2. Principais requisitos para a elaboração de quibe, segundo o Regulamento Técnico de Identidade e Qualidade de Quibe (BRASIL, 2000)

\begin{tabular}{|l|l|}
\multicolumn{1}{c|}{ Regulamento técnico } & \multicolumn{2}{c|}{ Requisitos } \\
\hline Classificação & Quibe, acrescido ou não de recheio \\
\hline Designação & Carne, trigo integral e água \\
\hline Composição obrigatória & $\begin{array}{l}\text { sal, gordura vegetal e/ou animal, proteínas de origem animal e/ou vegetal, } \\
\text { recheios, condimentos, aromas e especiarias, aditivos intencionais }\end{array}$ \\
\hline Composição opcional & 4,0 (máx.) \\
\hline Nível proteico não cárneo (\%) & 11 (mín.) \\
\hline Proteína (\%) & 0,1 (máximo em base seca) \\
\hline Cálcio (\%) &
\end{tabular}

Além disso, segundo Lustosa Neto e Gonçalves (2011), o quibe de pescado também pode ser chamado de formatado (formado), devido ao seu formato (em forma oval). Isto se deve ao fato de sua produção ser realizada a partir do uso de equipamentos que utilizam placas com diferentes formatos geométricos (form plates).

Quanto à forma de consumo, preparações culinárias como o quibe podem ser consumidas após cocção, mas também sem qualquer processo térmico capaz de destruir possíveis micro-organismos patogênicos presentes nesse tipo de produto. Além disso, para elaboração do quibe de pescado, geralmente os ingredientes são submetidos a uma excessiva manipulação desde a captura até a elaboração do produto final, podendo assim apresentar grandes riscos em relação à sua qualidade microbiológica.

A presença de micro-organismos em alimentos indica deficiência em algumas etapas do processamento do mesmo, indo desde a recepção, produção, armazenamento ou distribuição (FRANCO; LANDGRAF, 2008), de maneira que possa comprometer seriamente a qualidade do produto, além de causar sérios danos à saúde do consumidor.

Há ainda outros fatores que colaboram para a ocorrência deste tipo de contaminação, como o uso de ingredientes crus (VIEGAS, 2009), água contaminada (VOLKWEIS et al., 2015), refrigeração ou armazenamento inadequado, alimentos insuficientemente cozidos, contaminação cruzada de alimentos crus e cozidos (VIEGAS, 2009), deficiência no processo de sanitização dos equipamentos e utensílios utilizados durante o processamento (SOUZA et al., 2013), além da incorreta higienização por parte dos 
manipuladores (FRANCO; LANDGRAF, 2008; PONATH et al., 2016) e instalações (VIEGAS, 2009; SILVA et al., 2015a).

No Brasil, segundo a RDC № 12 de 02 de janeiro de 2001 da Agência Nacional de Vigilância Sanitária (ANVISA) (BRASIL, 2001), os "pratos prontos para o consumo", dentre eles produtos à base de carnes, pescado e similares (quibe cru, carpaccio, sushi, sashimi, etc.), possuem limites toleráveis para consumo com relação a contagem de coliformes a $45^{\circ} \mathrm{C}$ de $2 \log$ NMP.g-1; Staphylococcus coagulase positivo de $3 \log$ UFC. ${ }^{-1}$ ); Vibrio parahaemolyticus contagens $<3$ log UFC.g ${ }^{-1}$; e ausência em $25 \mathrm{~g}$ de amostra para análises de Salmonella spp. Entretanto, outros micro-organismos também podem ser encontrados nesses produtos, como por exemplo mesófilos, psicrotróficos (ROSENO et al., 2015; TEIXEIRA et al., 2015; CASSOL et al., 2016a; CASSOL et al., 2016b), psicrófilos (BAYGAR et al., 2008), coliformes a 35ํㅡ, Escherichia coli, fungos filamentosos e leveduras (ROSENO et al., 2015; TEIXEIRA et al., 2015; CASSOL et al., 2016a; CASSOL et al., 2016b)

Dessa forma, é importante ter conhecimento das características microbiológicas das matérias primas utilizadas na elaboração de formatados de pescado, tanto no que se refere à qualidade da carne de peixe como dos demais ingredientes. Isso, aliado a Boas Práticas de Fabricação e controle de temperatura, são itens essenciais para se evitar a distribuição de produtos contaminados que possam colocar em risco a saúde dos consumidores.

Por isso, o objetivo desse trabalho foi realizar uma avaliação e compilação de dados referentes a alguns trabalhos científicos que apresentaram resultados a respeito das condições microbiológicas de formatados de pescado, tipo quibe, elaborados com espécies de peixe de baixo valor comercial.

\section{MATERIAL E MÉTODOS}

Este trabalho foi elaborado através de uma compilação de dados (Tabela 3), parcialmente já publicados em resumos de congressos, de trabalhos realizados em uma parceria entre a Empresa Brasileira de Pesquisa Agropecuária (Embrapa Pantanal) e a Universidade Federal de Mato Grosso (UFMT).

Os dados referem-se às análises microbiológicas realizadas para formatados de pescado, tipo quibe, elaborados com diferentes espécies de pescado de baixo valor comercial. Para elaboração dos formatados foram utilizadas as espécies curimbatá (Prochilodus lineatus), piavuçu (Leporinus macrocephalus), barbado (Pirinampus pirinampu) e palmito (Ageneiosus valenciennesi). Os animais foram obtidos através da pesca extrativa no rio Paraguai, em Corumbá-MS, e os quibes foram produzidos artesanalmente, conforme fluxograma exposto na Figura 1, por mulheres de comunidade ribeirinha. A formulação utilizada para elaboração dos quibes consistiu de $1200 \mathrm{~g}$ de pescado, $500 \mathrm{~g}$ de farinha de quibe, 1 cebola média picada, suco de 1 limão, 1 colher de sopa de óleo vegetal, $30 \mathrm{~g}$ de sal de cozinha e hortelã e cheiro verde a gosto.

Figura 1. Fluxograma de produção de quibe, elaborado de forma artesanal

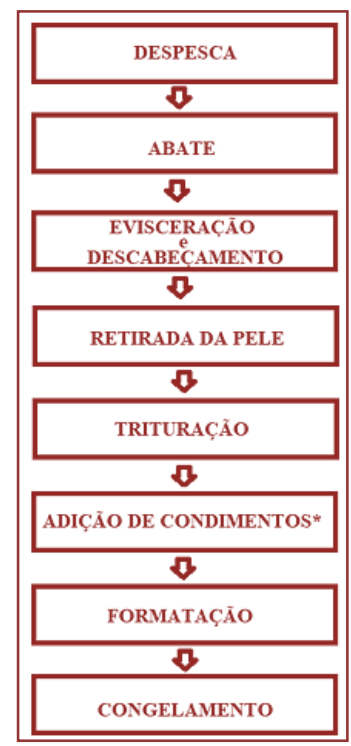

Fonte: (ROSENO et al., 2015; TEIXEIRA et al., 2015; CASSOL et al., 2016a; CASSOL et al., 2016b) 
Após o processo de congelamento, cerca de $3 \mathrm{Kg}$ de quibes foram encaminhados via transporte aéreo até o Laboratório de Higiene e Tecnologia de Pescado da Universidade Federal de Mato Grosso, Cuiabá-MT, sendo essa quantidade dividida em dois lotes, que foram armazenados sob congelamento em freezer a $18^{\circ} \mathrm{C}$, por um período de cerca de oito meses, quando então foram descongelados para a realização de análises microbiológicas.

Para todas as amostras foram realizadas análise de contagem total de micro-organismos aeróbios mesófilos, aeróbios psicrotróficos, coliformes a $35^{\circ} \mathrm{C}$ e $45^{\circ} \mathrm{C}$, Escherichia coli, Staphylococcus spp., Listéria spp., Shewanella spp., Aeromonas spp., fungos filamentosos e leveduras e testes de presença ou ausência para Salmonella spp. em $25 \mathrm{~g}$ de amostra. Todas as análises foram realizadas segundo Silva et al. (2010). Os resultados foram apresentados em forma de média dos dois lotes avaliados.

\section{RESULTADOS E DISCUSSÃO}

Observa-se, na Tabela 3, que em todas as amostras houve ausência de Salmonella spp. em 25g de amostra analisada, além de valores satisfatórios para Staphylococcus spp., Listeria spp., Shewanella spp e Aeromonas spp., uma vez que não houve contagem desses micro-organismos nas amostras e diluições avaliadas.

Quando comparado à legislação vigente (BRASIL, 2001), é possível observar que todas as amostras analisadas (Tabela 3) apresentaram resultados coerentes aos limites máximos tolerados pela mesma com relação à pesquisa de Salmonella spp. (ausência em 25g) e contagem de Staphylococcus coagulase positivo, uma vez que não houve contagem significativa para o grupo Staphylococcus spp. Entretanto, para

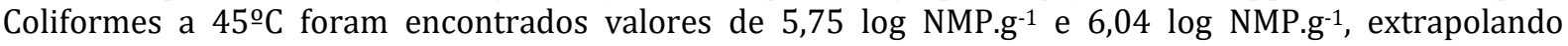
praticamente três vezes o limite máximo tolerado pela legislação, que é de 2 log NMP.g-1.

0 grupo dos Coliformes a $45^{\circ} \mathrm{C}$, é um grupo de micro-organismos comumente relacionado às práticas inadequadas de higiene do manipulador (SANTOS et al., 2014; SILVA-JÚNIOR et al., 2015), uma vez que são bactérias pertencente ao grupo de coliformes termotolerantes (FRANCO; LANDGRAF, 2008; SANTOS et al., 2014; PINHEIRO et al., 2015; SILVA-JÚNIOR et al., 2015). Em outros trabalhos da literatura, observase que quibes elaborados com truta (Oncorhynchus mykiss) (BAYGAR et al., 2008), com resíduos da rede de arrasto (RIBEIRO et al., 2018) e com Carne Mecanicamente Separada (CMS) de tilápia (Oreochromis niloticus) (VERDI; SOUZA, 2015), os valores encontrados para esse grupo de micro-organismos estavam dentro dos padrões estabelecidos pela legislação.Tabela 3. Resultados médios da avaliação da qualidade microbiológica de formatados, tipo quibe, elaborados com diferentes espécies de pescado de baixo valor comercial

Tabela 3. Resultados médios da avaliação da qualidade microbiológica de formatados, tipo quibe, elaborados com diferentes espécies de pescado de baixo valor comercial

\begin{tabular}{|c|c|c|c|c|c|}
\hline MICRO-ORGANISMO & Curimbatá* $^{*}$ & Palmito** & Piavuçü** & Barbado $^{* * * *}$ & $\begin{array}{l}\text { Limites máximos } \\
\text { tolerados pela } \\
\text { Legislação ou } \\
\text { literatura }\end{array}$ \\
\hline Mesófilos (log UFC.g-1) & 5,47 & 5,31 & 5,25 & 5,47 & $6^{\mathrm{a}}$ \\
\hline Psicrotróficos (log UFC.g-1) & 7,47 & 7,40 & 7,93 & 7,47 & $6^{a}$ \\
\hline Coliformes $35^{\circ} \mathrm{C}(\log$ NMP.g-1) & 6,04 & 6,04 & 5,75 & 5,74 & $3^{\mathrm{b}}$ \\
\hline Coliformes $45^{\circ} \mathrm{C}\left(\log \mathrm{NMP}^{-1}{ }^{-1}\right)$ & 6,04 & 6,04 & 5,75 & 6,04 & $2 \mathrm{c}$ \\
\hline Escherichia coli $(\log$ NMP.g-1) & 6,04 & 6,04 & 5,75 & 6,04 & $3^{\mathrm{d}}$ \\
\hline Staphylococcus spp. $\left(\log\right.$ UFC.g-1 $\left.{ }^{-1}\right)$ & $<3$ & $<3$ & $<3$ & $<3$ & $3^{c}$ \\
\hline Listeria spp. $(\log$ UFC.g-1) & $<1$ & $<1$ & $<1$ & $<1$ & $2 \mathrm{e}$ \\
\hline Shewanella spp. $\left(\log\right.$ UFC.g $\left.^{-1}\right)$ & $<3$ & $<3$ & $<3$ & $<3$ & $2^{f}$ \\
\hline Aeromonas spp. (log UFC.g-1) & $<1$ & $<1$ & $<1$ & $<1$ & $2 \mathrm{~g}$ \\
\hline $\begin{array}{l}\text { Fungos filamentosos e leveduras } \\
\left(\operatorname{logUFC.}^{-1}\right)\end{array}$ & 5,74 & $<3$ & $<3$ & 6,34 & $3^{\mathrm{h}}$ \\
\hline Salmonella spp. & $\begin{array}{l}\text { ausência } \\
\text { em } 25 \mathrm{~g}\end{array}$ & $\begin{array}{l}\text { ausência } \\
\text { em } 25 \mathrm{~g}\end{array}$ & $\begin{array}{l}\text { ausência } \\
\text { em } 25 \mathrm{~g}\end{array}$ & $\begin{array}{l}\text { ausência } \\
\text { em } 25 \mathrm{~g}\end{array}$ & ausência em $25 g^{c}$ \\
\hline
\end{tabular}

UFC = Unidades Formadoras de Colônias; NMP = Número Mais Provável; "CASSOL et al., 2016a; **TEIXEIRA et al., 2015; ${ }^{* * *}$ ROSENO et al., 2015; ${ }^{* * * *}$ CASSOL et al., 2016b; aICMSF, 1986; bKOLAWOLE et al., 2011; cBRASIL, 2001; 
Para questões de padrão de qualidade dos produtos elaborados, destaca-se que é válido estabelecer limites máximos aceitáveis também para os micro-organismos que não se encontram previstos nas legislações vigentes, como é o caso da Listeria spp. que, segundo a literatura, é um micro-organismos patogênico podendo ocorrer em diferentes tipos de alimentos, sendo recomendado valores abaixo de 2 log UFC.g-1 para se evitar possíveis contaminações alimentares (MELDRUM et al., 2010). Para Shewanella spp., a literatura sugere como tolerável, contagens máximas de 2 log UFC.g-1, e ainda alerta que em contagens a partir de 7 log UFC.g-1 ocorre produção de trimetilamina e detecção de off-flavor a partir de 8 log UFC.g-1 (JORGENSEN; HUSS, 1989). Da mesma forma, para Aeromonas spp., o recomendado também são contagens de até no máximo 2 log UFC.g-1, sendo que valores acima deste podem indicar que os produtos contaminados atuem como possíveis veículos de gastroenterite transmitida por alimentos (NEYTS et al., 2000).

Segundo Jay et al. (2005), estes três últimos micro-organismos podem ser encontrados em pescado, sendo os dois últimos frequentemente reportados por serem deteriorantes. Os mesmos autores indicam que também pode ser comum a presença de Escherichia spp. em amostras de pescado e produtos derivados, fato comprovado nas amostras analisadas, como pode ser verificado na Tabela 3. Percebe-se que os quibes elaborados com diferentes espécies de peixe apresentaram contagens significativas Escherichia coli (acima de 5,7 log NMP.g-1 ${ }^{-1}$, praticamente o dobro do recomendado pela literatura (máximo de 3 log MNP.g-1) (MANDAL et al., 2009) podendo esse resultado ser consequência de não conformidades higiênicas apresentadas no momento da despesca ou do preparo do formatado, seja via instrumentos de pesca, equipamentos e utensílios usados tanto no abate quanto no momento de elaboração dos quibes, e, principalmente, via falta de higiene do manipulador.

Esses dados tornam clara a importância da qualidade microbiológica não só da matéria prima, mas também dos cuidados que devem ser tomados quanto aos utensílios, equipamentos e manipuladores durante a elaboração de produtos alimentícios

Além destes, os Coliformes a 35ํㅡ e Staphylococcus coagulase positivo, também estão relacionados à precariedade na higiene tanto das instalações, quanto dos manipuladores, pois são encontrados no ar, solo, além de lesões da pele, vias aéreas e mucosas (FRANCO; LANDGRAF, 2008; SILVA-JÚNIOR et al., 2015; LUCINDO et al., 2016; COSTA et al., 2018; SANTOS et al., 2018), podendo ser facilmente transmitido aos alimentos manipulados. Além disso, esses micro-organismos podem indicar falhas nos processos de produção, empacotamento e estocagem dos produtos (SANTOS et al., 2018).

Sendo assim, os resultados verificados, neste presente estudo, para Coliformes a $35^{\circ} \mathrm{C}\left(5,74 \log \mathrm{NMP} . \mathrm{g}^{-1} \mathrm{e}\right.$ 6,04 log NMP.g-1) (Tabela 3), podem ser consequência de falhas na produção e também problemas de armazenamento, visto que os produtos analisados ficaram 8 meses estocados antes de serem submetidos as análises. Baygar et al. (2008), em seu trabalho com quibes de truta, encontraram valores para Coliformes a $35^{\circ} \mathrm{C}$ variando entre $2 \log _{\text {NMP.g-1 a } 3} \log$ NMP.g-1; e Verdi e Souza (2015), analisando quibes de CMS de tilápia, obtiveram valores $<1 \log \mathrm{NMP}^{-1}{ }^{-1}$. Esses resultados estão de acordo com os limites máximos sugeridos na literatura para Coliformes a 35ํㅡ, que é de 3 log NMP.g-1 (KOLAWOLE et al., 2011), todavia, diferente dos valores encontrados na compilação de resultados do presente trabalho, onde foram observadas contagens duas vezes maiores que esse limite.

Além disso, durante o armazenamento de produtos pode ocorrer o desenvolvimento de micro-organismos aeróbicos (mesófilos e psicrotróficos), que são capazes de produzir enzimas deteriorantes (BALDIN et al., 2016). O aumento na contagem desses micro-organismos para níveis superiores a 6 log UFC.g-1 é usualmente indicativo de armazenamento longo, seja a temperaturas ambientes, de resfriamento ou abuso de temperatura antes do processo de congelamento, não sendo recomendados o consumo do alimento quando atingirem esses valores, visto que haverá uma perda de qualidade dos mesmos (ICMSF, 1986).

Portanto, os quibes avaliados (Tabela 3), encontravam-se em desacordo com o citado na literatura (ICMSF, 1986) para psicrotróficos, estando impróprios para consumo, uma vez que apresentaram valores de 7 log UFC.g-1, aproximadamente. Esses resultados divergem do encontrado por Ribeiro et al. (2018), que observaram valores mais baixos, variando de 2 a 3 log UFC.g-1 em quibes elaborados com espécies consideradas resíduo de rede de arrasto.

Já para micro-organismos mesófilos, os valores encontrados na Tabela 3 estavam dentro do padrão literário (<6 log UFC.g-1) (ICMSF, 1986), com contagens de 5 log UFC.g-1 ${ }^{-1}$ aproximadamente. Entretanto, 
Baygar et al. (2008), trabalhando com quibes de peixe truta, encontraram valores acima desse recomendado, estando entre 6 log UFC.g-1 e 7 log UFC.g-1.

Desta forma, a contagem de placas aeróbicas é indicativa da qualidade geral e dos procedimentos de manuseamento e armazenagem (ICMSF, 1986), incluindo o beneficiamento, empacotamento e estocagem dos produtos (SANTOS et al., 2014; REIS et al., 2017; SOUSA et al., 2017). O que confirma, novamente, possível deficiência nessas etapas durante a elaboração dos produtos analisados neste presente trabalho.

Sabe-se ainda que outros micro-organismos também podem ser detectados, mesmo sob efeito de baixas temperaturas, como é o caso dos fungos filamentosos e leveduras. Segundo Jay et al. (2005), o crescimento de micro-organismos em temperaturas abaixo de $0^{\circ} \mathrm{C}$ é mais provável que seja de leveduras e bolores, do que bactérias, sendo ainda mais viável quando as amostras apresentam condições de menor atividade de água (Aw).

Dos resultados avaliados neste estudo (Tabela 3), apenas as amostras de quibes elaborados com peixes das espécies palmito e piavuçu não tiveram contagens para esses micro-organismos. 0 mesmo não pôde ser visto para as amostras analisadas de quibes elaborados com as espécies curimbatá e barbado, pois estas apresentaram contagens entre 5 e 6 log UFC.g-1 ${ }^{-1}$ acima do indicado pela literatura, que é de 3 log UFC.g-1 (RODRÍGUEZ et al., 2015). Vale ressaltar que, além desses micro-organismos estarem relacionados à precariedade na higiene das instalações a presença deles em alimentos pode tornar-se um perigo à saúde coletiva devido à produção de micotoxinas (NUNES et al., 2013).

Desta forma, a partir dos resultados apresentados, é possível inferir que, de maneira geral, houve falhas nas condições higiênico-sanitárias durante o processo de fabricação dos quibes analisados neste trabalho. Essas não conformidades podem ter ocorrido em diferentes etapas do processo de elaboração dos produtos, podendo ser citado como possíveis pontos de contaminação:

- Despesca: através do uso de utensílios de pesca contaminados ou práticas inadequadas de captura;

- Transporte/Abate: seja pelo deslocamento incorreto do pescado até o local de abate ou pelas condições higiênicas do local onde o pescado foi abatido, ou ainda exposição do pescado a temperaturas inadequadas durantes essas etapas;

- Instalações/Utensílios: incorreta ou deficiente higienização das instalações e utensílios utilizados na elaboração dos quibes;

- Manipuladores: falta de hábitos higiênicos dos manipuladores ou até mesmo ineficiente higienização das mãos antes, durante ou após contato direto com os produtos;

- Ingredientes utilizados: também é possível que parte da contaminação microbiológica observada tenha sido causada pelo uso de ingredientes já contaminados;

- Armazenamento: tempo de armazenamento muito prolongado, aliado a variação de temperatura, assim, o produto pode ter sido exposto a condições favoráveis para o crescimento de micro-organismos.

\section{CONSIDERAÇÕES FINAIS}

Conclui-se que as amostras avaliadas apresentaram alta contagem de micro-organismos deteriorantes e patogênicos, relacionados à falta de condições higiênico-sanitárias adequadas dos manipuladores, utensílios e da forma de armazenamento dos formatados, tipo quibe. Esses, interferem diretamente na qualidade final do produto, assim como no seu tempo de vida útil, além de oferecer riscos à saúde do consumidor.

Por ser um produto que valoriza a matéria prima local e disponibiliza o pescado de uma maneira diferente, rápida e prática, sugere-se a melhoria nas boas práticas higiênicas desde a captura, manipulações e processamento, de forma a garantir a elaboração de alimentos seguros.

\section{REFERÊNCIAS}

[1] Arbex, E. A. S.; Maciel, E. S.; Pérez, J. L. R.; Savay-da-Silva, L. K. Perfil De Consumidores De Pescado Em Comunidades Universitárias Da Região Metropolitana De Cuiabá-MT. Proceedings do VII SIMCOPE. Instituto de Pesca, São Paulo. 2017.

[2] Baldin, J. C.; Borges, L. A.; Gatti Junior, P.; Michelin, E. C.; Rossi Junior, O. D. Qualidade Microbiológica Do Gelo Utilizado Na Conservação De Pescado. Global Science And Technology, Rio Verde, 09(02): 74-78. 2016. 
[3] Barbosa, R. D.; Ribeiro, K. P.; Pinto, D. M.; Cassol, L. A. Desenvolvimento De Linguiça Frescal De Peixe Barbado Com Adição Farinha De Aveia: Características Físico-Química E Sensorial. Revista Connection Line n. 12. 2015.

[4] Baygar, T.; Erkan, N.; Mol, S.; Ozden, O.; Uçok, D.; Yildirim, Y. Determination of the Shelf-Life of Trout (Oncorhynchus mykiss) Raw Meatball That Packed under Modified Atmosphere. Pakistan Journal of Nutrition, 7(3):412-417. 2008.

[5] Bombardelli; R. A.; Syperreck, M. A.; Sanches, E. A. Situação atual e perspectivas para o consumo, processamento e agregação de valor ao pescado. Arquivos de Ciências Verinárias e Zoologia da UNIPAR, 8(2): 181195. 2005

[6] Bouwens, M.; Van De Rest, O.; Dellschaft, N.; Bromhaar, M. G.; Groot, L. C. P. G. M.; Geleijnse, J. M.; Muller, M.; Afman, L. A. Fish-Oil Supplementation Induces Antiinflammatory Gene Expression Profiles In Human Blood Mononuclear Cells ${ }^{1-3}$. The American Journal of Clinical Nutrition, 90:415-24. 2009.

[7] Brasil, Ministério da Agricultura, Pecuária e Abastecimento. Regulamentos Técnicos de Identidade e Qualidade de Almôndega, de Apresuntado, de Fiambre, de Hambúrguer, de Kibe, de Presunto Cozido e de Presunto. Instrução Normativa no 20, de 31 de julho de 2000, Brasília, DF. <Disponível em: http://extranet.agricultura.gov.br/sislegis-consulta/servlet/VisualizarAnexo?id=1685>

[8] Brasil, Ministério da Saúde. Agência Nacional de Vigilância Sanitária. Resolução RDC no 12, de 02 de janeiro de 2001: Regulamento Técnico sobre padrões microbiológicos para alimentos. Brasília, DF, 2001. <Disponível em: http://portal.anvisa.gov.br/documents/33880/2568070/RDC_12_2001.pdf/15ffddf6-3767-4527-bfac$740 \mathrm{a} 0400829 \mathrm{~b}>$

[9] Brasil. Regulamento da Inspeção Industrial e Sanitária de Produtos de Origem Animal. Decreto no 9.013, de 29 de março de 2017. Rio de Janeiro, 2017 <Disponível em: http://www.planalto.gov.br/ccivil_03/_ato20152018/2017/decreto/D9013.htm>

[10] Campos, J. M.; Moraes, C. R.; Rezende, P. V. D.; Pedroso, A. L.; Cassol, G. Z.; Savay-da-Silva, L. K. Comparação, Através De Parâmetros Físicos, De Fishburguer e Outros Hambúrgueres Comercializados Na Região De Cuiabá-MT. VIII Fórum Nacional de Formação Acadêmica e Atuação Profissional do Cientista de Alimentos, IV Simpósio Nacional em Ciência e Tecnologia de Alimentos. Venda Nova do Imigrante, ES. 2019

[11] Cassol, G. Z.; Teixeira, J. S.; Roseno, T. F.; Savay-da-Silva, L. K.; Lara, J. A. F.; Almeida Filho, E. S. Avaliação da qualidade microbiológica de patê de curimbatá. I Siman - Simpósio Mato-grossense de Alimentação e Nutrição, UFMT. Cuiabá. 2015.

[12] Cassol, G. Z.; Abreu, M. C. C.; Roseno, T. F.; Savay-da-Silva, L. K.; Lara, J. A. F.; Almeida Filho, E. S. Avaliação Da Qualidade Microbiológica De Formatados de curimbatá (Prochilodus lineatus). In: XV Congresso Brasileiro de Ciência e Tecnologia de Alimentos, 2016, Gramado, RS. Congresso Brasileiro de Ciência e Tecnologia de Alimentos, 2016a.

[13] Cassol, G. Z.; Teixeira, J. S.; Roseno, T. F.; Savay-da-Silva, L. K.; Lara, J. A. F.; Almeida Filho, E. S. Qualidade Microbiológica De Formatados De Barbado (Pinirampus pirinampu) Processados Artesanalmente. Simpósio de Ciência e Tecnologia de Alimentos, IFMT. Cuiabá. 2016b.

[14] Costa, A. L. P.; Nascimento, J. F.; Silva Júnior, A. C. S. Perfil de resistência de Staphylococcus aureus isolados de pescada amarela (Cynoscion acoupa) Comercializada em feira pública. Publicações em Medicina Veterinária e Zootecnia, 12(5):1-6. 2018.

[15] DEAN, L. M. Nutrition and Preparation. In: MARTIN, R. E.; FLICK, G. J. The Seafood Industry, Nek York. p. 255267. 1990

[16] Fao. The State of World Fisheries and Aquaculture: Contributing to food security and nutrition for all. Rome. 200 p. 2016 <Disponível em: http://www.fao.org/3/a-i5555e.pdf>

[17] Fao. The State of World Fisheries and Aquaculture: Meeting The Sustainable Development Goals. Rome. p. 227. 2018. <Disponível em: http://www.fao.org/3/i9540EN/i9540en.pdf>

[18] Figueiro, R. C. M.; Sousa, J. M.; Castro, E. M.Fatores Que Influenciam Na Decisão De Compra De Pescado No Mercado De Peixe De Bragança - PA. Revista Brasileira de Engenharia de Pesca 7(1): 60-72, 2014.

[19] Franco, B. D. G. M.; Landgraf, M. Microbiologia dos Alimentos. São Paulo: Atheneu, 2008. 182 p.

[20] Gava, A. J.; Silva, C. A. B.; Frias, J. R. G. Tecnologia de Alimentos: Princípios e Aplicações. São Paulo: Nobel, p. 511. 2008

[21] Gonçalves, A. A.; Nogueira, W. M.; Lourenço, L. F. H. Aproveitamento do Descarte do Processamento da Piramutaba (Brachyplatystoma vaillantii) e do Camarão-Rosa (Farfantepenaeus subtilis) na Produção de Salsicha Sabor Camarão. Boletim do Instituto de Pesca, 35(4): 623-635. São Paulo. 2009.

[22] Hibbeln, J. R. Seafood Consumption, The DHA Content Of Mothers' Milk And Prevalence Rates Of Postpartum Depression: A Cross-National, Ecological Analysis. Journal of Affective Disorders, 69: 15-29, 2002. 
[23] Icmsf - International Commission on Microbiological Specification for Foods. Microorganisms in Foods 2. Sampling for microbiological analysis: Principles and specific applications. Ed. 2. 131p. 1986

[24] Jay, J. M.; Loessner, M. J.; Golden, D. A. Modern Food Microbiology 7aㅡ Edition. New York: Springer Science. p. 782. 2005.

[25] Jorgensen, B. R.; Huss, H. H. Growth and activity of Shewanella putrefaciens isolated from spoiling fish. International Journal of Food Microbiology, 9: 51-62. 1989.

[26] Kolawole, O. M.; Ajayi, K. T.; Olayemi, A. B.; Okoh, A. I. Assessment of Water Quality in Asa River (Nigeria) and Its Indigenous Clarias gariepinus Fish. International Journal of Environmental Research and Public Health, 8: 43324352, 2011.

[27] Lopes, I. G.; Oliveira, R. G.; Ramos, F. M. Perfil Do Consumo De Peixes Pela População Brasileira. Biota Amazônia, Macapá, 6(2):62-65. 2016

[28] Lucindo, M. B.; Donatele, D. M.; Ferreira, M. F.; Guimarães, T. S. Qualidade microbiológica da pescada branca comercializada na região litorânea do sul do estado do Espírito Santo. Revista Brasileira de Higiene e Sanidade Animal, 10(2): 199-210. 2016

[29] Lustosa Neto, A. D.; Gonçalves, A. A. Formatados e Reestruturados (Hambúrguer, Nuggets etc.). In: Gonçalves, A. A. Tecnologia do Pescado: Ciência, Tecnologia, Inovação e Legislação. São Paulo: Atheneu. 2011.

[30] Maciel, E. S.; Savay-da-Silva, L. K.; Vasconcelos, J. S.; Galvão, J. A.; Sonati, J. G.; Silva, D.; Oetterer, M. Application Of Exploratory Factor Analysis To Assess Fish Consumption in a University Community. Food Science And Technology. Campinas, 33(1): 99-106, Jan.-Mar. 2013.

[31] Maciel, E. S.; Savay-da-Silva, L. K.; Galvão, J. A.; Oetterer, M. Atributos de Qualidade do Pescado Relacionados ao Consumo na Cidade de Corumbá, MS. Boletim do Instituto de Pesca, São Paulo, 41(1): 199-206. 2015.

[32] Mandal, S. C.; Hasan, M.; Rahman, M. S.; Manik, M. H.; Mahmud, Z. H.; Isla, S. Coliform Bacteria in Nile Tilapia, Oreochromis niloticus of Shrimp-Gher, Pond and Fish Market. World Journal of Fish and Marine Sciences 1 (3): 160$166,2009$.

[33] Meldrum, R. J.; Ellis, P. W.; Mannion, P. T.; Halstead, D.; Garside, J. Prevalence of Listeria monocytogenes in Ready-to-Eat Foods Sampled from the Point of Sale in Wales, United Kingdom. Journal of Food Protection 73 (8): 1515-1518, 2010.

[34] Neyts, K.; Huys, G.; Uyttendaele, M.; Swings, J.; Debevere, J. Incidence and identification of mesophilic Aeromonas spp. from retail foods. Letters in Applied Microbiology, 31: 359-363, 2000.

[35] Nunes, E. S. C. L.; Bittencourt, R. H. F. P. M.; Silva, M. C.; Mársico, E. T.; Franco, R. M. Avaliação da qualidade do camarão salgado seco (aviú) e da farinha de peixe (piracuí) comercializados em mercados varejistas da cidade de Belém, Pará. Revista Instituto Adolfo Lutz.72(2):147-54. 2013.

[36] Ogawa, M. O Pescado Como Alimentos. In: Ogawa, M.; Maia, E. L. Manual de Pesca, São Paulo: Livraria Varela. p. 1-6. 1999.

[37] Patriarca, J.; Ribeiro, A.T.; Silva, H.; Vieira, H.; Teixeira, B.; Rodrigues, M.J.; Gil, M.; Pousãoferreira, P.; Mendes, R. Efeito Da Armazenagem Em Refrigerado Na Qualidade De Fiambre De Corvina Com Fibras Dietéticas Embalado Em Vácuo E Em Atmosfera Modificada. Relatórios Científicos e Técnicos do IPMA, no 7, p. 45. 2015.

[38] Perspectivas de la Agricultura y Del Desarrollo Rural En Las Américas: Una Mirada Hacia América Latina y el Caribe 2017-2018 / Cepal, Fao, Iica. - San José, C.R.: Iica, 266 p. 2017. <Disponível em: http://www.fao.org/3/i8048es/I8048ES.pdf>

[39] Pinheiro, V. S.; Bisconsin-Junior, A.; Carvalho, A. L. Coliformes Totais E Termotolerantes Em Tambaqui Comercializado No Mercado Municipal De Ariquemes - RO. V Simpósio de Segurança Alimentar: Alimentação e Saúde. Bento Gonçalves, 2015.

[40] Ponath, F. S.; Valiatti, T. B.; Sobral, F. O. S.; Romão, N. F.; Alves, G. M. C.; Passoni, G. P. Avaliação da higienização das mãos de manipuladores de alimentos do Município de Ji-Paraná, Estado de Rondônia, Brasil. Revista Pan-Amazônica de Saúde, 7(1):63-69. 2016.

[41] Reis, D. H. C.; Meneguelli, M.; Muniz, I. M.; Caetano, A. R.; Araújo, K. F.; Osowski, A. Avaliação Do Perfil Microbiológico Do Peixe Pseudoplatystoma corruscans e Colossoma macropomum (Pintado e Tambaqui), Comercializado No Município De Rolim De Moura, Tendo Em Foco A Saúde Pública. Revista Brasileira de Ciências da Amazônia, 6(1): 1-62. 2017.

[42] Ribeiro, D.S.; Calixto, F.A.A.; Guimarães, J.L.B.; Aronovich, M.; Keller, L.A.M.; Mesquita, E.F.M. Produtos de pescado elaborados com resíduos de arrasto: análise físico-química, microbiológica e toxicológica. Arquivo Brasileiro de Medicina Veterinária e Zootecnia, 70(1):238-246. 2018. 
[43] Rodríguez, A.; Rodríguez, M.; Andrade, M. J.; Córdoba, J. J. Detection of filamentous fungi in foods. Current Opinion in Food Science, 5: 36-42. 2015

[44] Roseno, T. F.; Cassol, G. Z.; Teixeira, J. S.; Lara, J. A. F.; Savay-da-Silva, L. K.; Almeida Filho, E. S. Avaliação da qualidade microbiológica de formatados de piavuçu (Leporinus macrocephalus) processados artesanalmente. I Siman - Simpósio Mato-grossense de Alimentação e Nutrição, Ufmt. Cuiabá. 2015.

[45] Ruxton, C. H. S. The Benefits Of fish Consumption. Nutrition Bulletin, 36: 6-19, 2011.

[46] Santos, S. S.; Evangelista-Barreto, N. S.; Silva, R. A. R. Delineamento Do Perfil Dos Consumidores E Classificação Dos Estabelecimentos Que Comercializam Ostras Em Valença, Bahia, Brasil. Fortaleza: Arquivos de Ciências do Mar, 47(2): 72 - 79. 2014.

[47] Santos, E. L.; Soares, E. C.; Silva, T. J.; Januário, I. C. M.; Garcia, P. H. M.; Moura, S. C. S. Perfil do Consumo de Pescados na Cidade de Coruripe, Alagoas. Acta Veterinária Brasílica, 9(2):153-159. 2015.

[48] Santos, P. R.; Vasconcelos, E. L. Q.; Souza, A. F. L.; Silva Júnior J. L.; INHAMUNS, A. J. Qualidade físico-química e microbiológica de pescado congelado consumido na merenda escolar do estado do Amazonas. Publicações em Medicina Veterinária e Zootecnia, 12(5):1-6. 2018.

[49] Silva-Júnior, A. C. S.; Silva, A. S. S.; Brito, T. P.; Ferreira, L. R. Ocorrência de Staphylococcus coagulase positiva e coliformes termotolerantes em Jaraqui, Semaprochilodus brama (Valenciennes, 1850) comercializado na Feira do Pescado, Macapá-AP. Macapá: Biota Amazônia, 5(1): 32-36. 2015.

[50] Silva, L. C.; Santos, D. B.; São José, J. F. B.; Silva, E. M. M. Boas práticas na manipulação de alimentos em Unidades de Alimentação e Nutrição. Demetra, 10(4); 797-820. 2015 a.

[51] Silva, N.; Junqueira, V. F. A. S; Silveira, N. F. A.; Taniwaki, M. H.; Santos, R. F. S.; Gomes, R. A. R.; Okazaki, M. M. Manual De Métodos de Análise Microbiológica De Alimentos. Varela, 3ae edição, São Paulo. 2010.

[52] Silva, R. A.; Bonnas, D. S.; Silva, P.F. Aproveitamento Dos Resíduos Gerados No Processamento De Postas De Surubim (Pseudoplatystoma corruscans) Para Elaboração De Nuggets. São Paulo: Revista de Comportamento, Cultura e Sociedade 3(2). 2015b.

[53] Smith, G. I.; Julliand, S.; Reeds, D. N.; Sinacore, D. R.; Klein, S.; Mittendorfer, B.Fish Oil-Derived N-3 Pufa Therapy Increases Muscle Mass And Function In Healthy Older Adults ${ }^{1}$. The American Journal of Clinical Nutrition, 102:115-22. 2015.

[54] Sousa. T. M.; Demarque, I. L. D.; Freitas, L. L.; Fernandes, F. M. Análise microbiológica de esponjas de poliuretano utilizadas em cozinhas domésticas. Revista Científica da Faminas, 9: 27-37. 2013.

[55] Sousa, I. J. A.; Kirschnik, P. G.; Franco de Lima, L. K. Desenvolvimento e Avaliação de Linguiça de Pescado Elaborada Com Carne de Pirarucu. Jornada de Iniciação Científica e Jornada de Iniciação Científica, Tecnológica e de Extensão da Católica do Tocantins, 6:19-21. Palmas. 2016.

[56] Souza, A. L.M.; Guimarães, J.T.; Brigida, A. I. S.; Luiz, D. B.; Franco, R. M.; Mesquita, E. F. M. Qualidade Microbiológica No Glaciamento De Peixe-Prego. Proceedings do VII Simcope. Inst. Pesca, São Paulo. 2017.

[57] Tacon, A. G. J.; Metian, M.Fish Matters: Importance of Aquatic Foods in Human Nutrition and Global Food Supply. Reviews in Fisheries Science,21(1):22-38, 2013.

[58] Teixeira, J. S.; Roseno, T. F.; Cassol, G. Z.; Lara, J. A. F.; Savay-da-Silva, L. K.; Almeida Filho, E. S. Avaliação Da Qualidade Microbiológica De Formatados De Palmito (Ageneiosus valenciennesi) Processados Artesanalmente. I Siman - Simpósio Mato-grossense de Alimentação e Nutrição, UFMT. Cuiabá. 2015.

[59] Verdi, R.; Souza, M. L. R. Inclusão De Mix Desidratado De Peixe Em Linguiça Defumada E Quibe De Peixe. XXIV EAIC - Encontro Anual de Inicia Científica - UEM. Maringá. 2015.

[60] Viegas, S. J. Alterações do Estado de Saúde Associadas à Alimentação: Contaminação Microbiológica dos Alimentos. Lisboa: Instituto Nacional de Saúde Doutor Ricardo Jorge. p. 42.2009

[61] Vital de Jesus, D.; Baptista de Souza, R. T. Y.; Ragonha de Oliveira, S. Consumo De Pescado Pela População De São Gabriel Da Cachoeira-AM. Revista De Educação, Ciência e Tecnologia Do IFAM, 8(1). 2014

[62] Volkweis, D. S. H.; Lazzaretti, J.; Boita, E. R. F.; Benetti, F. Qualidade microbiológica da água utilizada na produção de alimentos por agroindústrias familiares do município de Constantina/RS. Revista Eletrônica em Gestão, Educação e Tecnologia Ambiental. Santa Maria, 19 (1): 18-26. 2015. 


\section{Capítulo 3}

Avaliação higiênico-sanitária e nutricional de linguiça tipo frescal com adição de cerveja

\section{Adna Quesia Costa de Oliveira}

Dorival Pereira Borges da Costa

Cleytton Luiz Bezerra de Paula

Willian Pinheiro Soares

Danielli Matos Santiago

Resumo: As linguiças constituem os derivados cárneos em maior quantidade em nosso país, isso porque a sua elaboração, além de não exigir tecnologia sofisticada utiliza poucos equipamentos e de baixos custos. A cerveja oferece tantas possibilidades de combinação e harmonização que é possível apreciá-la de diversas maneiras. 0 objetivo do presente trabalho foi obter uma linguiça com adição de cerveja, além de determinar as características físico-químicas e microbiológica. As linguiças foram produzidas utilizando-se carne bovina, suína, condimentos e cerveja. Os ensaios microbiológicos foram feitos $24 \mathrm{~h}$ depois da fabricação realizados segundo a RDC 12, onde não foi detectada a presença de E.coli e Salmonella spp. Já os testes de físico-químicas feitos num período de 15 dias, utilizando as normas Adolf Lutz. No produto final foram encontrados teores de umidade $(71,84 \%)$, pH $(5,54)$, cinzas $(9,13 \%)$, proteína $(16,18)$. Exceto pela umidade, as análises realizadas na linguiça mostraram um alimento dentro dos padrões pré-estabelecidos pelo regulamento técnico de identidade e qualidade.

Palavras-chave: embutido, características físico-químicas microbiológicas, harmonização 


\section{INTRODUÇÃO}

0 processamento de carnes, é de origem muito remota, surgiu quando a humanidade apreendeu de forma empírica, a trabalhar com o sal como agente de prevenção. 0 embutido está entre os vários processos fabris como por exemplo a secagem, a salga e a defumação (BARROS, 2011).

Desde a antiguidade o homem vem fabricando diferentes tipos de linguiças na busca de, ao conservar a carne, fornecer um produto à altura das aspirações do consumidor (SANTOS,2006).

No Brasil, a linguiça frescal é um dos produtos cárneos mais fabricados, provavelmente porque sua elaboração não exige tecnologia sofisticada e utiliza poucos equipamentos sendo a maioria de baixo custo. Estes embutidos cárneos são elaborados a partir de misturas de carne, toucinho e condimentos, podendo ser de carne suína, bovina e de aves, contidos em envoltórios (naturais ou artificiais).

Em relação à linguiça frescal, diversos são os fatores que podem afetar a estabilidade e/ou qualidade sanitária do produto final. Podemos citar o emprego de técnicas higiênico-sanitárias inadequadas durante sua elaboração, falta de tratamento térmico no processo, contaminações cruzadas e, consequentemente o desenvolvimento de microrganismos patogênicos e/ou deteriorantes. (CARVALHO, et all 2010).

Conforme o regulamento técnico de identidade e qualidade da linguiça, a tipificação depende dos processos utilizados, podendo se tratar de um produto fresco, seco, curado e/ ou maturado entre outros.

A palavra "beer" (cerveja) é proveniente do latim e significa). A cerveja já era conhecida por várias civilizações antigas e era muito popular em regiões onde o clima não era propício ao cultivo de uvas (REINOLD, 1997).

A cerveja predominante no mercado brasileiro, e consequentemente a mais consumida, é a Pilsen, que é produzida em larga escala principalmente em indústrias de grande porte (Companhia de bebidas das Américas - AMBEV, 2011). De acordo com Santos (1998, p. 217), "o nome Pilsen aparece em 40\% dos rótulos das mais conhecidas cervejas, sua origem, Urquell, significa em alemão "fonte original", provém naturalmente de Pilsen ou Plzen, em checo".

A cerveja do tipo Lager Pilsen - Combinam com aperitivos, harmonizam bem com carnes vermelhas e pratos orientais. As combinações de sabores da cerveja com os alimentos devem ser complementares e jamais deve predominar sobre outros ingredientes.

Condimentos é o termo usado para designar os ingredientes adicionados com finalidade de conferir, sabor, aroma, possuem efeitos antioxidante e antimicrobiano. São classificados de acordo com sua aplicação e sabor, como por exemplo salgados, picantes especiarias e ervas aromáticas.

O objetivo do presente trabalho foi a obtenção de uma linguiça frescal com adição de cerveja, bem como determinar as características físico-químicas e microbiológicas da mesma.

\section{MATERIAL E MÉTODOS OU METODOLOGIA}

A elaboração das linguiças com adição de cerveja foi realizada no Laboratório móvel de Alimentos do Instituto Federal de Mato Grosso - Campus Cuiabá - Bela Vista. Como matéria-prima da elaboração das 
linguiças foi utilizada carnes da variedade bovina (músculo dianteiro) e suína (pernil). Utilizou-se como condimentos pimentas vermelhas e do reino moídas, alho, cravo, orégano, noz-moscada, sal. 0 processo completo da elaboração das linguiças pode ser observado na Figura1.

Figura 1 - Fluxograma do processo da elaboração da linguiça com adição de cerveja

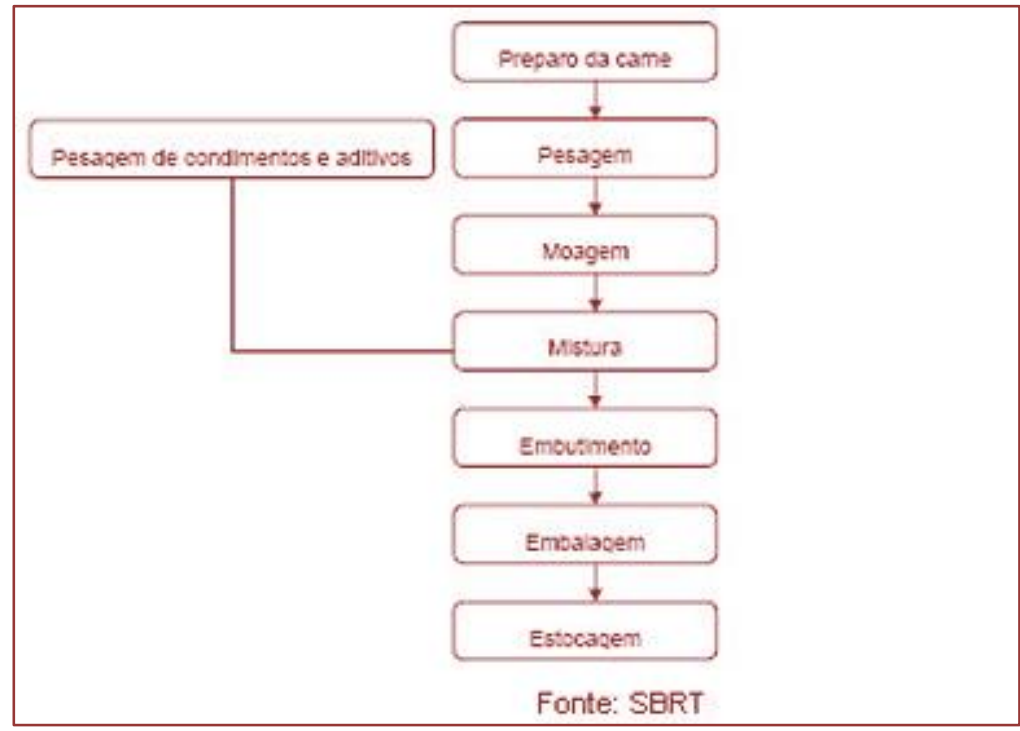

Realizou-se o preparo dos produtos cárneos: toucinhos, carne bovina e carne suína, removendo os excessos de gordura e tendões. Posteriormente foi feita a pesagem das carnes e condimentos. Realizou-se a redução da matéria através de moagem com auxílio de um moedor elétrico, misturou-se na massa (carnes e toucinhos) os condimentos e a cerveja referentes ao processo de forma que facilitou a distribuição homogênea na massa.

Os ingredientes utilizados foram as matéria-prima carne músculo bovino $(600 \mathrm{~g})$, carne suína $(600 \mathrm{~g})$, toucinho (300g) e os condimentos foram: sal fino (30g), pimenta vermelha $(1,5 \mathrm{~g})$, pimenta do reino $(1 \mathrm{~g})$, noz-moscada $(0,15 \mathrm{~g})$, orégano $(0,15 \mathrm{~g})$, cravo da índia $(0,15 \mathrm{~g})$, alho socado $(0,375 \mathrm{~g})$ e cerveja do tipo Lager (343ml). 0 embutimento das linguiças foi acondicionado em tripas artificiais e embaladas em sacos plásticos e armazenadas sob refrigeração.

As análises físico-químicas seguiram as normas do Instituto Adolfo Lutz, e ocorreram num período de 15 dias foram determinados os teores de umidade, cinzas, pH e proteínas.

As caracterizações microbiológicas das linguiças foram realizadas segundo a RDC 12, de 02 de janeiro de 2001, que fixam padrões microbiológicos para alimentos. As amostras foram analisadas na FANUTLaboratório da Faculdade de Nutrição, da Universidade Federal de Mato Grosso (UFMT), localizado no bairro Boa Esperança - Cuiabá. As análises realizadas foram aplicadas pelo método número mais prováveis (NMP) para: Coliformes termotolerantes, Salmonella spp., Echerichia coli, Clostridios Sulfito Redutores. 


\section{DISCUSSÃO DOS RESULTADOS}

A linguiça pode ser classificada como produto frescal conforme o Regulamento Técnico no 4, de 31 de março de 2000 de Identidade e Qualidade de linguiça (Brasil,2000). Este regulamento determina padrões de características físico-químicas para linguiça frescal, como 70\% umidade (máx.), 30\% de gordura (máx.) e $12 \%$ de proteína (mín.).

Tabela 1- valores encontrados durante as análises Físico-químicas.

\begin{tabular}{|c|c|}
\hline & Linguiça com adição de cerveja \\
\hline Umidade & $71,84 \%$ \\
\hline pH & 5,54 \\
\hline Proteína & $16,18 \%$ \\
\hline Cinzas & $9,13 \%$ \\
\hline
\end{tabular}

As linguiças com adição de cerveja encontravam-se em desacordo com a legislação para o teor de umidade, ou seja, teores acima do limite máximo (70\%). Isso pode estar relacionado à adição de cerveja que contém 90\% de água em sua composição.

Os valores de $\mathrm{pH}$ das amostras Linguiça de cerveja e Linguiça Tradicional, variaram entre 5,8 a 5,54. A importância do controle do $\mathrm{pH}$ de produtos cárneos está diretamente relacionada com o possível desenvolvimento microbiano, indicando que resultados encontrados para as amostras está na faixa aceitável para consumo. Os resultados obtidos nas análises de proteínas foram próximo encontrados por (Silva 2013), onde deparou-se com um percentual de 16,8\%. As linguiças apresentaram maiores teores de cinzas comparado com os resultados encontrado por (Nascimento 2012), que se deparou com teores de cinzas entre 3,21\% e 3,19\%, provavelmente se devem à utilização de cloreto de sódio, condimentos e especiarias na formulação das linguiças.

Os alimentos de origem animal, principalmente os manipulados, apresentaram condições favoráveis para multiplicação de microrganismos, destacando o grupo de linguiças tipo frescais que sofrem grande manipulação durante o processamento. Pela Tabela 2, observam-se os resultados obtidos nos ensaios microbiológicos.

Tabela 2 - Resultados das análises microbiológicas

\begin{tabular}{|l|c|c|}
\multicolumn{1}{|c|}{ Determinações } & Linguiça com adição de cerveja & Padrão Federal * \\
\hline Clostridios Sulfito Redutores & $<10 / \mathrm{g}$ & $3 \times 10^{3} / \mathrm{g}$ \\
\hline Coliformes a $45^{\circ} \mathrm{C}$ & $15 / \mathrm{g}$ & $5 \times 10^{3} / \mathrm{g}$ \\
\hline E.coli & Ausência em $25 \mathrm{~g}$ & - \\
\hline Salmonella spp & Ausência em $25 \mathrm{~g}$ & Ausência $25 \mathrm{~g}$ \\
\hline
\end{tabular}

*RDC N¹2/ 2011 da ANVISA- Item 5, alínea "f". 
Os resultados microbiológicos do presente estudo mostram que os processos de fabricação das linguiças foram realizados de acordo com as Boas Práticas de Fabricação, pois não houve detecção de E.coli, Salmonella, e os valores encontrados para coliformes termotolerantes e clostrídios sulfito redutores estão de acordo com a legislação vigente RDC12 (Brasil,2001).

\section{CONSIDERAÇÕES FINAIS}

A linguiça tipo frescal, principalmente se manipulada sem as condições ideais higiênico-sanitárias, apresentam maiores condições para multiplicação de microrganismos.

Para os parâmetros de físico-químicas, observou-se que exceto pela umidade os resultados adequam a legislação.

Com relação as determinações microbiológicas, todas as amostras analisadas atendiam ás condições higiênico- sanitária estabelecidas pela legislação sendo satisfatório para o consumo humano, uma vez que microrganismos do gênero Salmonella, Escherichia coli são um dos principais agentes de toxinfecções alimentares graves. Esses resultados mostraram que é possível, a obtenção de linguiça frescal com ausência de Salmonella sp, E.coli, utilizando-se matéria-prima de qualidade e adoção de técnicas de higiene adequada durante o processamento.

\section{REFERÊNCIAS}

[1] AMBEV (Companhia de bebidas das américas). 0 gosto da cerveja. In: _. Relatório Anual 2011. 2011. p. 25.

[2] BARROS, F. Avaliações Bromatológicas e Microbiológicas de Linguiça Colonial suína e Ligth. 2011. 49f. - Universidade UNIVATES, Lajeado, 2011.

[3] BOHATCH, A. Cerveja: Fabricação em pequena escala. Curitiba: Núcleo de produção gráfica da Emater, 1994. p. 3, 9-17,19-31.

[4] BRASIL. Ministério da Saúde. Regulamento Técnico de Atribuição de Função de Aditivos, e seus Limites Máximos de Uso para a Categoria 8 - Carne e Produtos Cárneos. Portaria no. 1002/1004, de 11de dezembro de 1998. Brasília: Ministério da Saúde, 1998.

[5] BRASIL, Ministério da saúde, Agência Nacional de Vigilância Sanitária (ANVISA), Resolução RDC no 12 de 02 de janeiro de 2001. Regulamento Técnico Sobre Os Padrões Microbiológicos para Alimentos. Diário Oficial. Brasília, DF. 10 de janeiro de 2011.

[6] Brasil. Ministério da Agricultura, Pecuária e Abastecimento. Instrução normativa no 4, de 31 de março de 2000. Anexo III - Aprova o Regulamento técnico de identidade e qualidade de linguiça. Diário Oficial [da] República Federativa do Brasil. Brasília, DF, 05 de abr. de 2000.

[7] CARVALHO, C.C.P; FILHO, F. L; HOFFMANN, F. L; ROMANELLI, P. F. Histórico e aspectos tecnológicos do processamento da linguiça cuiabana. Rev. Inst. Adolfo Lutz (impr) vol.69 no.3 São Paulo,2010. 
[8] GALAN, D. Seis motivos para beber cerveja. Revista viva saúde, ed. 120, mai. 2013.

[9] MENDES, A.C.R. Propriedades funcionais das proteínas: sua importância e aplicabilidade em produtos alimentícios. Higiene Alimentar, v.12, n.56, 1998.

[10] REINOLD, M. Manual prático de cervejaria. 1.ed. São Paulo: Aden, 1997. p. 213.

[11] NASCIMENTO, R. S; FONSECA, A. B. M; FRANCO, R. M; MIRANDA, Z. B. Linguiças frescais elaboradas com carne de avestruz: características físico-químicas. Ciência Rural, Santa Maria, v.42, n.1, p.184-188, jan, 2012.

[12] SANTOS, E. dos. Avaliação das Propriedades Tecnológicas de Tripas Naturais Submetidas ao Tratamento com Soluções Emulsificantes.101 f, Universidade Federal de Santa Catarina, Florianópolis, 2006.

[13] SANTOS, M. S. dos. Produção de cerveja. In Cervejas e refrigerantes. 21 ed. São Paulo: CETESB, 2005. p. 16. Cap 3.

[14] SANTOS, S. de P. Da cerveja: Pilsner Urquell, a grande cerveja. In Vinho e história. São Paulo: Dórea Books and Art, 1998. p. 217-219.

[15] SILVA, D.P da. SILVA, T.S da; SILVA, A. D. P.; JUNIOR, A.F. C.; SCHENEIDT, G. N.Análise físicoquímica e sensorial de linguiça frescal mista de carne suína e caprina. Revista Verde de Agroecologia e Desenvolvimento Sustentável, Mossoró - RN, v. 8, n. 3, p. 239 - 246, Jul - Set, 2013,

[16] SILVA, N; JUNQUEIRA V.C.A, SILVEIRA, N.F.A, TANIWAKI M.H, SANTOS R.F.S; GOMES R.A.R. Manual de métodos de análise microbiológica de alimentos. 3ํㅗ ed. São Paulo: Varela; 2007.

[17] TSCHOPE, E. C. Micro cervejarias e cervejarias: A história, a arte e a tecnologia. 1.ed. São Paulo: Aden, 2001. p.223.

[18] VENTURINI, Anna Cecilia; CAVENAGHI, Ângela Dulce Carmen; CASTILLO Josefina Contreras; QUIÑONES, Eliane Marta. Avaliação sensorial e microbiológica de linguiça de frango frescal não curada com reduzido teor de gordura. Ciênc. Tecnol.Aliment. vol.31 no.3 Campinas July/Sept. 2011. 


\section{Capítulo 4}

Análise dos extratos brutos da Stryphnodendron adstringens (Barbatimão) e Poincianella pluviosa (Sibipiruna) quanto a ação antifúngica no fungo Botrytis cinerea

Ana Rita Zulim Leite

Amanda Correia Gardenal

Iasmim Pereira de Moraes

João Carlos Palazzo de Mello

Leila Larisa Medeiros Marques

Márcia Regina Ferreira Geraldo Perdoncini

Ana Carolina Guidi

Danielly Chierrito

Taísa Dalla Valle Rorig Ribeiro

Resumo: Botrytis cinerea é o principal patógeno em frutas, como morango, tomate e uva, sobrevivendo saprofiticamente ou por escleródio ou ainda por micélio dormente, sendo que os conídios são dispersos pelo ar e pela água afetando culturas, mas também a contaminação de tecidos vivos por ser um patógeno necrótofico. Consequentemente leva a perdas econômicas pela multiplicação no período pós-colheita dos frutos. Os extratos brutos das plantas barbatimão e sibipiruna oferecem atividades importantes em diversas áreas. Dessa maneira, o objetivo deste trabalho foi avaliar a ação desses extratos, analisando a concentração inibitória mínima (CIM) e a concentração fungicida mínima (CFM) frente ao fungo Botrytis cinerea. As análises foram efetuadas de acordo com a norma M38 A da National Committee for Clinical Laboratory Standart. 0 extrato bruto do barbatimão apresentou como CIM e CFM para a ação de inibição ao B. cinerea, respectivamente, os valores de $0,125 \mathrm{~g} \cdot \mathrm{mL}-1$ e $12,5 \%$, enquanto a sibipiruna obteve tais valores igual a $0,0156 \mathrm{~g} \cdot \mathrm{mL}-1$ e $25 \%$. Desta forma esses extratos podem ser testados para o controle desse fungo, o que se torna importante na conservação de várias frutas. 


\section{INTRODUÇÃO}

O Fungo Botrytis cinerea, agente causador do mofo cinzento, é o principal patógeno contaminante no morango, tomate, uva e entre outras frutas, onde a infecção começa na flor e se desenvolve através das feridas presentes na superfície do fruto, causando perda do valor econômico (HUSAINI, 2012). Segundo Palaretti (2018), o B. cinerea pode sobreviver saprofiticamente ou por escleródio ou ainda por micélio dormente e assim a dispersão dos conídios pelo ar e pela água afeta as culturas susceptíveis. Mas também o fungo pode-se estabelecer e multiplicar em tecidos mortos, isso ocorre devido a este ser um patógeno necrotrófico, que posteriormente colonizam os tecidos vivos causando danos nos componentes celulares. Logo, o B. cinerea causa perdas econômicas em mais de 200 espécies de plantas devido ao desenvolvimento deste principalmente no período pós-colheita. Um exemplo, de acordo com Jia et al. (2016), da ação danosa deste fungo é na produção do morango, que por possuir atividades metabólicas altas, como também elevado teor de umidade, açúcares e ácidos, são suscetíveis á degradação por este fungo, podendo gerar grandes perdas econômicas.

Stryphnodendron adstringens Beth (Barbatimão) é uma árvore de estatura média presente no litoral e no cerrado brasileiro, sendo sua madeira caracterizada por apresentar o cerne bruto com laivos escuros e firmes, em que os constituintes químicos são principalmente os taninos, mas apresentam também as resinas, óleos essenciais, mucilagens e de matéria corante vermelha. De acordo, com Fonseca et al. (2018) os taninos, produtos naturais presentes no barbatimão, possuem a composição polifenóica produzida pelo metabolismo secundário e apresentam ação contra insetos. Segundo Brito (2010), o barbatimão é utilizado para tratar leucorreia, diarreia e infecções ginecológicas.

Poincianella pluviosa popularmente conhecidaa como Sibipiruna, faz parte das plantas febaceas, sendo uma árvore ornamental de grande porte cultivada principalmente no centro sul do Brasil para a arborização de ruas (KAYANO 2011), cultivada em clima tropical, apresenta folhas pequenas e caducas semelhantes à folhagem do Pau-Brasil (CARVALHO, 2012). De acordo com Kayano (2011) Poincianella pluviosa possui alta fonte de metabólitos bioativos, como também biflavonoides, terpenos, esteroides e entre outros na quais auxiliam em atividade antimicrobiana, anti-inflamatório, antirreumática e analgésica. Seu extrato de etanólico apresenta atividade antimalárica.

0 objetivo deste trabalho foi avaliar a ação antimicrobiana dos extratos brutos de Barbatimão e Sibipiruna, sobre o fungo Botrytis cinerea através da análise de concentração inibitória mínima (CIM) e concentração fungicida mínima (CFM).

\section{MATERIAL E MÉTODOS}

\subsection{LOCAL}

As análises foram realizadas nos laboratórios de microbiologia da Universidade Tecnológica Federal do Paraná, Campus Campo Mourão-PR.

\subsection{MICRO-ORGANISMO}

O fungo B. cinerea CCT 1252 da coleção André Toselo.

\subsection{EXTRATOS}

Foram utilizados os extratos brutos de Poincianella pluviosa (Sibipiruna) e Stryphnodendron adstringens (Barbatimão). Cascas de P. pluviosa foram coletadas em Maringá, Paraná, Brasil e cascas do caule de S. adstringens foram coletadas em São Jerônimo da Serra, Paraná, Brasil. Os extratos de P. pluviosa e S. adstringes foram obtidos de acordo com metodologia proposta por Bueno et al. (2014) e Ishida et al. (2006).

\subsection{MEIOS DE CULTURA}

O meio RPMI-1640 foi utilizado para o teste da concentração inibitória mínima, pois é considerado satisfatório para ensaios de compostos antimicrobianos com fungos filamentosos e utilizado como meio padrão da norma de terapia antifúngica M38-A (NCCLS). Para o preparo do meio pesou-se 10,4g de meio 
RPMI-1640 em pó e 34,53g de tampão MOPS (ácido 3-[N-morfolino] propanosulfônico). 0 meio em pó foi dissolvido em $900 \mathrm{~mL}$ de água destilada. Adicionou-se MOPS (concentração final de 0,165 mol/L), agitando até dissolver. Durante a homogeneização o pH foi ajustado para 7,0 a $25^{\circ} \mathrm{C}$ usando o hidróxido de sódio 1 $\mathrm{mol} / \mathrm{L}$. Foi acrescentado água adicional para o meio obter um volume final de $1 \mathrm{~L}$. A esterilização ocorreu por filtragem e $\mathrm{o}$ armazenamento a $4^{\circ} \mathrm{C}$ até a utilização.

0 meio de cultura ágar DG-18 foi preparado adicionando-se a quantidade necessária do pó em água destilada, conforme instruções do fabricante e dissolvido por aquecimento sob agitação até a completa dissolução do ágar. Logo após, foi esterilizado em autoclave a uma temperatura de $121^{\circ} \mathrm{C}$ por 20 minutos e vertidos em placas de Petri estéreis.

\subsection{DETERMINAÇÃO DA CONCENTRAÇÃO INIBITÓRIA MÍNIMA (CIM) E CONCENTRAÇÃO FUNGICIDA MÍNIMA (CFM)}

A concentração inibitória mínima (CIM) foi determinada de acordo com o documento da CLSI, norma M38 a preconizada pela National Committee for Clinical Laboratory Standart (NCCLS, 2002), que traz o Método de Referência para Testes de Diluição em Caldo para a Determinação da Sensibilidade a Terapia Antifúngica dos Fungos Filamentosos. Para a realização da CIM foram utilizados 12 tubos testes contendo o meio RPMI.

Os fungos foram inoculados em ágar DG-18 por 7 dias á $25^{\circ} \mathrm{C}$ para o crescimento dos esporos. Após, uma solução estéril de tween 80 a $0,1 \%$, foi vertida sobre o micélio e feita a raspagem da colônia para a liberação dos esporos, os quais foram contados em Câmara de Neubauer. 0 inóculo foi diluído para uma concentração final de 104 esporos/mL, o qual foi utilizado para a determinação da CIM. Esse procedimento foi realizado para cada um dos dois extratos.

0 ensaio da CIM ocorreu em placa de 24 poços onde foram utilizados 12 poços para cada extrato, 10 desses como tubos testes contendo o meio RPMI e a suspensão de cada extrato, e os demais como controle positivo, isto é, apenas com o meio e o inóculo (poço 11) e controle negativo contendo apenas o meio (poço 12). Para cada extrato foi adicionado $500 \mu \mathrm{l}$ do meio RPMI nos tubos 2 ao 10 e $1000 \mu \mathrm{l}$ no tubo controle negativo. Nos tubos 1 e 2 foi adicionado $500 \mu \mathrm{l}$ de cada extrato a $1 \mathrm{~g}$.mL-1. A partir do tubo 2 foi realizada a diluição seriada dos extratos até o tubo 10, transferindo-se $500 \mu \mathrm{l}$ para cada tubo teste e ao final desprezando $500 \mu \mathrm{l}$ do tubo 10. Em seguida, adicionou-se $500 \mu \mathrm{l}$ da suspensão à 104 esporos $/ \mathrm{mL}$ do fungo B. cinerea nos poços testes (1 ao 10$)$ e no controle positivo 11, reduzindo a concentração dos extratos em cada poço pela metade. As placas foram levemente agitadas para a homogeneização do conteúdo e incubadas em estufa a $25^{\circ} \mathrm{C}$ por $24-48$ horas. Após este período foi verificado o crescimento do fungo por meio da turvação do meio e confirmação em microscópio estereoscópio. Foi considerada a CIM, a menor concentração em que o extrato impediu o crescimento do inóculo em teste.

A concentração fungicida mínima (CFM) foi determinada após posterior inoculação de $10 \mu \mathrm{l}$ de cada poço negativo em CIM no ágar DG-18 e incubação á $25^{\circ} \mathrm{C}$ por $24-48$ horas. Logo, a CFM foi a menor concentração onde não houve o crescimento do fungo.

\section{RESULTADOS E DISCUSSÃO}

Após a incubação foi analisado cada poço visualmente a olho nu e através da leitura em microscópio estereoscópio encontrando os resultados que estão expressos na tabela 1. Dessa maneira pode-se observar, utilizando os controles negativo e positivo, que o extrato bruto do barbatimão com concentração 0,125g.mL-1 impediu o crescimento das cepas de B. cinerea, assim como impediu o crescimento do fungo com CFM de 12,5\%. Enquanto para o extrato de sibipiruna foi necessário o dobro da concentração da CFM, isto é $25 \%$, para atuar como fungicida e 0,0156g.mL-1 de concentração foi capaz de inibir o crescimento do inóculo (CIM). 
Tabela 1. Resultados da CIM e da CFM dos Extratos Brutos Barbatimão e Sibipiruna aplicados no fungo Botrytis cinerea.

\begin{tabular}{|c|c|c|}
\hline \multicolumn{2}{|c|}{ Extratos } & \multicolumn{2}{c|}{ CIM* $^{*}$} & CFM M* $^{* *}$ \\
\hline Barbatimão & $0,125 \mathrm{~g} \cdot \mathrm{mL}-1$ & $12,5 \%$ \\
\hline Sibipiruna & $0,0156 \mathrm{~g} \cdot \mathrm{mL}-1$ & $25 \%$ \\
\hline
\end{tabular}

*(CIM) concentração inibitórios mínima; ** (CFM) concentração fungicida mínima.

Os estudos de extratos P. pluviosa estão relacionados com a atividade antimalárica, sendo mostrando eficiência contra a cepa resistente a cloroquina da doença malária (KAYANO 2011). Estudos de atividade antifúngica em espécies do mesmo gênero apresentam atividade antimicrobiana e tem sido utilizado em tratamentos antifúngicos, anti-inflamatórios e analgésicos; apresentam também atividade contra o Proteus vulgaris, Bacillus subtilis, além de inibir o crescimento de outras bactérias Gram-positivas e Gramnegativas pelo método de concentração inibitória mínima (CIM) (Zanin et al., 2012).

Dentre os constituintes químicos presentes no barbatimão, os taninos apresentam-se em maioria, entre $25 \%$ a $30 \%$, e a partir das complexações com proteínas, esse elemento possui atividade fungicida e bactericida. 0 extrato da casca dessa planta reduziu a incidência do fungo Fusarium subglutinans em abacaxi (RICARDO, 2010).

\section{CONCLUSÃO}

Os extratos brutos de barbatimão e sibipiruna apresentaram efeitos inibitórios contra o fungo B. cinerea, sendo o barbatimão mais eficaz que a sibipurina. Estudos futuros são necessários para a verificação no controle deste fungo diretamente em frutos.

\section{AGRADECIMENTOS}

Universidade Tecnologica Federal do Paraná e Universidade Estadual de Maringá.

\section{REFERENNCIAS}

[1] BRITO, E. G. Efeitos in vitro de extratos naturais sobre Enterococcus faecalis, Staphylococcus aureus, Escherichia coli e Endotoxinas em canais radiculares. 130 f. Dissertação (mestrado) Odontologia, Universidade Estadual Paulista. São José dos Campos, 2010.

[2] BUENO, F. G. et al. Hydrolyzable tannins from hydroalcoholic extract from Poincianella pluviosa stem bark and its wound-healing properties: Phytochemical investigations and influence on in vitro cell physiology of human keratinocytes and dermal fibroblasts. Fitoterapia, v. 99, p. 252-260, 2014.

[3] CARVALHO, B. A. Estudo químico e avaliação das propriedades biológias de folhas e flores de Caesalpinia pluviosa var. peltophoroides. 90 f. Dissertação (mestrado) em Química, Universidade Federal de Alfenas. Alfenas-MG, 2012.

[4] FONSECA, J. et al. Efeito de extratos metanólicos de Stryphnodendron adstringens (MART) Coville na Alimentação e Reprodução de Plutella xylostella L. Comunicaciones Reports Comunicações, v.43, n.3, 2018.

[5] HUSAINI, A. M. et al. Modifying strawberry for better adaptability to adverse impact of climate change. Current Science, v. 102, n.12, 2012.

[6] ISHIDA, K. et al. Influence of tannins from Stryphnodendron adstringens on growth and virulence factors of Candida albicans. Journal of Antimicrobial Chemotherapy, v. 58, n. 5, p. 942-949, 2006.

[7] JIA, H. et al. Overexpressions of polyphenol oxidase gene in strawberry fruit delays the fungus infection process. Plant Molecular Biology Reporter, v. 34, n.3, p. 592-606, 2016.

[8] KAYANO, A. C. A. V. Avaliação in vivo e in vitro da atividade antimalárica de Caesalpinia pluviosa e análise da fração ativa. 116 f. Dissertação (mestrado) Instituto de Biologia, Universidade Estadual de Campinas. Campinas, 2011.

[9] NCCLS. Método de Referência para Testes de Diluição em Caldo para a Determinação da Sensibilidade a Terapia Antifúngica dos Fungos Filamentosos: Norma Aprovada. M38-A, v. 22, n. 16, 2002. 
[10] PALARETTI, V. V. Pressões hiperbáricas no controle de mofo cinzento e de mancha de alternaria na póscolheita de tomate Débora. 102 f. Tese (doutorado) Ciências Agrárias e Veterinárias, Universidade Estadual Paulista. Jaboticabal-SP, 2018.

[11] RICARDO, B. C. Avaliação da atividade antifúngica in vitro de extratos vegetais sobre Fusarium solani, causador de fitopatologias em culturas de batata-doce (Ipomoea batatas (L.) Lam.). 49 f. Monografia em Farmácia, Universidade Estadual da Paraíba. Campina Grande-PB, 2010.

[12] ZANIN, J. L. B. et al. The genus Caesalpinia L. (Caesalpiniaceae): phytochemical and pharmacological characteristics. Molecules, v. 17, p.7887-7902, 2012. 


\section{Capítulo 5}

\section{Utilização de biopolímeros \\ conservação de feijão-caupi}

\section{Solange de Sousa}

Gilmar Freire da Costa

Robson Rogério Pessoa Coelho

Resumo: 0 feijão é cultivado em quase todos os países de clima tropical e subtropical e, por isso, assume relevante importância na alimentação humana. Objetivou-se neste trabalho analisar a qualidade sanitária do feijão-caupi revestido com fécula de mandioca $1 \%$. Os grãos foram selecionados, submetidos à lavagem em água corrente, drenados em peneira e submetidos à secagem natural. Após a secagem, os grãos foram imersos na solução filmogênica, onde permaneceram por um minuto, sendo então drenados em peneira, seguindo para a etapa de secagem, realizada em estufa de secagem, à temperatura de $25^{\circ} \mathrm{C}$, durante 12 horas. Foram realizadas análises do teor de umidade inicial, grau de infestação, teste de sanidade e colorimetria. Os resultados mostraram que no período de armazenamento de um (1) ano, o feijão não apresentou crescimento dos insetos-praga, de micro-organismos, bem como não houve escurecimento do mesmo. Conclui-se, pois que o revestimento foi eficiente na conservação do feijão-caupi.

Palavras-chave: sanidade; cor; coberturas comestíveis. 


\section{INTRODUÇÃO}

O feijão é cultivado em quase todos os países de clima tropical e subtropical e, por isso, assume relevante importância na alimentação humana, fundamentalmente devido ao seu baixo custo, e por ser um alimento relativamente balanceado, tendo pronta aceitação nos mais diferentes hábitos alimentares. Sob o ponto de vista nutricional, o feijão é um bom alimento, pois proporciona elementos essenciais como aminoácidos indispensáveis, que complementam aqueles de origem animal para formar uma proteína de alto valor biológico no metabolismo humano, fornecendo também vitaminas, carboidratos, fibras e alguns minerais.

O feijão-caupi (Vigna unguiculata (L.) Walp.) é uma leguminosa que pertence à classe dicotyledoneae, ordem Fabales, família Fabaceae, subfamília Faboideae, tribo Phaseoleae, subtribo Phaseolinea, gênero Vigna e a espécie Vigna unguiculata.

É um dos principais componentes da dieta alimentar nas regiões Nordeste e Norte do Brasil, especialmente para os habitantes que residem na zona rural, sendo cultivado principalmente em áreas semiáridas.

O uso de revestimentos comestíveis vem sendo utilizando como uma alternativa tecnológica de baixo custo, alta sustentabilidade, sem causar impactos ambientais e boas propriedades na conservação de alimentos, principalmente vegetais, como frutas. Sousa (2011) utilizou revestimentos comestíveis de fécula de mandioca e cera de carnaúba na conservação de feijão-comum, não fumigado, observando também a influência dos mesmos nas características tecnológicas, sanitárias e nutricionais, tendo obtido bons resultados.

O Brasil, por apresentar características de país com dimensões continentais e pelo grande potencial agrícola que possui, se torna também um grande celeiro de problemas relacionados à produção e conservação pós-colheita de vegetais, principalmente aqueles mais perecíveis, como frutas e hortaliças, devido principalmente ao elevado teor de umidade. No entanto, grãos e cereais apresentam melhores características de conservação, se manipulados adequadamente na produção e no armazenamento póscolheita, por apresentarem menor valor de água contida em seus interstícios celulares.

O feijão-caupi apresenta propriedade nutricional superior à do feijão-comum (Phaseolus vulgaris L.), sendo consideravelmente de baixo custo de produção, tornando-se do ponto de vista alimentar, alimento importante não somente nas regiões Norte e Nordeste, mas em todo o país.

A barreira semipermeável proporcionada pelos revestimentos comestíveis é visada para aumentar a vida de prateleira pela redução da umidade e migração de solutos, troca gasosa, taxas de respiração e reação oxidativa, tão bem como suprimir desordens fisiológicas em frutas minimante processadas (Rojas-Graü et al., 2008).

Entre os filmes e revestimentos comestíveis à base de polissacarídios, os revestimentos desenvolvidos com amido já foram objeto de vários estudos em alimentos (Chen; Lai, 2008; Mathew; Abraham, 2008; Talja et al., 2008).

Phan The et al. (2009) utilizaram revestimentos comestíveis como agar, amido de mandioca e arabinoxilana, tendo observado melhoria nas propriedades de barreira ao vapor de água, além apresentarem de boa matriz coesiva para revestimentos de polissacarídios.

A mandioca (Manihot esculenta Crantz) é produzida na América Latina e outros países tropicais, principalmente no Brasil, e sua importância como fonte de amido cresce amplamente, por causa do preço baixo, quando comparado a outras fontes de amido (Matsui et al., 2004). Segundo Famá et al. (2005), o uso potencial da fécula de mandioca como matriz polimérica no desenvolvimento de filmes comestíveis para aplicação na superfície de alimentos vem recebendo atenção destacada.

A fécula de mandioca é o produto amiláceo extraído das partes subterrâneas comestíveis de vegetais como tubérculos, raízes e rizomas, que apresenta características de viscosidade próximas as do amido.

Segundo Resende et al. (2008), a presença do inseto-praga causa a deterioração intensa dos grãos de feijão, resultando numa qualidade tecnológica inferior. A temperatura de embebição aumenta a absorção de água dos grãos de feijão, sendo intensificada pela presença do inseto-praga, ao longo do período de armazenamento.

Quando o feijão é armazenamento em condições inadequadas, a preservação de suas qualidades é extremamente prejudicada, se não levarmos em consideração variáveis como teor de água, temperatura e o próprio período de armazenamento, são fatores que devem ser controlados, caso contrário podem ocorrer infestações por pragas, entre elas o Callosobruchus maculatus, que causam perdas qualitativas e 
quantitativas, reduzindo os valores nutritivos e comerciais do produto. Os insetos-praga estão entre os fatores bióticos que mais limitam o rendimento agronômico da cultura deste feijão.

Objetivou-se neste trabalho determinar a qualidade sanitária, bem como análise colorimétrica e teor de umidade dos grãos de feijão-caupi, revestidos com cobertura comestível de fécula de mandioca $1 \%$.

\section{MATERIAL E MÉTODOS}

O feijão do grupo caupi foi adquirido de um produtor rural do município de Bananeiras, PB. Os grãos utilizados no experimento não passaram por fumigação. Os experimentos serão conduzidos no Laboratório de Desenvolvimento de Produtos e Análise Sensorial e Laboratório de Microbiologia, do Departamento de Gestão e Tecnologia Agroindustrial (DGTA), situados no Campus III, da Universidade Federal da Paraíba (UFPB), em Bananeiras-PB.

Os grãos foram selecionados, submetidos à lavagem em água corrente, drenados em peneira e submetidos à secagem natural. Em seguida, serão armazenados em sacos de polietileno e mantidos em temperatura de refrigeração $(4 \pm 2 \stackrel{\circ}{ } \mathrm{C})$, até realização do experimento. Foram realizadas análises para determinação do teor de umidade inicial dos grãos.

\subsection{APLICAÇÃO DOS REVESTIMENTOS}

A fécula de mandioca foi adquirida em supermercado no município de Bananeiras-PB. 0 revestimento foi formulado utilizando como base polimérica um carboidrato (fécula de mandioca 1\%).

Os grãos de feijão serão imersos na solução filmogênica, onde permaneceram por um minuto, sendo então drenados em peneira, seguindo para a etapa de secagem, realizada em estufa de secagem, à temperatura de $25^{\circ} \mathrm{C}$, durante 12 horas.

Os tratamentos serão os seguintes: controle (sem revestimento), fécula de mandioca (FM), para as temperaturas ambiente e de refrigeração, totalizando três tratamentos.

0 período de armazenamento dos grãos de feijão foi de 360 dias, em sacos de polietileno de baixa densidade, com espessura de $0,09 \mathrm{~mm}$, por $25,5 \mathrm{~cm}$ de largura e $35 \mathrm{~cm}$ de comprimento, sob condições refrigeradas e temperatura ambiente. As análises físicas de cor foram realizadas a cada 15 dias.

\subsection{TEOR DE UMIDADE}

Determinado pelo método gravimétrico, em estufa à $105 \pm 1 \stackrel{\circ}{\circ}$, por 24 horas, até peso constante, com três repetições, segundo metodologia disponível nas Regras para Análise de Sementes (BRASIL, 2009). As análises foram realizadas em duplicata. Os resultados foram expressos em porcentagem em base úmida.

\subsection{GRAU DE INFESTAÇÃO}

Realizado no Laboratório de Microbiologia do Departamento de Gestão e Tecnologia Agroindustrial da UFPB. A amostra foi composta por três repetições de 100 sementes por tratamento. As sementes foram imersas por 12 horas em água destilada e, posteriormente, examinadas individualmente, sendo registrado o número de sementes de cada repetição que apresentava ovo, larva, lagarta, pupa ou inseto adulto e, ou, orifício indicativo da saída do inseto-praga, conforme recomendação das Regras para Análise de Sementes (BRASIL, 2009). 0 resultado obtido foi expresso como a média das sementes infestados por insetos nas três repetições, em porcentagem.

\subsection{TESTE DE SANIDADE}

Identificação dos patógenos - foi empregado o método do blotter test em placas de Petri estéreis, contendo três discos de papel de filtro esterilizados e umedecidos com água destilada estéril, onde foram colocadas cinco sementes por placa, em três repetições para cada tratamento. Em seguida, as placas foram incubadas em B.O.D. à temperatura de $20 \pm 2{ }^{\circ} \mathrm{C}$, na ausência de luminosidade, por um período de sete dias (Manual para Análise Sanitária de Sementes, BRASIL, 2009) (metodologia modificada). 


\subsection{COLORIMETRIA}

As amostras foram analisadas colorimetricamente quanto às coordenadas $\mathrm{L}^{*}, \mathrm{a}^{*} \mathrm{e} \mathrm{b}^{*}$, em colorímetro Colorquest XE HunterLab, utilizando-se o iluminante padrão D65 e observador a 10 (Sistema CIE-Lab). A leitura das coordenadas foi realizada em cinco pontos distintos de cada amostra dos grãos crus.

\subsection{DELINEAMENTO EXPERIMENTAL E ANÁLISE ESTATÍSTICA}

Foi utilizado o delineamento inteiramente casualizado (DIC), com os tratamentos dispostos num esquema fatorial $1 \times 2 \times 8$, sendo um revestimento, duas temperaturas de armazenagem (ambiente e de refrigeração), 12 períodos de armazenamento, em três repetições. As unidades experimentais foram representadas pelos tratamentos acondicionados em sacos de polietileno de baixa densidade, armazenados em bancada de laboratório, sem controle das condições de luminosidade, e sob refrigeração, em refrigerador doméstico.

Os dados de cor foram submetidos à análise de variância (ANOVA) pelo teste F. Para as interações significativas foi realizado o desdobramento dos dados, onde a partir dos valores obtidos foram feitas análises de regressão em função do tempo de armazenamento. Na análise de regressão, além da significância dos efeitos dos componentes $(\mathrm{p}<0,05)$, foi utilizado o coeficiente de determinação (R2), como critério adicional para a escolha do modelo.

Os dados do porcentual de sanidade e grau de infestação que apresentaram valores nulos foram ajustados, através de transformação dada pela equação (X + 0,5)1/2 (GOMES, 1985), sendo em seguida submetidos à análise de variância.

As análises foram realizadas com o software Statistical Analysis System (SAS®, 2014), versão 9.1, licenciado pela Universidade Federal da Paraíba, Campus III.

\section{RESULTADOS E DISCUSSÃO}

Os resultados do teor de umidade mostraram-se constantes em torno de 16\%, sem apresentar diferença estatística entre os períodos de armazenamento. Enquanto isso, as coordenadas de cor só apresentaram variação no tratamento-controle, cujos valores variaram entre 46,5 a 48,7.

A qualidade sanitária foi preservada pelo revestimento à base da fécula de mandioca, onde não foi verificada a presença de insetos-praga durante o período de armazenamento.

\section{CONCLUSÃO}

0 revestimento de fécula de mandioca possibilitou o armazenamento dos grãos de feijão-caupi durante um ano, sem que houvesse apresentação de danos que pudessem alterar sua qualidade sanitária, tanto do ponto de vista microbiológico, quando em relação ao crescimento de insetos-praga.

\section{REFERÊNCIAS}

[1] Brasil. Ministério da Agricultura, Pecuária e Abastecimento. 2009. Regras para Análise de Sementes. Secretaria da Defesa Agropecuária. Brasília: MAPA/ACS. 399 p.

[2] Brasil. Ministério da Agricultura, Pecuária e Abastecimento. 2009. Manual de Análise Sanitária de Sementes. Ministério da Agricultura, Pecuária e Abastecimento. Secretaria de Defesa Agropecuária. Brasília: Mapa/ACS. 200 p.

[3] Chen, L. S.; Lai, C. H. 2008. Mechanical and water vapour barrier properties of tapioca starch/decolorized hsian-tsao leaf gum films in the presence of plasticizer. Food Hydrocolloids, v. 22, p. 1584-1595.

[4] Famá, L.; Rojas, A. M.; Goyanes, S.; Gerschenson, L. 2005. Mechanical properties of cassava-starch edible films containing sorbates. Lebensmittel Wissenschaft und Technologie, v. 38, p. 631-639.

[5] Gomes, F. P. A estatística moderna na pesquisa agropecuária. 2. ed. Piracicaba: Potafos, 1985. 159 p.

[6] Mathew, S.; Abraham, T. E. 2008. Characterisation of ferulic acid incorporated starch-chitosan blend films. Food Hydrocolloids, v. 22, p. 826-835. 
[7] Matsui, K. N.; Lorotonda, F. D. S.; Paes, S. S.; Luiz, D. B. \& Pires, A. T. N.; Laurindo, J. B. 2004. Cassava bagassekraft paper composites: Analysis of influence of impregnation with starch acetate on tensile strength and water absorption properties. Carbohydrate Polymers, v. 55, p. 237-243.

[8] Phan The, D.; Debeaufort, F.; Voilley, A. \& Luu, D. 2009. Biopolymer interactions affect the functional properties of edible films based on agar, cassava starch and arabinoxylan blends. Journal of Food Engineering, v. 90, p. 548-558.

[9] Resende, O.; Corrêa, P. C.; Faroni, L. R. D’A. \& Cecon, P. R. 2008. Avaliação da qualidade tecnológica do feijão durante o armazenamento. Ciência e Agrotecnologia, v. 32, n. 2, p. 517-524.

[10] Rojas-Graü, M. A.; Tapia, M. S. \& Martín-Belloso, 0. 2008. Using polysaccharide-based edible coatings to maintain quality of fresh-cut Fuji apples. Food Science and Technology - LWT, v. 41, p. 139-147.

[11] Sousa, S. Revestimento ativo enriquecido com aminoácidos em feijão-comum. (2011). 133 f. Tese (Doutorado em Ciência e Tecnologia de Alimentos) - Universidade Federal de Viçosa - UFV, Viçosa-MG, 2011.

[12] Talja, R. A.; Helen, H.; Roos, Y. \& Joupplia, K. 2008. Effect of type and content of binary polyol mixtures on physical and mechanical properties of starch-based edible films. Carbohydrate Polymers, v. 71, p. 269-276. 


\section{Capítulo 6}

Nanopartículas de ouro suportadas em filmes biopoliméricos eficientes na atividade antimicrobiana

Carla Weber Scheeren

Maicon Roldão Borges

Larissa Morgana Ferreira Scopel

Otávio Bugoni

Resumo: Nanopartículas de $\mathrm{Au}$ foram sintetizadas pela redução do complexo tetracloroáurico triidratado $\left(\mathrm{HAuCl}_{4} .3 \mathrm{H}_{2} \mathrm{O}\right)$ em líquido iônico hexafluorofosfato de 1-nbutil-3-metil-imidazólio (BMI.PF6) usando boroidreto de sódio como redutor em temperatura ambiente. Posteriormente as nanopartículas de $\mathrm{Au}$ obtidas foram suportadas em filmes biopoliméricos, utilizando-se solução de acetato de celulose dissolvido em acetona. Os filmes biopoliméricos contendo nanopartículas de $\mathrm{Au}$ suportadas foram aplicados na investigação da atividade antimicrobiana frente às bactérias E.Coli e S. Aureus.

Palavras-chave: Filmes biopoliméricos, Nanopartículas de Au, Líquido iônico, Atividade antimicrobiana. 


\section{INTRODUÇÃO}

Multidisciplinar a nanociência tem potencial de aplicação em diferentes áreas como: alimentos, biologia, física, química e engenharia.1 A combinação de nanopartículas (NPs) metálicas e filmes biopoliméricos com atividade antibacteriana têm sido muito estudados, os quais exibem grande atividade tóxica frente a bactérias e outros microorganismos, como fungos e também o sistema humano.2-9 NPs metálicas são capazes de incapacitar micróbios através da interação com algumas enzimas, proteínas e/ou DNA, inibindo a proliferação celular ou divisão celular. Para estas aplicações, NPs têm sido suportadas em biopolímeros em várias formas (por ex. cateteres, material dentário, dispositivos médicos, implantes e curativos para queimaduras) com o objetivo de proteger contra a contaminação microbiana. Pra aplicações médicas, o acetato de celulose (AC) é um bom candidato, porque este polímero é hidrofílico, não tóxico, biodegradável e renovável.10 Podemos citar um exemplo, onde tecido de algodão foi usado como suporte para NPs de prata $(41 \pm 7 \mathrm{~nm})$ com efeito antimicrobiano em bactérias gram-positivas (Staphylococcus aureus) e gram-negativas (Escherichia coli). Filmes biopoliméricos de acetato de celulose semipermeáveis foram utilizados como suporte para NPs de Pt e Au.11 Entretanto, um filme polimérico pode exibir outras vantagens adicionais como um material com maior capacidade de imobilização e seletividade, redução no tamanho de partícula, prevenção da aglomeração das NPs e estabelecimento de uma região de contato poroso entre as fases líquida e gasosa com a estrutura polimérica.12 Neste trabalho, nós demonstramos a combinação de NPs de $\mathrm{Au}$ sintetizadas em líquido iônico BMI.PF 6 suportadas em filme biopolimérico de acetato de celulose com investigação em atividade antimicrobiana frente as bactérias S. aureus e E. coli. A combinação gerou a formação de um material com estrutura porosa com fácil incorporação das NPs de Au e boa atividade antimicrobiana. Este material pode ser utilizado na fabricação de filmes antimicrobianos para embalagem de alimentos, proporcionando assim maior tempo de conservação.

\section{MATERIAL E MÉTODOS}

Síntese de NPs de Au em líquido iônico BMI.PF 6 : Foi preparada uma solução dissolvendo borohidreto de sódio $\left(\mathrm{NaBH}_{4}\right),(9,25 \mathrm{mg}, 250 \mathrm{mmol})$ em $2 \mathrm{~mL}$ de metanol e disperso em $1 \mathrm{~mL}$ de líquido iônico (BMI.PF $)$. Separadamente, foi preparada uma solução contendo o precursor utilizado na síntese de NPs de Au, $\mathrm{HAuCl}_{4} \cdot 3 \mathrm{H}_{2} \mathrm{O}(10 \mathrm{mg}, 25 \mathrm{mmoL})$ dissolvido em $2 \mathrm{~mL}$ de metanol e disperso em $1 \mathrm{~mL}$ de líquido iônico $\left(\mathrm{BMI}_{\mathrm{P}} \mathrm{F}_{6}\right)$, esta solução formada foi agitada a temperatura ambiente por $15 \mathrm{~min}$, formando uma solução amarela. Posteriormente a primeira solução contendo $\mathrm{NaBH}_{4}$ foi adicionada a segunda solução contendo ouro formando uma solução vermelha (característica da formação de NPs de ouro). A solução de NPs de Au obtida foi analisada em espectrofotômetro UV-Vis e por MET.

Síntese da solução biopolimérica e dos filmes biopoliméricos contendo NPs de Au suportadas: Neste experimento, foi preparada uma solução contendo $35 \mathrm{~mL}$ de acetona e $2,5 \mathrm{~g}$ de acetato de celulose, após dissolução do acetato de celulose a mistura permaneceu em repouso por $1 \mathrm{~h}$, para obter a viscosidade desejada. Após $1 \mathrm{~h}$ os filmes biopoliméricos foram preparados, sendo que foram preparados filmes biopoliméricos sem NPs (denominados de branco, AC) e filmes contendo $10 \mathrm{mg}$ de NPs de $\mathrm{Au}$ (denominados $\mathrm{AC} / \mathrm{Au}$ ). A mistura foi imersa em equipamento ultrassom Maxiclean 750A Unique, para dispersão das NPs de Au e depois a solução foi vertida em placa de Petri formando os filmes biopoliméricos.

Investigação da atividade antimicrobiana frente às bactérias E. coli e S. aureus: Estas experiências foram realizadas num meio de Luria-Bertani (LB) Agar sólido em uma placa de Petri. Os filmes biopoliméricos liofilizados foram cortados em forma de disco de 1,5 cm de diâmetro, esterilizados por autoclave durante 15 minutos a $120^{\circ} \mathrm{C}$, e colocados em uma placa de Agar contendo bactérias E. coli- cultivadas e em outra placa Agar de bactérias S. aureus- cultivadas. As placas de Petri foram colocadas em incubadora durante $24 \mathrm{~h}$ a $37^{\circ} \mathrm{C}$ para formação dos halos de inibição bacteriana.

Avaliação dos resultados obtidos: Neste experimento as placas de Petri contendo as culturas de bactérias de E. coli e S. aureus incubadas na aula anterior foram analisadas para medir o halo de inibição bacteriana formado pelos filmes biopoliméricos contendo NPs de Au suportadas e os resultados obtidos foram avaliados. 


\section{ANÁLISES REALIZADAS}

Espectroscopia na região do Ultravioleta-Visível (UV-Vis): 0 espectro eletrônico da dispersão coloidal de NPs de Au foi realizado utilizando-se um Espectrofotômetro UV-visível modelo UV-2550 da Shimadzu, com leituras na região de 190 a $800 \mathrm{~cm}-1$, com celas de quartzo de $1 \mathrm{~cm}$ de caminho óptico.

Microscopia Eletrônica de Varredura (MEV): As análises por MEV para o estudo da morfologia dos filmes biopoliméricos contendo NPs de Au suportadas foram conduzidas utilizando-se um modelo JEOL JSM 5800 com 10 a $20 \mathrm{kV}$ e magnificação de 5000x.

Microscopia Eletrônica de Transmissão (MET): A análise de MET das NPs de Au foi realizada utilizando-se um microscópio JEOL JEM1200EXII operando em $120 \mathrm{kv}$. Para a análise foi utilizada uma amostra das NPs de Au obtidas no experimento. A análise da solução coloidal foi realizada com auxílio de pipeta de Pasteur, sobre o grid de cobre (300 mesh) recoberto com uma fina camada de Carbono. A contagem das partículas foi feita utilizando o software SigmaScan Pro 5. Os histogramas da distribuição foram obtidos usando o programa Origin 8, através da medida do diâmetro de aproximadamente 300 partículas de Au.

\section{RESULTADOS E DISCUSSÕES}

A síntese das NPs de Au coloidal está relacionada à redução do Au3+ para Au0 pela ação do boroidreto de sódio como agente redutor, resultando na formação de NPs que possuem rede cúbica de face centrada (fcc). Os íons Au3+ são introduzidos ao meio reacional a partir do ácido tetracloroáurico triidratado, sendo a forma ácida do cloreto de ouro (III). No nosso experimento observou-se a mudança de coloração do meio reacional de amarelo para vermelho, que se intensificou até o final da síntese. Após aproximadamente $5 \mathrm{~min}$, a solução resultante apresentou uma coloração vermelha intensa. Na Figura 1 está representado o espectro da solução de NPs de Au, obtidas no experimento, por espectroscopia de UVvisível. A banda de absorção para a amostra ocorreu em $524 \mathrm{~nm}$. A interação entre as NPs metálicas e a luz está relacionada com a ressonância plasmônica. Ao contrário do ouro em forma de sal ou metálico, que apresentam cor amarelada, o ouro coloidal apresenta coloração avermelhada, as NPs de ouro absorvem na região de $\sim 500 \mathrm{~nm}$ a $\sim 560 \mathrm{~nm}$.

As técnicas de caracterização utilizadas, ultravioleta-Visível (UV-Vis), microscopia eletrônica de varredura (MEV) e microscopia eletrônica de transmissão (MET) nos fornecem informações a respeito do tamanho, forma e composição das NPs de Au e dos filmes biopoliméricos. Estas informações são de suma importância, pois estão diretamente relacionadas com os resultados obtidos na aplicação destas NPs em diversas áreas como, catálise, ótica, médica, farmacêutica, eletroquímica e atividade biológica.

Figura 1. Espectro de Uv-vísivel da dispersão coloidal de NPs de Au

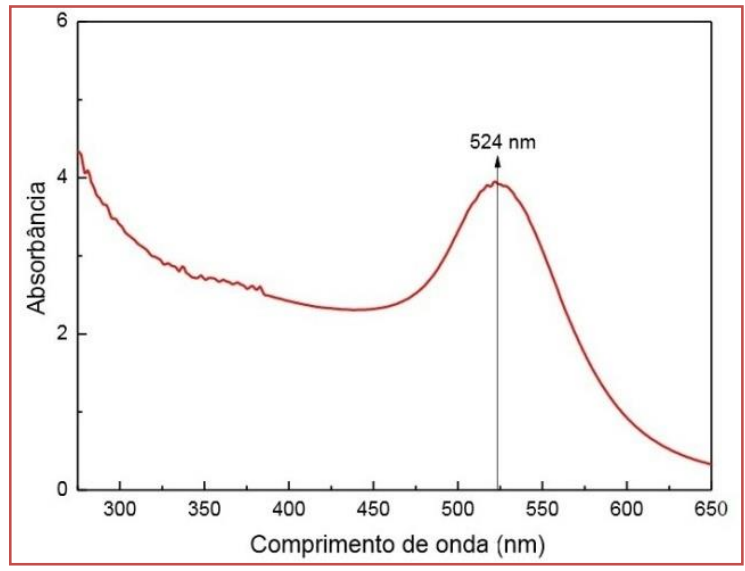

Se observarmos o espectro eletromagnético veremos que a região em que as NPs de ouro absorvem corresponde ao verde, ou seja, elas absorvem o verde e refletem o vermelho. As NPs de Au obtidas também foram analisadas por microscopia eletrônica de transmissão (MET). A micrografia e o histograma de distribuição de diâmetro médio das partículas obtidas são expostos na Figura 2. As NPs de Au (Figura 2A) exibiram diâmetro médio de $11 \pm 1.5 \mathrm{~nm}$. 0 histograma de distribuição de diâmetro (Figura 2B) foi obtido pela contagem de cerca de 300 partículas em diferentes regiões do grid analisado por MET. 
Figura 2. Micrografia obtida por MET (A) NPs de Au e (B) histograma de distribuição de diâmetro das NPs de Au.

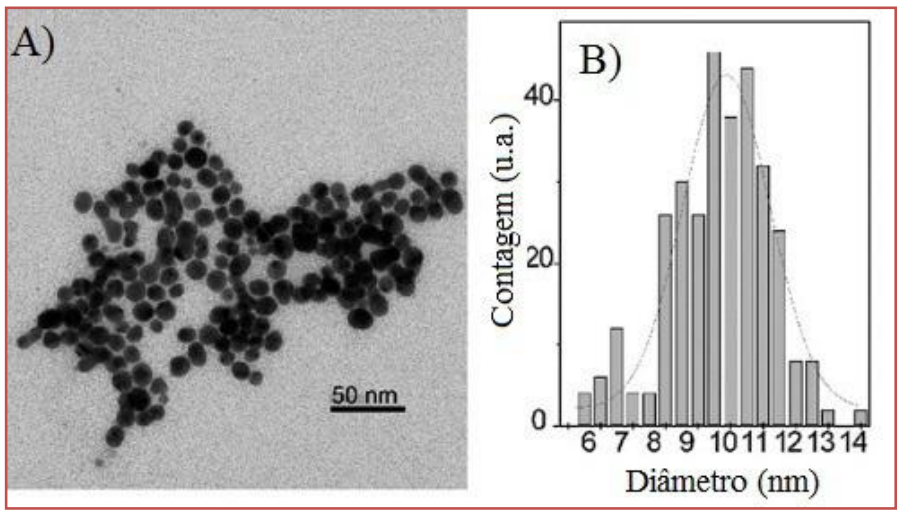

A dispersão coloidal vermelha de ouro preparada em líquido iônico BMI.PF6 foi misturada com uma solução de acetato de celulose (AC) dissolvida em acetona. A mistura obtida foi vertida em placa de Petri, após 5 min ocorreu à evaporação total do solvente e obtiveram-se os filmes biopoliméricos contendo NPs de Au suportadas, denominados $\mathrm{AC} / \mathrm{Au}$.

Os filmes biopoliméricos contendo NPs de $\mathrm{Au}$ suportadas (AC/Au) foram analisados por microscopia eletrônica de varredura (MEV). A Figura 3 expõe a micrografia obtida por MEV. Podemos observar que o filme apresenta estrutura porosa e que pequenos aglomerados de NPs de Au estão distribuídos homogeneamente sobre todo filme biopolimérico.

Figura 3. Micrografia obtida por MEV de pequenos aglomerados de NPs de Au distribuídos nos filmes biopoliméricos.

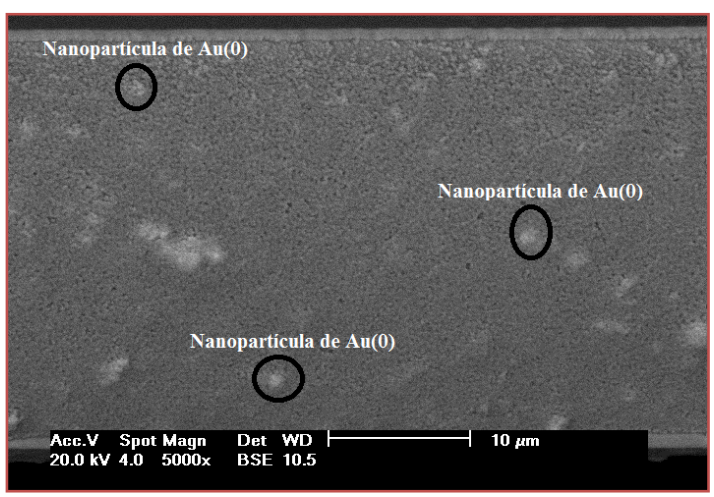

A atividade antimicrobiana dos filmes biopoliméricos foi investigada frente a bactérias gram-positivas (S. aureus) e gram-negativas (E.coli) através do método de disco com formação de halo de inibição. As bactérias $\mathrm{S}$. aureus, são cocos, gram-positivos, sendo que muitos pertencem à microbiota normal do trato respiratório superior ou da pele. As bactérias E. coli, se referem a gêneros diversos de bactéria bacilar gram-negativa, sendo um parasita intestinal generalizado de mamíferos. A habilidade dos filmes biopoliméricos contendo NPs de Au suportadas em inibir o crescimento destas bactérias está exposto na Figura 4. Nos experimentos utilizamos um disco de $1,5 \mathrm{~cm}$ de filme biopolimérico sem a presença NPs de $\mathrm{Au}$ (denominado de $\mathrm{AC}$ ), localizado na esquerda da placa de Petri, e um disco de filme biopolimérico contendo NPs de $\mathrm{Au}$ (denominado $\mathrm{AC} / \mathrm{Au}$ ), localizado à direita na placa de Petri.

A ação antibacteriana das NPs metálicas ocorre através da coordenação destas a camada superficial das bactérias ocasionando o rompimento da camada de peptidoglicano e consequente inativação. A camada de peptidoglicano da bactéria gram-negativa (E.coli) é mais fina do que nas bactérias gram-positivas (S.aureus),13 provavelmente este fato está relacionado às NPs de Au se coordenarem mais facilmente e eficientemente causando maior inibição nas bactérias E. coli do que nas bactérias S. aureus (a formação de $5 \mathrm{~mm}$ de halo de inibição bacteriana foram obtidos para E. coli e $3 \mathrm{~mm}$ para S. aureus, Figura 4). 13 
Figura 4. Atividade Antimicrobiana dos filmes biopoliméricos, AC (Branco, filme sem NPs Au) e AC/Au (filme contendo NPs de Au) frente as Bactérias: (A) E.coli e (B) S. aureus.

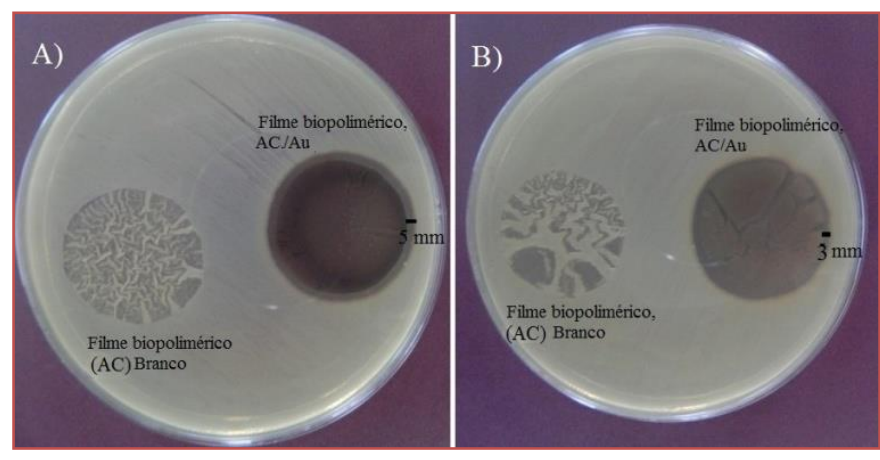

\section{CONCLUSÃO}

Podemos concluir que a síntese de filmes biopoliméricos contendo nanopartículas de Au suportada gerou um material eficiente com grande efeito antimicrobiano. As técnicas de caracterização utilizadas contribuíram para que a prática fosse bem sucedida e agregasse conhecimento a respeito dos fenômenos relacionados a sistemas em escala nano. A aplicação dos filmes biopoliméricos contendo NPs de Au suportadas em inativação antimicrobiana também despertou grande atenção dos alunos, devido a ser um tema sempre atual e resultado de extensa aplicação, os filmes biopoliméricos antimicrobianos podem ser utilizados como embalagens para a conservação de frutas e alimentos.

\section{AGRADECIMENTOS}

Agradecimentos à CAPES, FAPERGS e CNPq pelo suporte financeiro.

\section{REFERÊNCIAS}

[1] Hochella-Júnior, M. F.; Earth Planet Sci. Lett. 2002, 203, 593.

[2] Stoimenov, P. K.; Klinger, R. L.; Marchin, G. L.; Klabunde, K. J.; Langmuir 2002, 18, 6679.

[3] Balogh, L.; Swanson, D. R.; Tomalia, D. A.; Hagnauer, G. L.; McManus, A. T.; Nano Lett. 2001, 1, 18.

[4] Kasuga, T.; Kume, H.; Abe, Y.; J. Am. Ceram. Soc. 1997, 80, 777.

[5] Kasuga, T.; Kume, H.; Abe, Y.; J. Am. Ceram. Soc. 1999, 82, 65.

[6] Yang, M. R.; Chem, K. S.; Rsai, J. C.; Tseng, C. C.; Lin, S. F.; Mater. Sci. Eng., C. 2002, 20, 167.

[7] Scheeren, C. W.; Hermes, V.; Bianchi, O.; Hertz, P.; Dias, S. L. P.; Dupont, J.; J Nanosci. Nanotechnol. 2011, 11, 5114.

[8] Kwak, S. Y.; Kim, S. H.; Kim, S. S.; Environ. Sci. Technol. 2001, 35, 2388.

[9] Kierans, M.; Staines, A. M.; Bennett, H.; Gadd, G. M.; Biology of Metals 1991, 4, 100.

[10] Ciriolo, M. R.; Civitareale, P.; Carri, M. T.; De Martino, A.; Galiazzo, F.; Rotilio, G.; The Journal of Biological Chemistry 1994, 269, 25783.

[11] Edgar, K. J.; Buchanan, C. M.; Debenham, J. S.; Prog. Polym. Sci. 2001, 26, 1605.

[12] Viswanathan, G.; Murugesan, S.; Pushparaj, V.; Nalamasu, O.; Ajayan, P. M.; Linhardt, R. J.; Biomacromolecules $2006,7,415$.

[13] Xu, J.; Dozier, A.; Bhattacharyya, D.; J. Nanop. Res. 2005, 7, 449. 


\section{Capítulo 7}

\section{Avaliação da capacidade antioxidante de diferentes}

matrizes alimentares por voltametria*

\section{Júnio Gonçalves da Silva}

Flávia de Abreu Pinheiro

Leonardo Luiz Okumura

Astréa Filomena de Souza Silva

Edimar Aparecida Filomeno Fontes

Resumo: Frente às diversas causas que desencadeiam o estresse oxidativo no organismo humano, fazem-se necessários estudos que apontem fontes de antioxidantes naturais. Estes compostos impedem tal desequilíbrio oxidativo, e assim, previnem efeitos negativos ao organismo. Com isto, objetivou-se neste estudo avaliar a capacidade antioxidante de matrizes alimentares, por meio de técnicas voltamétricas. Foram estudadas doze amostras de vegetais em diferentes meios de extração. Utilizou-se as técnicas voltamétricas de pulso diferencial e onda quadrada, ambas no sentido anódico. Concluiu-se que, as técnicas voltamétricas, por fornecerem informações sobre processos redox, podem ser aplicadas para determinação da capacidade antioxidante. Dentre as amostras, destacou-se a hortelã por apresentar espécies químicas com alta tendência em atuarem como agentes redutores. Todas as matrizes estudadas apresentaram caráter antioxidante, e, apesar da intensidade desta ação ter variado entre elas, todas podem ser consideradas fontes naturais de antioxidantes, promovendo benefícios à saúde.

Palavras-Chave: antioxidantes; voltametria; métodos analíticos; alimentos. 


\section{INTRODUÇÃO}

Cerca de $90 \%$ do oxigênio que respiramos é utilizado pelas mitocôndrias por meio da cadeia transportadora de elétrons. Sendo que $2 \%$ a $5 \%$ dessa fração são convertidos em espécies reativas de oxigênio (ERO) (Halliwell e Gutteridge, 1999). Tais ERO são estruturas químicas altamente reativas que, embora atuem como mecanismo de defesa do organismo, quando em excesso, podem ser associadas a inúmeros processos fisiopatológicos, como doenças cardiovasculares, inflamatórias, respiratórias, envelhecimento, câncer, diabetes, catarata, doença de Parkinson, Alzheimer, dentre outros (Swapna et al., 2014).

Com o intuito de combater o excesso de ERO produzidas, o organismo utiliza-se dos antioxidantes (Egea et al., 2017), sendo a ação antioxidante no organismo obtida por vias enzimáticas, não enzimáticas e por compostos adquiridos na alimentação. Neste sentido, a busca por alimentos que contenham quantidades apreciáveis de antioxidantes em sua composição é necessária, pois apenas os mecanismos endógenos não são suficientes para combater as ERO.

Uma das maneiras de avaliar o potencial antioxidante dos alimentos é a partir da determinação da sua capacidade antioxidante. Novas metodologias têm sido desenvolvidas e adaptadas para esta análise, com destaque para os ensaios eletroquímicos, dentre eles as técnicas voltamétricas (Ferreira, 2009). Dentre estas técnicas, têm-se: voltametria cíclica (CV), voltametria linear (LSV), voltametria de onda quadrada (SWV) e voltametria de pulso diferencial (DPV). Estas se diferem, basicamente, pela forma como o potencial é aplicado ao eletrodo de trabalho, o que gera diferentes características às técnicas, tais como, limite de deteç̧ão e a velocidade da análise (Bard e Faulkner, 2001).

As técnicas voltamétricas, em sistemas de três eletrodos, baseiam-se na medição da corrente elétrica que surge entre o eletrodo de trabalho e o auxiliar mediante a aplicação de um potencial na forma de pulsos em varredura entre o eletrodo de referência e o eletrodo de trabalho, de modo que apenas este último se polarize. A corrente elétrica resultante desta aplicação de potencial deve-se a reações de oxidação (sentido crescente de aplicação do potencial) ou redução (sentido decrescente de aplicação do potencial) que ocorrem na superfície do eletrodo de trabalho devido à presença de espécies eletroativas em solução (Pacheco et al., 2013).

A voltametria apresenta como vantagens: baixo custo operacional; não necessidade de pré-tratamento da amostra (como realizado para aplicação de técnicas tradicionais); rapidez na obtenção de dados; sensibilidade e portabilidade. Pelas vantagens já mencionadas e por fornecer informações relevantes sobre o processo redox, essa técnica tem sido aplicada em diversos estudos para determinação da capacidade antioxidante em alimentos (Jiao et al., 2018; Pinheiro et al., 2018; Vasić et al., 2019), sendo um alternativa viável para análises desta natureza.

Neste sentido, o presente estudo teve como finalidade avaliar a capacidade antioxidante de diferentes matrizes alimentícias por meio de técnicas voltamétricas.

\section{MATERIAL E MÉTODOS}

Foram analisadas doze amostras de vegetais: pequi, hortelã, beterraba, tomate, gengibre, kiwi, batata doce, banana, morango, cenoura, batata e goiaba, adquiridas no comércio local de Viçosa-MG. A escolha dos alimentos foi feita a partir de uma investigação literária prévia, na qual se buscou pesquisar alimentos que possuíssem compostos antioxidantes em sua composição.

Para investigação das substâncias passíveis de oxidação presentes nas matrizes alimentares realizou-se extrações em diferentes meios: ácido (solução tampão pH 5,0), básico (solução tampão pH 10,0), neutro

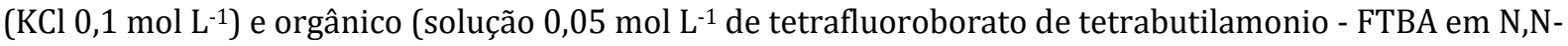
dimetilformamida - DMF). Os extratos foram preparados pela trituração de $15,0 \mathrm{~g}$ do vegetal juntamente com $30 \mathrm{~mL}$ do solvente extrator, utilizando-se um liquidificador e posterior filtração em papel filtro.

As análises foram realizadas imediatamente após o preparo dos extratos, com a finalidade de garantir a integridade de seus compostos bioativos que podem facilmente ser degradados por agentes externos, como luz, temperatura e oxigênio atmosférico. Foram utilizadas as técnicas voltamétricas de pulso diferencial e onda quadrada em varredura no sentido anódico (de oxidação).

As leituras foram realizadas utilizando-se um potenciostato/galvanostato $\mu$ Autolab Type III (Eco-Chemie, The Netherlands) interfaciado a um computador pelo software GPES (versão 4.9) e uma célula eletroquímica de aproximadamente $50 \mathrm{~mL}$, com arranjo de três eletrodos, sendo um eletrodo de trabalho 
de carbono vítreo com área geométrica de $0,127 \mathrm{~cm}^{2}$, um eletrodo auxiliar de platina e um eletrodo de referência de $\mathrm{Ag} \mid \mathrm{AgCl}, \mathrm{KCl}_{\text {sat. }} 3 \mathrm{~mol} \mathrm{~L}^{-1}$.

Os valores ajustados das variáveis em cada técnica voltamétrica estão descritos na Tabela 1.

Tabela 1. Valores ajustados das variáveis para as diferentes técnicas voltamétricas

\begin{tabular}{|c|c|c|c|}
\hline TÉCNICA & & VARIÁVEL & VALOR \\
\hline \multirow{3}{*}{$\begin{array}{l}\text { DPV(Differential Pulse } \\
\text { Voltammetry) }\end{array}$} & $A_{p}$ & Amplitude de pulso & $150 \mathrm{mV}$ \\
\hline & $v$ & Velocidade de varredura de potencial & $20 \mathrm{mV} \mathrm{s}^{-1}$ \\
\hline & $t_{p}$ & Tempo de pulso & $2 \mathrm{~ms}$ \\
\hline \multirow{3}{*}{$\begin{array}{l}\text { SWV(Square Wave } \\
\text { Voltammetry) }\end{array}$} & $A_{p}$ & Amplitude de pulso & $100 \mathrm{mV}$ \\
\hline & $f$ & Frequência & $100 \mathrm{~Hz}$ \\
\hline & $\mathrm{I}_{\mathrm{V}}$ & Incremento de varredura & $0,75 \mathrm{mV}$ \\
\hline
\end{tabular}

As leituras foram realizadas em triplicata com limpeza mecânica da superfície do eletrodo de trabalho após cada leitura. Para isto utilizou-se uma suspensão de alumina em filtro metalográfico.

As inferências sobre a capacidade antioxidante, de cada amostra, foram baseadas nos valores de potencial de pico anódico $\left(\mathrm{E}_{\mathrm{pa}}\right)$ médios, descritos nos voltamogramas gerados com auxílio do Software OriginPro 8. Os resultados foram expressos como valor médio da triplicata e desvio-padrão para o potencial anódico $\left(\mathrm{E}_{\mathrm{pa}}\right)$ e de corrente $\left(\mathrm{I}_{\mathrm{pa}}\right)$, utilizando-se estatística descritiva, por meio do programa Microsoft Windows Excel®, versão 2010.

O experimento foi realizado no Laboratório de Eletroanalítica Aplicada (GEAP), no Departamento de Química, da Universidade Federal de Viçosa, Viçosa-MG.

\section{RESULTADOS E DISCUSSÃO}

A análise proposta neste trabalho é baseada no fato dos antioxidantes serem bons agentes redutores, ou seja, substâncias que se oxidam facilmente. Desta forma, eles devem apresentar picos de oxidação em valores baixos de potencial, porque é pequena a energia necessária a se fornecer para que o processo de oxidação ocorra. Logo, quanto menor o valor de $\mathrm{E}_{\mathrm{pa}}$, maior o caráter antioxidante do analito em estudo.

Para ilustrar, na Figura 1 está apresentado um exemplo de voltamogramas obtidos com as análises das matrizes alimentares, em dois dos quatro sistemas extratores estudados (meio tamponado em pH 10,0 e solução $\mathrm{KCl} 0,1 \mathrm{~mol} \mathrm{~L}^{-1}$ ).

Figura 1. Voltamogramas de diferentes matrizes alimentares. Voltamogramas obtidos a partir de varredura em DPV no sentido anódico em (a) meio tamponado pH 10,0 e (b) solução KCl 0,1 mol L-1.

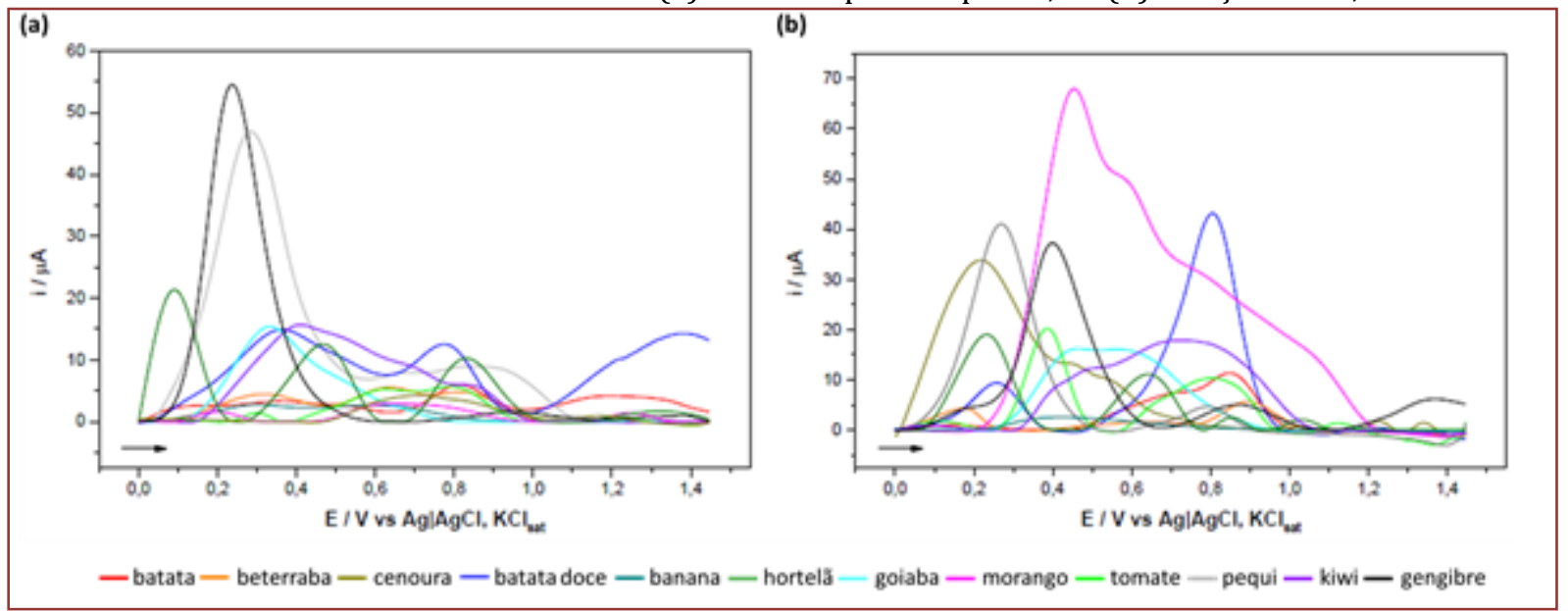


Comparando-se os resultados, é possível perceber que o $\mathrm{pH}$ do meio pode afetar tanto na intensidade de corrente $\left(\mathrm{I}_{\mathrm{pa}}\right)$ das espécies eletroativas, quanto no potencial de pico das mesmas $\left(\mathrm{E}_{\mathrm{pa}}\right)$. Isto se deve ao fato de que o $\mathrm{pH}$ do meio influencia o tipo de espécies químicas disponíveis para análise, seja devido a sua solubilidade, ou mesmo pelo fato de que as substâncias assumem diferentes formas dependendo do valor de pH, em decorrência da protonação ou desprotonação de um grupo químico. Tais alterações modificam as constantes termodinâmicas das espécies envolvidas, podendo torná-las mais ou menos susceptíveis a sofrer um processo redox, deslocando de tal modo, os potenciais de pico. Não obstante, as intensidades relativas de corrente também são influenciadas pelo meio, visto que diferentes formas de uma mesma espécie podem ser mais ou menos sensíveis à técnica em questão. Neste sentido, não se deve comparar intensidade de corrente de picos diferentes.

Na Figura 2, pode-se observar melhor estes efeitos. Nesta figura está inserido os voltamogramas do ácido ascórbico em três diferentes valores de pH e a curva de distribuição de espécies desta substância.

Figura 2. Voltamogramas do ácido ascórbico em três diferentes valores de $\mathrm{pH}$ e curva de distribuição de espécies deste ácido em função do pH do meio. Voltamogramas obtidos a partir de varredura em DPV no sentido anódico

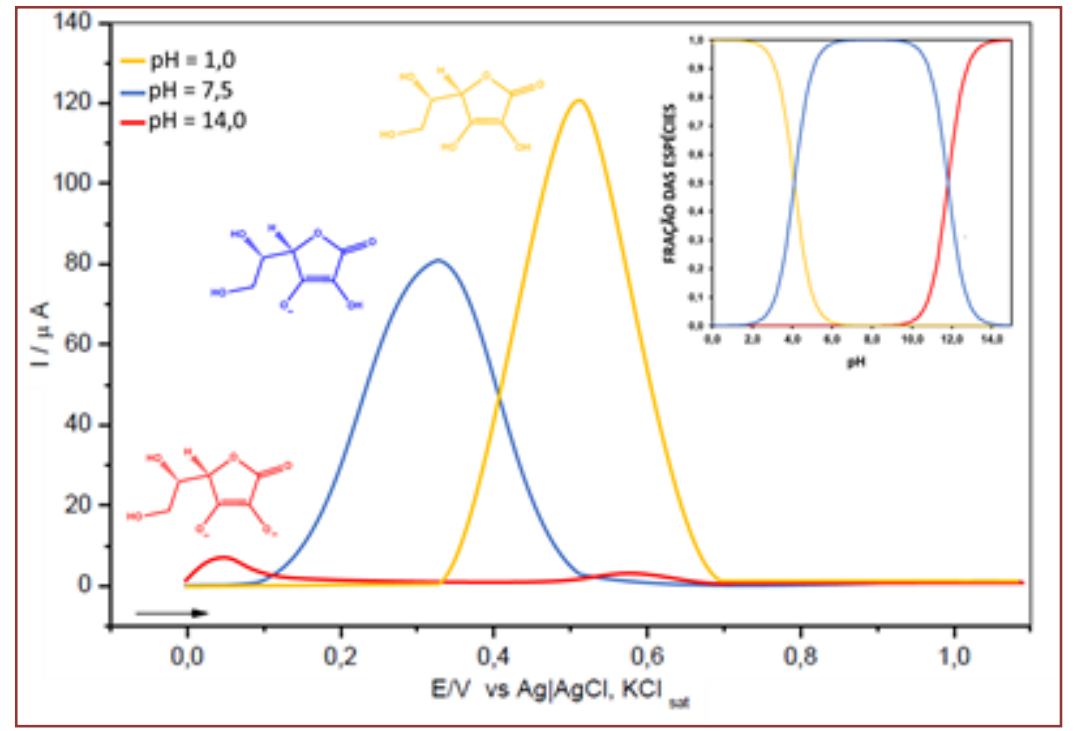

Por meio desta análise é possível concluir que, das três espécies do ácido ascórbico (totalmente protonado, ânion e diânion), a que se oxida mais facilmente é a espécie que possui duas cargas negativas. Isto pode ser observado pelo fato de em $\mathrm{pH}=14,0 \mathrm{o}$ voltamograma deste sistema foi o que apresentou o menor valor de $\mathrm{E}_{\mathrm{pa}}$. Logo, como já é sabido, pode-se concluir que o ácido ascórbico possui maior capacidade antioxidante em soluções básicas.

Portanto, observa-se a importância de se fazer as leituras voltamétricas em diferentes meios extratores com o intuito de investigar a maior quantidade possível de compostos eletroativos presentes nos alimentos. Quanto mais favorecida a solubilidade de determinada espécie química, mais disponível para a análise voltamétrica ela estará e, consequentemente, maior a intensidade do seu sinal analítico, pois a corrente medida é proporcional à concentração da substância (Bard e Faulkner, 2001).

A avaliação dos potenciais de pico das matrizes estudadas atende aos objetivos do presente estudo. Quanto menor o valor de potencial de pico anódico de uma substância, maior é seu poder redutor e assim, maior sua capacidade antioxidante (Arteaga et al., 2012). Para tanto, matrizes alimentares que apresentam picos com baixo valor de potencial, foram classificadas como matrizes que contêm antioxidantes em sua composição. É importante ressaltar que, a composição química das matrizes estudadas pode também sofrer variação dependendo da safra, condições climáticas e condições de armazenamento.

Na Tabela 2 estão apresentadas as médias dos valores de $\mathrm{I}_{\mathrm{pa}}$ e de $\mathrm{E}_{\mathrm{pa}}$ para os primeiros picos de cada matriz estudada, na melhor condição de análise. 0 enfoque dado aos primeiros picos deve-se ao fato deles serem representantes das substâncias que possuem maior capacidade antioxidante na matriz alimentar. 
Assim como na Figura 1 e 2, é possível notar na Tabela 2, que tanto o $\mathrm{E}_{\mathrm{pa}}$ quanto a $\mathrm{I}_{\mathrm{pa}}$ são influenciados pelo meio de extração, principalmente pelo pH do meio.

Tabela 2. Média e desvio padrão dos valores de potencial anódico ( $\mathrm{E}_{\mathrm{pa}}$ ) e de corrente $\left(\mathrm{I}_{\mathrm{pa}}\right)$ para os primeiros picos de cada matriz estudada, em diferentes meios de extração e técnicas voltamétricas

\begin{tabular}{|c|c|c|c|c|c|c|c|c|}
\hline \multirow{2}{*}{$\begin{array}{c}\text { Matriz } \\
\text { alimentar }\end{array}$} & \multicolumn{2}{|c|}{$\mathrm{KCl} 0,1 \mathrm{~mol} \mathrm{~L}^{-1}$} & \multicolumn{2}{|c|}{ FTBA / DMF } & \multicolumn{2}{|c|}{ Tampão pH 10,0 } & \multicolumn{2}{|c|}{ Tampão pH 5,0 } \\
\hline & $\mathrm{E}_{\mathrm{pa}}(\mathrm{V})$ & $\mathrm{I}_{\mathrm{pa}}(\mu \mathrm{A})$ & $\mathrm{E}_{\mathrm{pa}}(\mathrm{V})$ & $\mathbb{I}_{\mathrm{pn}}(\mu \mathrm{A})$ & $\mathrm{E}_{\mathrm{pu}}(\mathrm{V})$ & $\mathrm{I}_{\mathrm{pn}}(\mu \mathrm{A})$ & $\mathrm{E}_{\mathrm{pa}}(\mathrm{V})$ & $\mathrm{I}_{\mathrm{pn}}(\mu \mathrm{A})$ \\
\hline Banana & $0,45 \pm 0,01$ & $2,40 \pm 0,02$ & ...... & $\cdots+$. & $0,20 \pm 0,00$ & $6,14 \pm 0,02$ & $0,42 \pm 0,00$ & $5,54 \pm 0,00$ \\
\hline Batata & $0,14 \pm 0,00$ & $3,08 \pm 0,72$ & $0,37 \pm 0,06$ & $3,50 \pm 1,40$ & $0,18 \pm 0,00$ & $4,55 \pm 0,00$ & $0,11 \pm 0,00$ & $0,39 \pm 0,22$ \\
\hline $\begin{array}{c}\text { Batata } \\
\text { doce }\end{array}$ & $0,26 \pm 0,00$ & $9,58 \pm 0,00$ & $0,19 \pm 0,00$ & $5,21 \pm 0,65$ & $0,27 \pm 0,03$ & $4,13 \pm 2,14$ & $0,29 \pm 0,01$ & $6,64 \pm 0,71$ \\
\hline Beterraba & $0,18 \pm 0,00$ & $5,12 \pm 1,03$ & $0,38 \pm 0,00$ & $5,82 \pm 0,00$ & $0,11 \pm 0,00$ & $0,97 \pm 0,53$ & $0,18 \pm 0,02$ & $5,07 \pm 0,93$ \\
\hline Cenoura & $0,18 \pm 0,03$ & $29,80 \pm 2,41$ & $0,42 \pm 0,02$ & $4,44 \pm 0,21$ & $0,22 \pm 0,06$ & $3,41 \pm 0,82$ & $0,16 \pm 0,01$ & $4,40 \pm 1,72$ \\
\hline Gengibre & $0,17 \pm 0,00$ & $2,30 \pm 0,00$ & …... & $\cdots+\cdots$ & $0,23 \pm 0,00$ & $61,21 \pm 9,52$ & $0,21 \pm 0,00$ & $7,23 \pm 0,06$ \\
\hline Goiaba & ........ & $\cdots+. .$. & ....... & ....... & $0,34 \pm 0,00$ & $16,97 \pm 1,56$ & $0,43 \pm 0,01$ & $3,03 \pm 0,63$ \\
\hline Hortelã & $0,23 \pm 0,00$ & $15,22 \pm 4,21$ & ........ & $\cdots+\cdots$ & $0,09 \pm 0,00$ & $20,41 \pm 0,00$ & $0,32 \pm 0,01$ & $3,49 \pm 2,95$ \\
\hline Kiwi & $0,12 \pm 0,01$ & $1,34 \pm 0,25$ & …... & -...... & $0,22 \pm 0,01$ & $0,70 \pm 0,14$ & $0,44 \pm 0,00$ & $8,35 \pm 0,35$ \\
\hline Morango & $0,44 \pm 0,00$ & $74,26 \pm 11,3$ & $0,32 \pm 0,00$ & $5,45 \pm 0,00$ & $0,19 \pm 0,00$ & $1,46 \pm 0,00$ & $0,13 \pm 0,01$ & $1,55 \pm 0,91$ \\
\hline Pequi & $0,27 \pm 0,00$ & $32,65 \pm 7,54$ & $0,22 \pm 0,02$ & $3,44 \pm 0,13$ & $0,28 \pm 0,01$ & $51,17 \pm 10,2$ & $0,31 \pm 0,01$ & $35,58 \pm 7,56$ \\
\hline Tomate & $0,12 \pm 0,01$ & $1,70 \pm 0,51$ & $0,27 \pm 0,00$ & $2,30 \pm 0,47$ & $0,29 \pm 0,01$ & $3,37 \pm 0,91$ & $0,37 \pm 0,00$ & $3,80 \pm 0,79$ \\
\hline
\end{tabular}

Na Figura 3 estão descritas as matrizes alimentares conforme melhor resposta obtida para $E_{\text {pa }}$ em relação às condições de extração descritas na Tabela 2.

Figura 3. Valores de potencial e corrente de pico anódico $\left(\mathrm{E}_{\mathrm{pa}}\right)$ de diferentes matrizes alimentares nas melhores condições de extração e técnica voltamétrica.

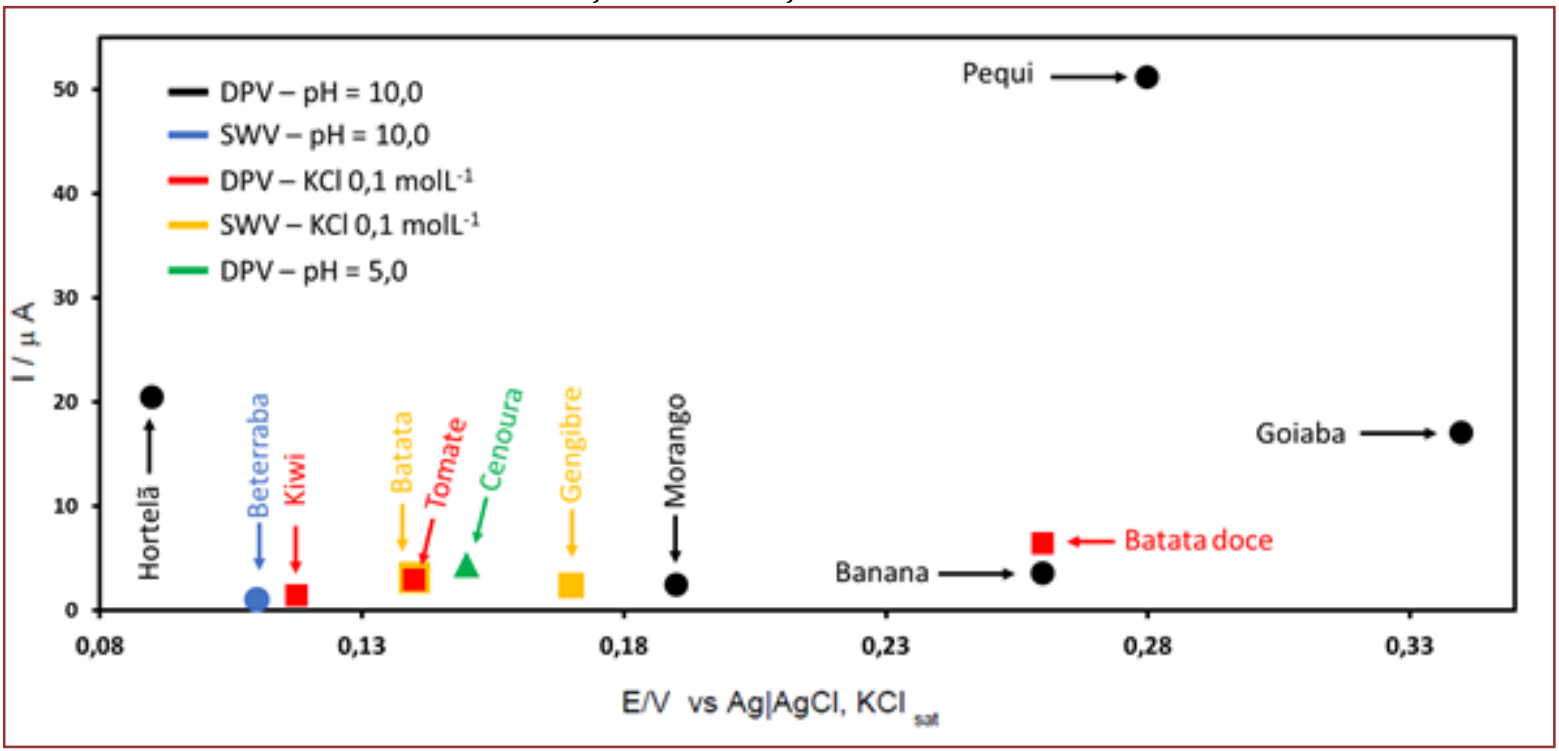




\section{CONCLUSÃO}

Por fornecer informações relativas ao processo redox, com este estudo, foi possível perceber que as técnicas voltamétricas podem ser aplicadas para determinação da capacidade antioxidante de alimentos. Por meio dos valores de $\mathrm{E}_{\mathrm{pa}}$ obtidos, observou-se que a capacidade antioxidante de matrizes alimentares, em geral, varia com as condições do meio de análise, tais como o pH.

Analisando-se os vegetais estudados, destaca-se a hortelã, por ter apresentado menor valor de potencial de pico anódico; o que nos leva a afirmar que esta matriz possui uma ou mais substâncias com grande potencial antioxidante. Apesar da capacidade antioxidante ter sido diferenciada entre as matrizes, pode-se inferir que todas as amostras analisadas são fontes de antioxidantes naturais, por terem apresentado substâncias que se oxidam facilmente, ou seja, possuem baixo valor de $\mathrm{E}_{\mathrm{pa}}$.

\section{AGRADECIMENTOS}

À FAPEMIG, ao CNPq e ao Departamento de Química/UFV.

\section{REFERÊNCIAS}

[1] Arteaga, J.F., Ruiz-Montoya, M., Palma, A., Alonso-Garrido, G., Pintado, S., \& Rodríguez-Mellado, J.M. (2012). Comparison of the Simple Cyclic Voltammetry (CV) and DPPH Assays for the Determination of Antioxidant Capacity of Active Principles. Molecules, 17, 5126-5138.

[2] Bard, A.J. \& Faulkner, L.R. (2001). Electrochemical methods: fundamentals and applications (2 ed), New York: John Wiley \& Sons.

[3] Egea, J., Fabregat, I., Frapart, Y. M., et al. (2017). European contribution to the study of ROS: A summary of the findings and prospects for the future from the COST action BM1203 (EU-ROS). Redox Biology, 14, 694-696, 2017.

[4] Ferreira, R.Q. (2009). Desenvolvimento e aplicação de um novo ensaio para a determinação eletroquímica da capacidade antioxidante de compostos modelo e de matrizes complexas (Tese de doutorado). Instituto de Química de São Carlos. Universidade de São Paulo, São Carlos-SP.

[5] Halliwell, B. \& Gutteridge, J.M.C. (1999). Free Radicals in Biology and Medicine (3 ed)., New York: Oxford University Press.

[6] Jiao, Y., Kilmartin, P.A., Fan, M, \& Quek, S.Y. (2018). Assessment of phenolic contributors to antioxidant activity of new kiwifruitcultivars using cyclic voltammetry combined with HPLC. Food Chemistry, 268, 77-85.

[7] Pacheco, W.F., Semaan, F.S., Almeida, V.G., Ritta, A.G.S., \& Aucélio, R.Q. (2013). Voltametrias: Uma Breve Revisão Sobre os Conceitos. Revista Virtual de Química, 5(4), 516-537.

[8] Pinheiro, F.A., Okumura, L.L., Silva, A.F.S., Silva, J.G., Ferreira, L.R., Barcellos, E.S., \& Fontes, E.A.F. (2018). Applicability of a voltammetric assay based on the electroreduction of oxygen to evaluate the antioxidant capacity of pequi. Journal of the Brazilian Chemical Society, 29(8), 1653-1662.

[9] Swapna, L.A., Pradeep, K., Reddy, P., Deepak, K., \& Goyal, S. (2014). Antioxidants and their implication in oral health and general health. International Journal of Case Reports and Images, 5(4), 258-263.

[10] Vasić, V., Gašić, U., Stanković, D., Lušić, D., Vukić-Lušić, D., Milojković-Opsenica, D., Tešić, Z., \& Trifković, J. (2019). Towards better quality criteria of European honeydew honey: Phenolic profile and antioxidant capacity. Food Chemistry, 274, 629-641. 


\section{Capítulo 8}

High turbulence-assisted extraction of crude guarana seeds to recover polyphenols and alkaloids: A comparative study with conventional methods

Ádina Lima de Santana

Júlia Azevedo Zanini

Gabriela Alves Macedo

Abstract: A fast and environmentally-friendly method to enhance the recovery of natural polyphenols and alkaloids from guarana was implemented and optimized. High turbulence assisted extraction (HTE) was efficient to recover catechins and methylxanthines in comparison with the conventional methods maceration, infusion and decoction. The phenolic composition detected in HTE extracts with the condensed tannins approach was correlated with the yield extract, the catechins, methylxanthines, and antioxidant capacity (phosphomolybdenum, P-Mo assay). For the conventional methods the TPC approach was correlated with the antioxidant capacities for the $\beta$ carotene inhibition, Trolox equivalent antioxidant capacity (TEAC) and P-Mo assays. For 1-min-HTE, the rotational speed of $24200 \mathrm{rpm}$ decreased the recovery of target compounds because of degradation induced by the excessive shearing transformed in heat. Considering the HTE for $10 \mathrm{~min}$, the extracts inhibited the oxidation of $\beta$-carotene oxidation similarly to the synthetic antioxidant BHT at $500 \mu \mathrm{M}$.

Keywords: Homogenizer-assisted extraction; tannins; methylxanthines; natural antioxidants; Paullinia cupana. 


\section{INTRODUCTION}

Brazil is the main producer of guarana, a plant crop widely used in industries as carbonated drinks, energy drinks, capsules, and cosmetics. For the formulation of such products, the extracts from crude seeds are used, commonly obtained by cold hydroalcoholic extraction for 24 hours.

The extensive investigation on the functional properties of guarana is justified due to its stimulant and antioxidant effects in human health, which have been associated with weight control, neuroprotection, and reduced inflammation.

Currently, extensive work have been done with the use of sustainable technologies to increase the recovery of target compounds from plant matrices. A sustainable process to be competitive requires the use of environmentally-friendly solvents, besides low solvent consumption and low processing times (SANTANA e MACEDO, 2019a).

High-turbulence-assisted extraction, also known as homogenizer-assisted extraction uses high rotational speeds that enhances the shearing of plant matrix, resulting on the increasing of solubility of target compounds in the solvent used (TORRES et al., 2015).

To the best of our knowledge information on the evaluation of process parameters of HTE for the recovery of bioactive compounds from guarana is scarce. In this context, this work propose a rapid and environmentally-friendly method to enhance the extraction of natural alkaloids and polyphenols from guarana as replacers to the synthetic ones.

\section{MATERIAL AND METHODS}

\subsection{RAW MATERIAL AND REAGENTS}

Crude guarana seeds were purchased from Guarana de Maués Corporation (Maués, Brazil). Ethanol (99\% pure) and butylated hydroxytoluene (BHT, 58500-82-6) were obtained from Êxodo Científica (Sumaré, Brazil), while Folin-Ciocalteu, was purchased from Dinâmica (Indaiatuba, Brazil). The 2,2-diphenyl-1picrylhydrazy (DPPH), vanillin, Trolox, L-ascorbic acid, gallic acid, $\beta$-carotene, caffeine, theobromine $(\geq 98 \%),(+)(-)$ catechin $(99 \%)$, (-)epicatechin $(\geq 97 \%$, and (-)epicatechin gallate $(\geq 98 \%)$ were obtained from Sigma-Aldrich (Darmstadt, Germany) and theophylline (97.50\%) was purchased from Abbott (São Paulo, Brazil).

\subsection{EXPERIMENTS}

\subsubsection{HIGH-TURBULENCE EXTRACTION (HTE)}

High-turbulence extraction (HTE) of crude seeds was done using an Ultra Turrax $®$ (IKA T 18 basic, Staufen, Germany) apparatus at $500 \mathrm{~W}$ and $60 \mathrm{~Hz}$. The solvent used was a hydroethanolic solution composed of $50 \%$ ethanol. The raw material:solvent ratio was 1:3 (w/w). At first, extractions for $1 \mathrm{~min}$ were done with the following rotational speeds: 3500, 7000, 11000, 15500, 20000, and $24200 \mathrm{rpm}$. Afterwards, three rotational speeds were selected to evaluate the effects of time on the recovery of bioactive compounds, considering the efficiency to recover target compounds associated with low expenses of energy.

\subsubsection{INFUSION}

Tea-type infusions were obtained by mixing guarana with boiling water at a ratio 1:10 $(\mathrm{w} / \mathrm{w})$, with subsequent brewing for $10 \mathrm{~min}$. Afterwards, mixture was filtered and the extract was collected (MA et al., 2019). Water was selected as solvent for infusion, as well as for decoction because it is suitable for human consumption.

\subsubsection{DECOCTION}

The decoctions were prepared by mixing guarana with deionized water $(1: 100, \mathrm{w} / \mathrm{w})$ in a stainless steel recipient and heated until boiling temperature of solvent. Afterwards, the mixture was left at boiling temperature for $5 \mathrm{~min}$ and the extract was separated from solid fraction (SILVA et al., 2019). 


\subsubsection{MACERATION}

Ethanol 50\% was used in hot hydroalcoholic maceration with a raw material:solvent ratio of 1:3 (w/w). The extractions were performed in a Dubnoff heating bath (Tecnal, TE-053, São Paulo, Brazil) at 60oC for 30 minutes. The temperature of $60 \mathrm{oC}$ was used because it was attributed with highest content of bioactive compounds in crude and waste guarana seeds (SANTANA e MACEDO, 2019b).

\subsection{GLOBAL YIELD}

Global yield, or the total extractable material, consisted on the mass of dried extract obtained by the removal of solvent. Global yield definition is explained by the Eq.1.

$$
X_{0}=\left(\frac{m_{E X T}}{F_{0}}\right) \times 100(1)
$$

Where $\mathrm{X} 0$ is the global yield (g dried extract/100g raw material), mEXT is the mass of dried extract obtained (g) and F0 is the mass of raw material $(\mathrm{g})$ used in the extractions.

\subsection{COMPOSITION}

\subsubsection{CONDENSED TANNINS (CT)}

Aqueous dilutions of extracts were mixed with vanillin reagent (1:5 ratio, v/v). After 20 minutes of reaction, $200 \mu \mathrm{L}$ aliquots were inserted in triplicate into 96-well plates and detected at $500 \mathrm{~nm}$ (PRICE et al., 1978). The calibration curve was plotted using catechin standard with concentration range between 0.1 and $5 \mathrm{mg} / \mathrm{mL}(\mathrm{R} 2=0.99)$. The results were expressed as g catechin equivalent $/ 100 \mathrm{~g}$ extract.

\subsubsection{TOTAL PHENOLIC CONTENT (TPC ASSAY)}

Aqueous dilutions of extracts were mixed with the Folin-Ciocalteu reagent, water and sodium carbonate solution (1:1:2:16, v/v/v/v) and incubated in the dark for $2 \mathrm{~h}$ prior to detection at $740 \mathrm{~nm}$ (SINGLETON e ROSSI, 1965). A calibration curve using gallic acid standard (16- $700 \mu \mathrm{g} / \mathrm{mL}$; R2=0.99) was plotted. The results were expressed as g of gallic acid equivalent (GAE)/ 100g extract.

\subsubsection{Antioxidant capacity: $\beta$-carotene-linoleic acid assay}

The capacity of extracts to inhibit the heat-oxidation of an aqueous system of $\beta$-carotene and linoleic acid was evaluated using the method of MARCO (1968), adapted by MILLER (1971) and LEAL et al. (2006). The inhibition of oxidation, was calculated using Eq. (2) (ŠKERGET et al., 2005).

$$
\operatorname{Inhibition}(\%)=100 \cdot\left\{1-\left[\frac{A B S_{S A M P L E}^{t=0}-A B S_{S A M P L E}^{t}}{A B S_{\text {CONTROL }}^{t=0}-A B S_{\text {CONTROL }}^{t}}\right]\right\}
$$

Where $A B S_{S A M P L E}^{t=0}$ is the absorbance of the sample at $\mathrm{t}=0 \mathrm{~h}, A B S_{C O N T R O L}^{t=0}$ is the absorbance of control sample at $\mathrm{t}=0 \mathrm{~min}, A B S_{S A M P L E}^{t}$ is the absorbance of the sample at $\mathrm{t}=120 \mathrm{~min}$ and $A B S_{\text {CONTROL }}^{t}$ is the absorbance of control sample at $\mathrm{t}=120 \mathrm{~min}$. For comparative purposes, BHT samples at 75, 500 and $1000 \mu \mathrm{M}$ were used.

\subsubsection{ANTIOXIDANT CAPACITY: TROLOX EQUIVALENT ANTIOXIDANT CAPACITY (TEAC)}

The Trolox equivalent antioxidant capacity (TEAC) was evaluated using the DPPH free radical. The reaction consisted by mixing dilutions of extracts with a methanolic solution of DPPH (1:3 v/v) for $30 \mathrm{~min}$, and reading of absorbance at $517 \mathrm{~nm}$ (BRAND-WILLIAMS et al., 1995). The calibration curve using synthetic antioxidant Trolox was plotted using concentrations ranging between 150 and $1500 \mu \mathrm{mol} / \mathrm{mL}$ (R2=0.94). The TEAC was expressed in terms of $\mu$ mol Trolox equivalent per $g$ of extract. 


\subsubsection{ANTIOXIDANT CAPACITY: PHOSPHOMOLYBDENUM (P-MO) COMPLEX ASSAY}

Aqueous dilution of extract was mixed with the P-Mo complex reagent $(1: 10, v / v)$. A calibration curve using ascorbic acid was plotted in the concentration range of $100-2100 \mathrm{mM} / \mathrm{mL}$ (R2=0.98). The results were expressed in terms of $\mu$ M Ascorbic Acid Equivalent per g of extract (PRIETO et al., 1999).

\subsubsection{CATECHINS AND METHYLXANTHINES}

High-performance liquid chromatography coupled with diode array detector (HPLC-DAD) was used to detect methylxanthines (caffeine, theobromine and theophylline) and catechins (catechin, epicatechin and epicatechin gallate) in selected guarana extracts according to procedures determined previously (SANTANA e MACEDO, 2019b).

\subsection{STATISTICAL EVALUATION}

The statistical difference among data was evaluated by the one-way analysis of variance (ANOVA) and the post-hoc comparison was performed by the Tukey's test. The software Statistica 8 was used and results were expressed as mean \pm standard deviation $(\mathrm{p} \leq 0.05)$

\section{RESULTS AND DISCUSSION}

The 1-min HTE resulted in extraction yields ranging approximately 7-20 g extract/100g seeds (Fig.1A). These results were comparable with those obtained in pressurized liquid extraction of guarana for $60 \mathrm{~min}$ (SANTANA et al., 2019).

The selected rotational speeds to evaluate the effects of time were 3500,7000 and $11000 \mathrm{rpm}$, because at higher levels associate with time of extraction may induce degradation due to excessive exposure to shearing forces. Extractions at 7000 and $11000 \mathrm{rpm}$ for $10 \mathrm{~min}$ yielded 70-80 g/100g seeds (Fig. 1B). Considering the conventional methods, the highest yield in extractable materials was attributed to the decoction, while the lowest yield was attributed to the infusion method (Fig. 1C).

For the $1 \mathrm{~min}$-HTE, the TPC reached the highest values in the rotational speeds of 11000,15500 and 20000 rpm (Fig.2A). Considering the effects of time, the behavior of TPC was similar for all the rotational speeds tested (Fig.2B). Differently from the TPC, the CT detected in the 1-min-HTE extracts showed the highest magnitudes at 15500 and 20000 rpm (Fig. 2C), similarly to the catechins detected by the HPLC (Table 1). The kinetic behavior detected by CT attributed the highest content to the rotational speeds of 7000 and 11000 rpm (Fig. 2D).

The BHT at $1000 \mu \mathrm{M}$ inhibited the oxidation of $\beta$-carotene at $100 \%$. The kinetic behavior of HTE extracts showed inhibition comparable with the BHT at 75 and $500 \mu$ M.(Fig.3A and B). For the TEAC approach, the antioxidant capacity of extracts was similar for all rotational speeds and times of extraction studied. Contrary effect was detected on the P-Mo assay, which detected highest antioxidant capacity at 15500 and $20000 \mathrm{rpm}$ in the 1min-HTE. Considering times of extraction, the highest antioxidant capacity was detected at $11000 \mathrm{rpm}$ (Fig.3C and D).

Among the conventional methods, the highest TPC was attributed to the maceration (Fig. 4A), while the highest content of condensed tannins was attributed to the decoction (Fig. 4B). The highest antioxidant capacity was attributed to the extract obtained with maceration, for the three approaches evaluated. Even so, the ability to inhibit $\beta$-carotene oxidation of these extracts was lower than those of BHT (Fig.4C and D). However, the TEAC and P-Mo detected were next with those obtained from the extracts of barley (MAREČEK et al., 2017) and Ceratonia siliqua L. (LAKKAB et al., 2019).

The highest recovery of catechin $(134.36 \mathrm{~g} / 100 \mathrm{~g}$ extract) and caffeine $(92.33 \mathrm{~g} / 100 \mathrm{~g}$ ext) was raised by the 1-min-HTE of crude seeds at $20000 \mathrm{rpm}$. These mentioned results were higher than those obtained with supercritical fluid extraction, assisted and not assisted with enzymes (SANTANA et al., 2019, MARQUES et al., 2016, SALDAÑA et al., 2002).

At $242000 \mathrm{rpm}$ the levels of target compounds decreased because of excessive energy promoted by the rotational speed, that induced sudden thermal degradation. Even so, the recovery of target compounds was effective in comparison with conventional methods (Table 1). 
The catechins and methylxanthines detected from the extract obtained with maceration were close to those detected in the HTE extract at $7000 \mathrm{rpm}$. Considering the conventional methods used, the hot hydroalcoholic maceration was effective, in comparison with infusion and decoction.

Fig. 1. Total extractable mass of HTE of guarana considering the effects of rotational speed (A) and time of extraction (B); and total extractable mass of guarana obtained with the use of conventional methods (C).

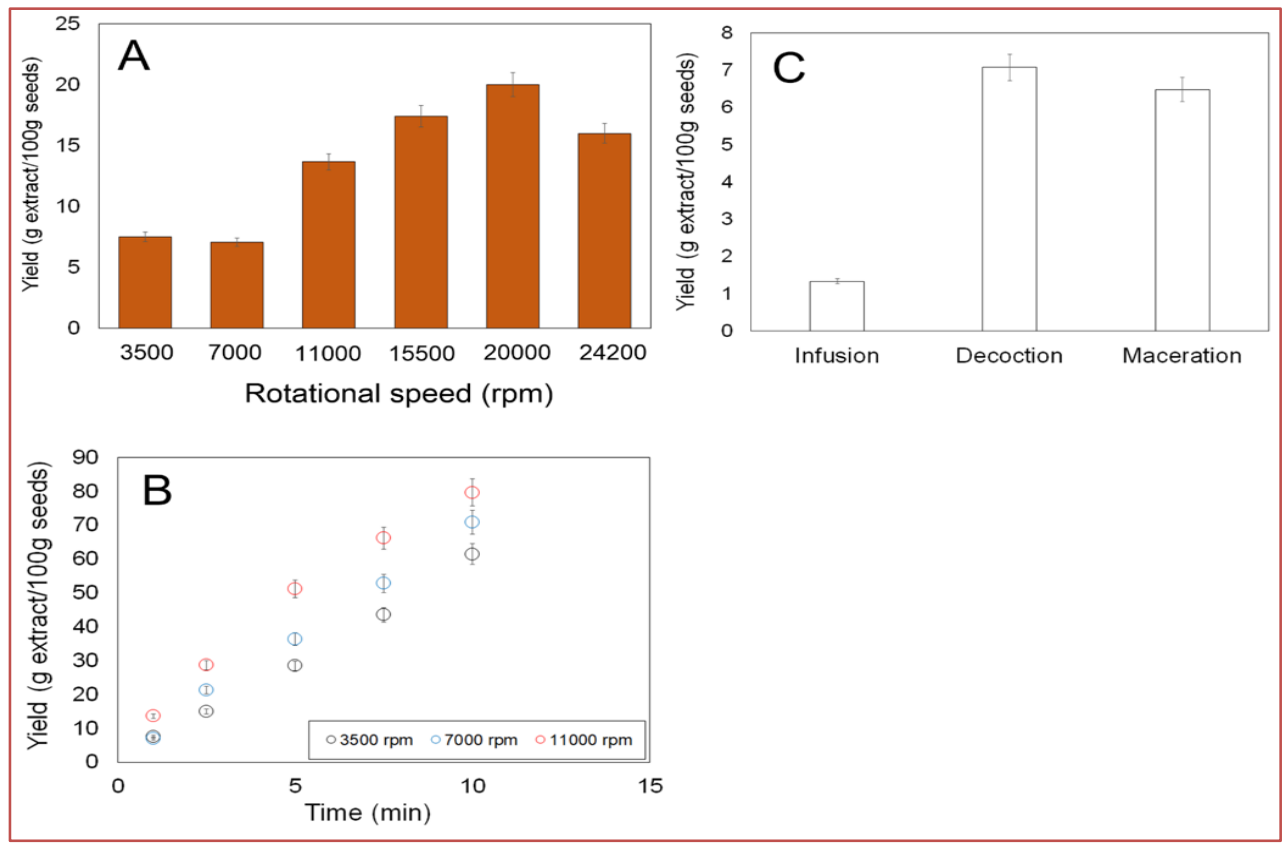

Fig. 2. The total phenolic content (A and B), and condensed tannins (C and D) detected in HTE of guarana, considering the effects of rotational speed and time of extraction.
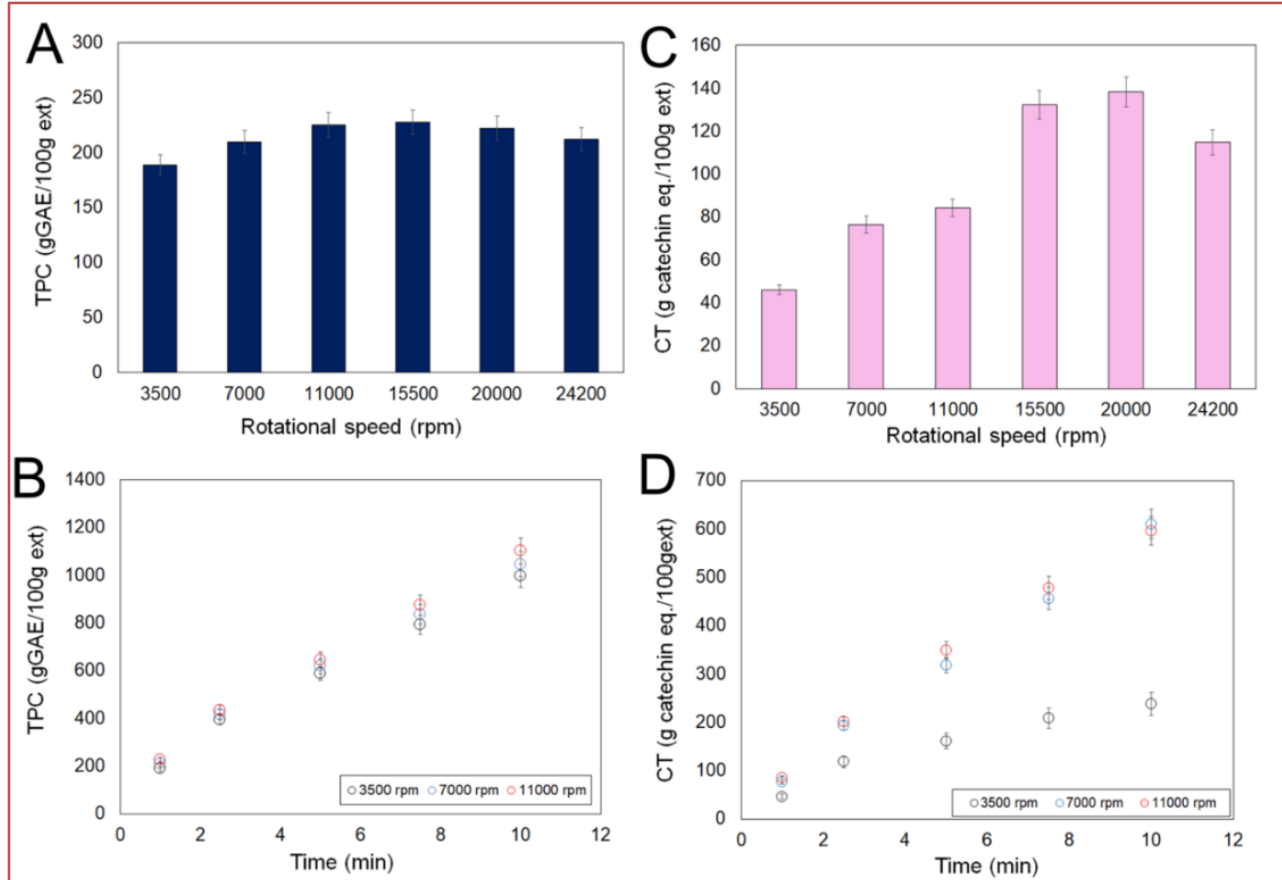

Fig. 3. Antioxidant capacities for the $\beta$-carotene (A and B), and TEAC/P-Mo assays (C and D) detected in guarana extracts, obtained with THE, considering the effects of rotational speed and time of extraction. 


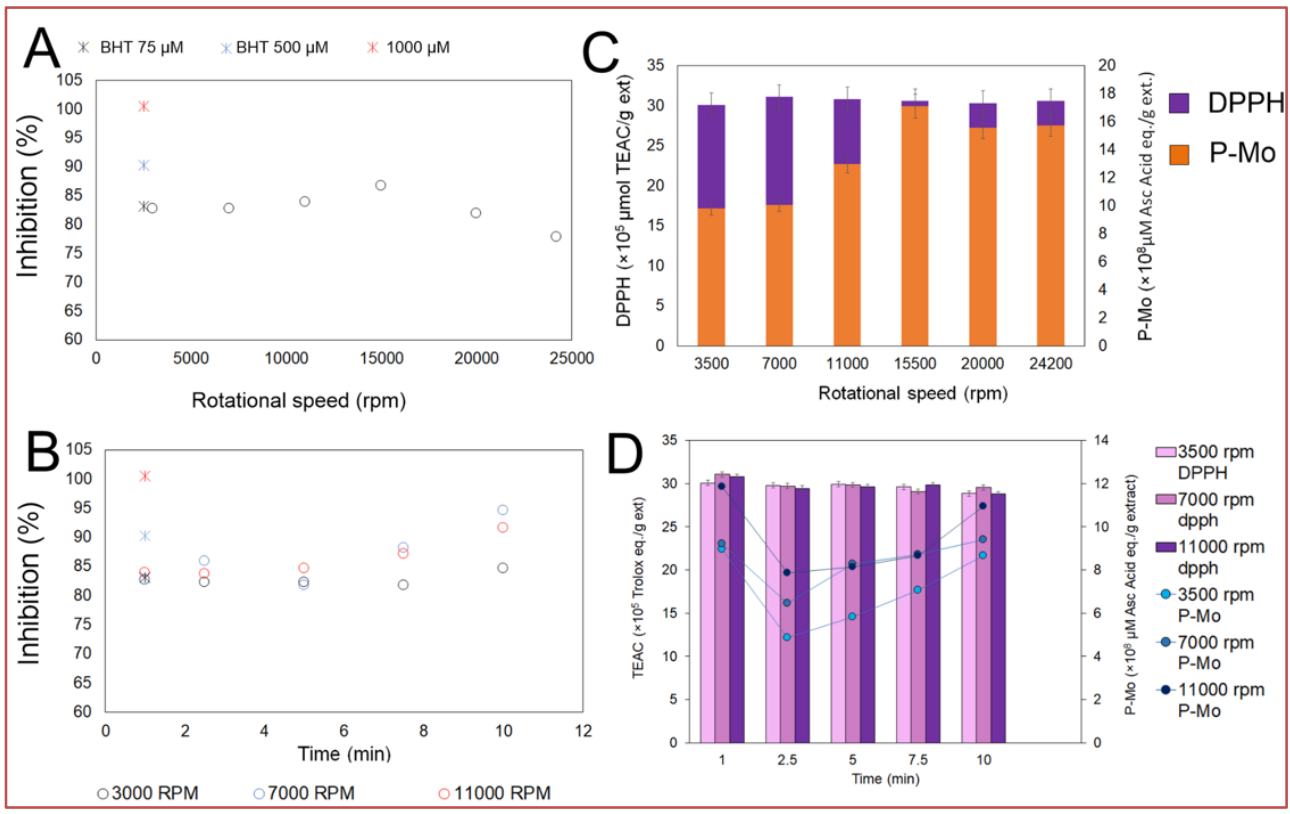

Fig. 4. The total phenolic content (A), condensed tannins (B) and antioxidant capacities for the $\beta$-carotene (C), and TEAC/P-Mo assays (D) detected in guarana extracts, obtained with conventional methods.

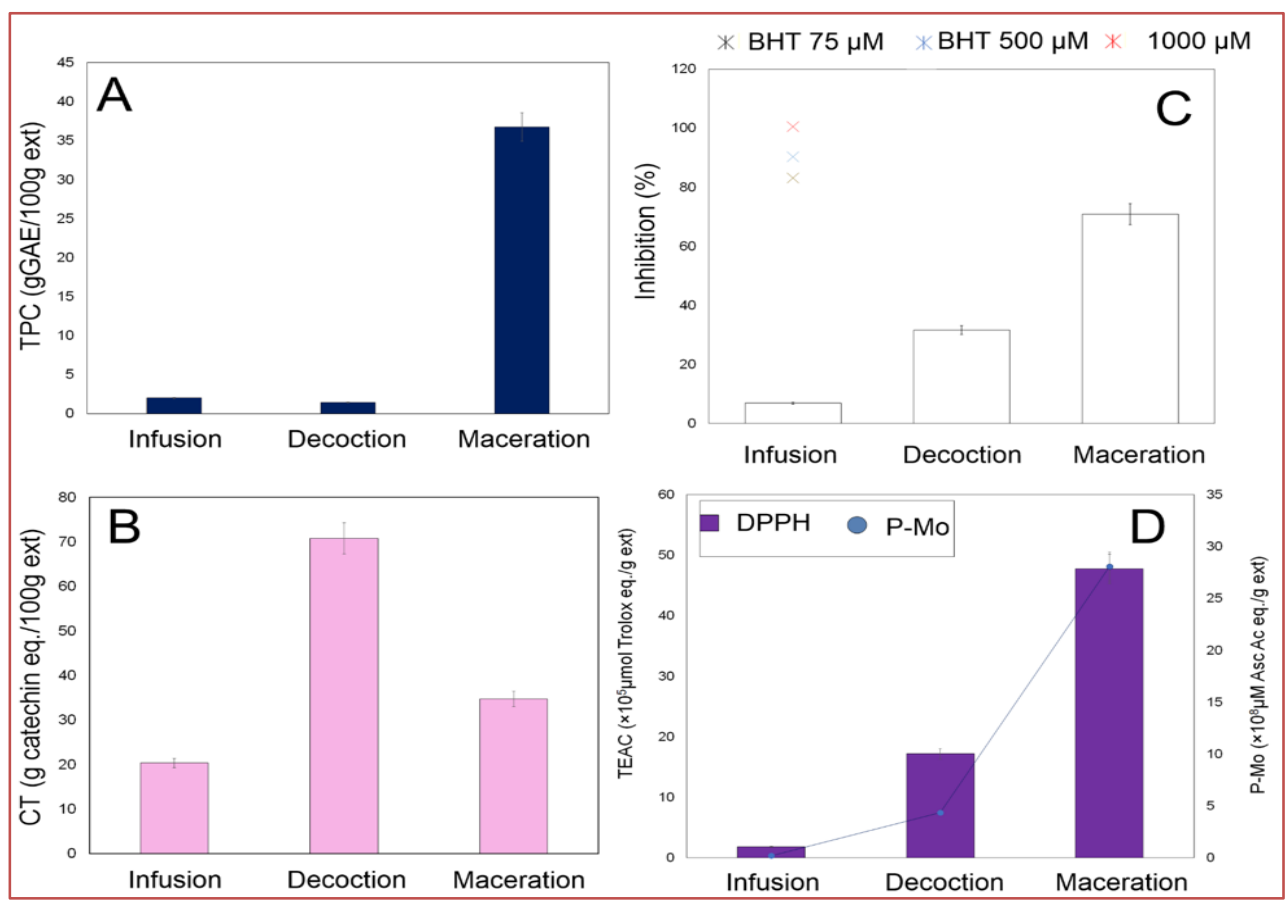


Table 1. The catechins and methylxanthines (g/100g extract, w.b.) detected in guarana extracts.

\begin{tabular}{|c|c|c|c|c|c|c|}
\hline Process & CAT & EC & ECG & CAF & $\mathrm{TBr}$ & $\mathrm{TPh}$ \\
\hline $\begin{array}{c}\text { 1min-HTE/3500 } \\
\text { rpm }\end{array}$ & $50.00 \pm 0.15^{\mathrm{a}}$ & $29.30 \pm 0.05^{\mathrm{a}}$ & $0.05 \pm 0 \mathrm{a}$ & $37.09 \pm 0.06^{\mathrm{a}}$ & $0.32 \pm 0 \mathrm{a}$ & $1.75 \pm 0.01^{\mathrm{a}}$ \\
\hline $\begin{array}{c}\text { 1min-HTE/7000 } \\
\text { rpm }\end{array}$ & $62.35 \pm 0.32 \mathrm{~b}$ & $39.62 \pm 1.36 b$ & $0.29 \pm 0.14 b$ & $43.82 \pm 0.06 b$ & $0.37 \pm 0.01 b$ & $1.75 \pm 0.02^{\mathrm{a}}$ \\
\hline $\begin{array}{c}1 \mathrm{~min}-\mathrm{HTE} / 11000 \\
\mathrm{rpm}\end{array}$ & $96.17 \pm 4.49 c$ & $59.67 \pm 1.92 c$ & $1.75 \pm 0.07 \mathrm{c}$ & $66.89 \pm 2.22 c$ & $0.66 \pm 0.02 \mathrm{c}$ & $2.27 \pm 0.59 \mathrm{~b}$ \\
\hline $\begin{array}{c}1 \mathrm{~min}-\mathrm{HTE} / 15500 \\
\mathrm{rpm}\end{array}$ & $128.79 \pm 0.59 d$ & $74.35 \pm 0.24 \mathrm{~d}$ & $0.63 \pm 0.02 \mathrm{~d}$ & $86.41 \pm 0.31 d$ & $0.69 \pm 0 c$ & $2.32 \pm 0.15 b$ \\
\hline $\begin{array}{c}\text { 1min-HTE } / 20000 \\
\text { rpm }\end{array}$ & $134.36 \pm 0.06 \mathrm{e}$ & $82.91 \pm 0.2 \mathrm{e}$ & $2.88 \pm 1.08 \mathrm{e}$ & $92.33 \pm 0.06 \mathrm{e}$ & $0.85 \pm 0 \mathrm{~d}$ & $2.64 \pm 0.01 \mathrm{c}$ \\
\hline $\begin{array}{c}1 \mathrm{~min}-\mathrm{HTE} / 24200 \\
\mathrm{rpm}\end{array}$ & $108.19 \pm 3.61 f$ & $63.43 \pm 2.74 f$ & $1.98 \pm 0.37 f$ & $75.62 \pm 2.31 \mathrm{f}$ & $0.68 \pm 0.02 \mathrm{c}$ & $2.22 \pm 0.19 \mathrm{~d}$ \\
\hline Infusion & $0.78 \pm 0.01 \mathrm{~g}$ & $0.47 \pm 0.01 \mathrm{~g}$ & $\mathrm{NI}^{*}$ & $0.68 \pm 0.01 \mathrm{~g}$ & $0.01 \pm 0 \mathrm{e}$ & $0.14 \pm 0 \mathrm{e}$ \\
\hline Decoction & $1.84 \pm 0.01 \mathrm{~h}$ & $1.01 \pm 0 \mathrm{~h}$ & $\mathrm{NI}^{*}$ & $1.54 \pm 0.01 \mathrm{~h}$ & $0.01 \pm 0 \mathrm{e}$ & $0.15 \pm 0 \mathrm{e}$ \\
\hline Maceration & $61.32 \pm 0.96 \mathrm{i}$ & $37.53 \pm 0.77 i$ & $0.56 \pm 0.26 \mathrm{~g}$ & $50.33 \pm 0.78 \mathrm{i}$ & $0.42 \pm 0 \mathrm{~b}$ & $1.82 \pm 0.01 \mathrm{f}$ \\
\hline
\end{tabular}

Mean \pm standard deviation of determinations. Different letters in the same column indicate significant difference related to the effects of process parameters $(\mathrm{p} \leq 0.05)$.

CAT - catechin, EC - epicatechin, ECG - epicatechin gallate, CAF - caffeine, TBr - theobromine, TPh - theophylline.

*ND, not detected, under detection limit for this methodology and equipment.

\section{CONCLUSION}

This work showed the high-turbulence assisted extraction (HTE) was efficient to obtain natural alkaloids and polyphenols from crude guarana, in comparison with conventional infusion, decoction and maceration.

The rotational speeds of 15500 and $20000 \mathrm{rpm}$ raised the maximum extraction yields, besides the recovery of catechins and methylxanthines, while at $24200 \mathrm{rpm}$ the decreased levels of target compounds was observed. Considering the effect of time, the behavior of total phenolic compound, condensed tannins and antioxidant capacities showed similarity at the rotational speeds of 7000 and $11000 \mathrm{rpm}$.

\section{CONFLICT OF INTEREST}

The authors confirm that this article content has no conflict of interest.

\section{ACKNOWLEDGMENTS}

Ádina L. Santana thanks CAPES (Coordination of Superior Level Staff Improvement, Brazil, Finance Code 001) for her post-doctoral financial assistantship.

\section{REFERENCES}

[1] BRAND-WILLIAMS, W.; CUVELIER, M. E. ; BERSET, C. Use of a free radical method to evaluate antioxidant activity. LWT - Food Science and Technology, v. 28, n. 1, p. 25-30, 1995.

[2] LAKKAB, I.; EL HAJAJI, H.; LACHKAR, N.; LEFTER, R.; CIOBICA, A.; EL BALI, B. ; LACHKAR, M. Ceratonia siliqua L. seed peels: Phytochemical profile, antioxidant activity, and effect on mood disorders. Journal of Functional Foods, v. 54, n. p. 457-465, 2019.

[3] LEAL, P. F.; ChAVES, F. C. M.; MING, L. C.; PETENATE, A. J. ; MEIRELES, M. A. A. Global yields, chemical compositions and antioxidant activities of clove basil (Ocimum gratissimum L.) extracts obtained by supercritical fluid extraction. J. Food Proc. Eng., v. 29, n. 5, p. 547-559, 2006. 
[4] MA, X.; MOILANEN, J.; LAAKSONEN, O.; YANG, W.; TENHU, E. ; YANG, B. Phenolic compounds and antioxidant activities of tea-type infusions processed from sea buckthorn (Hippophaë rhamnoides) leaves. Food Chemistry, v. 272, n. p. 1-11, 2019.

[5] MARCO, G. J. A rapid method for evaluation of antioxidants. J. Americ. Oil Chem. Soc., v. 45, n. 9, p. 594-598, 1968.

[6] MAREČEK, V.; MIKYŠKA, A.; HAMPEL, D.; ČEJKA, P.; NEUWIRTHOVÁ, J.; MALACHOVÁ, A. ; CERKAL, R. ABTS and DPPH methods as a tool for studying antioxidant capacity of spring barley and malt. Journal of Cereal Science, v. 73, n. p. 40-45, 2017.

[7] MARQUES, L. L. M.; PANIZZON, G. P.; AGUIAR, B. A. A.; SIMIONATO, A. S.; CARDOZO-FILHO, L.; ANDRADE, G.; DE OLIVEIRA, A. G.; GUEDES, T. A. ; MELLO, J. C. P. D. Guaraná (Paullinia cupana) seeds: Selective supercritical extraction of phenolic compounds. Food Chem, v. 212, n. p. 703-711, 2016.

[8] MILLER, H. E. A simplified method for the evaluation of antioxidants. J. Americ. Oil Chem. Soc., v. 48, n. 2, p. 91, 1971.

[9] PRICE, M. L.; VAN SCOYOC, S. ; BUTLER, L. G. A critical evaluation of the vanillin reaction as an assay for tannin in sorghum. Journal of Agriculture and Food Chemistry, v. 26, n. 5, p. 1214-1218, 1978.

[10] PRIETO, P.; PINEDA, M. ; AGUILAR, M. Spectrophotometric Quantitation of Antioxidant Capacity through the Formation of a Phosphomolybdenum Complex: Specific Application to the Determination of Vitamin E. Analytical Biochemistry, v. 269, n. 2, p. 337-341, 1999.

[11] SALDAÑA, M. D. A.; ZETZL, C.; MOHAMED, R. S. ; BRUNNER, G. Decaffeination of guaraná seeds in a microextraction column using water-saturated CO2. J Supercrit Fluid, v. 22, n. 2, p. 119-127, 2002.

[12] SANTANA, Á. L. ; MACEDO, G. A. Challenges on the processing of plant-based neuronutraceuticals and functional foods with emerging technologies: Extraction, encapsulation and therapeutic applications. Trends in Food Science \& Technology, v. 91, n. p. 518-529, 2019a.

[13] SANTANA, Á. L. ; MACEDO, G. A. Effects of hydroalcoholic and enzyme-assisted extraction processes on the recovery of catechins and methylxanthines from crude and waste seeds of guarana (Paullinia cupana). Food Chem, v. 281 , n. p. 222-230, 2019b.

[14] SANTANA, Á. L.; QUEIRÓS, L. D.; MARTÍNEZ, J. ; MACEDO, G. A. Pressurized liquid- and supercritical fluid extraction of crude and waste seeds of guarana (Paullinia cupana): Obtaining of bioactive compounds and mathematical modeling. Food and Bioproducts Processing, v. 117, n. p. 194-202, 2019.

[15] SILVA, A. M.; PINTO, D.; FERNANDES, I.; GONÇALVES ALBUQUERQUE, T.; COSTA, H. S.; FREITAS, V.; RODRIGUES, F. ; OLIVEIRA, M. B. P. P. Infusions and decoctions of dehydrated fruits of Actinidia arguta and Actinidia deliciosa: Bioactivity, radical scavenging activity and effects on cells viability. Food Chemistry, v. 289, n. p. 625-634, 2019.

[16] SINGLETON, V. L. ; ROSSI, J. A. J. Colorimetry of total phenolics with phosphomolybdic-phosphotungstic acid reagents. Am J Enol Vitic, v. 16, n. p. 144-158, 1965.

[17] ŠKERGET, M.; KOTNIK, P.; HADOLIN, M.; HRAŠ, A. R.; SIMONIČ, M. ; KNEZ, Ž. Phenols, proanthocyanidins, flavones and flavonols in some plant materials and their antioxidant activities. Food Chem., v. 89, n. 2, p. 191-198, 2005.

[18] TORRES, R. A. C.; SANTOS, D. T. ; MEIRELES, M. A. A. Novel Extraction method to produce active solutions from plant materials. Food and Public Health, v. 5, n. 2, p. 38-46, 2015. 


\section{Capítulo 9}

Influência da luminosidade na conservação do Pinhão [Araucaria Angustifolia (Bertoloni) Otto kuntze]

\section{Pérsia Barcellos Carrasco}

Shanise Lisie Mello El Halal

\section{Eliezer Avila Gandra}

Carla Rosane Barboza Mendonça

Caroline Dellinghausen Borges

Resumo: 0 pinhão é a semente comestível da Araucaria angustifolia, é constituído de um envoltório (casca), polpa e embrião, ricos em celulose, amido e lipídios, respectivamente. Técnicas de conservação e industrialização do pinhão devem ser desenvolvidas para promover a sua comercialização e consumo em outras épocas do ano, além do período sazonal, visando tornar o seu mercado mais atraente, incentivando a sua produção, extração e comercialização de forma sustentável, tendo em vista seu caráter essencialmente extrativista. Objetiva-se com este estudo avaliar o efeito da luminosidade na conservação do pinhão por 90 dias de armazenamento a temperatura ambiente. 


\section{INTRODUÇÃO}

O pinhão é a semente comestível da Araucaria angustifolia, é constituído de um envoltório (casca), polpa e embrião, ricos em celulose, amido e lipídios, respectivamente. Apresenta elevada firmeza quando cru e necessita de processo de cocção para haver o abrandamento de sua textura (CAPELLA et al., 2010).

As sementes apresentam elevado grau de perecibilidade, em virtude da alta atividade de água, sendo facilmente atacadas por fungos durante a estocagem (BALBINOTI et al., 2008) e susceptíveis ao processo de germinação e infestação por larvas (OLIVERA, 2008).

Uma alternativa para estender a comercialização do pinhão, é a inibição da germinação pela luz, induzindo a semente ao estado de dormência, para propiciar a redução da atividade metabólica. Em algumas espécies, a germinação é estimulada pela presença da luz (fotoblásticas positivas), em outras inibidas (fotoblásticas negativas), e há ainda aquelas que não são afetadas pela luz, ou seja, elas germinam na luz ou no escuro (fotoblásticas neutras) (FLORIANO, 2004).

Segundo Piña-Rodrigues (1988), na maioria das sementes, a maior taxa germinativa ocorre na região vermelha, seguido por uma zona de inibição na região do vermelho extremo e na cor azul. A luz branca, devido a sua composição espectral e características de absorção do fitocromo, têm efeito semelhante ao da luz vermelha. Além de influenciar na germinação, a incidência de luz, em diferentes comprimentos de onda, pode influenciar no teor de compostos fenólicos e assim, na atividade antioxidante de vegetais (DU, 2014; YUAN et al., 2015).

Técnicas de conservação e industrialização do pinhão devem ser desenvolvidas para promover a sua comercialização e consumo em outras épocas do ano, além do período sazonal, visando tornar o seu mercado mais atraente, incentivando a sua produção, extração e comercialização de forma sustentável, tendo em vista seu caráter essencialmente extrativista (DAVID; SILOCHI, 2010). Na literatura há trabalhos de avaliação da conservação sob diferentes temperaturas (AMARANTE et al., 2007; DAVID; SILOCHI, 2010), entretanto, o armazenamento sob baixas temperaturas apresenta como desvantagem o elevado custo.

Assim, objetiva-se com este estudo avaliar o efeito da luminosidade na conservação do pinhão por 90 dias de armazenamento a temperatura ambiente.

\section{MATERIAL E MÉTODOS}

\subsection{MATERIAL}

As amostras de pinhão (Araucaria angustifolia) foram adquiridas de um produtor na cidade de Vacaria, no estado do Rio Grande do Sul. As sementes foram coletadas, embaladas em saco de estopa e encaminhadas para a cidade de Pelotas - RS, sendo o processamento realizado dois dias após a coleta.

\subsection{MÉTODO}

Os pinhões foram dispostos em uma única camada em cabines de aço inox, dotadas de diferentes sistemas de iluminação: A) luz branca; B) luz vermelho extremo e C) escuro. A luz branca foi fornecida por diodo emissor de luz (LED) de $20 \mathrm{~W}$, instalado na parte superior da câmara. Para propiciar o fornecimento do vermelho extremo, a área da câmara foi revestida com duas folhas de papel celofane vermelho e uma azul, sendo a luz branca incidida sobre o filtro de papel celofane (BERGO et al., 2010). Ambas fontes luminosas foram fixadas a $43 \mathrm{~cm}$ de distância dos pinhões. A ausência de luz foi obtida pelo envolvimento da área da câmara com duas folhas de papel alumínio. Amostras controle (D) foram armazenadas com luminosidade ambiente. A posição dos pinhões foi voluntariamente alterada durante o experimento procurando minimizar uma eventual influência da intensidade luminosa. 0 experimento foi conduzido a temperatura ambiente.

0 delineamento experimental utilizado foi inteiramente ao acaso em esquema fatorial $4 \times 5$, sendo 4 tratamentos (A, B, C e D) e 5 períodos de avaliação $(0,15,30,60$ e 90 dias de armazenamento). Cada tratamento foi composto de 330 unidades de pinhão. 


\subsection{PERDA DE MASSA}

A perda de massa foi obtida relacionando-se a diferença entre a massa inicial do pinhão e a massa obtida ao final de cada tempo de armazenamento de acordo com a equação 1. Os resultados foram expressos em porcentagem de perda de massa.

$$
\text { Perda de massa }(\%)=\left[\frac{(\text { massainicial-massafinal })}{(\text { massainicial })}\right] \times 100
$$

\subsection{ACIDEZ TOTAL TITULÁVEL}

A acidez total titulável foi determinada por titulação potenciométrica de $10 \mathrm{~g}$ de amostra homogeneizada com $100 \mathrm{~mL}$ de água destilada. A amostra foi titulada usando-se solução de $\mathrm{NaOH} 0,1 \mathrm{~mol} \cdot \mathrm{L}^{-1}$ até uma faixa de $\mathrm{pH}(8,2-8,4)$. Os resultados foram expressos em porcentagem (IAL, 2008).

\subsection{AÇÚCARES REDUTORES}

Um extrato aquoso a partir de 2,5 g de pinhões descascados e triturados foi preparado em $50 \mathrm{~mL}$ de água sob agitação por $2 \mathrm{~h}$, após a suspensão foi filtrada em papel qualitativo. Para determinação dos açúcares redutores foi seguida a metodologia descrita por Vasconcelos et al. (2013). Foram pipetados $1,0 \mu \mathrm{L}$ de extrato aquoso e 1,0 $\mu \mathrm{L}$ do reagente 3,5 ácido dinitrosalicílico e transferidos para balão volumétrico de 10 $\mathrm{mL}$, a solução foi agitada em vórtex por 1 min. Posteriormente, a amostra foi colocada em banho maria a $100{ }^{\circ} \mathrm{C}$ por $5 \mathrm{~min}$, após foi resfriada em banho de água fria. Para após, o volume do balão ser completado com água destilada. A absorbância da solução resultante foi medida em espectrofotômetro (AAKER) a 540 $\mathrm{nm}$. Foi preparado um branco para a calibração do equipamento. A quantificação foi realizada utilizando uma curva de calibração com glicose nas concentrações de 0 a $3 \mathrm{mg} \mathrm{mL}^{-1}\left(517,88 \mathrm{x}+45,851 \mathrm{R}^{2}=0,9907\right)$. Os resultados foram expressos em g.100 $\mathrm{g}^{-1}$ de pinhão.

\subsection{VITAMINA C}

A amostra foi triturada e $20 \mathrm{~g}$ transferida para um erlenmeyer de $300 \mathrm{~mL}$, adicionado de $50 \mathrm{~mL}$ de água, $10 \mathrm{~mL}$ de solução de ácido sulfúrico a $20 \%, 1 \mathrm{~mL}$ da solução de iodeto de potássio a $10 \%$ e $1 \mathrm{~mL}$ da solução de amido a $1 \%$. A amostra foi titulada com solução de iodato de potássio $0,02 \mathrm{M}$ até coloração rosada. Os resultados foram expressos em mg.100 $\mathrm{g}^{-1}$ de amostra (IAL, 2008).

\subsection{FIRMEZA}

Os pinhões foram descascados e posteriormente foi determinada a firmeza utilizando-se um texturômetro (Stable Micro Systens modelo TA.XTplus). Foi utilizada como ponteira a lamina de corte HDP/BS e a plataforma-base HDP/90. 0 teste realizado foi de compressão para medir a firmeza ou força para ocasionar a ruptura do fruto. Os parâmetros operacionais utilizados foram: velocidade de pré-teste de $1,50 \mathrm{~mm} \cdot \mathrm{s}^{-1}$, velocidade de teste de $1,00 \mathrm{~mm} \cdot \mathrm{s}^{-1}$, velocidade pós-teste de $10,00 \mathrm{~mm} \cdot \mathrm{s}^{-1}$, distância de $4 \mathrm{~mm}$ e força de acionamento de 0,147 N. A firmeza obtida foi automaticamente registrada mediante o software Texture Exponent 32. A leitura foi realizada na região central equatorial do pinhão, sendo os resultados expressos em Newton $(\mathrm{N})$.

\section{$2.8 \mathrm{COR}$}

A cor foi determinada utilizando-se um colorímetro (Minolta CR 400). No padrão C.I.E $L^{*} a^{*} b^{*}$, a coordenada $L^{*}$ expressa o grau de luminosidade da cor medida $\left(L^{*}=100=\right.$ branco; $L^{*}=0=$ preto), a coordenada $a^{*}$ expressa o grau de variação entre o vermelho $(+60)$ e o verde $(-60)$ e a coordenada $b^{*}$ expressa o grau de variação entre o azul (-60) e o amarelo (+60). 


\subsection{COMPOSTOS FENÓLICOS TOTAIS}

Os pinhões com casca foram submetidos ao cozimento em panela de pressão por 20 min. Para o preparo do extrato hidroalcoólico os pinhões foram descascados, triturados e $5 \mathrm{~g}$ destes foram adicionados de 50 $\mathrm{mL}$ de solução metanólica (70\% metanol/30\% de água). 0 extrato ficou $3 \mathrm{~h}$ sob agitação a temperatura ambiente, após foi submetido a filtração em papel qualitativo.

A determinação dos compostos fenólicos totais seguiu a metodologia proposta por Singleton et al. (1999) com algumas modificações. Alíquotas de $1 \mathrm{~mL}$ do extrato hidroalcoólico (70\% metanol/30\% água) foram adicionados de $1 \mathrm{~mL}$ de solução Folin-Ciocalteau e, posteriormente, $8 \mathrm{~mL}$ de água destilada. Após 3 min de reação, $1 \mathrm{~mL}$ de $\mathrm{Na}_{2} \mathrm{CO}_{3} 1 \mathrm{~mol} . \mathrm{L}^{-1}$ foi adicionado e a mistura incubada a $37{ }^{\circ} \mathrm{C}$ por $30 \mathrm{~min}$. A absorbância da solução resultante foi medida em espectrofotômetro (AAKER) a $750 \mathrm{~nm}$. A quantificação foi realizada utilizando a curva de calibração realizada com o ácido gálico nas concentrações de 0 a $0,5 \mathrm{mg} \mathrm{mL}^{-1}$ $\left(y=1,9772 x+0,072 R^{2}=0,9832\right)$. Os resultados foram expressos em mg EAG.100g-1 de pinhão.

\subsection{ATIVIDADE ANTIOXIDANTE}

A determinação da atividade antioxidante foi realizada seguindo o método DPPH (2,2-difenil-1-picrilhidrazil) de acordo com Brand-Willians et al. (1995). Foram utilizados $750 \mu \mathrm{L}$ do extrato hidroalcoólico (70\% metanol/30\% água) preparado na análise de compostos fenólicos totais, em $3750 \mu \mathrm{L}$ de DPPH $(0,5$ $\mathrm{mM}$ ), a leitura realizada após $20 \mathrm{~min}$, em espectrofotômetro (AAKER), a $515 \mathrm{~nm}$. Os resultados foram expressos em porcentagem de inibição.

\subsection{ANÁLISE MICROBIOLÓGICA}

Realizou-se contagem dos microrganismos, segundo Downes e Ito (2001). Para todas as amostras foram feitas diluições seriadas em água peptonada tamponada $0,1 \%$ até a diluição $10^{-4}$.

\subsection{QUANTIFICAÇÃO DE MICRORGANISMO AERÓBIOS MESÓFILOS}

A quantificação dos microrganismos aeróbios mesófilos foi efetuada pelo método de semeadura em superfície utilizando-se Agar Padrão para Contagem (PCA). As placas foram incubadas a $35^{\circ} \mathrm{C}$ por $48 \mathrm{~h}$. Os resultados foram expressos em Log UFC.g-1.

\subsection{ENUMERAÇÃO DE FUNGOS}

Para a contagem de fungos (bolores e leveduras), utilizou-se o método de plaqueamento direto em superfície de Ágar Batada Dextrose (BDA). Diluições decimais foram inoculadas por espalhamento e submetidas à incubação, a $25^{\circ} \mathrm{C}$. Foram realizadas contagens aos três e aos cinco dias de incubação. Os resultados foram expressos em Log UFC.g ${ }^{-1}$.

\subsection{ANÁLISE ESTATÍSTICA}

Os resultados obtidos foram submetidos à análise de variância e à comparação de médias entre os tratamentos foi realizada pelo Teste de Tukey com nível de significância de 5 \%, utilizando-se o programa STATISTIX 10. Para a avaliação do tempo de armazenamento foi avaliado o intervalo de confiança a $95 \%$.

\section{RESULTADOS E DISCUSSÃO}

\subsection{PERDA DE MASSA}

Ao analisar os dados de perda de massa em relação ao tempo, pode-se observar que houve aumento significativo dos valores durante o armazenamento, independente da luminosidade $(\mathrm{p} \leq 0,05)$ (Figura 1). Entretanto, ao término do armazenamento não houve diferença significativa $(\mathrm{p} \leq 0,05)$, na perda de massa de pinhões armazenados sob diferentes condições de luminosidade (dados não mostrados). 
Figura 1: Perda de massa (\%) em pinhões armazenados sob diferentes condições de luminosidade por 90 dias a temperatura ambiente. As barras verticais representam o intervalo de confiança a $95 \%$. Controle (pinhões armazenados com a luminosidade ambiente; Vermelho (vermelho extremo); Luz (luz branca); Escuro (ausência de iluminação).

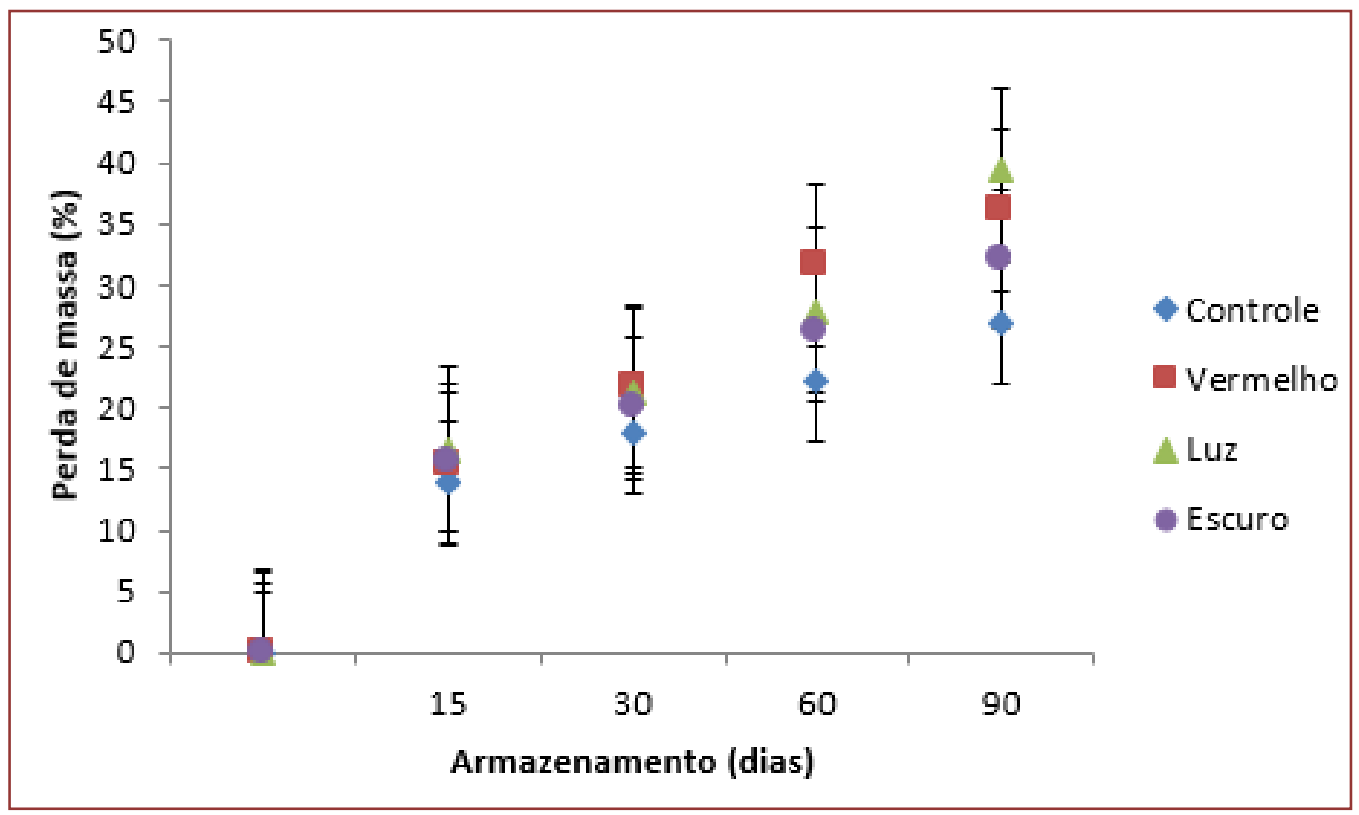

O aumento da perda de massa em pinhões resulta, principalmente, da perda de água e do consumo de substratos respiratórios. Amarante et al. (2007) e Costa (2014) também observaram o aumento da perda de massa em pinhões armazenados em distintas temperaturas sob o abrigo da luz, entretanto distintos valores foram observados. Amarante et al. (2007) obtiveram, aproximadamente, $40 \%$ de perda em pinhões armazenados por 60 dias a $30{ }^{\circ} \mathrm{C}$, já Costa (2014) observaram, aproximadamente, $20 \%$ em pinhões armazenados por 90 dias a temperatura ambiente. Segundo Amarante et al. (2007), o armazenamento de sementes de pinhão ocasiona perdas significativas de viabilidade, devido ao gasto energético com a respiração e a desorganização celular associada à desidratação e a senescência dos tecidos. Todavia, essa não é uma limitação para consumo na forma de alimento. Na verdade, a germinação do pinhão representa uma desvantagem, já que sementes brotadas não apresentam valor comercial para consumo humano. Entretanto, em função da perda de massa não foi observado germinação de nenhuma semente no presente estudo.

\subsection{ACIDEZ TOTAL}

Houve aumento significativo $(\mathrm{p} \leq 0,05)$ da acidez total titulável durante os 90 dias de armazenamento dos pinhões controle, armazenados sob a luz branca e vermelha, já para aqueles armazenados na ausência de luz, observou-se manutenção dos valores. Ao término do armazenamento os pinhões armazenados sob a luz branca e vermelha obtiveram significativamente $(p \leq 0,05)$ os maiores valores, enquanto que os pinhões armazenados no escuro, apresentaram significativamente os menores valores (dados não mostrados). 0 aumento da acidez pode estar relacionado com a degradação da parede celular em função do metabolismo (SIQUEIRA, 2012). 
Figura 2: Acidez total titulável (\%) em pinhões armazenados sob diferentes condições de luminosidade por 90 dias a temperatura ambiente. As barras verticais representam o intervalo de confiança a 95\%. Controle (pinhões armazenados com a luminosidade ambiente; Vermelho (vermelho extremo); Luz (luz branca); Escuro (ausência de iluminação).

\subsection{AÇÚCARES REDUTORES}

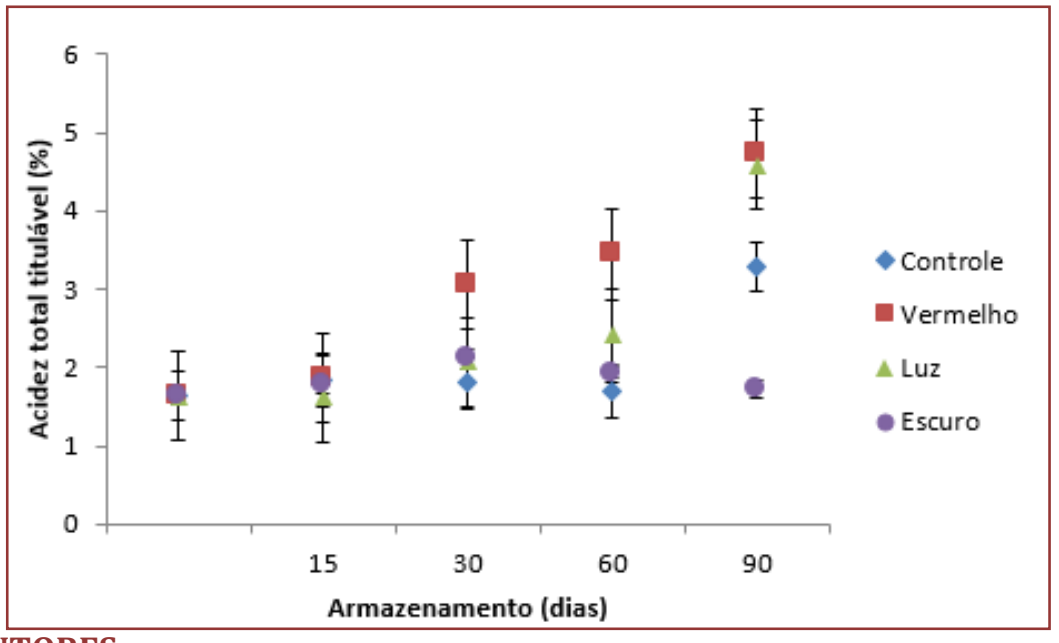

Pode-se observar na Figura 3, que houve aumento significativo nos teores de açúcares redutores dos pinhões submetidos aos distintos tratamentos $(\mathrm{p} \leq 0,05)$. Apenas no tratamento em que os pinhões foram armazenados na ausência de luz houve redução em 60 dias com posterior aumento. Ao término do armazenamento, houve variação significativa entre os valores, os pinhões armazenados sob a luz vermelha apresentaram os maiores teores, seguidos dos tratamentos, luz branca, escuro e controle (luz ambiente).

0 aumento nos teores de açúcares redutores pode ser proveniente da degradação do amido em função da maturação (CHITARRA; CHITARRA, 2005; HUSSAIN et al., 2008).

Figura 3: Açúcares redutores (g.100g-1) em pinhões armazenados sob diferentes condições de luminosidade por 90 dias a temperatura ambiente. As barras verticais representam o intervalo de confiança a 95\%. Controle (pinhões armazenados com a luminosidade ambiente; Vermelho (vermelho extremo); Luz (luz branca); Escuro (ausência de iluminação).

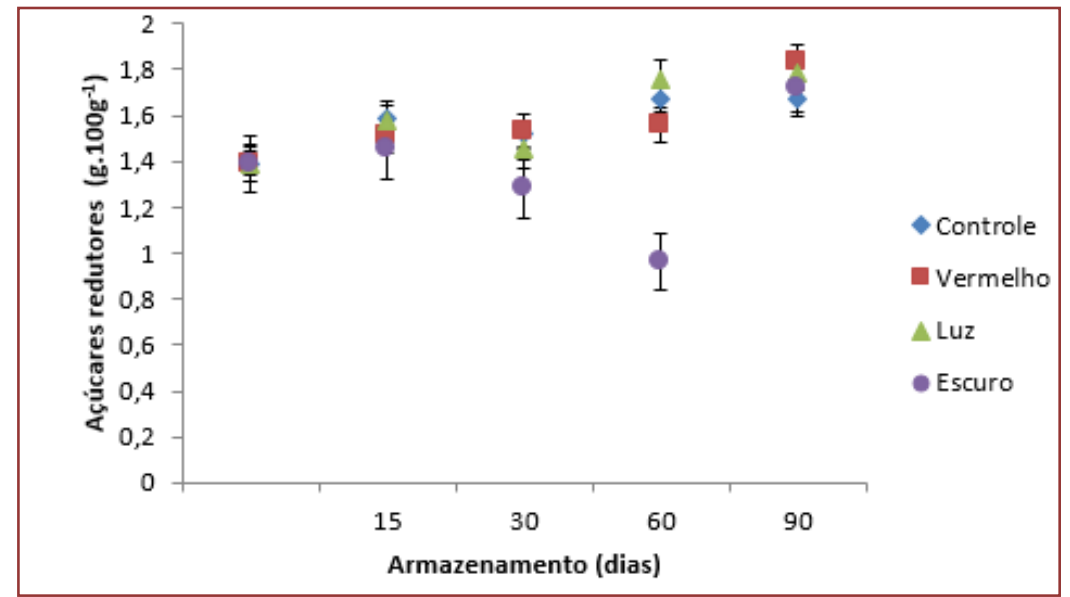




\subsection{VITAMINA C}

De acordo com a Figura 4, houve aumento significativo ( $\mathrm{p} \leq 0,05)$ do teor de vitamina $\mathrm{C}$ durante $\mathrm{o}$ armazenamento dos pinhões, independente do tratamento. Ao término do armazenamento, não houve influência significativa $(\mathrm{p} \geq 0,05)$ da luminosidade nos valores obtidos (dados não mostrados). De acordo com a tabela TACO (2011), o pinhão apresenta teor de vitamina C de $27,7 \mathrm{mg} .100 \mathrm{~g}$-1, estando os valores obtidos no presente estudo condizentes com a tabela de composição de alimentos.

Figura 4: Vitamina C (mg.100g-1) em pinhões armazenados sob diferentes condições de luminosidade por 90 dias a temperatura ambiente. As barras verticais representam o intervalo de confiança a 95\%. Controle (pinhões armazenados com a luminosidade ambiente; Vermelho (vermelho extremo); Luz (luz branca);

Escuro (ausência de iluminação).

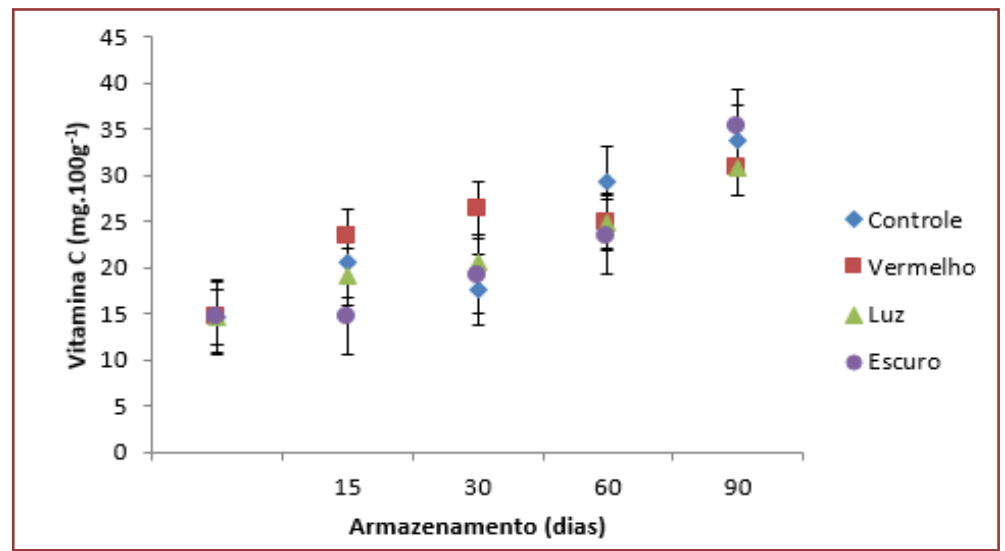

\subsection{FIRMEZA}

Pode-se observar aumento significativo $(\mathrm{p} \leq 0,05)$ da firmeza dos pinhões (Figura 5), independente da luminosidade. Em noventa dias de armazenamento, os pinhões armazenados sob a luz vermelha, apresentaram firmeza significativamente superior em relação aos pinhões dos demais tratamentos (dados não mostrados). Possivelmente, o aumento de firmeza observado esteja relacionado a perda de massa.

Figura 5: Firmeza (N) de pinhões armazenados sob diferentes condições de luminosidade por 90 dias a temperatura ambiente. As barras verticais representam o intervalo de confiança a 95\%. Controle (pinhões armazenados com a luminosidade ambiente; Vermelho (vermelho extremo); Luz (luz branca); Escuro (ausência de iluminação).

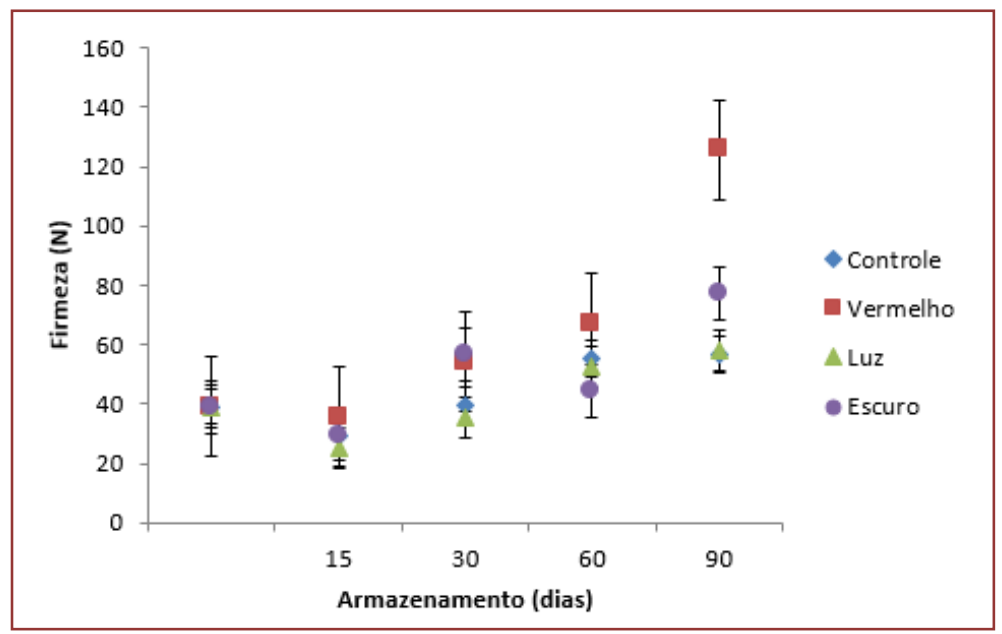




\subsection{COR}

Pode-se observar na Figura 6, redução da luminosidade dos pinhões armazenados em diferentes condições de luminosidade. Ao término do armazenamento não houve distinção entre os valores das amostras submetidas aos tratamentos controle, luz branca e vermelha, assim como entre luz branca, vermelha e escuro (dados não mostrados).

Figura 6: Cor ( $\left.\mathrm{L}^{*}\right)$ de pinhões armazenados sob diferentes condições de luminosidade por 90 dias, a temperatura ambiente. As barras verticais representam o intervalo de confiança a $95 \%$. Controle (pinhões armazenados com a luminosidade ambiente; Vermelho (vermelho extremo); Luz (luz branca); Escuro (ausência de iluminação).

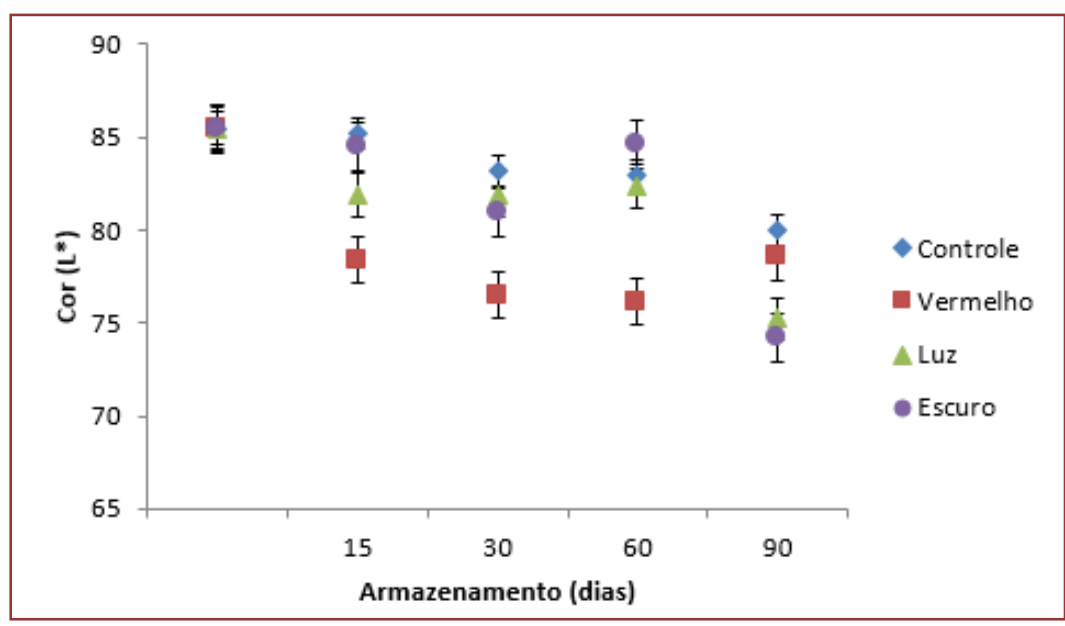

Para as coordenadas a* e b* observou-se aumento significativo $(\mathrm{p} \leq 0,05)$ dos valores, independente do tratamento avaliado, ou seja, houve a intensificação da cor vermelha e amarela, respectivamente (Figura 7 e 8). Em 90 dias de armazenamento, não houve distinção entre os valores das amostras submetidas aos tratamentos luz branca, vermelha e escuro para a coordenada $\mathrm{a}^{*}$, sendo os menores valores obtidos na amostra controle. Já para a coordenada b*, a amostra controle não diferiu da luz branca e do escuro, sendo obtido os maiores valores para as amostras armazenadas na luz vermelha (dados não mostrados).

Possivelmente, a intensificação da cor esteja relacionada a migração de flavonoides da casca para a polpa como a catequina e a quercetina, responsáveis pelas cores vermelha e amarela, respectivamente (CORDENUNSI et al., 2004).

Figura 7: Cor ( $\left.\mathrm{a}^{*}\right)$ de pinhões armazenados sob diferentes condições de luminosidade por 90 dias, a temperatura ambiente. As barras verticais representam o intervalo de confiança a 95\%. Controle (pinhões armazenados com a luminosidade ambiente; Vermelho (vermelho extremo); Luz (luz branca); Escuro (ausência de iluminação).

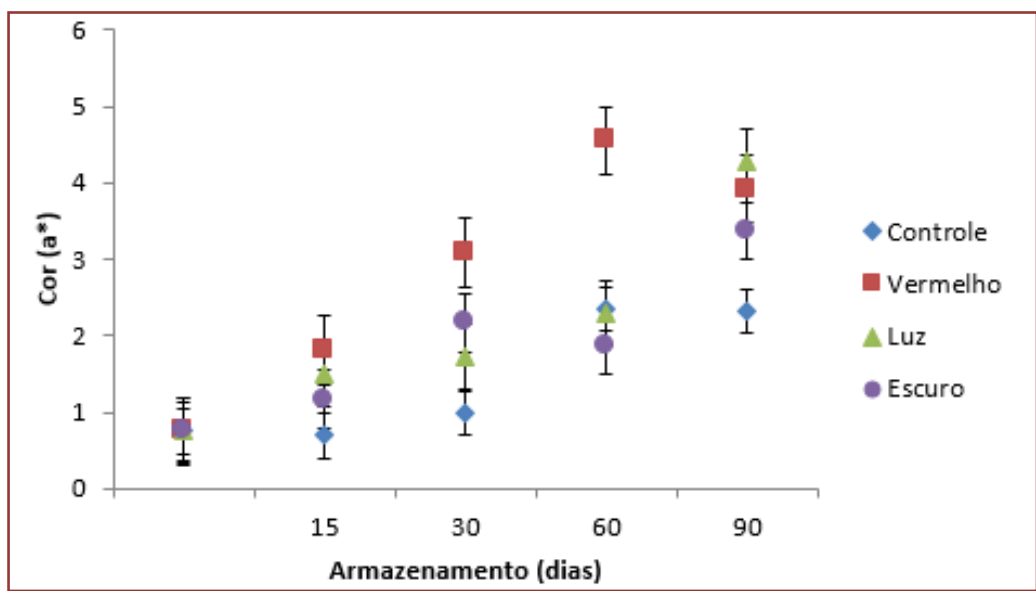

Figura 8: Cor $\left(\mathrm{b}^{*}\right)$ de pinhões armazenados sob diferentes condições de luminosidade por 90 dias, a temperatura ambiente. As barras verticais representam o intervalo de confiança a 95\%. Controle (pinhões 
armazenados com a luminosidade ambiente; Vermelho (vermelho extremo); Luz (luz branca); Escuro (ausência de iluminação).

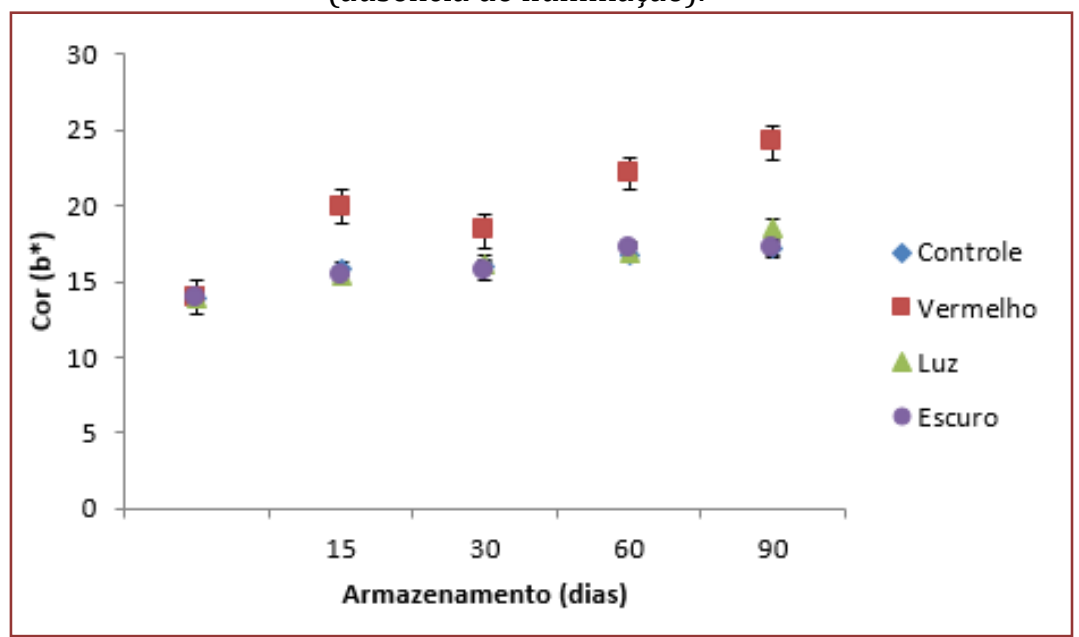

\subsection{COMPOSTOS FENÓLICOS TOTAIS}

De acordo com a Figura 9, os pinhões armazenados sob luz ambiente não apresentaram variação significativa no teor de compostos fenólicos durante o armazenamento $(p>0,05)$, já aqueles armazenados na luz branca observou-se aumento significativo $(\mathrm{p}<0,05)$. Para aqueles armazenados na ausência de luminosidade, os valores oscilaram com aumento significativo $(\mathrm{p}<0,05)$ em 90 dias de armazenamento e para as amostras armazenadas na luz vermelha, os valores oscilaram, sem diferença de valores entre $o$ primeiro e último dia de armazenamento $(\mathrm{p}>0,05)$. Ao término do armazenamento, os pinhões armazenados no escuro apresentaram os maiores valores de compostos fenólicos, seguido do armazenamento na luz branca, luz ambiente (controle) e luz vermelha (dados não mostrados). Distintos valores têm sido relatados na literatura para o teor de compostos fenólicos de pinhões, com variação de $54 \mathrm{mg}$ a $5140 \mathrm{mg} .100 \mathrm{~g}^{-1}$ (CORDENUNSI et al., 2004; SANT'ANNA et al., 2016).

Figura 9: Compostos fenólicos (mg EAG.100g-1) de pinhões armazenados sob diferentes condições de luminosidade por 90 dias, a temperatura ambiente. As barras verticais representam o intervalo de confiança a 95\%. Controle (pinhões armazenados com a luminosidade ambiente; Vermelho (vermelho extremo); Luz (luz branca); Escuro (ausência de iluminação).

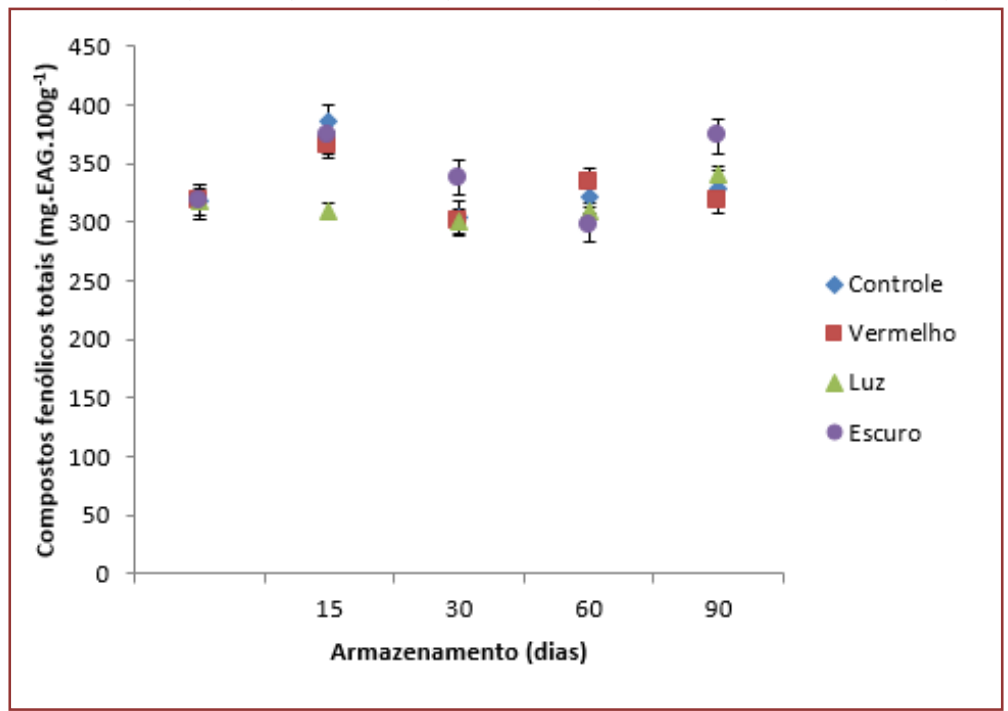




\subsection{ATIVIDADE ANTIOXIDANTE}

Pode-se observar na Figura 10, distintos comportamentos da atividade antioxidante dos pinhões em relação ao tempo de armazenamento. Para os pinhões armazenados na luz branca não se observou variação significativa ( $>0,05)$, para os armazenados sob a luz vermelha, os valores oscilaram, mas ao se comparar o primeiro e último dia de armazenamento, não houve distinção significativa $(p>0,05)$ e para aqueles armazenados em luz ambiente (tratamento controle), houve redução significativa somente em 90 dias de armazenamento $(\mathrm{p}<0,05)$. Já para as amostras armazenadas na ausência de luminosidade houve redução significativa desde 15 dias de armazenamento $(\mathrm{p}<0,05)$. Em 90 dias de armazenamento os maiores valores obtidos foram para os pinhões armazenados na luz vermelha, seguido da luz branca, controle e escuro (dados não mostrados).

Não se observou influência do teor de compostos fenólicos e do teor de vitamina C dos pinhões na atividade antioxidante, entretanto, houve relação do aumento da atividade antioxidante com o aumento das coordenadas $a^{*}$ e $b^{*}$, as quais possivelmente estejam relacionadas com os compostos catequina e quercetina, respectivamente.

Figura 10: Atividade antioxidante (\% de inibição) de pinhões armazenados sob diferentes condições de luminosidade por 90 dias, a temperatura ambiente. As barras verticais representam o intervalo de confiança a 95\%. Controle (pinhões armazenados com a luminosidade ambiente; Vermelho (vermelho extremo); Luz (luz branca); Escuro (ausência de iluminação).

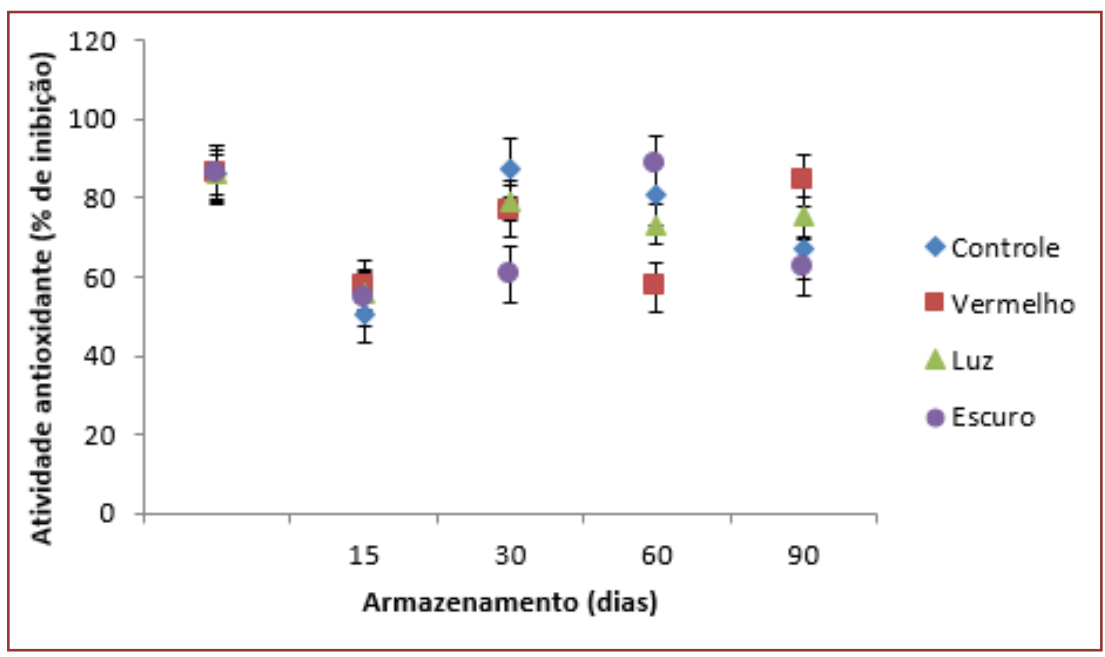

\subsection{ENUMERAÇÃO DE BACTÉRIAS AERÓBIAS MESÓFILAS E FUNGOS}

De uma forma geral, houve redução significativa $(\mathrm{p} \leq 0,05)$ da contagem das bactérias aeróbias mesófilas e fungos durante o armazenamento a temperatura ambiente, independente da luminosidade (Figura $11 \mathrm{e}$ 12). Possivelmente, esse comportamento seja decorrente da perda de água durante o armazenamento. 
Figura 11: Contagens de bactérias aeróbias mesófilas (Log UFC.g-1) em pinhões armazenados sob diferentes condições de luminosidade por 90 dias. As barras verticais representam o intervalo de

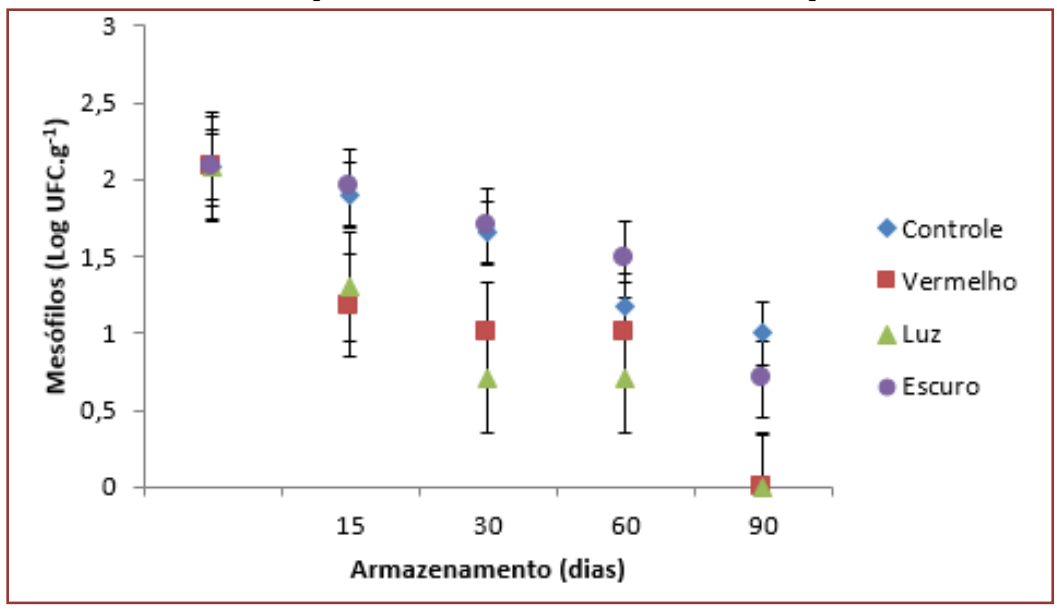

confiança a $95 \%$.

Figura 12: Contagens de fungos (Log UFC.g-1) em pinhões armazenados sob diferentes condições de luminosidade por 90 dias. As barras verticais representam o intervalo de confiança a 95\%. Controle (pinhões armazenados com a luminosidade ambiente; Vermelho (vermelho extremo); Luz (luz branca); Escuro (ausência de iluminação).

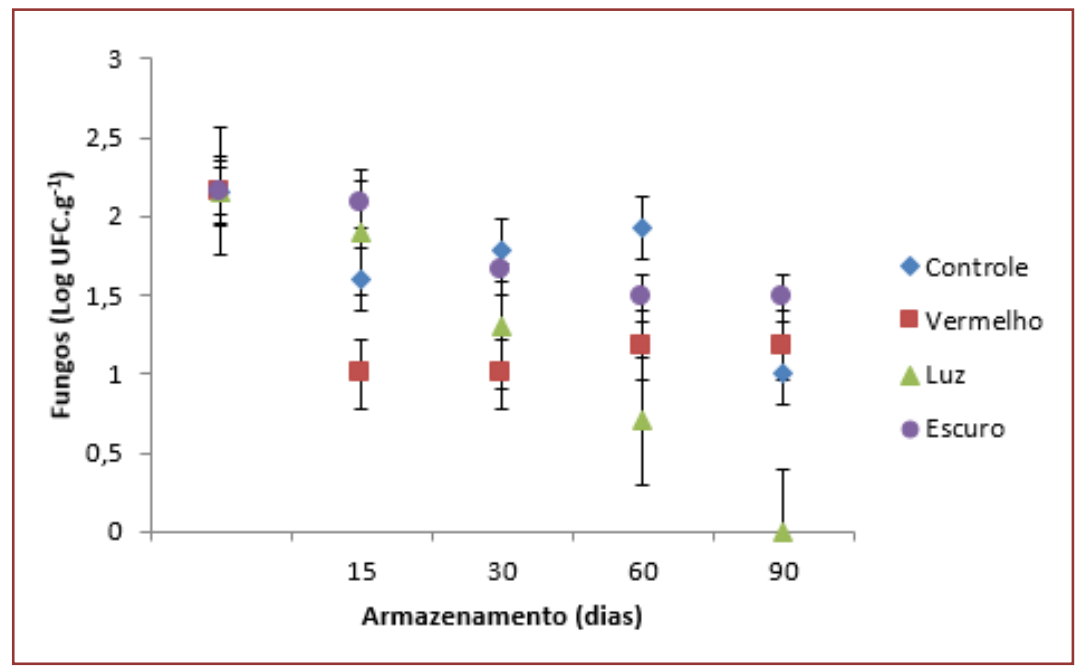

Os pinhões armazenados na ausência de luz e aqueles da amostra controle, de uma forma geral, apresentaram contagens de bactérias aeróbias mesófilas e fungos significativamente superiores $(\mathrm{p} \leq 0,05)$. As menores contagens $(p \leq 0,05)$ foram obtidas nos pinhões armazenados na luz branca e vermelho extremo, possivelmente em função da maior perda de água, decorrente do aquecimento gerado pela lâmpada.

Comportamento distinto foi obtido por Oliveira (2008), que observaram aumento significativo na contagem de bactérias aeróbias mesófilas e fungos em 61 dias de armazenamento dos pinhões a temperatura ambiente, obtendo valores de 7,23 Log UFC.g. ${ }^{-1}$ e 7,39 Log UFC.g-1.

A legislação brasileira, através da Resolução da Diretoria Colegiada-RDC n¹2 da Agência Nacional de Vigilância Sanitária (ANVISA), não estabelece limites máximos para a presença de aeróbios mesófilos e fungos em vegetais (BRASIL, 2001). Entretanto, a determinação desses é um indicativo da presença de microrganismos patogênicos ou deteriorantes (FRANCO; LANDGRAF, 1996). 


\section{CONCLUSÃO}

De uma forma geral, houve aumento significativo dos parâmetros físico-químicos durante o armazenamento dos pinhões, já para as avaliações microbiológicas observou-se redução significativa dos valores.

Ao término do armazenamento, não houve distinção entre os tratamentos em relação a perda de massa e teor de vitamina $\mathrm{C}$.

Dentre os tratamentos, o armazenamento na ausência de luminosidade, sob a luz vermelho extremo e luz branca ocasionaram as principais alterações tanto positivas quanto negativas. 0 armazenamento dos pinhões na ausência de luminosidade possibilitou a obtenção de menores valores de acidez e açúcares redutores, maiores valores de compostos fenólicos e de crescimento de microrganismos aeróbios mesófilos e fungos. Já o armazenamento na luz vermelho extremo e luz branca ocasionou os maiores valores para os parâmetros de cor $\left(\mathrm{a}^{*} \mathrm{e} \mathrm{b}^{*}\right)$ e também para a atividade antioxidante, menores valores de microrganismos aeróbios mesófilos, entretanto maiores valores de açúcares redutores e acidez. Maior firmeza foi obtida para as amostras armazenadas sob a luz vermelho extremo e menor crescimento de fungos para os pinhões armazenados na luz branca.

\section{AGRADECIMENTOS}

O presente trabalho foi realizado com apoio da Coordenação de Aperfeiçoamento de Pessoal de Nível Superior - Brasil (CAPES) - Código de Financiamento 001

\section{REFERÊNCIAS}

[1] Amarante, C. V. T; Mota, C. S.; Megguer, C. A.; Ide, G. M. Conservação pós-colheita de pinhões [sementes de Araucaria angustifolia (Bertoloni) Otto Kuntze] armazenados em diferentes temperaturas. Revista Ciência Rural, v. 37, n. 2, p 346-351, 2007.

[2] Balbinot, R.; Garzel, J. C. L; Weber, K. S.; Ribeiro, A. B. Tendências de consumo e preço de comercialização do pinhão (semente da Araucaria angustifolia (Bert.) 0. Ktze.), no estado do Paraná. Ambiência, v. 4, n. 3, p. 463-472, 2009.

[3] Bergo, C. L.; Silva, R. C.; Ohlson, O. C.; Biasi, L. A.; Panobianco, M. Luz e temperatura na germinação de sementes de pimenta longa (Piper hispidinervum) e pimenta-de-macaco (Piper aduncum). Revista Brasileira de Sementes, v. 32, n. 3, p. 170-176, 2010.

[4] Brand-Williams, W.; Cuvelier, M.E.; Berset, C. Use of a free radical method to evaluated antioxidante activity. LWT - Food Science and Technology, v.28, n. 1, p.25-30, 1995.

[5] Brasil. Ministério da Saúde. Agência Nacional de Vigilância Sanitária. Resolução RDC no 12, de 02 de janeiro de 2001. Aprova o Regulamento sobre padrões microbiológicos para alimentos. Diário Oficial da República Federativa do Brasil, Brasília, Distrito Federal, n. 7, 10 Jan. 2001. Seção 1, 53p.

[6] Capella, A. C. V.; Penteado, P. T. P. S.; Balbi, M. E. Semente de Araucaria angustifolia: aspectos morfológicos e composição química da farinha. Boletim do Centro de Pesquisa de Processamento de Alimentos, v. 27, n. 1, p. 135-142, 2010.

[7] Chitarra, M. I. F.; Chitarra, A. B. Pós-colheita de frutos e hortaliças: fisiologia e manuseio. Lavras: Esal/Faepe, 2005. 735p.

[8] Cordenunsi, B. R.; DE Menezes, E. W.; Genovese, I. G.; Colli, C.; de Souza, A. G.; Lajoto, F. M. Chemical composition and glycemic index of Brazilian pine (Araucaria angustifolia) seeds. Journal Agriculture Food Chemistry, v. 52, n. 11, p. 3412-3416, 2004.

[9] Costa, F. J. de O. G. Avaliação, caracterização de pinhão (sementes de Araucaria angustifolia) nativas do estado do Paraná e seu uso em um produto alimentício. 2014. 146 f. Tese (Doutorado em Engenharia de Alimentos), Departamento de Engenharia Química, Universidade Federal do Paraná, 2014.

[10] David, A. A. R.; Silochi, R. M. H. Q. Avaliação de métodos para conservação de pinhão. Revista Faz Ciência, v.12, n.15, p. 207-216, 2010.

[11] Downes, F.P.; ITO, K. Compendium of methods for the microbiological examination of foods. 4.ed. Washington: American Public Health Association, 2001. 676p. 
[12] Du, W.; Avena-Bustillos, R. J.; Breksa III, A. P.; Mchugh, T. H. UV-B light as a factor affecting total soluble phenolic contents of various whole and fresh-cut specialty crops. Postharvest Biology and Technology, v. 93, p. 72-82, 2014.

[13] Floriano, E. P. Germinação e dormência de sementes florestais. Santa Rosa: Anorgs, 2004.19p.

[14] Franco, B.D.G.M.; Landgraf, M. Microbiologia de alimentos. São Paulo: Atheneu, 1996. 182p.

[15] Hussain, P.R.; Meena, R.S.; Dar, M.A.; Wani, A.M. Studies Onenhacing the keeping quality of peach (Prunus persica Bausch/c.v).Elberta by gamma irradiation. Radiation Phisics and Chemistry, v.77, n.4, p-473-481, 2008.

[16] IAL-Instituto Adolfo Lutz. Métodos físico-químicos para análise de alimentos. São Paulo: Instituto Adolfo Lutz, 2008. 1020p.

[17] Moreira, Michele Krüger Vaz. Conservação de pinhões minimamente processados por meio de revestimentos comestíveis com características antimicrobianas. 2018.107f. Dissertação (Mestrado em Nutrição e Alimentos), Universidade Federal de Pelotas, Pelotas, Rio Grande do Sul, 2018.

[18] Oliveira, F. C. Estudos tecnológicos e de engenharia para o armazenamento e processamento do pinhão. 2008 197 f. Tese (Doutorado em Engenharia de Alimentos) Escola de Engenharia. Universidade Federal do Rio Grande do Sul, Porto Alegre, 2008.

[19] Olivera, F. C. Estudos tecnológicos e de engenharia para o armazenamento e processamento do pinhão. 2008 197 f. Tese (Doutorado em Engenharia de Alimentos) Escola de Engenharia. Universidade Federal do Rio Grande do Sul, Porto Alegre, 2008.

[20] Piña-Rodrigues, F. C. M. Manual de análise de sementes florestais. Campinas: Fundação Cargil, 1988. 100p.

[21] Sant'anna, V.; Voltaire, N.M.; Mercali, G.D.; Corrêa, A.P.F.; Brandelli, A. Effect of cooking on polyphenols and antioxidant activity of Araucaria angustifolia seed coat evaluation of phytochemical and microbiological stability over storage. International Journal of Food Science Tecnology, v.51, p.1932-1936, 2016.

[22] Singleton, V. L.; Orthofer, R.; Lamuela-Raventós, R. M. Analysis of total phenols and other oxidation substrates and antioxidants by means of Folin-Ciocalteu reagent. Methods in Enzymology, v. 299, p. 152-178, 1999.

[23] Taco. Tabela brasileira de composição de alimentos - TACI. 4. Ed. E ampl. Campinas, SP: Unicamp/NEPA, 2011. 161p.

[24] Vasconcelos, N.M; Pinto, G.A. S; Aragão, F.A.S. Determinação de açúcares redutores pelo ácido 3,5 dinitrosalicílico: Histórico do desenvolvimento do método e estabelecimento de um protocolo para o laboratório de bioprocessos. Boletim de Pesquisa e desenvolvimento. $1^{\circ}$ ed. Fortaleza: Embrapa Agroindústria Tropical, 2013. 29p.

[25] Yuan, M.; JIA, X.; Ding C.; Zeng, H.; Du, L.; Yuan, S.; Zhang, Z.; WU Q.; HU, C.; LIU, J. Effect of fluorescence light on phenolic compounds and antioxidant activities of soybeans (Glycine max L. Merrill) during germination. Food Science and Biotechnology, v 24, n.5, p. 1859-1865, 2015. 


\section{Capítulo 10}

Avaliação e caracterização de substâncias potencialmente tóxicas no chá de folha de cagaita pelo bioensaio da artemia salina e por espectrometria de massas com ionização electrospray

Rafael Resende Assis Silva

Amauri Geraldo de Souza

Júlio Onésio Ferreira Melo

Eric Marsalha Garcia

Hosane Aparecida Taroco

Resumo: As folhas de chá de cagaita podem apresentar toxinas naturais, também, encontradas em outros alimentos como os glicoalcalóides e os glicosídeos cianogênicos. No setor ervateiro à falha no alcance do binômio tempo/temperatura podem comprometem a retirada de substâncias tóxicas presente nas folhas. Portanto, se faz necessário a vertente de estudo para a avaliação da toxicidade e da caracterização de compostos tóxicos presentes nas folhas de cagaita. A avaliação da toxicidade foi realizada por meio do bioensaio com Artemia Salina e a caracterização do perfil de substâncias por meio da Espectrometria de Massas. As folhas que possuíam a maior toxidade frente às Artemias Salinas foram aquelas quando submetidas às variáveis de tratamento natural e coleta na estação de floração. Conclui-se que a produção de chá por meio das folhas da árvore de cagaita demonstrou ser de caráter atóxico e a redução da toxicidade deste chá pode ser realizada por meio do processo de secagem das folhas e da extração por solventes polares.

Palavras-Chave: Artemia Salina. Toxidade. Chá. Folha de Cagaita. Plantas cianogênica. 


\section{INTRODUÇÃO}

A população brasileira tem um importante conhecimento etnobotânico e etnofarmacológico em decorrência da miscigenação entre os colonizadores e escravos vindos do oriente e aliado ao conhecimento indígena local. Tais observações populares em relação ao uso e a eficácia de plantas em geral, principalmente, medicinais contribuem de forma relevante para a divulgação das propriedades terapêuticas dos vegetais, em virtude dos efeitos que produzem tanto no âmbito medicinal quanto alimentício (Maciel et al., 2002).

Os frutos da cagaita (Eugenia dysenterica) têm efeito laxante e as folhas antidiarreicas (Carneiro et al., 2014). No entanto o consumo indiscriminado dessas folhas por chá pode ter um efeito antagônico. Uma vez que estas podem apresentar toxinas naturais também encontradas em outros alimentos como, o glicoalcalóide encontrado em batatas e os glicosídeos cianogênicos encontrado na mandioca.

Plantas que apresentam glicosídeos cianogênicos na sua composição são consideradas tóxicas, pois o cianeto liberado desses compostos inibe a enzima citocromoxidase, essencial no processo de respiração celular (Nóbrega Júnior et al., 2006). Existem mais de 2.500 espécies vegetais que apresentam glicosídeos cianogênicos e estes funcionam como uma defesa química dessas plantas (Bak et al., 2006).

A secagem do material vegetal na produção de chá em escala industrial é realizada com controle rigoroso em relação ao binômio tempo e temperatura para assegurar a remoção de substâncias potencialmente tóxicas, evitar contaminações, controlar a umidade e padronizar a qualidade do material. As temperaturas ideais para secagem de erva-mate são entre 80 e $110{ }^{\circ} \mathrm{C}$ e não deve exceder a temperatura de $130{ }^{\circ} \mathrm{C}$ (Muello et al., 1946).

0 teste de toxicidade contra a Artemia salina é um ensaio biológico considerado como uma das ferramentas mais utilizadas para a avaliação preliminar de toxicidade. Desta forma, A. salina tem sido utilizada como um organismo alvo para detectar compostos bioativos em extratos de plantas, a toxicidade para este crustáceo tem demonstrado uma boa correlação com a atividade citotóxica contra tumores humanos e atividade contra o Trypanossoma cruzi, protozoário causador da doença de Chagas (Alves et al., 2002). PEREIRA et al. (2015) avaliaram o potencial toxicológico de plantas condimentares frente Artemia salina, expostas às concentrações dos extratos das plantas erva-doce (Pimpinella anisum L.), pimenta malagueta (Capsicum frutescens), endro (Anethum graveolens L.) e alecrim (Rosmarinus officinalis L.), demonstrando que após 24 horas os extratos de endro e alecrim não se mostraram tóxicos para as artemias, mas sim os extratos de erva-doce e pimenta malagueta.

O bioensaio com A. salina tem demonstrado eficiência na avaliação do potencial biológico de extratos de plantas (Leite et al., 2009). De acordo com CALIXTO et al. (2001) os estudos de plantas e de novas substâncias torna-se um balanço entre a atividade biológica versus a toxicidade, que é um parâmetro fundamental para verificar sua aplicabilidade na indústria alimentícia. 0 bioensaio com Artemia salina (BST - Brine Shrimp Test) serve tanto como indicador de toxicidade como de bioatividade de diversas substâncias químicas, inclusive para os extratos de plantas. Este método de avaliação de toxicidade detém diversas vantagens como: rapidez, praticidade, simplicidade, baixo custo, requer pouca quantidade de amostra, além de apresentar uma boa correlação com testes in vivo (Parra et al., 2001).

Diante deste cenário objetivou-se realizar estudos toxicológicos por meio do bioensaio com Artemias Salinas frente a extratos de folhas da cagaita em diferentes épocas e após a simulação do processo de secagem no setor ervateiro.

\section{METODOLOGIA}

Foram coletadas cerca de 200 gramas das folhas de três diferentes árvores de cagaita situadas na proximidade da Universidade Federal de São João Del Rei-Campus de Sete Lagoas (Figura 1), em cada ciclo de vida (Pré-floração, Floração e Pós-floração). 
Figura 1. Localização por GPS das árvores de cagaita.

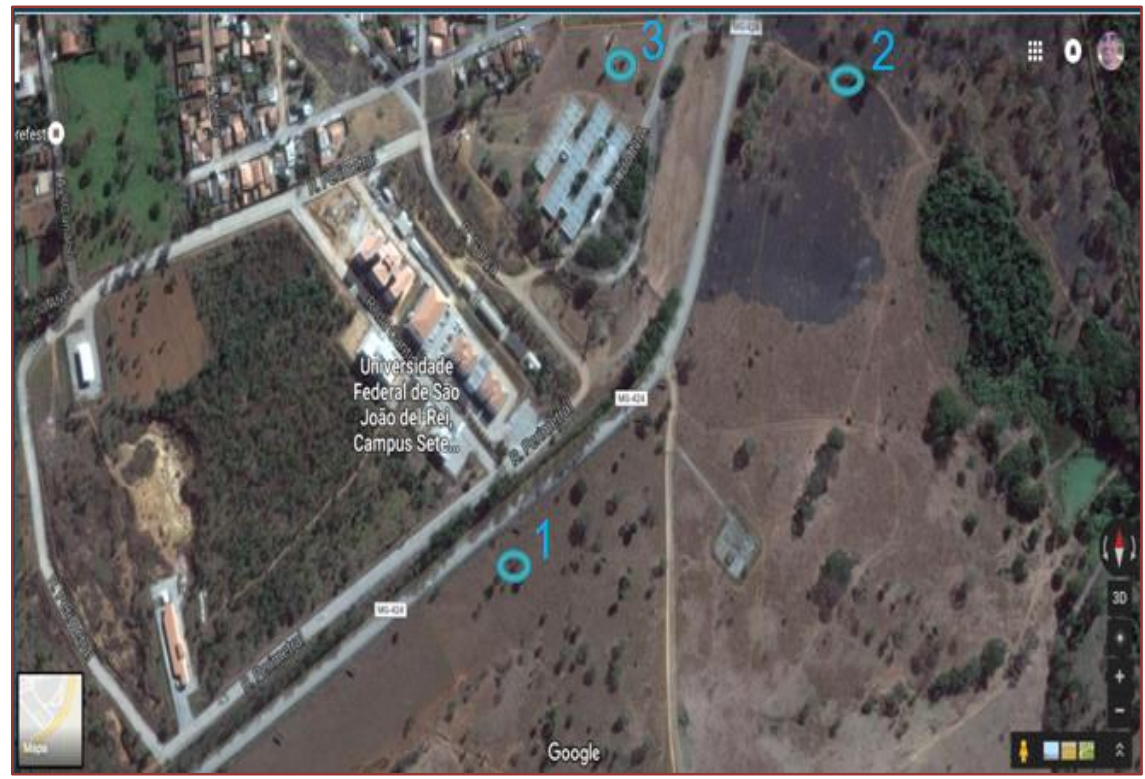

0 processo de secagem das folhas de cagaita foi realizado por meio do método de leito fixo (Barbaquá) com modificações e os parâmetros de secagem submetidos ao material vegetal foram descritos na Tabela 1.

Tabela 1. Parâmetros de secagem das folhas de cagaita na estufa.

\begin{tabular}{|l|c|}
\hline Parâmetros & Estufa \\
\hline Pressão & Atmosférica (760 mmHg) \\
\hline Operação & Batelada \\
\hline Fornecimento de energia térmica & Resistencia elétrica \\
\hline Agente de secagem & $\mathrm{Ar}$ \\
\hline Direção do fluxo de ar & Livre \\
\hline Controle de tempo e temperatura & Automático \\
\hline Tempo de secagem & 24 horas \\
\hline Temperatura de secagem & $100 \pm 2{ }^{\circ} \mathrm{C}$ \\
\hline Temperatura de saída do ar & $30-55^{\circ} \mathrm{C}$ \\
\hline
\end{tabular}

As folhas foram moídas com a utilização de um triturador e foram submetidas à extração por éter dimetílico e etanol $(0,48 \mathrm{~g}$ da folha/mL do solvente) durante $24 \mathrm{e} 48$ horas. Foram retiradas alíquotas de 3 $\mathrm{mL}$ do extrato, em triplicata, e eliminado o solvente de cada amostra com o uso de uma capela de exaustão em potência máxima por 24 horas, sendo verificado a eliminação do solvente por meio do espectro de massas. 0 extrato obtido foi recuperado com $2 \mathrm{~mL}$ de água destilada, homogeneizado e submetido ao bioensaio de toxicidade e diluído de $10^{-1}$ a $10^{-6}\left(\mathrm{~mL}^{\left.-\mathrm{mL}^{-1}\right)}\right.$ para encontrar a região de concentração da dose letal média de 50 \% (DL50) das A. Salinas após 48 horas de incubação em tubos de ensaio com o extrato.

As Artemias Salinas foram cultivadas no próprio laboratório de Química da UFSJ - Campus Sete Lagoas, sob condições controladas de temperatura $\left(24^{\circ} \mathrm{C}\right.$ ) e luminosidade ( 800 Lumens). 0 cultivo das A. Salinas foi realizado em meio aquoso contendo 30,00 g. $\mathrm{L}^{-1}$ de sal marinho para assegurar alimentação (NaCl) e inocuidade alimentar, devido ausência de Iodo. Após 24 horas do cultivo foi observado a eclosão dos ovos e foram transferidas 10 larvas para tubos de ensaio contendo $9 \mathrm{~mL}$ da solução salina e $1 \mathrm{~mL}$ do extrato diluído de diferentes amostras. 0 controle foi realizado na solução salina de cultivo e sem a adição do extrato das folhas de cagaita. Foi realizado a contagem dos crustáceos mortos, em triplicata, após 24 e 48 horas da eclosão dos ovos (Meyer et al., 1982). A $\mathrm{DL}_{50}$ foi calculada por meio da equação obtida com o melhor ajuste do modelo usando a regressão parcial de mínimos quadrados.

A porcentagem de mortes das Artemias Salinas para cada experimento após 48 horas foi obtida por meio da Equação 1. 


$$
\mathrm{M}_{\mathrm{as}}=\sum\left(\frac{\mathrm{Q}_{\mathrm{ams}}-\mathrm{Q}_{\mathrm{amb}}}{\mathrm{Q}_{\mathrm{at}}}\right) * 100 \%
$$

Em que: $\mathrm{M}_{\mathrm{as}}=$ Porcentagem de mortes de A. Salinas, $\mathrm{Q}_{\mathrm{ams}}=$ Quantidade de A. Salinas mortas no sistema avaliado, $\mathrm{Q}_{\mathrm{amb}}=\mathrm{Quantidade}$ de A. Salinas mortas na solução salina (branco), $\mathrm{Q}_{\mathrm{at}}=$ Quantidade de A. Salinas totais adicionadas em cada sistema.

As alíquotas dos extratos da folha de cagaita foram congeladas em eppendorf em congelador a temperatura constante de $5{ }^{\circ} \mathrm{C}$ até o momento das análises de caracterização do perfil das substâncias por espectrometria de massas. A caracterização dos compostos presentes na folha da cagaita foi realizada por meio da técnica de Espectrometria de Massas com Ionização Electrospray utilizando o Figerprint das substâncias presentes no extrato. Utilizou-se o intrumento LCQFleet (ThermoScientific, San CA, USA) equipado com uma fonte ESI. O espectro de massas foi adquirido pelo software (Xcalibur), com as condições do massas de $15 \mathrm{~V}$, spray de voltagem entre 1 e $6 \mathrm{Kv}$, temperatura do capilar de $275{ }^{\circ} \mathrm{C}$, gás nitrogênio e com fluxo de $10 \mu \mathrm{L}$. min $^{-1}$. Para a injeção no equipamento utilizou-se $30 \mu \mathrm{L}$ de metanol para facilitar o processo de solvatação e ionização das amostras.

Foram avaliadas quatro variáveis independentes para análise da toxicidade: tempo de extração do solvente (24 e 48 horas), estação do ano para a coleta das folhas (Pré-Floração, Floração e Pós-Floração), tipo de solvente (Éter Dimetílico e Álcool Etílico) e tipo de conservação do material vegetal (estado natural e estado seco).

\section{RESULTADOS E DISCUSSÃO}

As coordenadas geográficas das árvores de cagaita de onde foram coletadas as folhas para avaliação da toxicidade foram disponibilizados na Tabela 2.

Tabela 2. Coordenadas geográficas das árvores de cagaita.

\begin{tabular}{|c|c|c|c|}
\hline $\begin{array}{c}\text { Árvore } \\
\text { (amostra) }\end{array}$ & Latitude & Longitude & Altitude (metros) \\
\hline 1 & $19^{\circ} 28^{\prime} 38.0^{\prime \prime S}$ & $44^{\circ} 11^{\prime} 42.5^{\prime \prime W}$ & 787,38385 \\
\hline 2 & $19^{\circ} 28^{\prime} 27.2^{\prime \prime S}$ & $44^{\circ} 11^{\prime} 30.5^{\prime \prime W}$ & 779,017944 \\
\hline 3 & $19^{\circ} 28^{\prime} 27.1^{\prime \prime S}$ & $44^{\circ} 11^{\prime} 39.3^{\prime \prime W}$ & 818,53009 \\
\hline
\end{tabular}

A faixa de valores para os ensaios de determinação da dose letal média de $50 \%$ das A. Salinas foi estimada por meio do ajuste de modelos por regressão linear da mortalidade em função da concentração do extrato vegetal (mg.mL ${ }^{-1}$ ) (Figura 2).

Figura 2. Ajuste do modelo de regressão linear, intervalo de confiança e de predição.

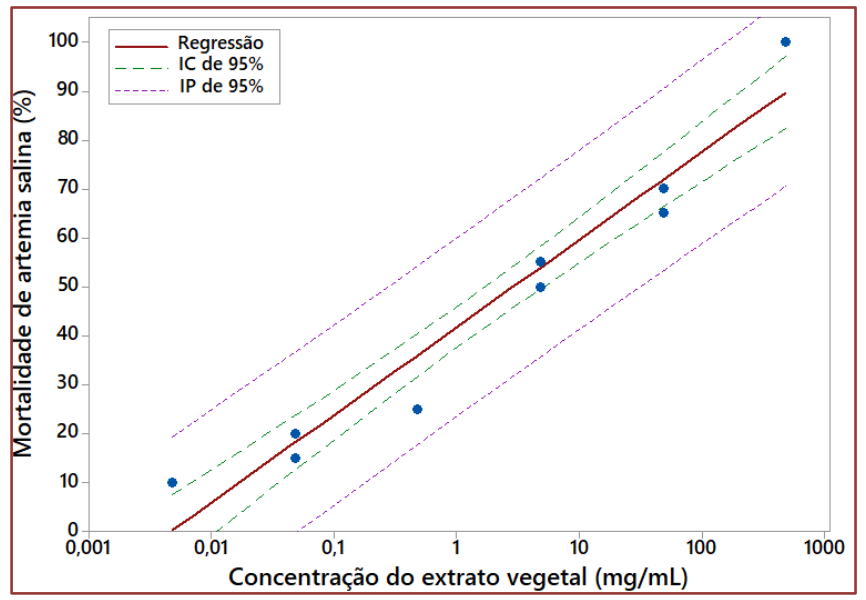


A equação obtida por meio do ajuste da regressão linear foi de $Y=41,75+17,90 * \log _{10}(X)$, enquanto o $R^{2}$ (ajustado) foi de 93,40 e o coeficiente significativo pelo teste de $t$ de Student (p-valor) foi menor que $5 \%$ de probabilidade. Por meio do modelo de regressão foi determinado a faixa de valores para o teste de toxicidade (DL45 a $\mathrm{DL}_{55}$ ) contra as $A$. Salinas nas concentrações entre 1,518 e 5,498 mg.mL $\mathrm{mL}^{-1}$ do extrato vegetal das folhas de cagaita.

Os pesquisadores ROSA et al. (2016) avaliaram o efeito tóxico da composição química do óleo essencial de Myrcia sylvatica (G.Mey) D.C contra Aedes aegypti e A. Salina. Os valores da dose letal de $50 \%$ para as $A$. Salina foram de aproximadamente $79,44 \mu \mathrm{g} . \mathrm{L}^{-1}$, enquanto frente as larvas do Aedes aegypti não foi verificado a DL50 para a maior concentração avaliada $\left(500 \mu \mathrm{g} . \mathrm{L}^{-1}\right)$. Os valores destas concentrações avaliados para o óleo essencial foram cerca de 10 a 120 vezes menores em relação aos aplicados para as folhas de cagaita. Este efeito é justificável, possivelmente, devido a maior presença de componentes bioativos nos óleos essenciais em relação aos componentes extraídos das folhas de cagaita.

A média dos valores de mortalidade de A. Salinas (\%) em função de diferentes condições submetidas as folhas de cagaita foram disponibilizadas na Figura 3.

Figura 3. Mortalidade de Artemia Salina em função de diferentes condições submetidas as folhas de cagaita.

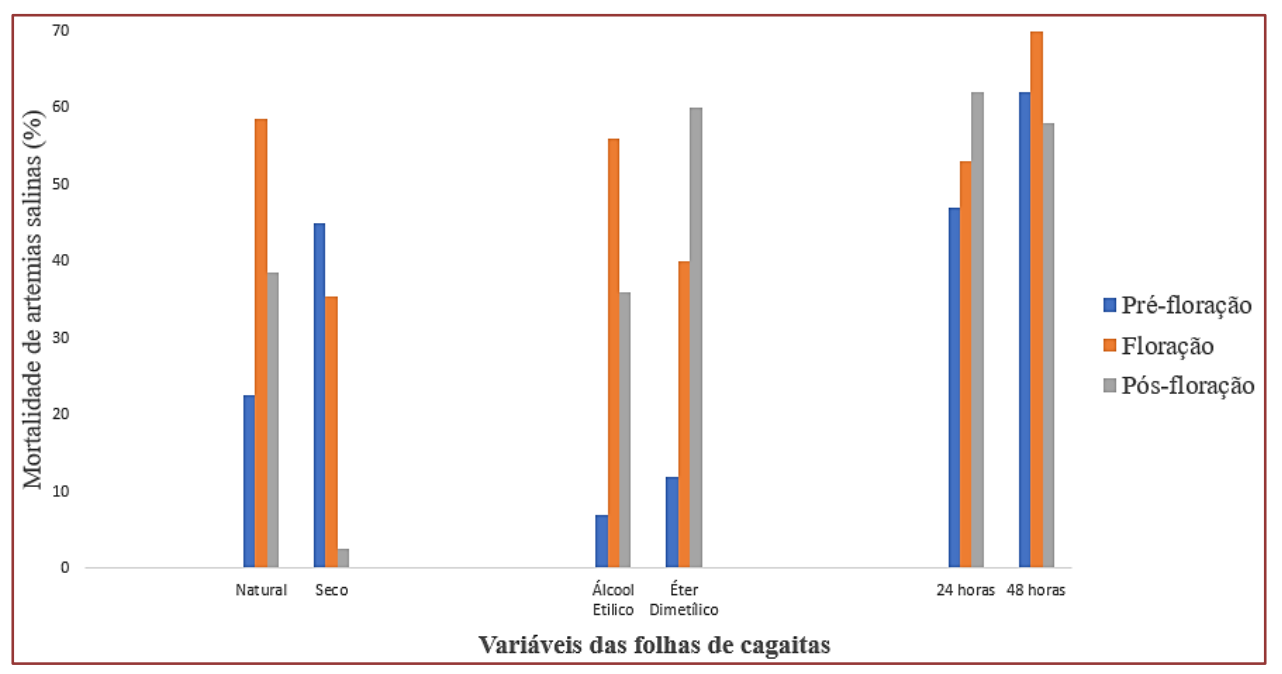

Foi verificado que a toxicidade dos extratos das folhas de cagaita frente $A$. Salina foi, em todos os casos, maior para a variável que manteve o tempo de extração igual a 48 horas. Logo, é possível inferir que o tempo de extração de 24 horas não foi o suficiente para, possivelmente, saturar o solvente em questão. Desta forma após 48 horas houve uma possível acumulação das substâncias tóxicas para a A. Salina.

Foi possível identificar que o estado de conservação natural da folha foi o mais tóxico no teste do bioensaio (Figura 3). Tendo um alcance de mortalidade de até 58,5 \% das A. Salinas contra $45 \%$ quando as folhas foram submetidas ao tratamento térmico. Dessa forma, o tratamento térmico pode ser crucial para a retirada de substâncias tóxicas para a A. Salina por meio de uma possível ebulição ou degradação de substâncias tóxicas.

0 teste de toxicidade em função da extração por diferentes solventes orgânicos teve o solvente éter dimetílico como o mais tóxico no bioensaio frente à $A$. Salina. Neste sentido foi possível associar a presença de substâncias, possivelmente, tóxicas de caráter apolar na folha de cagaita. Enquanto a maior toxicidade do extrato vegetal frente as A. Salinas, em função da variação das estações do ano, foi obtida na estação da época de floração das árvores de cagaitas. Isto pode estar relacionado à produção do fruto da cagaita em que diferentes metabólitos da planta são produzidos e encaminhados para a folha durante esta estação. Por conseguinte, houve uma maior liberação de substâncias, possivelmente, tóxicas nestas folhas de cagaita. 
De acordo com NGUTA et al. (2011) tanto extratos orgânicos, quanto extratos aquosos com valores de DL $_{50}$ menores que $100 \mu \mathrm{g} \cdot \mathrm{mL}^{-1}$ apresentam alta toxicidade, DL $\mathrm{L}_{50}$ entre 100 e $500 \mu \mathrm{g} \cdot \mathrm{mL}^{-1}$ apresentam toxicidade moderada, $\mathrm{DL}_{50}$ entre de 500 e $1000 \mu \mathrm{g} \cdot \mathrm{mL}^{-1}$ apresentam fraca toxicidade e $\mathrm{DL}_{50}$ acima de 1000 $\mu \mathrm{g} . \mathrm{mL}^{-1}$ são considerados atóxicos. Segundo BUSSMANN et al. (2004) tanto para extratos etanólicos, quanto aquosos com valores de $\mathrm{DL}_{50}$ menores que $249 \mu \mathrm{g} \cdot \mathrm{mL}^{-1}$ apresentam alta toxicidade, $\mathrm{DL}_{50}$ entre 250 e $499 \mu \mathrm{g} \cdot \mathrm{mL}^{-1}$ apresentam toxicidade moderada, DL 50 entre 500 e $1000 \mu \mathrm{g} \cdot \mathrm{mL}^{-1}$ apresentam leve toxicidade, e DL 50 acima de $1000 \mu \mathrm{g} \cdot \mathrm{mL}^{-1}$ são considerados atóxicos. A partir destas classificações e por meio da determinação da DL50 igual a $2880 \mu \mathrm{g} \cdot \mathrm{mL}^{-1}$ para os extratos orgânicos e etanólicos das folhas de cagaita foi possível classificar as folhas de cagaita como atóxicos.

0 extrato obtido com o solvente éter dimetílico foi o mais tóxico no bioensaio frente à $A$. Salinas, tendo um alcance de mortalidade de até $60 \%$ das artemias contra $56 \%$ quando comparado com a extração utilizando o solvente etanol. Neste sentido foi possível associar a presença de substâncias, possivelmente, tóxicas e de caráter apolar nas folhas de cagaita (Figura 4).

Na Tabela 2 é visualizado os tipos de variáveis submetidos para cada amostra de cagaita com o intuito de viabilizar a discussão dos resultados da espectrometria de massas para as amostras que apresentaram somente um tipo de variável distinta da outra.

Tabela 2. Descrição das amostras submetidas a diferentes variáveis.

\begin{tabular}{|c|c|c|c|c|c|c|}
\hline $\begin{array}{l}\text { Código da } \\
\text { amostra }\end{array}$ & Planta & $\begin{array}{l}\text { Localização da } \\
\text { árvore }\end{array}$ & Solvente & $\begin{array}{c}\text { Tipo de } \\
\text { Conservação }\end{array}$ & $\begin{array}{l}\text { Tempo de } \\
\text { extração }\end{array}$ & Estação do ano \\
\hline 224 & Cagaita & Árvore 1 & Álcool & Seco & 48 horas & Pré-floração \\
\hline 247 & Cagaita & Árvore 1 & Éter & Natural & 48 horas & Pré-floração \\
\hline 248 & Cagaita & Árvore 1 & Álcool & Natural & 48 horas & Pré-floração \\
\hline
\end{tabular}

Os espectros de massas foram realizados na faixa de razão massa carga (m.z $\left.{ }^{-1}\right)$ de 50 a 1000 m.z. ${ }^{-1}$ para avaliar o comportamento dos compostos presentes nos extratos quando submetidos a diferentes tratamentos. As Figuras 4 e 5 mostram um fingerprint do extrato vegetal das folhas de cagaita em função da variação no processo de conservação das folhas (natural e seco, respectivamente).

Figura 4. Espectro da amostra 248 submetida ao tratamento de conservação natural.

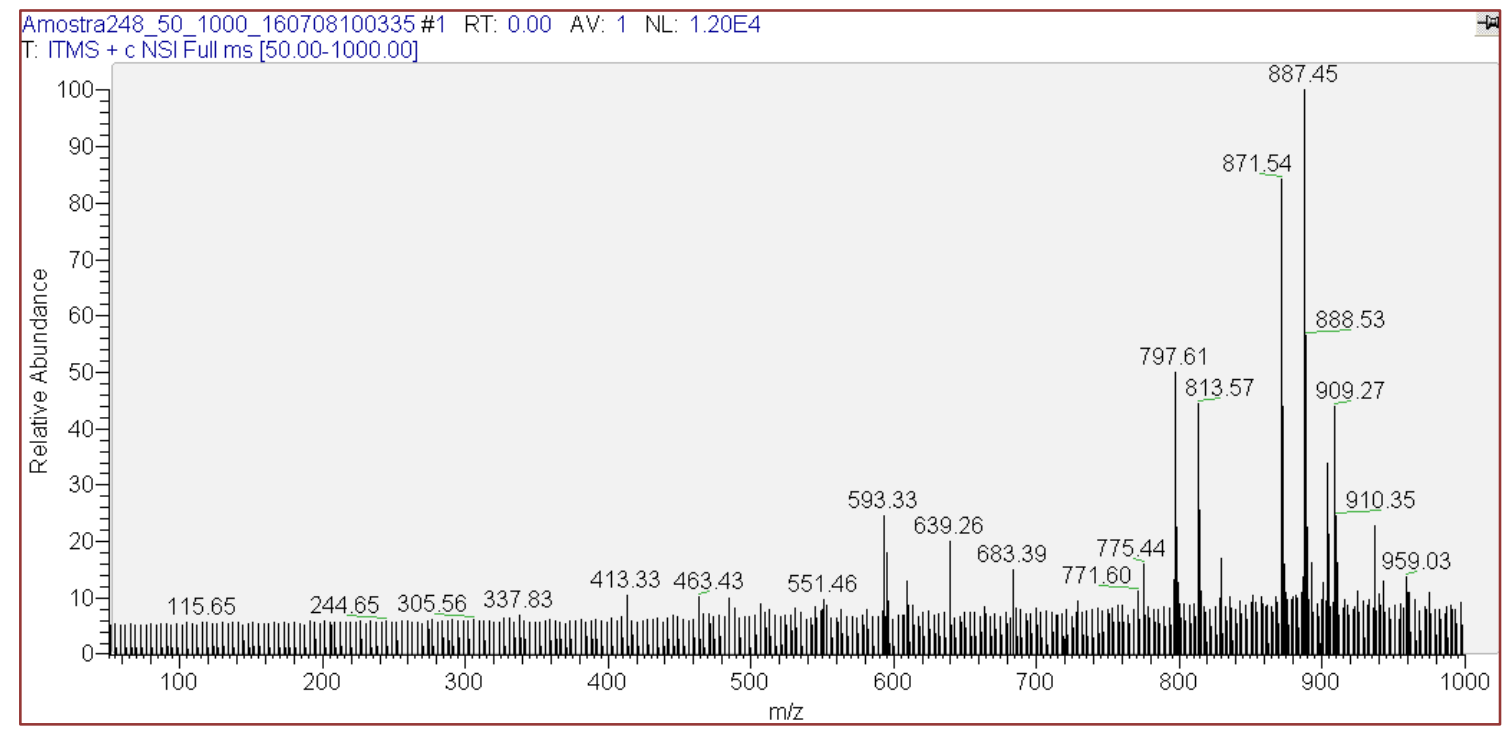


Figura 5. Espectro da amostra 224 submetida ao tratamento de conservação a seco.

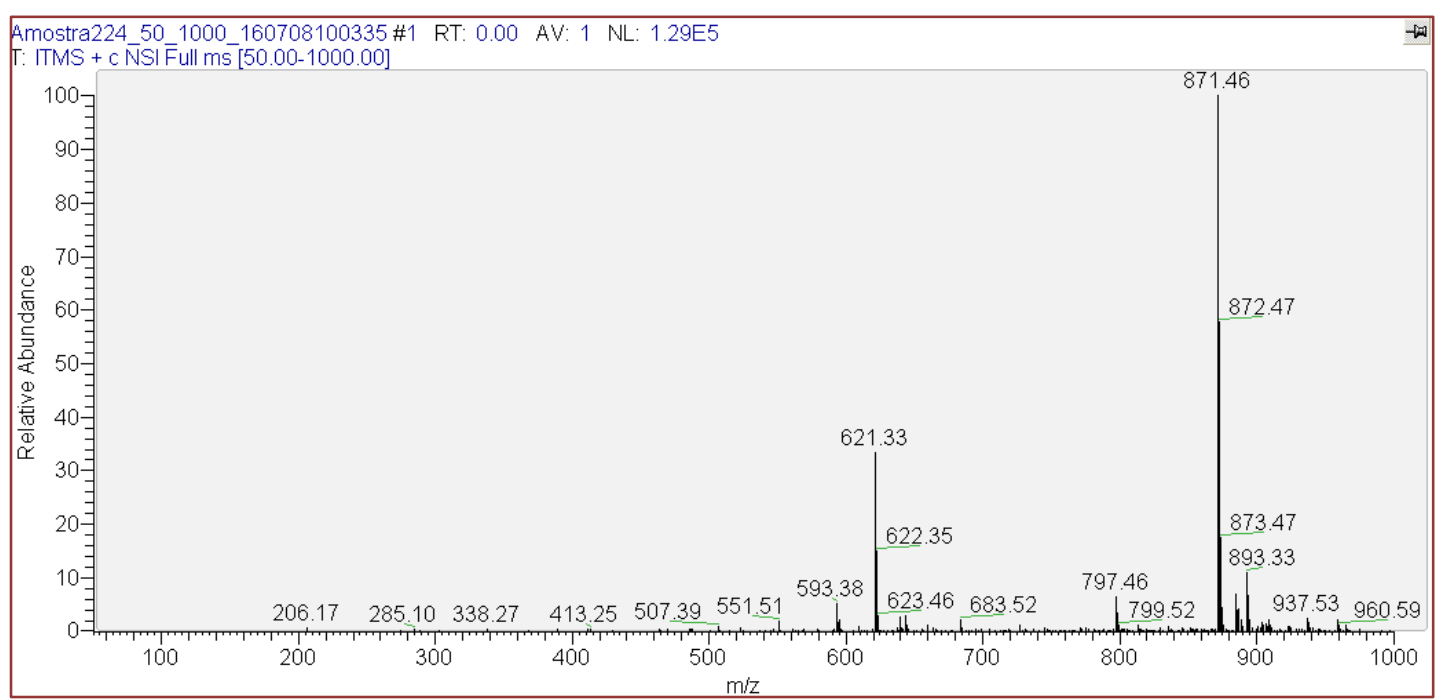

No espectro da Figura 4 (conservação natural) é possível notar a maior quantidade de substâncias presentes no extrato das folhas em relação a amostra tratada pela conservação a seco. Esta ocorrência é justificável devido à aplicação do tratamento térmico de $100 \stackrel{\circ}{\circ}$ por 24 horas nas folhas de cagaita da conservação a seco e, que por conseguinte, eliminou ou degradou substâncias potencialmente tóxicas contidas folhas.

Os compostos de relação massa/carga (797; 813; 887 e 909) que apareceram no espectro de massas do tratamento de conservação natural são os compostos potencialmente tóxicos para as A. Salinas. Pois, quando submetido ao bioensaio, a amostra 248 demonstrou maior toxicidade do que a amostra 224 . Enquanto, após o tratamento de secagem apenas os íons 621 e $871\left(\mathrm{~m} \cdot \mathrm{z}^{-1}\right)$ foram os únicos compostos que apresentaram a abundancia relativa maior que $30 \%$ no extrato vegetal, sendo outras substâncias possivelmente tóxicas.

Na Figura 6 foi disponibilizado o espectro de massas da amostra 247 e no qual diferencia-se da amostra 246 somente pela extração com o uso do solvente apolar (Éter Dimetílico) e foi possível verificar a presença de diferentes picos no espectro em relação a Figura 6 (Álcool Etílico).

Figura 6. Espectro da amostra 247 submetida a extração pelo solvente apolar

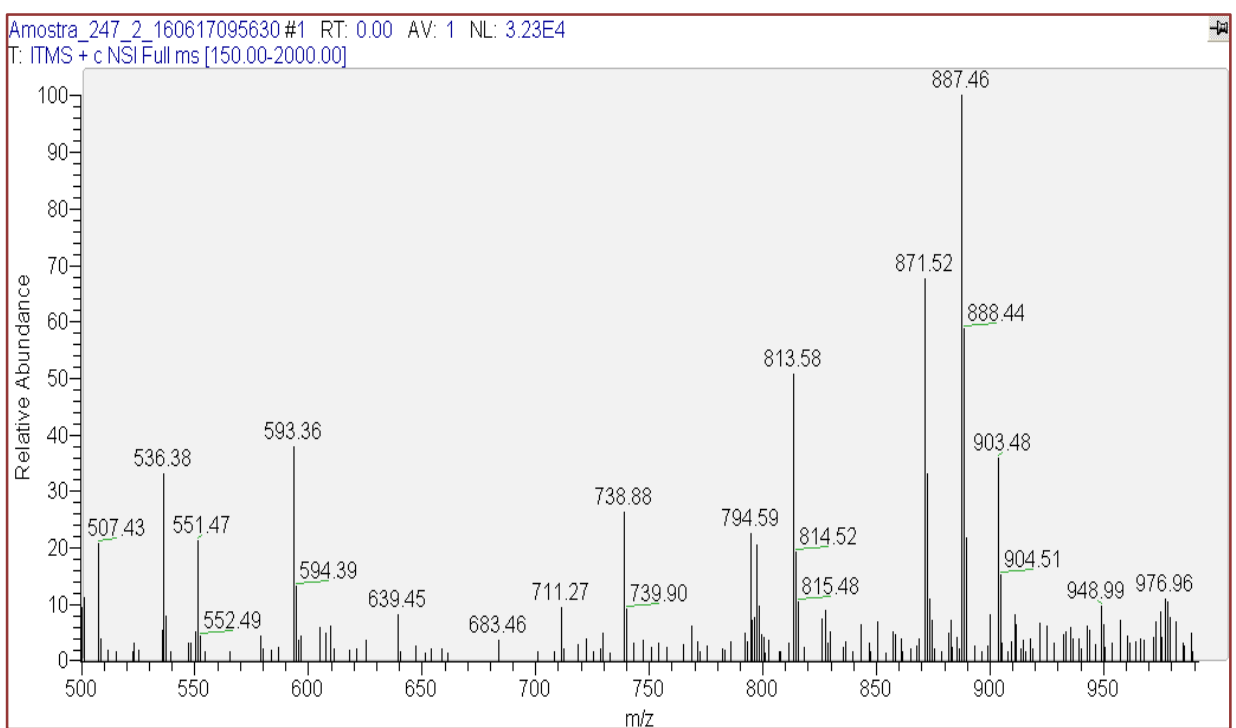


Os picos correspondentes aos compostos de relação massa/carga 813, 871 e 887 são característicos de compostos anfipáticos, devido à presença no espectro de massas dos extratos vegetais obtidos por extração com solventes polares e apolares. A substância de relação massa/carga 797 é possivelmente uma molécula polar, devido à presença no espectro de massas da Figura 4 e 5 e no qual os componentes foram extraídos com o uso do álcool etílico. Enquanto a substância com maior abundancia relativa do espectro da Figura $6\left(887 \mathrm{~m}^{-1} \mathrm{z}^{-1}\right)$ é possivelmente uma molécula hidrofóbica, devido à ausência nos espectros da Figuras 4 e 5.

Foi possível verificar que os extratos vegetais das folhas de cagaita possuem compostos com toxicidade para as A. Salinas de caráter hidrofóbico, hidrofílico e anfipática, devido a presença de picos característicos nos espectros das Figuras 4, 5 e 6. Contudo a abundancia relativa destes compostos são influenciadas pelos tratamentos de conservação, extração por solventes e época de coleta e podem ser avaliadas por meio de combinações fatoriais para possíveis reduções no índice de mortalidade das A. Salinas. Enquanto a identificação destes compostos deve ser realizada em conjunto com outras técnicas e instrumentos de caracterização para a verídica descrição do perfil de substâncias possivelmente tóxicas presentes nas folhas das árvores de cagaita.

\section{CONCLUSÕES}

A produção de chá por meio das folhas da árvore de cagaita demonstrou ser de caráter atóxico e a redução da toxicidade deste chá pode ser realizada por meio do processo de secagem das folhas e da extração por solventes polares, tornando o consumo do chá potencialmente seguro para os seres humanos. Contudo, deve-se ampliar o número de amostragem das árvores, de onde são coletadas as folhas, para a obtenção de resultados mais representativos na escala nacional.

\section{AGRADECIMENTOS}

FAPEMIG, CNPq, aos professores do Departamento de Ciências Exatas e Biológicas e a UFSJ pelo apoio financeiro para a realização desta pesquisa.

\section{REFERENCIAS}

[1] ALVES, T. M. A.; SILVA, A. F.; BRANDÃO, M.; GRANDI, T. S. M.; SMÂNIA, E. F. A.; SMÂNIA, J, A.; ZANI, C. L. Biological screening of Brazilian medicinal plants. Memó-rias do Instituto Oswaldo Cruz, 95: p. 367-373, 2000.

[2] BAK, S.; PAQUETTE, S. M.; MORANT, M.; RASMUSSEN, A. V.; SAITO, S.; BJARNHOLT, N.; ZAGROBELNY, M.; JORGENSEN, K.; HAMANN, T.; OSMANI, S.; SIMONSEN, H. T.; PÉREZ, R. S.; VAN HESSWIJCK, T. B.; ORGENSEN, B.; MOLLER, B. L. Cyanogenic glycosides: a case study for evolution and application of cytochromes P450. Phytochem. Rev, 5: p. 309-329, 2006.

[3] BUSSMANN R.W. Ethnobothany and Biodiversity and Conservation. http://www.olorien.org/rbussmann/academicCV.php., 2004.

[4] CALIXTO, J. B. Medicamentos Fitoterápicos In: YUNES, R. A. e CALIXTO, J. B. (orgs.) Plantas Medicinais sob a ótica da Química Medicinal Moderna Chapecó: Argos. p. 297-315, 2001.

[5] CARNEIRO, F. M.; SILVA, M. J. P.; BORGES, L. L.; ALBERNAZ, L. C.; COSTA, J. D. P. Tendencia dos estudos com plantas medicinais no Brasil. Revista Sapiciência, ISSN: 2238-3565, 2014.

[6] LEITE, J. J. G.; BRITO, E. H. S.; CORDEIRO, R. S.; BRILHANTE, R. S. N.; SIDRIM, J. J. C.; BERTINI, L .M.; MORAIS, S. M.; ROCHA, M. F. G. Chemical composition toxicity and larvicidal and antifungal activities of Persea americana (avocado) seed extracts. Rev. Soc. Bras. Med. Trop, 42(2): p. 110-113, 2009.

[7] MACIEL, M. A. M.; PINTO, A. C.; VIGA J. R. Plantas medicinais: a necessidade de estudos multidisciplinares. Química Nova 25(3): p. 429-438, 2002.

[8] MEYER, N. et al. Brine shrimp: a convenient general bioassay for active plant constutints. Planta Médica, v. 45, [s.n.], p. 31, 1982.

[9] MUELLO, A. C. Yerba mate su cultivo y explotacion. Buenos Aires: Editorial Sudamericana, p.102-138, 1946. 
[10] NGUTA, J. M.; MBARIA, J. M.; GAKUYA, D. W.; GATHUMBI, P. K.; KABASA, D. J.; KIAMA, S. G. Biological screening of kenya medicinal plants using Artemia salina L. (Artemiidae). Pharmacologyonline, v.2, p.458-78, 2011.

[11] NÓBREGA JÚNIOR, E. da, RIET-CORREA, F., MEDEIROS, R. M. T.; DANTAS, A. F. M. Intoxicação por Sorhgum halepense (Poaceae) em bovinos no semi-árido. Pesq. Vet. Bras, 26: p. 201-204, 2006.

[12] PARRA, A. L; YHEBRA, R. S; SARDIÑAS, I. G; BUELA, L. I. Comparative study of the assay of Artemia salina L. and the estimate of the medium lethal dose (LD50 value) in mice, to determine oral acutetoxicity of plant extracts. Phytomedicine, v. 8(5), p. 395-400, 2001.

[13] PEREIRA, E. M.; FILHO, M. T. L.; MENDES, F. A.; MARTINS, A. N. A.; ROCHA, A. P. T. Potencial toxicológico frente Artemia Salina em plantas condimentares comercializadas no município de Campina Grande-PB. Revista Verde de Agroecologia e Desenvolvimento Sustentável, v. 10, n.1, p. 52 - 56, 2015.

[14] ROSA, C. S.; VERAS, K. S.; SILVA, P.R.; NETO, L. J. J.; CARDOSO, H. L. M.; ALVES, L. P. L.;BRITO, M. C. A.; AMARAL, F. M. M.; MAIA, J.G.S.; MONTEIRO, O. S.; MORAES, D. F. C. Composição química e toxicidade frente Aedes aegypti L. e Artemia salina Leach do óleo essencial das folhas de Myrcia sylvatica (G. Mey.) DC. Revista Brasileira de Plantas Medicinais, V.18, n.1, p. 19-26, 2016. 


\title{
Capítulo 11
}

Qualidade físico-química de néctares de caju comercializados na cidade de São Luís-MA

\author{
Alexsandra Iarlen Cabral Cruz. \\ Leidiana de Sousa Lima \\ Deydyane dos Santos Moreira \\ Nuberlene Ferreira Carvalho \\ Edna Maria Silva Santos \\ Valeria Sousa Mota \\ Rayanne Araújo Pessoa \\ Francisco José da Conceição Lima
}

Resumo: 0 néctar é uma opção de bebida à base de caju que possui menor teor de suco, que tem ganhado espaço entre os consumidores devido ao seu custo mais baixo. A presente pesquisa teve por objetivo avaliar as características físico-químicas de néctares de caju comercializados na cidade de São Luís - Maranhão. Para isso, realizaram-se as determinações de pH, acidez titulável expressa em ácido cítrico, sólidos solúveis (ํBrix) e ácido ascórbico em néctares de caju de 5 marcas comerciais. Os resultados obtidos nas avaliações mostram que os néctares de caju comercializados nos supermercados da cidade de São Luís-MA, apresentaram-se em sua maioria (90\% a 100\%) teores significativos de vitamina $\mathrm{C}$ e valores de $\mathrm{pH}$, acidez titulável e sólidos solúveis ( ${ }^{\circ} \mathrm{Brix}$ ) dentro dos padrões exigidos, e portanto, estão aptos para consumo.

Palavras-chave: Bebidas; Ácido ascórbico; Sólidos solúveis. 


\section{INTRODUÇÃO}

O Brasil ocupa lugar de destaque na produção de frutas, representando um dos três maiores produtores de frutas do mundo, sua produção tem superado os 40 milhões de toneladas (BRASIL, 2016). Neste cenário, destaca-se o cultivo do caju, a produção desse fruto no Brasil é responsável por $11 \%$ da produção mundial. 0 cultivo desse fruto corresponde a uma atividade tradicional do nordeste brasileiro, cuja a extração e processamento possui importância socioeconômica para a população, pois é uma atividade que gera renda e empregos tanto para a comunidade rural como nos polos industriais (FIGUEIRA et al., 2015).

O cajueiro pertence à família (Anacardium occidentale L), é uma planta tropical da família das Anacardiaceae originária da América do Sul, ocorrem em clima tipicamente tropical, sendo encontrados em agroecossistemas brasileiros. 0 caju é um alimento de grande importância nutricional já que apresenta em sua composição, nutrientes, ácidos orgânicos, carboidratos e vitaminas, dentre estas, a vitamina C (QUINTÃO et al., 2016; SAPATA et al., 2017).

O caju apresenta um pseudofruto de alto valor nutritivo, que possui sais minerais como, por exemplo, cálcio, ferro e fósforo. Esse pseudofruto possui ainda níveis de vitamina $\mathrm{C}$ cinco vezes maiores do que os níveis encontrados na laranja (ARAÚJO et al., 2018). Conhecido como pedúnculo do caju, esse pseudofruto pode ser consumido in natura ou pode ser utilizado na fabricação de diversos produtos alimentícios, no entanto, é bastante desperdiçado, apenas $10 \%$ da sua produção é aproveitada para a fabricação de produtos como sucos, cajuína, vinho, refrigerantes, doces e néctares (COSTA et al., 2016). Nos mercados, o preço dos néctares é menor que os preços dos sucos integrais pasteurizados e sucos reconstituídos, e por isso tem atraído atenção dos consumidores (FIGUEIRA et al., 2015).

No mercado de bebidas no Brasil, os néctares e sucos são um importante segmento. Em 2016 eles representaram uma movimentação de cerca 7,9 $\mathrm{R} \$$ bilhões na economia do país com um consumo de 2,3 bilhões de litros dessas bebidas pela população, isto é, vem apresentando um crescimento significativo. Enquanto o mercado de refrigerantes cresce em média $2 \%$ ao ano, o de néctares e sucos vem crescendo cerca de 9\% (ABREU, 2013; SNA, 2017).

A legislação define o néctar como bebida fermentada, obtida da dissolução, em água potável, da parte comestível do caju (Anacordium occidedentale, L.) e açucares destinado ao consumo direto, podendo ser adicionado de ácidos. E deve obedecer às seguintes características de composição: cor amarela clara, sabor característico e aroma próprio, podendo ser composto por suco ou polpa da fruta sendo no mínimo 15 gramas por cada 100 gramas de néctar (BRASIL, 2003).

Nesse contexto, esse trabalho objetivou-se avaliar as características físico-químicas dos néctares de caju comercializados na cidade de São Luís do Maranhão, a fim de verificar, se estes, atendem as exigências da legislação para o padrão de identidade e qualidade.

\section{MATERIAL E MÉTODOS}

Foram coletadas cinco amostras de néctar de caju, de fabricantes e marcas distintas que são comercializados nos supermercados da cidade de São Luís, Maranhão. De cada marca foram adquiridos $400 \mathrm{ml}$ de néctar em embalagens adequadas e dentro do prazo de validade, as quais foram encaminhadas ao Laboratório de Frutas e Hortaliças do Instituto Federal do Maranhão - IFMA - Campus Maracanã. As marcas pesquisadas foram designadas de A1, B2, C3, D4 e E5, para não vincular marcas e fabricantes e evitar favorecimentos ou prejuízos indesejáveis.

As determinações físico-químicas obedeceram à metodologia preconizada pelo Instituto Adolfo Lutz (2008) para os parâmetros pH, Acidez Titulável expressa em percentagem de ácido cítrico, determinação do teor de ácido ascórbico e Sólidos Solúveis (Brix), onde fez-se uso dos aparelhos pHmetro e refratômetro devidamente calibrados e de soluções padronizadas. Todas as análises foram realizadas em triplicata.

\section{RESULTADOS E DISCUSSÃO}

Os resultados obtidos nas análises mostraram que o néctar de caju comercializado nos supermercados de São Luís- MA apresenta valores de pH similares entre as marcas, como mostra a Tabela I, o que comprova uma acidez mais alta causada tanto pela presença de ácido cítrico contido no caju ou adicionado como conservante. 0 pH do néctar de caju não é um parâmetro estipulado pela legislação. No entanto, existem 
disponíveis na literatura trabalhos que envolvem a aferição desse parâmetro, dentre eles podemos ter como referência o estudo realizado por LIMA (2015) (Tabela 1) que apresenta valores para pH que se assemelham aos resultados encontrados no presente estudo. É importante ressaltar que esse baixo $\mathrm{pH}$ presente nos néctares pode ser visto, em parte como fator positivo, uma vez, que o produto mais ácido favorece o processo de conservação, evitando possível contaminação de origem microbiológica.

Tabela 1: pH dos néctares de caju analisados

\begin{tabular}{|c|c|c|c|}
\hline \multicolumn{2}{|c|}{ LIMA (2015) } & Marcas \\
\hline Marcas & $\mathrm{pH}$ & $\mathrm{A}$ & 3,53 \\
\hline A1 & $3,07 \pm 0,007$ & $\mathrm{~B}$ & 3,35 \\
\hline B2 & $3,42 \pm 0,031$ & $\mathrm{C}$ & 3,20 \\
\hline C3 & $3,33 \pm 0,0007$ & & \\
\hline D4 & $3,09 \pm 0,333$ & \\
\hline
\end{tabular}

Em relação à acidez dos néctares, os valores foram expressos em mg de ácido cítrico por $100 \mathrm{~g}$ de amostra, Tabela 2. É possível observar que os resultados variaram, no entanto, apresentaram-se dentro dos padrões exigidos pela legislação brasileira, que estabelece o valor mínimo de 0,12 g de ácido cítrico por $100 \mathrm{~g}$ de amostra. LIMA (2015) em sua pesquisa encontrou para o parâmetro acidez, valores próximos aos relatados no nosso estudo. Essa acidez mais elevada possui relação com os valores de $\mathrm{pH}$ anteriormente citados, embora essa acidez mais alta atue como forma de conservação do produto, os néctares que apresentarem acidez elevada podem causar alguns problemas aos consumidores, se ingeridos com frequência, no estudo realizado por MARTINS (2011), os pesquisadores relacionaram o consumo de bebidas ácidas a perda de minerais dentários, tanto por erosão, como por cárie dentária.

Tabela 2: Acidez total expressa em ácido cítrico dos néctares de caju analisados

\begin{tabular}{|c|c|c|c|c|c|}
\hline Parâmetro & \multicolumn{5}{|c|}{ Marcas analisadas } \\
\hline \multirow[b]{2}{*}{$\begin{array}{c}\text { Acidez } \\
\text { Tilulável g }\end{array}$} & A1 & B2 & $\mathrm{C} 3$ & D4 & E5 \\
\hline & $\begin{array}{l}0,45 \\
\pm 0,1\end{array}$ & $\begin{array}{r}0,40 \\
\pm 0,07\end{array}$ & $\begin{array}{c}0,27 \\
\pm 0,31\end{array}$ & $\begin{array}{l}0,48 \\
\pm 0,0\end{array}$ & $\begin{array}{l}0,56 \\
\pm 0,1\end{array}$ \\
\hline
\end{tabular}

g de ácido cítrico/100 g de amostra

Os sólidos solúveis, expressos em ${ }^{\circ}$ Brix, é um parâmetro de avaliação exigido pela legislação para néctar de caju e é de grande importância, pois determina a quantidade aproximada de açúcares presentes, sendo usado também como um parâmetro no estudo de polpas e néctares em um considerável número de publicações. Os valores encontrados no presente estudo, Tabela 3, atendem a legislação que exige no mínimo 10,00, para Sólidos solúveis medidos em ํㅡrix, a $20^{\circ} \mathrm{C}$, sendo, que as marcas B2 e E5 apresentaram valores mais elevados em relação às demais marcas o que pode ter decorrido da variedade de espécies de caju utilizada para as formulações dos néctares ou da quantidade de conservantes adicionado ao néctar.

Vale lembrar que esse alto teor de o-Brix presente nas amostras analisadas pode ser um indicativo do alto teor de açúcares utilizado nas composições dos produtos, como, a sacarina de sódio e o ciclamato de sódio, que quando são consumidos nas bebidas com frequência pode causar problemas a saúde do consumidor, de acordo com pesquisa do Instituto Brasileiro de Defesa do Consumidor (Idec), em 2010, algumas bebidas apresentaram um teor significativo de açúcar e esse excesso de açúcar no organismo foi relacionado a problemas de saúde, como, prisão de ventre, dificuldade para fazer digestão, além de possivelmente favorecer a obesidade. Portanto, o consumidor deve ter atenção às informações nutricionais dos rótulos, por exemplo, com o tipo e a quantidade de açúcar utilizado na fabricação do néctar. 
Tabela 3: Sólidos solúveis medidos em ${ }^{\circ} \mathrm{Brix}$, a $20^{\circ} \mathrm{C}$ das amostras de néctares de caju.

\begin{tabular}{|c|c|c|c|c|c|} 
Parâmetro & \multicolumn{5}{|c|}{ Marcas analisadas } \\
\hline \multirow{2}{*}{$*$ Brix } & A1 & B2 & C3 & D4 & E5 \\
\cline { 2 - 6 } & $10,66 \pm 1,0$ & $11,7 \pm 0,74$ & $10,4 \pm 0,28$ & $10,66 \pm 0,33$ & $11,66 \pm 0,33$ \\
\hline
\end{tabular}

Os teores de vitamina $\mathrm{C}$, como podem ser observados na Tabela 4, variaram bastante com diferenças significativas entre as amostras estudadas, a amostra D4 apresentou o maior teor, enquanto, as amostras C3 e E5 apresentaram os menores teores de ácido ascórbico e não atendem a exigência da legislação que estipula o valor de no mínimo $15 \mathrm{mg}$ por cada $100 \mathrm{~g}$ de amostra.

Tabela 4: Determinação de vitamina C nas amostras de néctares de caju analisadas.

\begin{tabular}{|l|c|c|c|c|c|}
\multicolumn{2}{|c|}{ Parâmetro } & \multicolumn{5}{|c|}{ Marcas analisadas } \\
\hline \multirow{2}{*}{ Ácido ascórbico } & A1 & B2 & C3 & D4 & E5 \\
\cline { 2 - 6 } & $61,65 \pm 1,0$ & $46,6 \pm 0,1$ & $14,08 \pm 1,0$ & $64,57 \pm 2,0$ & $14,08 \pm 1,0$ \\
\hline
\end{tabular}

As demais amostras apresentaram valores significativos de ácido ascórbico (Tabela 4), corroborando com os resultados de $\mathrm{pH}$ e acidez, comprovando alto teor de vitamina $\mathrm{C}$ presente no caju. Essas diferenças nos valores de ácido ascórbico pode estar relacionado à formulação utilizada pelos fabricantes, por exemplo, de acordo com os rótulos das embalagens das amostras analisadas a marca A1 utilizou em sua composição o suco concentrado de caju, enquanto, a amostra C3 utilizou a polpa com a formulação mínima de $15 \mathrm{~g}$ por $100 \mathrm{~g}$ da polpa de caju, além disso, a marca C3 pode ter sofrido algum tipo de exposição, uma vez que a vitamina C é muito sensível ao oxigênio, luz e temperatura (LIMA, 2007).

\section{CONCLUSÃO}

Os néctares comercializados nos supermercados de São Luís do Maranhão mostraram-se, em média, dentro dos padrões de identidade e qualidade exigidos pela legislação brasileira para néctares, somente as amostras C3 e E5 apresentaram-se fora do padrão para teor de ácido ascórbico, fato não observado na análise dos demais parâmetros. Portanto, os néctares apresentaram qualidade atendendo aos requisitos exigidos para néctar de caju e estão aptos para o consumo.

\section{AGRADECIMENTOS}

Instituto Federal de Educação, Ciência e Tecnologia do Maranhão- Campus- Maracanã.

\section{REFERÊNCIAS}

[1] ABREU, G. M. Posicionamento de marca no mercado de sucos e néctares: Uma análise do caso "Do bem". Revista Augustus, v.18, n.35, p. 75-90, Rio de Janeiro, 2013.

[2] ARAÚJO, W. F. et al. Sustentabilidade em agroindústrias: alternativas para evitar o desperdício de resíduos agroindustriais do pedúnculo de caju-uma revisão de literatura/Sustainability in agroindustrys: alternatives to avoid waste of agro-industrial residue peduncle cashew-a literature review. Brazilian Journal of Development, v. 4, n. 7, p. 4546-4569, 2018.

[3] BRASIL. Ministério da Agricultura, Pecuária e Abastecimento. Secretaria da agricultura e do abastecimentoSEAB. Departamento de economia rural- DERAL. Análise da conjuntura agropecuária safra 2016/17. Disponível<http://www.agricultura.pr.gov.br/ > Acesso: 01 set. 2019.

[4] BRASIL. Ministério da Agricultura, Pecuária e do Abastecimento. Portaria DSA no. 12, de 12 de setembro de 2012. Regulamento Técnico para Fixação dos Padrões de Identidade e Qualidade Gerais para Suco Tropical; os 
Padrões de Identidade e Qualidade dos Sucos e os Padrões de Identidade e Qualidade dos Néctares. Diário Oficial da União, Brasília, DF, 2003.

[5] COSTA, J. A. et al. Avaliação Microbiológica e Sensorial de Doce em Pasta Elaborado com Soro de Leite e Pedúnculo do Caju. Acta Veterinaria Brasilica, v. 10, n. 1, p. 9-15, 2016.

[6] FIGUEIRA, R. et al. Caracterização química e legalidade em bebidas não alcoólicas de caju. Energia na Agricultura, v. 30, n. 4, p. 437-441, 2015.

[7] IDEC, Instituto Brasileiro de Defesa do Consumidor. Menos saudáveis do que parecem, 2010. Disponível em: http://www.idec.org.br. Acesso em: 19. Maio. 2019.

[8] INSTITUTO ADOLFO LUTZ. Normas Analíticas do Instituto Adolfo Lutz: Métodos químicos e físicos para análise de alimentos. 4. ed., São Paulo, 2008, p.1020.

[9] LIMA, A. F.; RAIOL, A. M.; BINO, G. O.; BARBOSA, I. C. C.; SOUZA, E. C.; SILVA, A. S.; Estudo físico-químico e quimiométrico de néctar de cajú industrializados. Congresso Brasileiro de Quimica, 55., 2015, Goiania- GO. Anais eletrônicos. Goiás, 2015. Disponível em: http://www.abq.org.br/cbq/2015/trabalhos/10/7858-20862.html. Acesso em: 02. Ago. 2019.

[10] LIMA, E. S.; SILVA, E. G. D; NETO, J. M. M; MOITA, G. C. Redução de vitamina C em suco de caju (Anacardium occidentale L.) industrializado e cajuína. Química Nova, v. 30, n. 5, p. 1143-1146, Teresina - PI, 2007.

[11] MARTINS, A. L.; LAURINDO, A. B.; MELO, I. A.; SEVIDANIS, M. M.; VANZELA, P. F.; Problemas dentários no consumo de sucos industrializados. Simpósio nacional de iniciação científica, 1., 2011, Londrina- PR. Anais eletrônicos. Paraná, 2011. Disponível: https://unifil.br/portal/images/pdf/documentos/livros/praticas-em-iniciacaocientifica.pdf. Acesso em 07. Ago. 2019.

[12] QUINTÃO, A. L. et al. Avaliação do teor de ácido ascórbico presentes nos sucos de caju natural, na polpa industrializada e na polpa desidratada. ÚNICA Cadernos Acadêmicos, v. 2, n. 1, p. 1-9, 2016.

[13] SAPATA, M. M. et al. Secagem do pseudofruto de caju para alimentação humana. Vida Rural, p. 30-31, 2017.

[14] SNA- Sociedade Nacional de Agricultura- Boas perspectivas para o mercado de sucos, 2017. Disponível<https://www.sna.agr.br/boas-perspectivas-para-o-mercado-de-sucos/> Acesso: 01. Set. 2019. 


\section{Capítulo 12}

Análise da composição de pães industrializados dos tipos tradicional e light para comparação dos teores dos seus constituintes

Ana Luiza Alves Faria

Paula André Borba

Roni Antonio Mendes

Maurielen Guterres Dalcin

Resumo: Com o aumento do índice de doenças causadas por alimentação inadequada, os consumidores têm buscado produtos mais saudáveis. Visando isso, foram desenvolvidos os pães light, que possuem uma redução de no mínimo $25 \%$ do valor energético ou no conteúdo do nutriente em comparação com o alimento de referência. Com o intuito de verificar a veracidade de algumas informações sobre a composição do pão light e do pão tradicional (referência), foram determinados os teores de açúcar, amido, glúten, umidade, sólidos totais, cinzas, fibra bruta e colesterol de amostras de uma determinada marca industrial. Os ensaios foram realizados segundo a metodologia descrita pelo Instituto Adolfo Lutz para análises físico-químicas de alimentos. 0 pão light apresentou teores de umidade, glúten, colesterol e amido maiores que o pão tradicional. Os teores de sólidos totais (pelo método de dessecação), sólidos totais (pelo método resíduo seco), resíduos por incineração, glicídios redutores em glicose, glicídios não-redutores em sacarose e glicídios totais em glicose do pão light foram inferiores aos apresentados pelo pão tradicional. Nenhum teor de fibra bruta foi detectado nas amostras analisadas. 


\section{INTRODUÇÃO}

A alimentação é definida como uma ação natural e consciente praticada pelos seres humanos para atender às suas necessidades fisiológicas e biológicas, através da transformação dos nutrientes em energia (RODRIGUES et al., 2007).

Antigamente, as pessoas cultivavam seu próprio alimento, ricos em vitaminas, proteínas e sem adição de conservantes. Entretanto, nos últimos anos os hábitos alimentares passaram por grandes mudanças através da substituição de alimentos minimamente processados por produtos industrializados que são rápidos, práticos e rotulados, para facilitar o acesso do consumidor às informações nutricionais úteis e confiáveis, possibilitando identificar a origem e composição do produto (MINISTÉRIO DA SAÚDE, 2014; CÂMARA E MARINHO, 2008).

Contudo, com o crescimento do consumo desses alimentos ricos em gorduras, açúcar, conservantes e pobres em vitaminas e proteínas, aumentou-se a incidência de obesidade, doenças cardíacas, diabetes e câncer, atingindo pessoas de diferentes faixas etárias.

Por isso, foram introduzidos no mercado produtos lights que possuem uma redução de no mínimo $25 \%$ do valor energético ou no conteúdo dos nutrientes em relação ao alimento de referência ou convencional (ANVISA E SENACON, 2013).

Atualmente, vários alimentos tradicionais, como o pão, possuem sua versão light. Porém, em alguns casos, para manter as características sensoriais desses alimentos, a quantidade de outros componentes que podem ser prejudiciais à saúde é aumentada na composição desses produtos.

Por esse motivo, o presente estudo foi realizado com o intuito de analisar as possíveis variações dos constituintes do pão, comparando o pão tradicional com o pão light e verificando a veracidade de algumas informações divulgadas nos rótulos desse alimento.

\section{MATERIAL E MÉTODOS}

Amostras de pão tradicional e light foram adquiridas em estabelecimento comercial, trituradas e homogeneizadas para redução do tamanho e uniformização. A análise dessas amostras foi realizada de acordo com o método físico-químico para análise de alimentos do Instituto Adolfo Lutz descrito em Zenebon et al. (2008).

\section{RESULTADOS E DISCUSSÃO}

A Tabela 1 contém os resultados dos parâmetros avaliados para as amostras de pão tradicional e pão light.

Tabela 1. Resultados encontrados para os parâmetros avaliados

\begin{tabular}{|c|c|c|}
\hline Parâmetro avaliado & Pão tradicional (\%) & Pão light $(\%)$ \\
\hline Perda por dessecação & $26,19 \pm 0,47$ & $33,79 \pm 0,43$ \\
\hline Sólidos totais método dessecação & $73,81 \pm 0,47$ & $66,21 \pm 0,43$ \\
\hline Sólidos totais método resíduo seco & $71,59 \pm 1,91$ & $66,92 \pm 0,19$ \\
\hline Resíduos por incineração & $1,96 \pm 0,03$ & $1,81 \pm 0,07$ \\
\hline Glicídios redutores em glicose & $5,80 \pm 0,02$ & $2,79 \pm 0,06$ \\
\hline Glicídios não-redutores em sacarose & $1,47 \pm 0,06$ & $1,02 \pm 0,07$ \\
\hline Glicídios totais em glicose & $15,17 \pm 0,49$ & $10,01 \pm 0,42$ \\
\hline Colesterol & $0,04 \pm 0,01$ & $0,08 \pm 0,01$ \\
\hline Glúten & $12,13 \pm 0,30$ & $23,84 \pm 5,67$ \\
\hline Fibra bruta & -- & -- \\
\hline Amido & $8,84 \pm 0,37$ & $10,30 \pm 0,72$ \\
\hline
\end{tabular}

0 teste de perda por dessecação nos pães foi realizado para determinar o teor de umidade e de substâncias que evaporam nessas circunstâncias e temperatura. 0 pão light a $105^{\circ} \mathrm{C}$ apresentou $28,80 \%$ de substâncias voláteis a mais que o pão tradicional, sendo 7,60 a diferença do teor de perda.

O regulamento técnico para fixação de identidade e qualidade de pão da ANVISA, Resolução - RDC no 90, de 18 de outubro de 2000, determina o limite máximo de umidade em pães de $38 \%$ para pães preparados 
exclusivamente com farinha de trigo comum e/ou farinha de trigo especial. Os teores de umidade do pão tradicional e light estão dentro do padrão exigido, $(26,19 \pm 0,45) \%$ e $(33,79 \pm 0,43) \%$, respectivamente.

Em relação aos métodos para determinação de teores de sólidos totais, os resultados obtidos em ambos foram próximos, quando considerados os desvios padrões das amostras. 0 teor de sólido obtido pelo método de dessecação revelou que o pão tradicional possui $11,49 \%$ de sólidos a mais do que o pão light. Pelo método de resíduo seco, a percentagem a mais foi de 6,97\%.

A análise do teor de cinzas presente nos alimentos industrializados está relacionada com a quantidade de sais e matéria inorgânica neles contidos, que após a queima da matéria orgânica representa o resíduo remanescente (CECCHI, 2003). 0 pão tradicional e o pão light apresentaram teores de cinzas próximos, com uma pequena diferença de $0,15 \%$. Isto pode indicar que os pães analisados possuem teores parecidos de macronutrientes (potássio, cálcio, magnésio), micronutrientes (alumínio, ferro, cobre) inorgânicos, além de possíveis outros elementos em níveis de traços, que podem garantir as propriedades funcionais e o valor nutricional desses alimentos (CECCHI, 2003).

O pão tradicional apresentou $108,1 \%$ a mais de teor de glicídios redutores em glicose e $45,47 \%$ de glicídios não redutores em sacarose em relação ao pão light, ou seja, há uma maior quantidade de açúcares presente nesse tipo de pão.

Assim como nos resultados analisados anteriormente, o pão tradicional apresentou um teor de glicídios totais de $51,51 \%$ a mais que o pão light. Entretanto, esperava-se que a soma dos teores de glicídios redutores e não redutores totalizasse o teor determinado de glicídios totais, o que não ocorreu. Uma explicação para essa diferença é que os resultados das análises de glicídios redutores em glicose e nãoredutores em sacarose não levam em consideração o amido presente nas amostras.

Os teores de colesterol determinados para o pão tradicional e light, ainda que pequenos, $(0,04 \pm 0,01) \% \mathrm{e}$ $(0,08 \pm 0,01) \%$, respectivamente, são superiores aos indicados em seus rótulos (teor de $0 \%$ de colesterol). 0 teor de colesterol contido no pão light é $117,58 \%$ maior que o do pão tradicional.

0 glúten é a principal proteína de armazenamento do trigo, que quando misturado com água forma uma massa viscoelástica capaz de aprisionar o gás durante a fermentação. Isso possibilita um aumento da resistência da massa com o amassamento até um valor limite (DAMODARAN et al., 2011).

Os teores determinados de glúten para o pão tradicional e light foram, respectivamente, de $(12,13 \pm$ $0,29) \%$ e $(23,84 \pm 5,67) \%$. Tais valores indicam que os pães contêm glúten em sua composição, e seus rótulos estão de acordo com a LEI № 10.674 , de 16 de maio de 2003, que torna obrigatório a indicação "Contém Glúten" nos rótulos de alimentos industrializados.

O pão light possui teor de glúten $96,52 \%$ a mais que o pão tradicional, sendo a diferença entre os teores de $11,71 \%$. Essa diferença pode ser explicada devido a diminuição dos teores de açúcar do pão light, sendo necessário adicionar mais farinha de trigo, e consequentemente mais glúten, para manter a resistência da massa e com isso a consistência do pão.

Ao realizar o experimento para determinar o teor de fibra bruta presente nos pães, nenhum teor foi detectado, pois após a etapa de extração ácida nenhuma massa ficou retida em cadinho de Gooch durante a filtração à vácuo. Isso se deve ao fato de que, apesar do método de determinação de fibra bruta adotado ser oficial, é uma técnica falha, pois estima valores baixos da proporção de fibra presente nos alimentos (CECCHI, 2003). Por isso, atualmente, é utilizada a metodologia de fibra alimentar que diminui os erros provenientes do método de fibra bruta (LOPES et al., 2014).

Ao comparar os teores de amido nos pães, o pão light apresentou teores maiores de glicídios não redutores em amido em relação ao pão tradicional. Sendo o amido utilizado para alterar ou controlar diversas características dos alimentos (ADITIVOS E INGREDIENTES, p. 32, 2017), como estrutura, textura e consistência (KOBLITZ, 2008), a sua maior presença no pão light pode ser justificada devido à redução no seu teor de glicídios, buscando, assim, manter as mesmas características do pão tradicional.

Apesar dos teores de umidade, sólidos totais, cinzas e fibra brutas terem sido obtidos experimentalmente, não foi possível estabelecer comparações, uma vez que o fabricante não disponibilizou esses valores nos rótulos dos pães. 


\section{CONCLUSÃO}

Com base nos resultados obtidos, o pão light apresentou teores menores de glicídios redutores em glicose, não-redutores em sacarose e glicídios totais em sacarose quando comparado com o pão tradicional, ou seja, há uma menor quantidade de açúcares presentes nesse tipo de pão, assim como de sólidos totais tanto pelo método de resíduo seco quanto pelo método de resíduo por incineração. Com relação à umidade, glúten, colesterol e amido, o pão light apresentou maiores valores que o pão tradicional.

Portanto, cabe ao consumidor analisar os rótulos desses pães e escolher o produto que melhor se adequa à sua dieta ou restrição alimentar.

\section{AGRADECIMENTOS}

Agradecemos a Universidade Federal de Alfenas - Campus Poços de Caldas, por nos proporcionar o crescimento intelectual e profissional. A nossa orientadora Maurielen Guterres Dalcin pelos ensinamentos, disponibilidade, incentivo e apoio. Ao nosso coorientador Roni Antonio Mendes pelos ensinamentos e conselhos. Aos técnicos do Laboratório da Universidade Federal de Alfenas - Campus Poços de Caldas pelo auxílio na parte experimental. Por fim, agradecemos a Deus pela sabedoria e paciência nos momentos de dificuldade.

\section{REFERÊNCIAS}

[1] Agência Nacional de Vigilância e Secretária Nacional do Consumidor. Consumo e Saúde Alimentos diet e light - entenda a diferença. 2013.

[2] Agência Nacional de Vigilância. Resolução-RDC № 90, de 18 de outubro de 2000. Regulamento Técnico para fixação de identidade e qualidade do pão. Diário Oficial da República Federativa do Brasil, Brasília, 2000.

[3] AS Propriedades Funcionais do Amido. Revista Aditivos e Ingredientes, São Paulo, 2015.

[4] Brasil. Lei № 10.674 , de 16 de maio de 2003. Obriga a que os produtos alimentícios comercializados informem sobre a presença de glúten, como medida preventiva e de controle da doença celíaca. Dísponivel em: < http://www.planalto.gov.br/ccivil 03/leis/2003/L10.674.htm>. Acesso em: 10/03/2018.

[5] Câmara, C. C. et al. A produção acadêmica sobre a rotulagem de alimentos no Brasil. Revista Panamericana de Salud Pública. 23.ed, pag. 52-58, 2008.

[6] Cecchi, H. M. Fundamentos teóricos e práticos em análise de alimentos. Campinas: Editora Unicamp, 2003.

[7] Damodaran, S.L.; Parkin, K.L.; Fennema, O. F. Química de alimentos de Fennema. 4. ed. Porto Alegre: ArtMeD, 2011.

[8] Koblitz, M. G. B. Bioquímica dos alimentos. Rio de Janeiro: Editora Guanabara Koogan, 2008.

[9] Lopes, L. H. et al. Determinação de fibras brutas em diferentes matrizes alimentares. VII Micti. Mostra Nacional de Iniciação científica e Tecnológica Interdisciplinar. Instituto Federal Catarinense- Campus Concórdia, 2014.

[10] Ministério da Saúde, Guia alimentar para a população brasileira. Brasília: editora ms - os 2014/0536, 2014.

[11] Rodrigues, M. L. C. F. et al., Alimentação e nutrição no Brasil. Brasília: Universidade de Brasília, 2007.

[12] Zenebon, O.; Pascuet, N. S.; Tiglea, P. Métodos físico-químicos para análise de alimentos. São Paulo: Instituto Adolfo Lutz, 2008. 


\section{Capítulo 13}

Teor de lactose em produtos destinados a alimentação infantil e estudo dos parâmetros estabelecidos pela nova legislação da ANVISA RDC 136/2017

\section{Alana de Almeida Oliveira \\ Suelen Pereira Ruiz Herrig \\ Juliana Scanavacca}

Resumo: A incapacidade de digestão da lactose devido à ausência da enzima lactase denomina-se intolerância a lactose, que vem afetando principalmente as crianças. Visando a preocupação com produtos destinados aos intolerantes a lactose, torna-se um desafio para a indústria de alimentos garantir confiabilidade que o produto informado zero lactose é totalmente isento de lactose. 0 objetivo do trabalho foi avaliar quantitativamente o teor de lactose nos produtos destinados as crianças, ditos "zero lactose" ou "sem lactose" verificando sua conformidade em seus rótulos e com a legislação vigente RDC 136/2017. 0 teor de lactose, determinado pelo método LaneEynon, para os produtos sem lactose foram $3,14 \%, 3,23 \%$ e $3,11 \%$ para leite semidesnatado, bebida láctea achocolatada e leite fermentado, respectivamente, verificando sua eficiência pelo teste de glicose-oxidase. Portanto, além dos teores de lactose encontrados, apresentarem-se acima do prescrito pela legislação, visto que encontram-se no prazo de adequação, sendo viável inserir informações rotuláveis mais esclarecedoras.

Palavras-Chave: análises; intolerância à lactose; leite; rótulo. 


\section{INTRODUÇÃO}

A lactose é um dissacarídeo composto por uma molécula de glicose ligada a uma de galactose, conhecida como o principal açúcar presente no leite de mamíferos (Soares et al., 2016). A digestão da lactose acontece pela sua hidrólise através da enzima lactase ou $\beta$-D-galactosidase, localizada nas microvilosidades do intestino, tornando-se possível suas absorções na corrente sanguínea. A ausência da enzima no organismo, leva o indivíduo a intolerância à lactose, tornando-a energia para os microorganismos do colón, sendo fermentada a ácido lático, gás hidrogênio $\left(\mathrm{H}_{2}\right)$ e metano $\left(\mathrm{CH}_{4}\right)$, gerando um desconforto intestinal (Bacelar Júnior et al., 2013; Barbosa e Andreazzi, 2011).

Essa patologia pode apresentar-se de três formas, primária, secundária e congênita. A deficiência primária ou hipolactasia adulta é uma alteração no gene que codifica a lactase, herdada de forma autossômica, podendo ser ocasionada pela falta relativa ou definitiva da produção da enzima lactase após o desmame que pode ocorrer a qualquer idade ou desde a infância (Kuchay et al., 2011; Gasparin et al., 2010). A deficiência secundária é ocasionada pela morte das células intestinais devido a diarreia persistente comum no primeiro ano de vida das crianças, ou por outras doenças que podem vir a destruir essas células, e após o tratamento, as células intestinais se recompõem. A deficiência congênita é permanente, é ocasionada por um erro genético raro desde o nascimento (Soares et al., 2016).

A prevalência e a idade de manifestação da intolerância à lactose variam, consideravelmente, conforme o grupo étnico e não há a determinação de um único limite de lactose digerível para todos os intolerantes a lactose. Com base nisso, as indústrias de alimentos desenvolveram produtos sem lactose e com baixo teor de lactose, destinados a alimentação infantil (Montia et al, 2017). Com o intuito de contribuir na proteção da saúde dos consumidores intolerantes a lactose, a Agência Nacional de Vigilância Sanitária (ANVISA) publicou a Lei no 13.305, 4 de Julho de 2016 para acrescentar aos rótulos dos alimentos a informação da presença de lactose. Posteriormente, a ANVISA publicou uma nova legislação para os alimentos ditos com lactose, baixo teor de lactose e sem lactose/zero lactose como Resolução RDC no 136, de 8 de fevereiro de 2017.

Desta forma, o objetivo deste trabalho foi avaliar quantitativamente o teor de lactose nos produtos destinados a crianças como o leite semidesnatado UHT, bebida láctea achocolatada e leite fermentado, ditos "zero lactose" ou "sem lactose", e verificar sua conformidade em seus rótulos e com a legislação em vigor.

\section{MATERIAL E MÉTODOS}

\subsection{MATERIAIS}

As amostras comerciais selecionadas para análise foram produtos com lactose (amostra controle) e sem lactose, como bebida láctea achocolatada UHT, leite semidesnatado UHT, e leite fermentado desnatado. Todas as amostras foram obtidas nos supermercados da cidade de Umuarama - Paraná.

\subsection{DETERMINAÇÃO DE GLICÍDIOS REDUTORES EM LACTOSE}

A metodologia para a determinação de lactose foi a titulometria de Lane-Eynon, conforme recomendado pelo Ministério da Agricultura, Pecuária e Abastecimento - MAPA, Instrução Normativa 68/2006. Para a determinação de lactose, foi utilizado o equipamento Redutec ${ }^{\circledR}$ adicionando $5 \mathrm{~mL}$ da solução de Fehling A e $5 \mathrm{~mL}$ de solução de Fehling B, juntamente com $40 \mathrm{~mL}$ de água. A solução foi mantida em ebulição para o início do gotejamento da amostra, contida na bureta, sem agitação, até que a solução no interior do equipamento apresentasse uma cor levemente azulado. Manteve-se a ebulição e adicionou-se 1 gota de solução de azul de metileno a $1 \%$, e continuou a titulação até a descoloração do indicador para a cor vermelho tijolo. Os produtos controle serviram como base para a quantificação do teor de lactose pelo método Lane-Eynon, onde os mesmos são comparados com os produtos sem a presença de lactose.

\subsection{DETERMINAÇÃO DO TEOR DE GLICOSE PELO MÉTODO ENZIMÁTICO}

Para verificar a concentração de glicose nos produtos com e sem lactose, utilizou-se o Kit de Glicose Enzimática Liquiform Labtest. 0 método baseia-se na oxidação da glicose a ácido glucônico e peróxido de hidrogênio, com a enzima glicose oxidase atuando como catalisador. 0 peróxido de hidrogênio formado reage com 4 - aminoantipirina e fenol, formando um complexo de cor vermelha. Para o procedimento, 
houve a centrifugação das amostras na centrífuga Mtd III plus, depois foram adicionados 1 mL do reagente e $0,01 \mathrm{~mL}$ da amostra, e em seguida incubou-as em banho-maria a $37{ }^{\circ} \mathrm{C}$ por 15 minutos. A coloração foi determinada em espectrofotômetro modelo 700 plus, marca FEMTO, ajustado para comprimento de onda de $505 \mathrm{~nm}$ (Motta, 2009). Ao encontrar a concentração de glicose para cada produto, a mesma foi comparada com o teor de lactose encontrado pelo método de Lane-Eynon para a confiabilidade da análise. Segundo Mattanna et al. (2012), a hidrólise da lactose pode ser determinada por meio da estequiometria da reação, considerando que para cada molécula de lactose degradada são formadas uma molécula de glicose e uma molécula de galactose, desta forma consegue-se estimar a quantidade de lactose presente.

\subsection{ANÁLISE ESTATÍSTICA}

As análises foram realizadas em triplicada para cada amostra. Os resultados foram avaliados estatisticamente, utilizando-se o programa software Statística 8.0, fazendo-se a análise de variância (ANOVA) de um único fator entre cada produto com e sem a presença de lactose, seguido do Teste de Tukey $(\mathrm{p}<0,05)$. Considerou-se diferenças entre médias estatisticamente significativas quando o nível de probabilidade (p) foi menor do que 0,05 .

\section{RESULTADOS E DISCUSSÕES}

\subsection{TEOR DE LACTOSE PELO MÉTODO LANE-EYNON}

A declaração da presença de lactose será obrigatória em qualquer alimento que contenha acima de 0,1\%, e deverá trazer a expressão "Contém Lactose" em seu rótulo. Segundo a ANVISA o limite de $100 \mathrm{mg}$ foi definido pois tem se mostrado seguro para as pessoas com intolerância a lactose nos países que já adotam esta regulação há bastante tempo, como Alemanha e Hungria. Os produtos analisados de diferentes marcas, apresentam em seus rótulos os dizeres "0\% Lactose" para o leite semidesnatado e bebida láctea achocolatada, e "Sem Lactose" para o leite fermentado. Todos os 3 produtos apresentam em seus rótulos a técnica de hidrólise enzimática usando a enzima lactase e possuem quantidade de $0 \mathrm{~g}$ de lactose em seus rótulos. Já os produtos controle não apresentam os dizeres “Com Lactose" ou "Baixo Teor de Lactose" e nem a quantidade de lactose presente.

Os resultados para o teor de lactose nos produtos com e sem lactose estão apresentados na Tabela 1. Verificou-se que não houve diferença significativa entre o tratamento $(p>0,05)$ para os produtos leite fermentado e bebida láctea achocolatada, mas apresentou diferença significativa entre os tratamentos para o produto leite semidesnatado $(\mathrm{p}<0,05)$.

Tabela 1 - Teor de lactose para os produtos lácteos com e sem lactose.

\begin{tabular}{|c|c|c|}
\hline Produtos & Com Lactose $(\%)$ & Sem Lactose (\%) \\
\hline Leite Semidesnatado & $4,07^{\mathrm{a}} \pm 0,14$ & $3,14^{\mathrm{b}} \pm 0,22$ \\
\hline Leite Fermentado & $3,92^{\mathrm{a}} \pm 0,00$ & $3,11^{\mathrm{a}} \pm 0,58$ \\
\hline Bebida láctea achocolatada & $3,64^{\mathrm{a}} \pm 0,15$ & $3,23^{\mathrm{a}} \pm 0,43$ \\
\hline
\end{tabular}

*Letras iguais na mesma linha não diferem estatisticamente entre si pelo Teste de Tukey $(\mathrm{p}<0,05)$.

Os resultados dos teores de lactose obtidos pelo método Lane-Eynon, indicado pelo MAPA, para os produtos ditos zero lactose apresentaram valores elevados, constatando-se que o teor obtido não está de acordo com a legislação anterior (RDC 29/1998) e vigente (RDC 136/2017). Deste modo, é de se questionar a eficiência do método Lane-Eynon para estes produtos comparado ao método HPLC, pois tal análise possui maior precisão, além de ser um dos diferentes métodos analíticos citados pela ANVISA para a quantificação de lactose nos alimentos (Brasil, 2017). Portanto, é importante que se tenha uma padronização de um método eficiente e uma fiscalização mais rígida dos produtos ditos zero lactose, para o cumprimento da nova legislação em vigor RDC 136/2017. 


\subsection{TEOR DE GLICOSE PELO MÉTODO DA GLICOSE - OXIDASE}

As concentrações de glicose presentes nos produtos lácteos com e sem lactose estão apresentados na Tabela 2.

Tabela 2 - Teor de glicose nos produtos lácteos com e sem lactose.

\begin{tabular}{|c|c|c|}
\multicolumn{1}{|c}{ Produtos } & \multicolumn{2}{c|}{ Clicose $(\mathrm{g} / 100 \mathrm{~mL})$} \\
\hline Leite Semidesnatado UHT & $0,24^{\mathrm{b}} \pm 0,04$ & $2,13^{\mathrm{a}} \pm 0,31$ \\
\hline Bebida láctea Achocolatada UHT & $0,47^{\mathrm{b}} \pm 0,06$ & $2,13^{\mathrm{a}} \pm 0,41$ \\
\hline Leite Fermentado & $0,21^{\mathrm{b}} \pm 0,01$ & $1,70^{\mathrm{a}} \pm 0,02$ \\
\hline
\end{tabular}

*Letras iguais na mesma linha não diferem estatisticamente entre si pelo Teste de Tukey $(\mathrm{p}<0,05)$.

A quantidade de glicose presente nos produtos com e sem lactose estão coerentes apresentando teores baixos de glicose para produtos com lactose devido ao açúcar do leite estar presente na forma de lactose, e possuindo teores maiores de glicose para os produtos sem lactose, devido a hidrólise da mesma. Deste modo, tem-se que os teores de glicose determinados para os produtos sem lactose são de $2,13 \mathrm{~g} / 100 \mathrm{~mL}$ para leite semidesnatado e bebida láctea achocolatada, e de $1,70 \mathrm{~g} / 100 \mathrm{~mL}$ para leite fermentado, conforme a estequiometria da hidrólise da lactose. A comparação da quantidade de glicose encontrada pelo método Lane-Eynon, pode ser feita com confiabilidade somente para os produtos com lactose, os quais são leite semidesnatado, bebida láctea achocolatada e leite fermentado com teor de lactose $4,07 \%$ (2,03\% de glicose), 3,92\% (1,96\% de glicose) e 3,64\% (1,82\% de glicose) respectivamente. Portanto as quantidades de lactose estão próximas das glicoses medidas, sendo assim o método Lane-Eynon foi eficiente apenas para os produtos com lactose

As informaç̧ões dos dizeres "Sem Lactose", "Com Lactose" ou "Baixo Teor de Lactose" são importante para compreensão dos pais da criança /adultos leigos sobre este assunto, pois muitos ainda confundem alergia com intolerância a lactose.

\section{CONCLUSÃO}

Ao comparar os teores de lactose nos produtos leite UHT semidesnatado, leite fermentado desnatado e bebida láctea achocolatada UHT, ditos zero lactose, com a legislação RDC 136/2017 conclui-se que os valores estão acima do prescrito pela mesma, porém foi observado através da análise da glicose que o método Lane-Eynon não apresentou sensibilidade eficiente para estes produtos destinados aos intolerantes a lactose. Contudo sabe-se que a RDC 136/2017 é uma nova diretriz criada para melhor confiabilidade, segurança aos intolerantes a lactose e para fiscalização das indústrias, portanto as mesmas deverão automatizar seu processo para retirada parcial ou total do teor da lactose conforme o tempo de adequação estabelecido pela norma. Conclui-se também além de especificarem as quantidades dos ingredientes evitados pelos intolerantes e alérgicos, devem também esclarecer melhor os dizeres nos rótulos ajudando assim as pessoas leigas e que possuem algum tipo de intolerância ou alergia a escolherem o produto correto para consumo.

\section{REFERÊNCIAS}

[1] Bacelar Júnior, A. J., Kashiwabara, T. G. B., \& da Silva, V. Y. N. E. (2013). Intolerância a lactose - Revisão de Literatura. Brazilian Journal of Surgery and Clinical Research - BJSCR, 4(4), 38-42.

[2] Barbosa, C. R., \& Andreazzi, M. A. (2011). Intolerância à Lactose e suas consequências no metabolismo do cálcio. Saúde e Pesquisa, 4 (1), 81-86.

[3] Brasil, Ministério da Saúde - Agência Nacional de Vigilância Sanitária. (2017). Estabelece os requisitos para declaração obrigatória da presença de lactose nos rótulos dos alimentos - RDC $N^{\circ} 136$, de 8 de Fevereiro de 2017. Diário Oficial da República Federativa do Brasil.

[4] Gasparin, F. S. R., Teles, J.M., \& Araújo, S. C. (2010). Alergia à proteína do leite da vaca versus intolerância a lactose: as diferenças e semelhanças. Revista Saúde e Pesquisa. 3(1), 107-112.

[5] Kuchay, R. H. A., Thapa, B. R., Mahmood, A., \& Mahmood, S. (2017). Effect of C/T -13910 cis-acting regulatory variant on expression and activity of lactase in Indian children and its implication for early genetic screening of adulttype hypolactasia. Clínica Chimica Acta, 412 (21-22), 1924-1930. 
[6] Mattanna, P., Richards, N. S. P. S., Back, D., \& Gusso, A. P. (2012). Parâmetros tecnológicos e sensoriais de requeijões cremosos com baixo teor de lactose. Revista do Instituto de Laticínios Cândido Tostes, 387 (67), 30-37.

[7] Montia, L., Negria, S., Meuccia, A., Stroppab, A., Gallia, A., \& Contarinia, G. (2017). Lactose, galactose and glucose determination in naturally "lactose free" hard cheese: HPAEC-PAD method validation. Food Chemistry, 220, $18-24$.

[8] Motta, V. T. (2009). Bioquímica (2. ed). Rio de Janeiro: Medbook.

[9] Soares, L. F., Peracini, L. C., Freitas, S., Ferreira, F. P., Dos Santos, L. F., Manhani, L. C., Manochio-Pina, M. G. (2016). Aspectos nutricionais e metabólicos da intolerância à lactose. Revista Investigação Medicina Veterinária, 15(4):103-107. 


\section{Capítulo 14}

Elaboração de chocolate branco com adição de café

\section{Jéssica Maria Ferreira de Almeida do Couto}

\section{Fabiana de Melo Caldereiro}

\section{Iolanda Cereza Zago}

\section{Gisele Cristina dos Santos Bazanella}

Resumo: É conhecido o reduzido valor nutricional que o chocolate branco possui, devido, principalmente, ao elevado percentual de gordura e açúcar em sua composição, em contrapartida, tem-se o café e seus inúmeros benefícios à saúde. Neste sentido, o objetivo da pesquisa foi melhorar o valor nutricional do chocolate branco por meio da adição de grãos de café triturados. Dois tipos de cafés foram analisados, arábica e robusta. As análises indicaram que ambas as formulações apresentaram quantidades significativas de antioxidantes e compostos fenólicos, mais especificamente catequinas. A análise sensorial demonstrou que a formulação com a mistura dos dois tipos de cafés foi o produto melhor aceito, entretanto com baixo percentual de compra. Conclui-se que embora a adição de café ao chocolate branco aumente o valor nutricional do produto, os parâmetros sensoriais devem ser melhorados.

Palavras-chave: Antioxidantes; Compostos Fenólicos; Catequinas; Arábica e Robusta. 


\section{INTRODUÇÃO}

Segundo a Resolução-RDC n 264, de 22 de Setembro de 2005 chocolate é o produto obtido a partir da mistura de derivados de cacau (Theobroma cacao L.), massa (ou pasta ou liquor) de cacau, cacau em pó e ou manteiga de cacau, com outros ingredientes, contendo, no mínimo, $25 \%$ (g/100 g) de sólidos totais de cacau. E chocolate branco é o produto obtido a partir da mistura de manteiga de cacau com outros ingredientes, contendo, no mínimo, $20 \%$ (g/100 g) de sólidos totais de manteiga de cacau.

O cacau é rico em polifenóis, sendo uma das maiores fontes de alimentos conhecidas de flavan-3-ols, principalmente epicatequinas, catequinas e procianidinas. A manteiga de cacau possui um perfil lipídico caracterizado principalmente por ácidos oleico, esteárico $(\approx 34 \% \mathrm{p} / \mathrm{p})$ e palmítico $(\approx 27 \% \mathrm{p} / \mathrm{p})$, seguidos de frações menores dos ácidos linoléico, araquídico, palmitoleico, margarico, $\alpha$-linoleico e mirísticos (PazYépez et al., 2019).

Pode-se dizer, então, que o chocolate branco é rico em açúcar e gordura e pobre em flavonóides e na maioria dos minerais, quando ingerido em excesso é responsável pelo aumento dos níveis de colesterolLDL e pelo desenvolvimento de doenças cardiovasculares, obesidade e outros (OLIVEIRA et al., 2011).

Em contrapartida, o chocolate preto, é uma fonte rica de flavonoides, antioxidantes, anti-inflamatórios e minerais da dieta, com potencial para beneficiar a saúde óssea (Seem; Yuan; Tou, 2019). Inclusive, estudos afirmam que o consumo de chocolate melhora a função endotelial em pacientes pós-síndrome coronariana aguda e este efeito é mais pronunciado com o consumo de chocolate amargo (Colombo; Valente Filho; Moreira, 2015).

Nos últimos anos estudos relatam uma relação entre o consumo de derivados de cacau com efeitos benéficos à saúde, sobre doenças cardiovasculares e degenerativas, relacionados à atividade antioxidante das procianidinas (Paz-Yépez et al., 2019).

Dentro deste contexto, os potenciais benefícios à saúde de consumir chocolate estão sendo relacionados ao cacau presente em sua composição, ou seja, como o chocolate branco não contém cacau, mas sim manteiga de cacau, não traz os benefícios à saúde como os que contêm.

0 café está associado na maioria das vezes à cafeína, que embora não seja o único composto capaz de promover benefícios à saúde, é o mais conhecido. Contudo, a composição físico-química do café é mais ampla e complexa, contendo outros tipos de constituintes que também são benéficos à saúde, tais como antioxidantes e compostos fenólicos (SILVA; BITTENCOURT; TORQUATO, 2013).

Dentre as inúmeras espécies de cafés cultivadas no mundo, as comercializadas no Brasil de maior importância econômica são Coffea arábica e Coffea canephora, variedade conillon, genericamente conhecido por robusta. 0 café arábica é conhecido por sua elevada qualidade e requinte, enquanto que o café robusta apesar de apresentar mais sólidos solúveis e maior teor de cafeína, têm baixa acidez e não possui sabores variados como o arábica (OLIVEIRA; OLIVEIRA; MOURA, 2012).

Portanto, o objeto da presente pesquisa foi adicionar diferentes tipos de grãos de cafés triturados em chocolate branco, afim de oferecer ao consumidor um produto nutricionalmente mais completo, visto que os cafés do tipo arábica e robusta são ricos em cafeína, possuem antioxidantes e compostos fenólicos em sua composição.

\section{MATERIAIS E MÉTODOS}

\subsection{MATÉRIAS-PRIMAS}

Para a produção dos bombons de chocolate branco foram utilizados uma barra de cobertura sabor chocolate branco da marca Harald Top Cobertura e grãos de cafés do tipo arábica e robusta. 0 café arábica (variedade catuaí), teve procedência de Muzambinho-MG e o café robusta (variedade conilon) teve procedência de Venda Nova-ES, ambos safra de 2014.

\subsection{CLASSIFICAÇÃO DO CAFÉ}

0 café passou por peneiramento em uma peneira de 16 pol, na sequência realizou-se uma classificação de acordo com o tipo, retiraram-se os defeitos, tais como: brocados, verdes, conchas, mal granados, quebrados e outros. Prosseguiu-se com o processo de torrefação do café utilizando-se o equipamento RodBel modelo Porto, seguindo o padrão de torra italiano ou padrão expresso. Em seguida, realizou-se uma 
segunda classificação em função dos defeitos, a fim de melhorar a qualidade final do café. Finalmente, reduziu-se o tamanho das amostras em um moedor acoplado ao torrador. A figura 1 mostra o equipamento utilizado na torrefação e redução de tamanho.

Figura 1 Torrador com moedor acoplado Rod- Bel

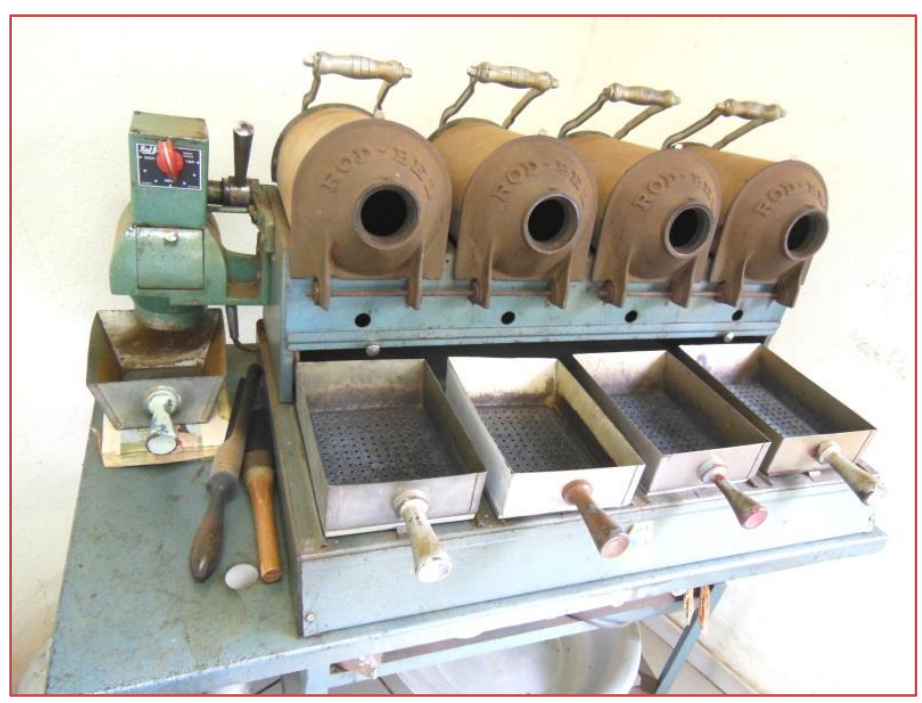

O café arábica utilizado foi classificado como tipo 2 ( 4 defeitos), suas características sensoriais no teste de xícara foram: aroma achocolatado, acidez suave cítrica agradável, balanceada doçura versus amargor, fundo caramelizado (after teste) e sutil adstringência com fundo aveludado. Já o café robusta foi classificado como tipo 3 (12 defeitos) sendo uma bebida Sui generis.

\subsection{PRODUÇÃO DOS BOMBONS}

A produção dos bombons foi feita a partir do derretimento do chocolate branco em banho-maria mantendo-se a temperatura do produto a $45^{\circ} \mathrm{C}$ e a temperatura do banho em torno de $50^{\circ} \mathrm{C}$. A composição da mistura utilizada foi $86,9 \%$ de chocolate branco e $13,1 \%$ de café. Foram avaliadas três formulações, as quais estão apresentadas na tabela 1

Tabela 1 Formulações dos bombons

\begin{tabular}{|l|c|c|}
\multicolumn{2}{|c|}{ Café robusta (\%) } & Café arábica (\%) \\
\hline Formulação 1 & 100 & 0 \\
\hline Formulação 2 & 0 & 100 \\
\hline Formulação 3 & 50 & 50 \\
\hline
\end{tabular}

Depois das operações de derretimento e mistura, seguiu-se para a moldagem dos bombons, resfriamento e desmolde.

\subsection{ANÁLISE DA CAPACIDADE ANTIOXIDANTE TOTAL}

A determinação da capacidade antioxidante total das amostras de café foi feita pelo método DPPH e realizada no Laboratório de Bioquímica e Fisiologia de Microrganismos (LBFM) do Departamento de Bioquímica da Universidade Estadual de Maringá (DBQ/UEM) conforme descrito pela metodologia de Mensor et al. (2011). 


\subsection{ANÁLISE DE COMPOSTOS FENÓLICOS - CATEQUINAS}

A determinação de compostos fenólicos em catequinas, nas amostras de café, foi feita pelo método colorimétrico de Folin Ciocalteu no LBFM do DBQ/UEM conforme Singleton e Rossi (1965).

\subsection{ANÁLISE SENSORIAL}

A análise sensorial dos bombons foi realizada no Laboratório de Análise Sensorial do Departamento de Engenharia de Alimentos da Universidade Estadual de Maringá (DAL/UEM), empregando a metodologia de escala hedônica de 9 pontos, variando de "desgostei muitíssimo" (1) a "gostei muitíssimo" (9) e escala de atitude ou intenção de compra com 125 provadores não treinados.

\section{RESULTADOS E DISCUSSÃo}

\subsection{CAPACIDADE ANTIOXIDANTE TOTAL}

A atividade antioxidante total dos cafés arábica e robusta foram 92,9 mg/L e 91,1 mg/L, respectivamente. Salvador (2011) estudou a capacidade antioxidante em chocolates e não encontrou atividade antioxidante em chocolate branco. Neste sentido, acrescentar ao chocolate branco o café, consequentemente, compostos antioxidantes serão adicionados.

\subsection{COMPOSTOS FENÓLICOS - CATEQUINAS}

Os compostos fenólicos presentes nos cafés arábica e robusta foram 9,38 mg de catequinas $/ \mathrm{mL}$ de café e $13,43 \mathrm{mg}$ de catequinas/mL de café, respectivamente. De acordo com Rodarte et al. (2009) o ponto de torrefação é um fator importante para as concentrações de compostos fenólicos nos grãos de café, onde a torra mais escura apresenta maior degradação desses compostos em comparação às torras mais claras. Dentro deste contexto, pode-se afirmar que o padrão de torra utilizado é adequado para a conservação desses compostos, uma vez que, apresentaram altos índices de fenólicos.

Zanchet et al. (2016) estudou o teor de fenólicos no chocolate branco com extrato de erva-mate e pode observar que quanto maior o teor de fenólicos, maior é a atividade antioxidante do produto. Entretanto, tal correlação não foi encontrada para o chocolate branco com café, uma vez que, o café robusta que possui $9,38 \mathrm{mg} / \mathrm{mL}$ de catequinas, apresentou menor valor de atividade antioxidante.

\subsection{ANÁLISE SENSORIAL}

Aplicou-se a análise de variância ao nível de $5 \%$ nos resultados obtidos na sensorial. Para as amostras que obtiveram diferença significativa, foi aplicado o teste de Tukey para a identificação das mesmas. Os resultados se encontram na Tabela 2.

Tabela 2 . Média das notas atribuídas pelos provadores para as formulações.

\begin{tabular}{|c|c|c|c|c|c|c|c|}
\hline \multirow{2}{*}{ Amostras } & \multirow{2}{*}{ Cor } & \multirow{2}{*}{ Sabor } & \multirow{2}{*}{ Aroma } & \multirow{2}{*}{ Textura } & \multirow{2}{*}{ Global } & \multicolumn{2}{|c|}{ Intenção de Compra } \\
\hline & & & & & & $\operatorname{Sim}$ & Não \\
\hline Arábica & $7,15 a$ & $6,983333 b$ & $7,216667 \mathrm{c}$ & $6,208333 d$ & $7,175 \mathrm{e}$ & $57,6 \%$ & $42,4 \%$ \\
\hline Robusta & $7,175 a$ & $7,175 b$ & 6,891667c & $6,375 d$ & $6,7 \mathrm{f}$ & $53,6 \%$ & $46,4 \%$ \\
\hline Mistura & $7,275 a$ & $7,425 b$ & $7,266667 \mathrm{c}$ & $6,808333 d$ & 7,258333f,e & $64,8 \%$ & $35,2 \%$ \\
\hline
\end{tabular}

Médias com letras iguais em uma mesma coluna não diferem entre si pela análise de variância ao nível de 5\%.

Observa-se pela tabela 2 que os atributos cor, aroma, sabor e textura não obtiveram diferenças significativas entre as três formulações, arábica, robusta e a mistura, ao nível de significância de 5\%. Somente a análise do parâmetro global, teve diferença significativa ao nível de $5 \%$ entre as amostras (arábica e robusta). Os atributos cor, sabor, aroma e global apresentaram uma pontuação média de em 
torno de 7,0, denotando uma boa aceitação. Somente o atributo textura, teve uma média abaixo de 7, onde se teve a menor nota das médias.

O produto que teve maior intenção de compra foi o chocolate que continha a mistura entre os dois cafés, porém a porcentagem de intenção de compra não foi tão alta. Isso significa que o produto deve ser melhorado em suas características sensoriais.

\section{CONSIDERAÇÕES FINAIS}

Pode-se concluir que adicionar café ao chocolate branco melhorou suas características nutricionais, embora não tenha apresentado um elevado índice de aceitação pelos consumidores. Os compostos fenólicos e antioxidantes encontrados e quantificados no café irão compor um papel importante no chocolate branco, trazendo consigo efeitos funcionais e de durabilidade do produto, no qual a grande quantidade de antioxidantes encontrados no café possivelmente contribuirá para o aumento da vida de prateleira dos bombons. Entretanto, devem-se ajustar os parâmetros sensoriais do produto para alcançar uma melhor aceitação.

\section{REFERÊNCIAS}

[1] ANVISA. Resolução-RDC n² 264, de 22 de Setembro de 2005. Disponível em: <http://portal.anvisa.gov.br>. Acesso em: 25/08/2019.

[2] BRASIL. Instrução Normativa no 8, de 11 de Junho de 2003. Regulamento Técnico de Identidade e de Qualidade para a Classificação do Café Beneficiado Grão Cru. Diário Oficial da República Federativa do Brasil, Ministério da Agricultura, Pecuária e Abastecimento. Brasília, DF, 13 jun. 2003. Seção 1, p. 22-29.

[3] Colombo, Ana Maria Junkes; Valente Filho, Jamil Mattar; Moreira, Daniel Medeiros. Effects of Chocolate in the Endothelial Function of Patients with Acute Coronary Syndrome. Internacional Journal of Cardiovascular Sciences. v. 28, n. 2, p. 89-94, 2015.

[4] MENSOR, Luciana L.; MENEZES, Fábio S.; LEITÃO, Gilda G.; REIS, Alexandre S.; dos SANTOS Tereza C.; COUBE, Cintia S; LEITÃO, Suzana G. Screning of Brazilian plant extracts for antioxidante activity by the use of DPPH free radical method. Phytotherapy Research, v. 15, n.2, p. 127-130, 2001.

[5] OLIVEIRA, Itamar Pereira de; OLIVEIRA, Luana Carvalho; MOURA, Camila Stéffane Fernandes Teixeira de. Cultura de café: histórico, classificação botânica e fases de crescimento. Revista Faculdade Montes Belos, v.5, n.4, p. 17-32, 2012.

[6] OLIVEIRA, Leandra Natalia de; ALMEIDA, Mariana Ramos; OLIVEIRA, Luiz Fernando Cappa de. Aspectos nutricionais do chocolate branco: uma visão por espectroscopia Raman. Nutrire: Revista da Sociedade Brasileira de Alimentação e Nutrição, v. 36, Supl., p. 38, 2011.

[7] Paz-Yépez, Carolina; Peinado, Irene; Heredia, Ana; Andrés, AnA. Lipids digestibility and polyphenols release underin vitrodigestion of dark,milk and white chocolate. Journal of Functional Foods, v. 52, p. 196-203, 2019.

[8] RODARTE, M. P.; ABRAHAO, S. A.; PEREIRA, R. G. F. A.; MALTA, M. R. Compostos não voláteis em cafés da região sul de minas submetidos a diferentes pontos de torração. Ciência Agrotecnológica, v. 33, n.5, p. 1366-1371, 2009.

[9] SALVADOR, I. Antioxidante e teor de resveratrol em cacau chocolates achocolatados em pó e bebidas lácteas achocolatadas. 90 f. Dissertação (Mestrado em Ciências) - Centro de Energia Nuclear na Agricultura, Universidade de São Paulo, Piracicaba, 2011.

[10] Seem, Stephanie A.; Yuan, Yvonne V.; Tou, Janet C. Chocolate and chocolate constituents influence bone health and osteoporosis risk. Nutrition, v. 65, p. 74-84, 2019.

[11] SILVA, Emerson Geremias da; BITTEnCOURT, Paulo Rodrigo Stival; TORQUATO, Alex Sanches Café e seus constituintes: benefícios e malefícios para a saúde humana. Uningá Review, n. 13 (1), p. 15-26, 2013.

[12] SINGLETON, V. L.; ROSSI, J. A. Coloritmetry of total phenolics with phosphomolybdic-phosphotungstic acid reagents. American Journal of Enology and Viticulture, v.16, p.144-158, 1965.

[13] ZANCHETT, Catia Santin; MIGNONI, Marcelo Luis; BARRO, Najara Pinto Ribeiro; ROSA, Clarissa Dalla. Desenvolvimento de chocolate branco com extrato de erva-mate. Brazilian Journal of Food Technology, v.19, 2016. 


\section{Capítulo 15}

\section{Elaboração de Cookies a base de quinoa e linhaça, para Celíacos}

\section{Jordânia de Sousa Gomes \\ Karine Almeida Paula \\ Samuel de Oliveira Santos \\ Fábia Costa}

Resumo: 0 presente trabalho tem por finalidade a apresentação de um novo produto, com o intuito de agregar valores ao cookie, desenvolvendo uma nova opção de alimento a base do grão de quinoa e ainda poder enriquecê-lo com a linhaça, com objetivo de satisfazer as necessidades nutricionais dos indivíduos portadores de doença celíaca. Visando assim, colaborar na elaboração de novos produtos para celíacos e exibir uma nova alternativa para este público. De modo que também seja possível, propor um alimento para os consumidores em geral, por conta dos inúmeros benefícios apresentados pela quinoa onde a mesma possui todos os aminoácidos essenciais, em especial a Lisina, importante para a fase do crescimento e manutenção de músculos e órgãos, quanto à linhaça é um alimento fundamental para uma dieta saudável. 0 trabalho foi realizado no laboratório de biologia da EEEP Alan Pinho Tabosa, localizada no município de Pentecoste (CE), onde foi elaborado três biscoitos tipo cookie e feito análise sensorial com 50 provadores não treinados para determinação do melhor produto relacionado ao sabor. Assim, com base nos resultados foi verificado que o cookie de quinoa enriquecido com a linhaça, apresentou aceitabilidade tal como o cookie padrão, no entanto pode-se constatar a necessidade de mais pesquisas relacionadas ao teor da quantidade da farinha de quinoa para conseguir o sabor aceitável para os consumidores portadores de doença celíaca.

Palavras-chave: Alimentação Saudável; Cereal; Biscoito; Análise Sensorial. 


\section{INTRODUÇÃO}

A quinoa trata-se de um pseudocereal, cultivado principalmente na região andina. Tem se destacado atualmente, por possuir uma importante fonte de proteínas de alta digestibilidade e apresentar composição equilibrada de aminoácidos e alto teor de lipídios, e principalmente ácidos graxos insaturados. (León e Rossel, 2007). A mesma, também é fonte de cálcio, ferro e ômega 3 e 6, como qualquer cereal, é muito rica em fibras, portanto, sendo uma ótima fonte de carboidratos para alimentação. Além disso, possui quantidades notáveis de vitaminas do complexo B. A quinoa em flocos, é rica em tirosina que ajuda a regenerar as células do sangue e a defesa do organismo (Improta e Kellms, 2001;Gewehr, et al.2001 ). Seus benefícios são inúmeros, por ser rica em proteína, em ênfase para quem pratica atividades físicas.

Com quantidades significativas de ômega 3 e 6 são aliados na preservação de doenças cardiovasculares e redução do colesterol. A mesma também atua no fortalecimento dos ossos e preservação de doenças como osteoporose e hipertensão, devido a suas quantidades de cálcio. Outra grande propriedade da quinoa trata-se de não possuir glúten em sua composição, sendo essencial para um grupo de pessoas que tem intolerância ao mesmo, doença conhecida com Celíaca. A doença celíaca (DC) é uma intolerância à ingestão de glúten, contido em cereais como cevada, centeio, trigo e malte, em indivíduos geneticamente predispostos, caracterizada por um processo inflamatório que envolve a mucosa do intestino delgado, levando a atrofia das vilosidades intestinais, má absorção e uma variedade de manifestações clínicas. As proteínas do glúten são relativamente resistentes às enzimas digestivas, resultando em derivados peptídeos que podem levar à resposta imunogênica em pacientes com DC. 0 tratamento da doença celíaca é basicamente dietético, devendo-se excluir o glúten da dieta por toda a vida. Após realizá-lo, ocorre o desaparecimento dos sintomas gastrointestinais dentro de dias ou semanas, assim como o reaparecimento das vilosidades e recuperação da capacidade de digestão e absorção. (Castro e Villa Real, et,.al. 2007).

Com o propósito de satisfazer as necessidades nutricionais deste grupo de pessoas, e ainda apresentar um produto com um alto valor nutritivo, levando em conta todos os aspectos, que incluem uma vida saudável, visando conduzir a uma melhoria do estado geral de saúde e provocar uma redução do risco de doenças, sendo assim um alimento funcional é essencial para o adequado desenvolvimento do organismo. E como a população em geral, está optando por alimentos mais saudáveis, que proporcionem mais benefícios a saúde e ainda mantenham uma dieta bastante equilibrada, utilizou-se a linhaça ,como um dos componentes para o novo produto, uma pequena semente de formato oval, tendo um alto valor nutritivo. A mesma trata-se de um grão oleaginoso, de cor marrom ou amarelo dourado, rico nos ácidos graxos poliinsaturados $\alpha$-linolênicos (ALA) e, em menor quantidade, linoléico (AL), além de conter teores significativos de proteína vegetal, lignanas, fibra alimentar solúvel e insolúvel, goma ou mucilagem, ácidos fenólicos, flavonóides, ácido fítico, vitaminas e minerais. Todas essas substâncias são consideradas importantes devido aos efeitos benéficos à saúde, reforçando as propriedades funcionais da linhaça (Oomah; Mazza, 2000; Collins et al., 2003; Bombo, 2006; Chen; Xu; Wang, 2007).

Em razão de das propriedades apresentadas pela quinoa e a linhaça, realizamos a união das mesmas, produzindo um alimento saboroso, nutritivo e possível de ser adquirido por pessoas em qualquer nível social, e com o objetivo de determinar o nível de aceitação de jovens e adultos realizamos uma análise sensorial, o que proporcionou a melhoria na qualidade do produto.

\section{MATERIAL E MÉTODOS}

No presente trabalho foram utilizadas as amostras de quinoa em flocos integral, da marca Vitalin, e linhaça marrom tipo moída, comercializada em Fortaleza e Pentecoste, CE. Foi realizado as preparações de acordo com receitas de cookies padrão já elaboradas, mediante inúmeras alterações, dentre as quais temos a substituição da farinha de trigo sem fermento pela quinoa e linhaça e foi adicionado a essência de maracujá para suavizar o sabor forte, ocasionado pela quinoa. Tais ingredientes modificaram as carcterísticas organolépticas do produto como alterações na cor, aroma, textura e sabor. Foram feitos quatro testes na receita do produto, antes de ser elaborado para efeitos de aceitação do consumidor.

A análise sensorial foi realizada no Laboratório de Microbiologia da Escola de Educação Profissional Alan Pinho Tabosa, (EEEP). Foi elaborado três amostras de cookies onde o primeiro é o produto tradicional que existe no mercado feito a base farinha de trigo sem fermento, o segundo cookie foi feito a base de farinha de trigo com linhaça mais quinoa, e o terceiro a base de quinoa enriquecido com linhaça. Na tabela 1 , estão todos os ingredientes e suas respectivas medidas a qual foram utilizadas nas preparações 
Tabela 1- Ingredientes utilizados em cada preparação submetida à análise sensorial, pelo método de escala hedônica de nove pontos, em que A: Cookie de quinoa e linhaça; B: Cookie de quinoa, trigo e linhaça; C: Cookie de farinha de trigo sem fermento.

\begin{tabular}{|l|c|c|c|}
\multicolumn{1}{c}{ Ingredientes(g) } & A & B & C \\
\hline Quinoa em flocos & 70 & 80 & \\
\hline Linhaça Moída & 120 & 160 & \\
\hline Ovo & 80 & 80 & 80 \\
\hline Açúcar Cristal & 180 & 160 & 200 \\
\hline Maracujá & 100 & 100 & 100 \\
\hline Manteiga Light & 90 & 120 & 150 \\
\hline Farinha de trigo sem fermento & & & 300 \\
\hline
\end{tabular}

Fonte: autoria própria

Logo após a elaboração das três amostras de cookies, foi efetuada a análise sensorial, onde 50 provadores não treinados foram direcionados para as cabines individuais, entre homens e mulheres com idades variando de 14 a 50 anos, cada cabine tinha nas mesas um copo com água, um biscoito de água e sal, a qual se orientou que ingerissem os biscoitos. Na figura 1, está especificada a ficha de avaliação de análise sensorial utilizada para expressar a aceitação e realizar algum comentário, para efeitos de melhorias no produto. Para a avaliação da análise sensorial, foi utilizado a escala hedônica de 9 pontos.

Figura 1 Ficha para avaliação da análise

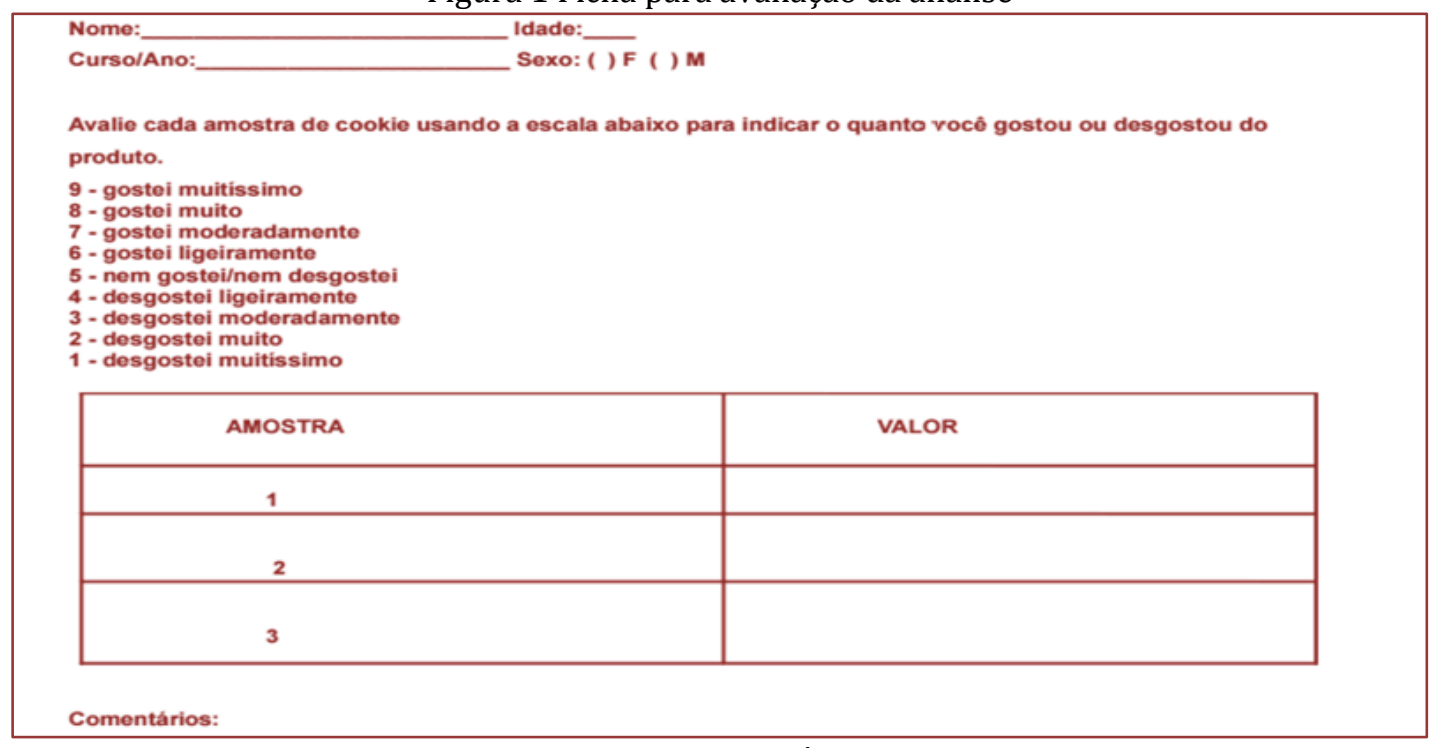

Fonte: autoria própria

Para a determinação do índice de aceitação, aplicamos a seguinte fórmula do Índice de Aceitabilidade (I.A):

IA (\%) = A X 100/B, em que A: a nota média atingida para o biscoito e B: a nota máxima atribuída ao biscoito .

\section{RESULTADOS E DISCUSSÃO}

Tabela 2- Índice de Aceitabilidade das elaborações avaliadas sensorialmente pelo método da escala hedônica de 9 pontos para biscoito tipo cookie.

\begin{tabular}{|c|c|}
\hline Amostras & Índice de Aceitabilidade \\
\hline Cookie de Quinoa e Linhaça & $81,11 \%$ \\
\hline Cookie de Quinoa, Linhaça e Farinha do trigo & $72,22 \%$ \\
\hline Cookie de Cookie Padrão & $87,77 \%$ \\
\hline
\end{tabular}

Fonte: autoria própria

Deste modo conforme apresentado na tabela 2, seguindo os resultados apresentados é possível perceber que ainda há uma preferência mínima pelo cookie comum, pelo fato de ter trago um sabor mais característico do maracujá, o que mais foi citado ao assar o biscoito, pois se sabe que o superaquecimento 
pode, além de diminuir o valor nutricional da proteína, afetar a funcionabilidade desta no alimento, por diminuir a solubilidade, além de levar a formação de ligações cruzadas entre o grupo amino da lisina e o grupo amida do ácido glutâmico ou aspártico, impedindo a ação das proteases e diminuindo assim a digestibilidade ( Castro e Villa Real, C.M et,.al. 2007).

Em tese o único produto com o nível de aceitabilidade significativamente baixo foi o cookie a base de trigo, quinoa e linhaça, por ter apresentado um sabor um tanto amargo, necessidade de mais aroma e uma aparência mais atrativa. Sendo assim, é possível determinar que o cookie de quinoa enriquecido com a linhaça, apresentou aceitabilidade tal como o cookie padrão, conforme medido pelo índice de aceitabilidade na escala hedônica. É relevante atentar-se que todos os ingredientes utilizados para a elaboração dos produtos, não possuem glúten, sendo assim de total confiança e indicado para pessoas portadoras de doença celíaca. Todavia, mesmo se tratando de provadores com faixa etária entre 16 e 50 anos, os dados alcançados foram bastante significativos. Onde através dos mesmos, é possível constatar que produtos com quinoa e linhaça apresentam expressivas características organolépticas favoráveis para que os indivíduos consumam o cookie diariamente. 0 fator que mais influenciou na análise foi o sabor, por se tratar da necessidade do desenvolvimento de um novo produto, é possível atentar-se para pontos como suavizar o gosto, pois possuía o sabor forte característico da quinoa.

\section{CONCLUSÃO}

Portanto, seguindo os aspectos apresentados pelos resultados desta análise, é possível perceber que os produtos produzidos com quinoa e linhaça, são bem aceitos por indivíduos em qualquer faixa etária, e que se torna claro a necessidade do desenvolvimento de alimentos para portadores de doença celíaca, a possibilidade da troca por alimentos que não contém glúten, como forma de fazer com que esse grupo de pessoas tenham mais opções de alimentos no mercado consumidor.Desde modo, é correto afirmar que ainda há necessidades de mais pesquisas como a elaboração de cookies com diversos níveis de farinha de quinoa para verificar qual o melhor sabor, e que possa haver investimentos nestas pesquisas, pois o que está em questão é a saúde e o bem-estar de milhares de pessoas que atualmente sofrem as consequências da doença celíaca.

\section{AGRADECIMENTOS}

Agradeço primeiramente a Deus pelo fôlego de vida, e por ajudarmo-nos em todos os aspectos. A direção e coordenação da EEEP Alan Pinho Tabosa, em especial ao diretor Elton Luz, aos coordenadores Carmem, Renato e Ednaldo pelo incentivo. A todo o grupo de docentes da escola, em especial as professoras do Curso Técnico em Agroindústria, senhora Fábia Costa, Kátia Alcilene e Luciana Lobo. Aos nossos pais por todo o apoio em custear e motivar-nos. E a todos que nos ajudaram de alguma forma.

\section{REFERÊNCIAS}

[1] Bombo, A.J.Obtenção e caracterização nutricional de snacks de milho(Zea mays L.) e linhaça (Linum usitatissimum L.).2006. Dissertação (Mestrado em Saúde Pública) Universidade de São Paulo, São Paulo, 2006.

[2] Castro, L. I. A.; Vila Real, C. M.; Pires, I. S. C.; Pires, C. V.; Pinto, N. A. V. D.; Miranda, L. S.; Rosa, B. C.; Dias, P. A. Quinoa (Chenopodium quinoa Willd): in vitro digestibility, development and sensorial analysis of preparations for celiac patients. Alim.Nutr., Araraquara, v.18, n.3, p. 413-419, out./dez. 2007.

[3] Chen, H.-H.; Xu, S.-Y; Wang, Z. Gelation properties of flaxseed gum. Journal of Food Engineering, v.77, n.2, p.295-303, 2006.

[4] Collins, T.F.X. et al. Effects of flaxseed and defatted flaxseed meal on reproduction and development in rats. Food and Chemical Toxicology , v.41, n.6, p. 819-834, jun.2003.

[5] Gewehr. F. M, Danelli D. 2012. Análises químicas em flocos de quinoa: caracterização para a utilização em produtos alimentícios. Brazilian Journal of Food Techonology. Campinas, v. 15, n. 4, p. 280-287, out./dez. 2012.

[6] Improta, F.; Kellems, R. O. Comparison of raw, washed and polished quinoa (chenopodium quinoa willd.) to wheat, sorghum or maize based diets on growth and survival of broiler chicks. Livestock Research for Rural Development, Cali, v. 13, n. 1, 2001. Disponível em: . Acesso em: 28 dez. 2009.

[7] León, A. E.; Rosell, C. M. De Tales Harinas, Tales Panes: Granos, Harinas y Productos de Panificación en Iberoamérica. Córdoba: Hugo Báez Editor, 2007. 478 p. 
[8] Marques Castro, A. Propriedades Funcionais da Linhaça em diferentes condições de preparo e de uso de alimentos. Dissertação apresentada ao Programa de Pós-graduação em Tecnologia de alimentos, da Universidade Federal de Santa Maria, UFSM, 2008.

[9] Omah, B.D.; Mazza, G. Productos de linaza para la prevención de enfermedades. In: Mazza, G. (Coord.). Alimentos funcionales: aspectos bioquímicos y de procesado, Zaragoza: Acribia, 2000. 457p.

[10] Autor a ser contatado: Jordânia de Sousa Gomes, Estudante do curso técnico em Agroindústria-Eeep Alan Pinho Tabosa; E-mail: jordaniasousa27@gmail.com 


\section{Capítulo 16}

\section{Produção de xarope de açúcar invertido por hidrólise ácida através do planejamento experimental}

\section{Camila Mika Sassai Sato}

Pedro Bitencourt

Rita de Cássia Bergamasco

Gisele Cristina dos Santos Bazanella

Resumo: Os açúcares redutores são obtidos pela inversão da sacarose. Eles reúnem diversas vantagens como a solubilidade da frutose e a difícil cristalização, aumentando o poder edulcorante, desejável em produtos alimentícios. Ao realizar a inversão, pode ser formado um composto chamado de 5-hidroximetilfurfural (HMF) que altera a qualidade do açúcar e em muitos casos impróprio para o consumidor, devido ao seu potencial carcinogênico. Dentro deste contexto, o objetivo do trabalho foi determinar as condições ótimas para o processo de produção do xarope de açúcar invertido por hidrólise ácida com a mínima produção de HMF e a máxima hidrólise da sacarose utilizando o planejamento fatorial associado à análise de superfície de respostas. Concluiu-se que as temperaturas mais baixas e os menores tempos resultaram na maior quantidade de açúcar redutor e a menor quantidade de HMF.

Palavras-chave: Condições ótimas, HMF, Açúcar Redutor. 


\section{INTRODUÇÃO}

Um dos componentes mais utilizados no ramo alimentício é o açúcar, sendo o açúcar redutor o mais amplamente empregado. Os açúcares redutores são obtidos através da inversão da sacarose, numa reação que é favorecida em meio ácido e tem como produtos finais a frutose e a glicose, também chamados de açúcares invertidos, devido às suas propriedades físicas (HOPPE; MALLMANN; OLIVEIRA, 2015). Esta inversão pode ser feita através de hidrólise ácida, natural ou enzimática (BARRETO et al, 2015).

Em meio ácido, a solução de sacarose se hidrolisa em baixos pH's, longos tempos de contato e altas temperaturas (SOUSA FILHO; SILVA; ASSUNÇÃO, 2017). Neste caso, os ácidos mais utilizados na inversão são os ácidos orgânicos, como o cítrico e o ascórbico (BARRETO et al, 2015). Este processo por vezes é desejado nas indústrias de alimentos, pois a frutose é mais doce que a sacarose. Além disso, a glicose, o outro produto da inversão, é um controlador da cristalização, ou seja, inibe a movimentação e formação de cristais de açúcar, indesejados em alguns produtos, tais como balas e doces (BARRETO et al, 2015).

Açúcares redutores podem formar um produto chamado de 5-hidroximetilfurfural (HMF) (Ogando, 2015). Este produto tem sua formação favorecida em meio ácido, temperaturas altas e longos tempos de permanência, entretanto é um produto por vezes indesejado, uma vez que pode interferir na composição e qualidade do açúcar, alterando-o. E em muitos casos, ser impróprio ao consumo humano (LINHARES et al, 2014), devido ao seu potencial carcinogênico (RIBEIRO et al., 2012).

Alguns estudos mostraram que o seu metabolismo pode ser convertido in vivo em 5-sulfoximetilfurfural (SMF), um componente genotóxico. Ademais, em altas concentrações é citotóxico, podendo causar irritação aos olhos, trato respiratório superior, pele e mucosas (RIBEIRO et al., 2012).

Portanto, o objetivo do presente trabalho foi determinar as condições ótimas de produção de xarope de açúcar invertido por hidrólise ácida, visando a mínima produção do composto HMF.

\section{MATERIAIS E MÉTODOS}

\subsection{MATÉRIAS-PRIMAS}

As matérias-primas utilizadas para o preparo do xarope de açúcar invertido foram: água destilada, açúcar refinado e ácido cítrico.

\subsection{PRODUÇÃO DO XAROPE DE AÇÚCAR INVERTIDO}

0 xarope de açúcar invertido foi produzido em um béquer de $500 \mathrm{ml}$, onde se adicionou a quantidade de açúcar determinada no planejamento experimental com $250 \mathrm{ml}$ de água destilada. A mistura foi aquecida em banho e controlada por termômetro imerso na solução. Após estabilização da temperatura, de acordo com o planejamento experimental, se adicionou o ácido cítrico e misturou-se com um bastão de vidro por alguns segundos. Manteve-se sob aquecimento pelo período definido no planejamento. Após este tempo, retirou-se imediatamente e obteve-se o xarope de açúcar invertido, o qual foi submetido às análises físicoquímicas.

\subsection{ANÁLISES FÍSICO-QUÍMICAS}

\subsubsection{AÇÚCAR REDUTOR}

Os açúcares redutores foram quantificados pelo método DNS conforme o Departamento de Bioquímica e Biologia Celular (2007). Foram colocados em um tubo de ensaio $250 \mu \mathrm{L}$ da amostra e $250 \mu \mathrm{L}$ de DNS e para o branco foram adicionadas $250 \mu \mathrm{L}$ de água e $250 \mu \mathrm{L}$ de DNS. Todos os tubos foram colocados em banho fervente por $5 \mathrm{~min}$ e rapidamente colocados em água fria. Completou-se todos os tubos com 2,5 mL de água. Ao final, realizou-se a leitura da absorbância em espectrofotômetro a $540 \mathrm{~nm}$.

\subsubsection{HIDROXIMETILFURFURAL (HMF)}

O HMF foi quantificado pelo método 175/IV Méis - Determinação de hidroximetilfurfural, segundo Instituto Adolpho Lutz (2008). As leituras foram realizadas em triplicata. A equação 1 representa a quantificação de HMF em solução utilizando a média das leituras obtidas. 


$$
\frac{\left(A_{284}-A_{336}\right) * 149,7 * 5}{P}=H M F_{-} m g / K g
$$

Em que, A284 é a leitura da absorbância a 284 nm; A336 é a leitura da absorbância a 336 nm; P é a massa da amostra em gramas; 5 é a massa nominal da amostra e 149,7 = (126/16830) x (1000/10) x (1000/5), sendo 126 = peso molecular do HMF; 16830 = absortividade molar do HMF a $284 \mathrm{~nm} ; 1000=$ conversão de g para mg; 10 = diluição de 5 g de mel para $50 \mathrm{~mL}$ e 1000 = conversão de g para kg.

\subsection{PLANEJAMENTO DE EXPERIMENTOS}

Foi utilizado o planejamento fatorial associado à análise de superfície de respostas, com quatro variáveis, dois níveis e dois pontos centrais, totalizando 10 ensaios. Os parâmetros de variação foram a concentração da solução de sacarose, o tempo, a temperatura e a concentração do ácido cítrico. A tabela 1 apresenta a codificação e a distribuição das variáveis nos diferentes níveis do planejamento de experimentos.

Tabela 1 Codificação e distribuição das variáveis concentração da solução de sacarose, tempo, temperatura e concentração de ácido cítrico nos diferentes níveis do planejamento

\begin{tabular}{|c|c|c|c|}
\hline Variável/nível & -1 & 0 \\
\hline Concentração de sacarose (g/mL) & 0,3 & 0,5 & 0,7 \\
\hline Tempo (min) & 20 & 115 & 210 \\
\hline Temperatura (0C) & 60 & 76 & 92 \\
\hline Concentração de ácido cítrico (g/L) & 3 & 5 & 7 \\
\hline
\end{tabular}

O quadro 1 apresenta a distribuição dos experimentos no planejamento experimental.

Quadro 1 Distribuição dos Experimentos no planejamento experimental

\begin{tabular}{|c|c|c|c|c|}
\hline Ensaios & $\begin{array}{l}\text { Temperatura } \\
(\mathrm{oC})\end{array}$ & $\begin{array}{l}\text { Tempo } \\
\text { (min) }\end{array}$ & $\begin{array}{l}\text { Concentração de açúcar } \\
\qquad(\mathrm{g} / \mathrm{mL})\end{array}$ & $\begin{array}{c}\text { Concentração de ácido } \\
\text { cítrico }(\mathrm{g} / \mathrm{L})\end{array}$ \\
\hline 1 & -1 & -1 & -1 & -1 \\
\hline 2 & +1 & -1 & -1 & +1 \\
\hline 3 & -1 & +1 & -1 & +1 \\
\hline 4 & +1 & +1 & -1 & -1 \\
\hline 5 & -1 & -1 & +1 & +1 \\
\hline 6 & +1 & -1 & +1 & -1 \\
\hline 7 & -1 & +1 & +1 & -1 \\
\hline 8 & +1 & +1 & +1 & +1 \\
\hline 9 & 0 & 0 & 0 & 0 \\
\hline 10 & 0 & 0 & 0 & 0 \\
\hline
\end{tabular}




\subsection{ANÁLISE ESTATÍSTICA}

Para a análise de variância (ANOVA) e o teste de Tukey para comparação das médias, a um nível de 5\% de significância utilizou-se o software SISVAR 5.6 e o software TIBCO Statistica 13.3 foi utilizado para a análise estatística dos resultados do planejamento de experimentos.

\section{RESULTADOS E DISCUSSÕES}

\subsection{AÇÚCAR REDUTOR E HMF}

As quantidades de glicose e HMF para cada xarope estão apresentadas na tabela 2.

Tabela 2 Dados experimentais para glicose e HMF

\begin{tabular}{|c|c|c|c|c|c|c|}
\hline Ensaio & Temperatura $\left({ }^{\circ} \mathrm{C}\right)$ & $\begin{array}{c}\text { Tempo } \\
\text { (min) }\end{array}$ & $\begin{array}{c}\text { Sacarose } \\
(\mathrm{g} / \mathrm{mL})\end{array}$ & $\begin{array}{c}\text { Ácido } \\
(\mathrm{mg} / \mathrm{mL})\end{array}$ & $\begin{array}{l}\text { Glicose } \\
(\mathrm{g} / \mathrm{mL})\end{array}$ & HMF (mg/Kg) \\
\hline 1 & 60 & 20 & 0,3 & 3 & $0,378 a \pm 0,016$ & $0 \mathrm{~g}$ \\
\hline 2 & 92 & 20 & 0,3 & 7 & $0,182 \mathrm{f} \pm 0,008$ & $6,19 c \pm 0,169$ \\
\hline 3 & 60 & 210 & 0,3 & 7 & $0,378 a \pm 0,005$ & $0 \mathrm{~g}$ \\
\hline 4 & 92 & 210 & 0,3 & 3 & $0,200 \mathrm{e}, \mathrm{f} \pm 0,003$ & $20,64 b \pm 0,445$ \\
\hline 5 & 60 & 20 & 0,7 & 7 & $0,179 \mathrm{f} \pm 0,007$ & $0,899 f, g \pm 0,541$ \\
\hline 6 & 92 & 20 & 0,7 & 3 & $0,251 \mathrm{c}, \mathrm{d} \pm 0,022$ & $2,687 \mathrm{e}, \mathrm{f} \pm 0,395$ \\
\hline 7 & 60 & 210 & 0,7 & 3 & $0,318 b \pm 0,011$ & $0,746 \mathrm{~g} \pm 0,147$ \\
\hline 8 & 92 & 210 & 0,7 & 3 & $0,276 c \pm 0,009$ & $25,59 a \pm 1,676$ \\
\hline 9 & 76 & 115 & 0,5 & 5 & $0,216 d, e, f \pm 0,021$ & $3,338 \mathrm{~d}, \mathrm{e} \pm 0,610$ \\
\hline 10 & 76 & 115 & 0,5 & 5 & $0,238 c, d, e \pm 0,008$ & $3,035 \mathrm{~d}, \mathrm{e} \pm 0,819$ \\
\hline
\end{tabular}

Letras diferentes na mesma coluna diferem-se entre si a uma significância de 5\%.

Os dados apresentados na tabela 2 indicam que a quantidade de HMF produzida durante o experimento são menores que a instrução normativa $n^{\circ}$ 11, de 20 de outubro de 2000 , que indica quantidade máxima limite de $60 \mathrm{mg} / \mathrm{Kg}$ para o mel. Portanto, todas estão abaixo do limite máximo. Desta forma, as melhores condições do processo envolvem a maior quantidade de glicose produzida, adequado principalmente nos ensaios 1 e 3 que não produzem nenhuma quantidade de HMF. Como não há diferença significativa entre as duas amostras, o mais adequado é realizar de acordo com os parâmetros do ensaio 1 que possui menor tempo e menor utilização de ácido cítrico como reagente.

A figura 1 apresenta os gráficos de superfície de resposta para o planejamento de experimentos, em relação ao teor de HMF. 
Figura 1 Superfícies de respostas em relação ao teor de HMF variando A: Tempo e temperatura; B: Sacarose e temperatura; C: Ácido e temperatura; D: Sacarose e t empo; E: Ácido e tempo e F: Ácido e sacarose.

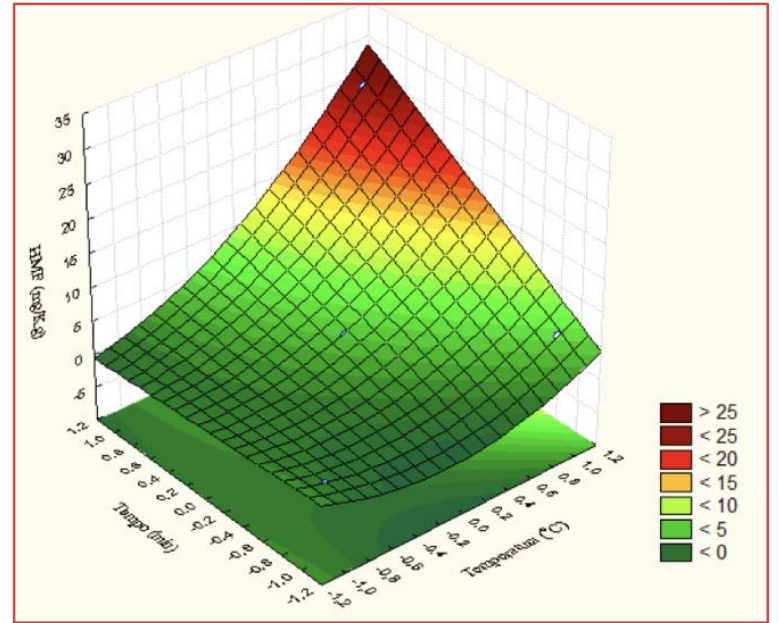

A
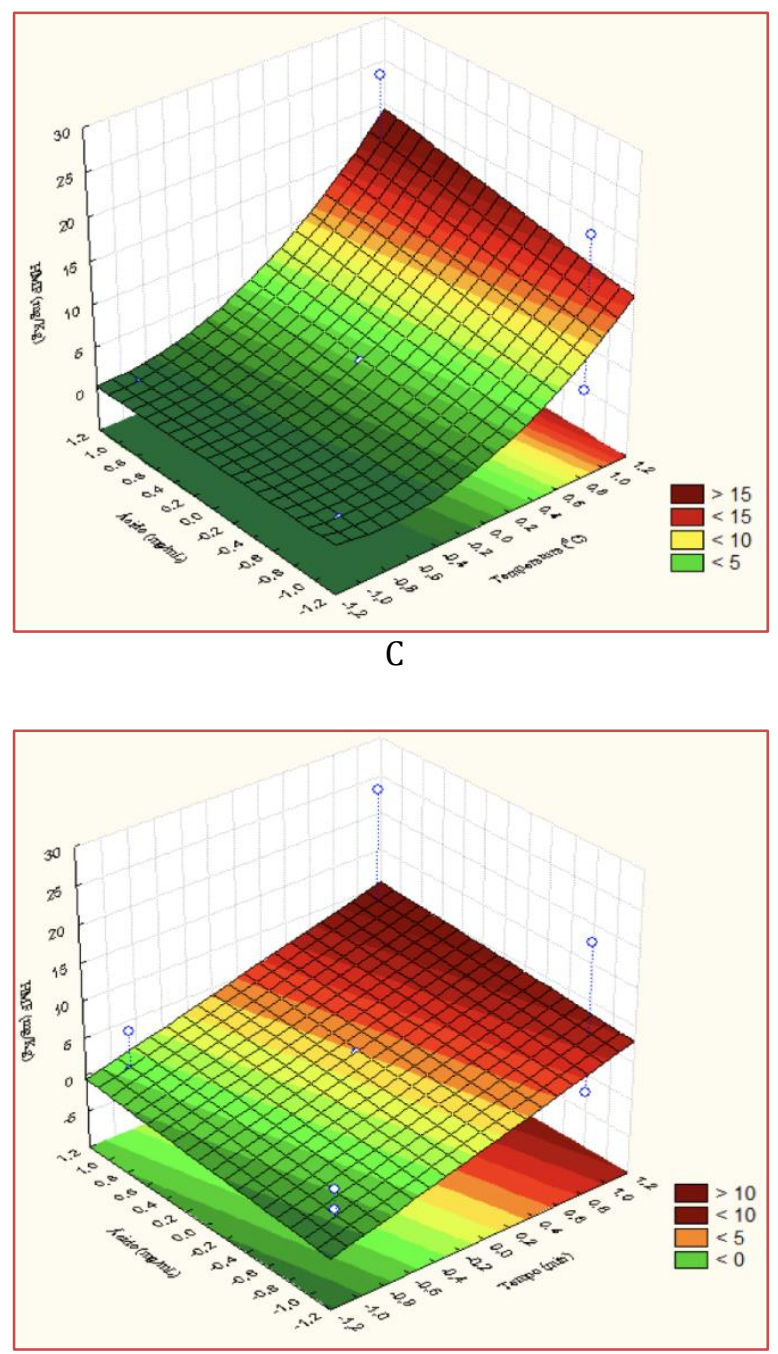

$\mathrm{E}$
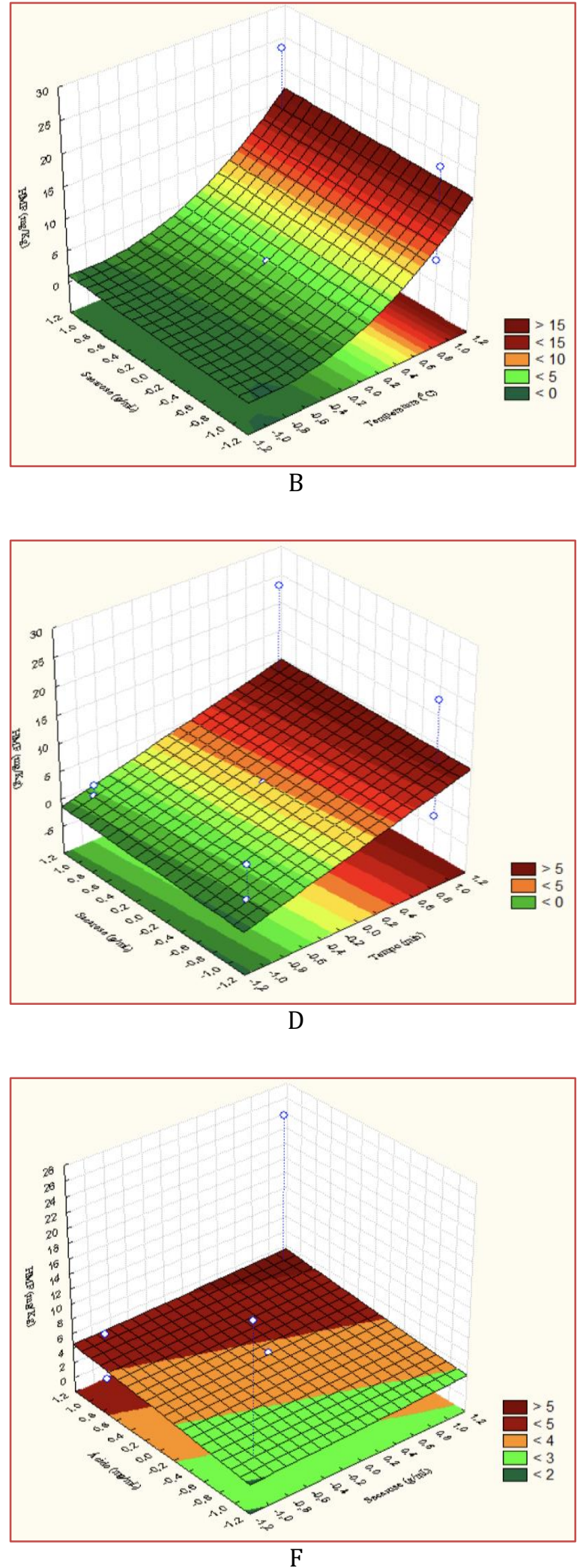
Os gráficos, divididos de dois em dois parâmetros, mostram uma tendência observada através da diferença significativa entre os resultados. Os experimentos 1 e 3 não apresentaram diferença significativa mesmo com alguns parâmetros diferentes, mostrando que a baixa temperatura influencia em uma menor formação de HMF. As amostras 4 e 8, mesmo que diferentes a uma significância de 5\%, apresentam um tempo longo de reação, sendo um parâmetro determinante para a formação de HMF, pois nestes experimentos que se obteve maior quantidade de HMF, porém nenhuma amostra ultrapassou a quantidade de $60 \mathrm{mg} / \mathrm{Kg}$ de produto, limite máximo conforme instrução normativa no 11, de 20 de outubro de 2000 .

A partir dos coeficientes de regressão gerados pelo tratamento estatístico para o modelo matemático referente à análise de HMF montou-se a equação que representa o modelo (equação 2).

$\mathrm{HMF}=3,7+6,6775 \mathrm{~T}+3,39 \mathrm{~T}^{\wedge} 2+4,645 \mathrm{t}+0,3925 \mathrm{~S}+1,08 \mathrm{~A}+4,6825 \mathrm{~T} . \mathrm{t}-0,02 \mathrm{~T} . \mathrm{S}+1,0425 \mathrm{~T} . \mathrm{A}(2)$

Pode-se perceber que a equação que representa o modelo ajustado para a variável resposta, HMF, é de segundo grau. Sendo que T representa a temperatura; $t$ o tempo; $\mathrm{S}$ a concentração de sacarose e A a concentração de ácido cítrico.

A figura 2 apresenta os gráficos de superfície de resposta para o planejamento de experimentos, em relação ao teor de açúcar redutor.

A Figura 2 comprovada que a diminuição na temperatura influencia na produção de glicose, mostrada pela temperatura de $60^{\circ} \mathrm{C}$, o ponto mais baixo das variáveis.

A partir dos coeficientes de regressão gerados pelo tratamento estatístico para o modelo matemático referente à análise de HMF montou-se a equação que representa o modelo (equação 3).

$$
\mathrm{HMF}=0,237333-0,043 \mathrm{~T}+0,032917 \mathrm{~T}^{\wedge} 2+0,02275 \mathrm{t}-0,01425 \mathrm{~S}-0,0165 \mathrm{~A}-0,012 \mathrm{~T} . \mathrm{t}+0,0505 \mathrm{~T} . \mathrm{S}+
$$

Pode-se perceber que a equação que representa o modelo ajustado para a variável resposta, açúcar redutor também é de segundo grau.

Analogamente a figura 1, a figura 2 é organizada em gráficos com dois parâmetros cada. Os experimentos 1 e 3 que não diferiram significativamente entre si, mostraram a maior formação de glicose com baixas concentrações de ácido cítrico e temperaturas menores que as outras usadas mostrando uma influência destes parâmetros, com o tempo não tendo esta influência. Por outro lado, as amostras 2, 4, 5 e 9 apresentaram menores quantidades de glicose, sem diferença significativa entre eles, com as maiores quantidades de ácido cítrico presente, sendo um parâmetro portanto, que não favorece a inversão da sacarose de modo a formar glicose. 
Figura 2 Superfícies de respostas em relação ao teor de glicose variando A: Tempo e temperatura; B: Sacarose e temperatura; C: Ácido e temperatura; D: Sacarose e tempo; E: Ácido e tempo e F: Ácido e sacarose.
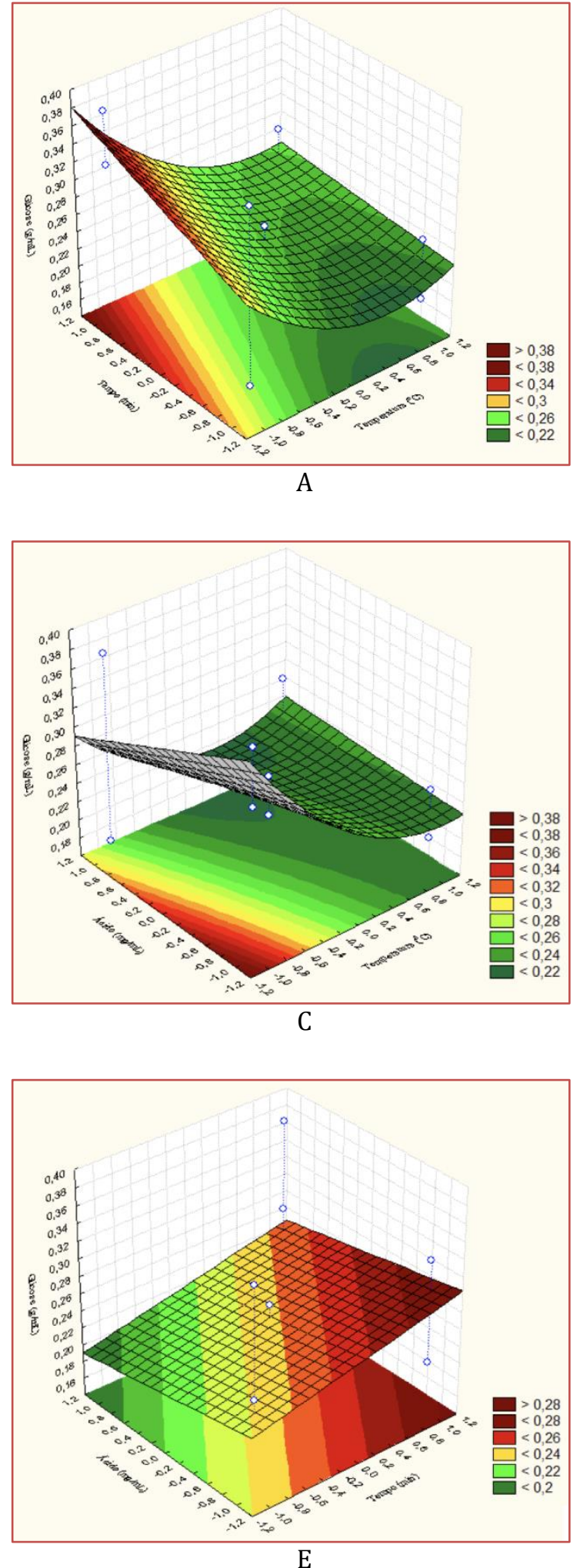
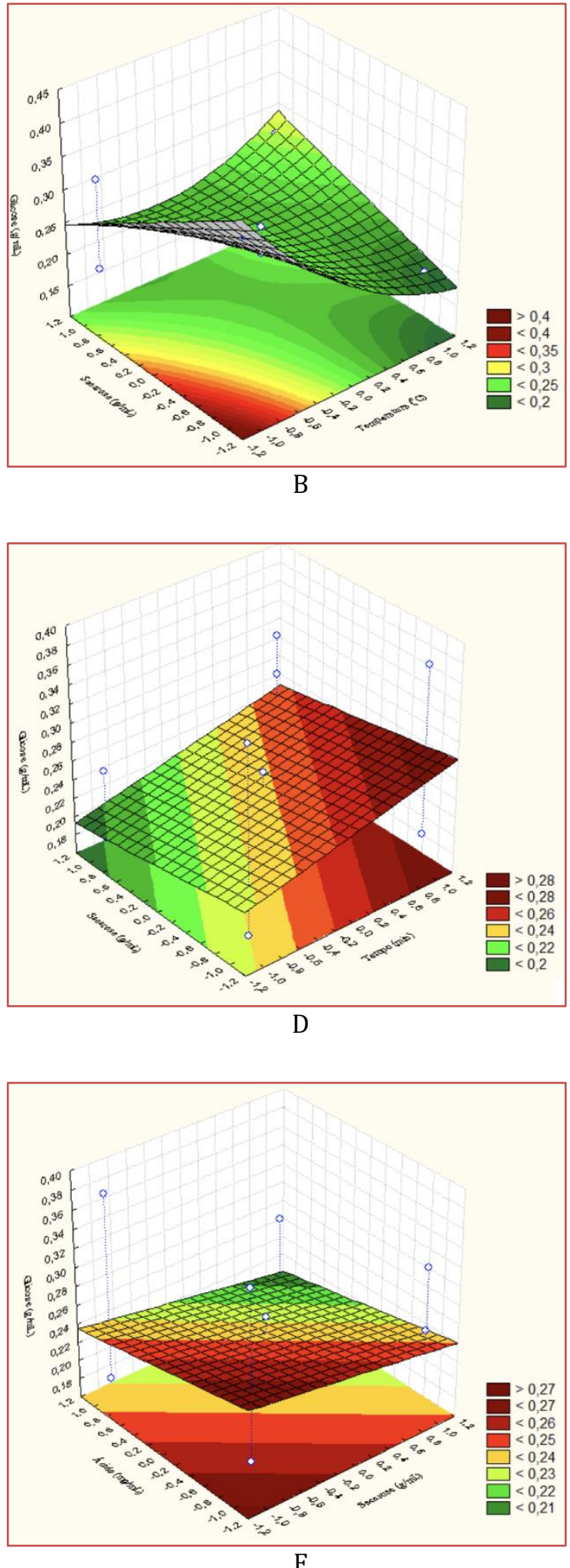


\section{CONCLUSÃO}

Observou-se que tempos maiores de exposição e altas temperaturas favorecem a formação de HMF, o que já era esperado. Quantidades maiores de ácido cítrico também favorecem a formação de HMF, enquanto que a sacarose não mostrou ter influência sobre a mesma. Em relação à glicose, conclui-se que a temperatura é inversamente proporcional a formação da glicose, assim como a concentração de ácido cítrico e de sacarose. Com isso, a inversão da sacarose tem maior rendimento com a reação à temperaturas médias, com concentrações pequenas de ácido cítrico e sacarose, havendo assim economia de reagentes para a maior formação de glicose e menor formação de HMF.

\section{REFERÊNCIAS}

[1] BARRETO, P. P. A. F. A. P.; BETTANI, S. R.; BORGES, M. T. M. R.; VERRUMA-BERNARDI, M. R.; Avaliação FísicoQuímica E Sensorial De Diferentes Melados. Revista de Agricultura, v. 90, n. 3, p. 217-228, 2015.

[2] DEPARTAMENTO DE BIOQUÍMICA E BIOLOGIA MOLECULAR. Bioquímica: Aulas Práticas. 7 edição. Editora UFPR. 2007. 178 p.

[3] HOPPE, C. D’0.; MALLMANN, P. R.; OLIVEIRA, E. C. Determinação De Umidade Em Balas Duras E Balas Mastigáveis. Revista Destaques Acadêmicos, v. 7, n. 4, p. 185-192, 2015.

[4] INSTITUTO ADOLFO LUTZ (São Paulo). Métodos físico-químicos para análise de alimentos /coordenadores Odair Zenebon, Neus Sadocco Pascuet e Paulo Tiglea - São Paulo: Instituto Adolfo Lutz, 2008. IAL- p337.

[5] Linhares, Marcus Vinícius Dantas; Quintella, Cristina Maria Assis Lopes Tavares da Mata Herminda; Borges, Valdivino Francisco dos Santos; Borges, Valter Francisco dos Santos. A formação de hidroximetilfurfural em méis de abelhas. Anais do EITEC. V. 3, n. 2, 2014.

[6] OGANDO, F. I. B. Determinação Da Degradação Térmica De Sacarose E Da Contaminação Microbiológica No Processo De Fabricação De Açúcar. Piracicaba, 2015. 90p. Dissertação (Mestrado em Ciências na Área de Microbiologia Agrícola), Escola Superior de Agricultura “Luiz de Queiroz”, Universidade de São Paulo, Piracicaba.

[7] RIBEIRO, R. O. R.; CARNEIRO, C. S.; MÁRSICO, E. T.; CUNHA, F. L.; CONTE JUNIOR, C. A.; MANO, S. B. Influência do binômio tempo e temperatura nos teores de hidroximetilfurfural em méis florais submetidos ao aquecimento Ciência e Agrotecnologia, V. 36, n. 2, p. 204-209, 2012.

[8] SOUSA FILHO, J. W.; SILVA, C. C.; ASSUNÇÃO, L. F. Determinação Da Inversão De Sacarose Em Caldo De CanaDe-Açúcar Submetido A Tratamento Por Irradiação Micro-Ondas Para Produção De Açúcar. Revista Brasileira de Ciência, Tecnologia, e Inovação (RBCTI), V. 2, n. 1, p. 6-12, 2017. 


\section{Capítulo 17}

\section{Desenvolvimento de doce a base de arroz e feijão}

\section{Bruna Demarchi}

\section{Liziane Dantas Lacerda}

Resumo: Tendo como principais ingredientes o arroz branco (Oryza sativa L.) e o feijão preto (Phaseolus vulgaris L.), dois insumos tradicionalmente muito consumidos pelos brasileiros devido as suas propriedades sensoriais e nutricionais, desenvolveu-se um doce muito popular, o brigadeiro. 0 doce teve como base um extrato condensado de arroz e uma pasta desidratada de feijão, sem a adição de leite em sua composição, elaborado para atender uma parcela da população que sofre com dietas restritivas, além de acrescentar valores nutricionais à dieta, como menor valor energético e maior percentual de fibras quando comparado ao brigadeiro convencional. A avaliação físico química, pesquisa de mercado e análise sensorial demonstraram grande potencial para inserção no mercado, sendo necessário pequenos ajustes na formulação para melhora do atributo textura.

Palavras-chave: arroz; feijão; brigadeiro; lactose 


\section{INTRODUÇÃO}

O surgimento dos brigadeiros na culinária brasileira aconteceu em meados de 1940 e se tornou popular, pois conquistou o paladar dos brasileiros. Hoje em dia, todas as comemorações costumam servir o doce como protagonista, principalmente nas festas infantis. Segundo a Anvisa (Agência Nacional de Vigilância Sanitária), caracteriza-se por brigadeiro o produto "cozido preparado à base de leite condensado e chocolate, podendo ser adicionado de outras substâncias como: manteiga, nozes, castanha-do-Pará, castanha-de-caju e uva passa e envolvido em chocolate granulado ou confeitos coloridos" (Resolução CNNPA no 12, de 1978).

0 arroz, Oryza sativa L., é um cereal que apresenta em sua composição uma série de nutrientes importantes para o organismo, como proteínas, lipídios, fibras e vitaminas. 0 grão de "arroz polido cru possui aproximadamente 79\% de carboidratos", de acordo com Weber (2012), além de cerca de 7\% de proteínas e 3\% de lipídeos. Além disso, o arroz contém grande quantidade do aminoácido metionina, importante para a nutrição do corpo. Já o feijão, Phaseolus vulgaris L., é rico em fibras, vitaminas, proteínas e ferro. Ajuda no bom funcionamento do intestino, no fortalecimento da memória e no controle do colesterol e da glicose. 0 principal aminoácido presente no feijão é a lisina, que, juntamente com o aminoácido metionina presente no arroz, gera uma proteína de boa qualidade semelhante à proteína da carne.

A lactose é o açúcar encontrado no leite. A intolerância à lactose, segundo Téo (2002), é uma inabilidade para digerir completamente a lactose, causada pela deficiência de fabricação da enzima lactase pelo corpo humano. Como consequência, o intestino não consegue digerir a lactose que passa pelo cólon, sendo fermentada por bactérias, havendo produção de ácidos orgânicos de cadeia curta e gases. Isso resulta em cólicas, flatulência, dor e diarreia osmótica. Freitas (2016) explica que enquanto a intolerância é um problema digestivo, a alergia ao leite é uma reação desencadeada pelo sistema imunológico a uma ou mais proteínas do leite, como a caseína. Os principais sintomas da alergia à proteína do leite de vaca se concentram nos sistemas digestório e respiratório, além de alterações na pele e perda de peso.

Os extratos vegetais podem substituir o leite de vaca sem excluir da dieta os nutrientes que ele apresenta. 0 condensado de arroz foi elaborado a partir de um extrato de arroz adicionado de açúcar, como forma de substituição ao leite condensado tradicionalmente usado para a elaboração do brigadeiro. 0 alimento, antes apenas considerado uma fonte de nutrientes fundamentais à manutenção da vida, se tornou instrumento de estudos que o associam às precauções com relação às doenças e melhoria das atividades de órgãos e tecidos (JENNRICH, 2017).

0 objetivo do estudo foi desenvolver um brigadeiro tendo como principais ingredientes o arroz branco (Oryza sativa L.) e o feijão preto (Phaseolus vulgaris L.), dois ingredientes muito consumidos pelos brasileiros e que apresente vantagens nutricionais, sem o acréscimo de leite em seu preparo, fazendo com que ele possa ser consumido por pessoas que possuem dietas restritivas a lactose, além de poder ser consumido no período entre as refeições.

\section{MATERIAIS E MÉTODOS}

Toda a pesquisa foi realizada na Unisinos, campus São Leopoldo, durante o segundo semestre de 2017. Na mini-usina de cereais do curso de Engenharia de Alimentos, desidratou-se a pasta de feijão para a elaboração do DOCE. Já nos laboratórios do curso de Gastronomia, foram testados os insumos que fazem parte do brigadeiro - arroz branco (Oryza sativa L.), feijão preto (Phaseolus vulgaris L.) e cacau 100\% -, o tempo de cozimento dos ingredientes e a proporção adequada para o resultado final. Ao todo, foram realizados quatro testes práticos com proporções de ingredientes diferentes, a fim de identificar a formulação que ficasse mais parecida quanto ao sabor e textura com o brigadeiro convencional.

0 processo de elaboração do brigadeiro deu-se em três etapas, conforme mostra o fluxograma da Figura 1. 
Figura 1 - Fluxograma de processo de elaboração do brigadeiro de arroz e feijão

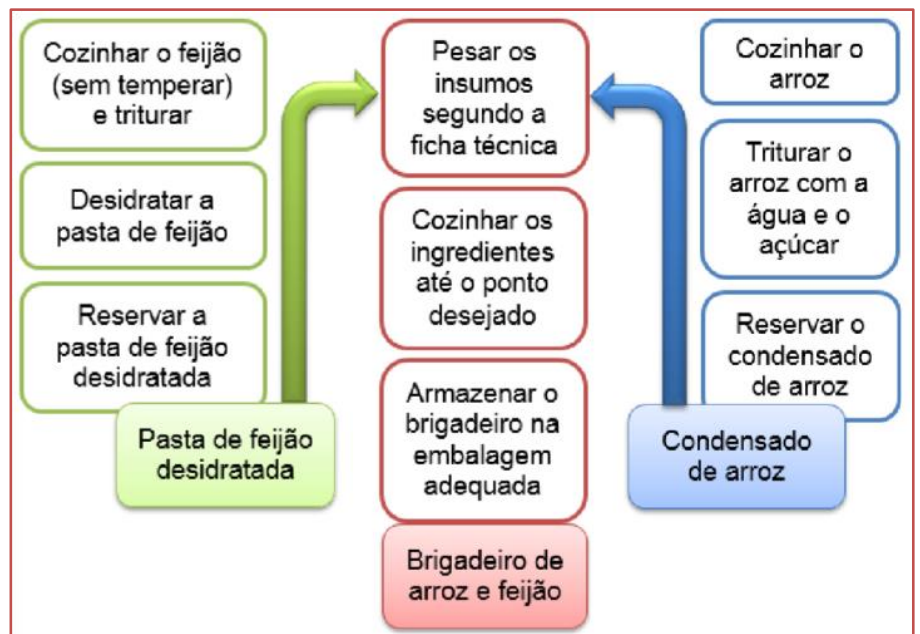

Fonte: Elaborado pela autora

0 primeiro processo realizado foi a pasta de feijão desidratada. 0 feijão foi limpo e cozido em água, sem o acréscimo de sal ou tempero, por 20 min em panela de pressão. A seguir, foi processado junto com parte da água do cozimento e colocado para desidratar, com temperatura controlada em torno de $40^{\circ} \mathrm{C}$, até obter uma pasta com mínima umidade. Antes de utilizada, a pasta foi processada novamente até virar uma farinha fina. $\mathrm{O}$ segundo processo a ser feito foi a produção do extrato condensado de arroz. $\mathrm{O}$ arroz branco foi cozido em água, também sem acrescentar sal ou tempero, por 23 min. Após cozido, o arroz foi processado com o restante da água do cozimento até virar uma pasta lisa. Em seguida, foi acrescentado o açúcar, novamente processado, e ao final, resfriado. Por fim, o terceiro processo consiste em separar todos os insumos de acordo com a receita final do brigadeiro, conforme a Tabela 1.

Tabela 1 - Descrição dos insumos e quantidades utilizadas no brigadeiro de arroz e feijão

\begin{tabular}{|c|c|}
\hline \multicolumn{2}{|c|}{ Ingredientes } \\
\hline Ingredientes & Percentual \\
\hline Pasta de feijão desidratada & $25 \%$ \\
\hline Condensado de arroz & $70 \%$ \\
\hline Cacau em pó & $5 \%$ \\
\hline \multicolumn{2}{|c|}{ Fonte: elaborada pela autora } \\
\hline
\end{tabular}

Em seguida, levado ao fogo e cozido em fogo baixo até o ponto desejado. Após frio, foram separadas porções de cerca de 10g, onde as mesmas foram moldadas e passadas no feijão desidratado. As amostras foram utilizadas para as análises físico químicas e a avaliação sensorial do brigadeiro.

Nos laboratórios de Química da instituição foram realizadas as determinações de umidade, atividade de água, sólidos solúveis totais, cinzas e pH segundo método descrito por AOAC (1995). No laboratório de análise sensorial do curso de Gastronomia foi aplicado o teste ADQ Análise Descritiva Quantitativa em sessão única com vinte alunos do curso de Gastronomia de ambos os sexos, painelistas não treinados, utilizando uma escala quantitativa, crescente, de 5 pontos, sendo (1) ruim; (2) regular; (3) bom; (4) muito bom; (5) ótimo e os atributos qualitativos do brigadeiro, como a cor, o odor, o sabor e a textura. Uma unidade de brigadeiro, cerca de $10 \mathrm{~g}$, foi servida na temperatura usual de consumo (temperatura ambiente) em recipientes plásticos codificados, acompanhados de copo com água mineral.

Com o propósito de avaliar a intenção de compra do brigadeiro de arroz e feijão para com o consumidor final, realizou-se uma pesquisa de mercado on-line com 87 participantes, de ambos os sexos, contendo entre 15 e 70 anos, onde os mesmos responderam a nove perguntas elaboradas pela autora. 


\section{RESULTADOS E DISCUSSÃO}

Os resultados da determinação de umidade, atividade de água, sólidos solúveis totais, quantidade de cinzas e pH do produto, podem ser observados na Tabela 2.

Tabela 2 - Resultados das análises químicas

\begin{tabular}{|c|c|}
\hline Item analisado & Resultado \\
\hline Umidade & $54,89 \%$ \\
\hline Atividade de água & 0,9557 \\
\hline Sólidos solúveis totais & $50,3^{\circ}$ \\
\hline Cinzas & $0,56 \%$ \\
\hline $\mathrm{pH}$ & 6,80 \\
\hline
\end{tabular}

0 resultado de $54,89 \%$ de umidade tem relação com a alta atividade de água encontrada, tornando o brigadeiro, conforme esperado, um doce de consumo imediato. Para o aumento de sua vida útil sugere-se conservação em ambiente refrigerado ou adição de conservantes, pois é um alimento propício ao desenvolvimento de microrganismos patogênicos. 0 valor de sólidos solúveis totais, indicador da quantidade de açúcar, revelou-se inferior ao proposto para um leite condensado, normalmente de $52^{\circ}$ a 68 . Observou-se que o produto apresenta $0,56 \%$ de matéria inorgânica, enquanto um brigadeiro normalmente apresenta 1,04\%, e pH praticamente neutro, equivalendo-se ao $\mathrm{pH}$ do leite (GAVA; SILVA; FRIAS, 2008).

De acordo com a Figura 2, o critério cor teve uma média de 3,75 pontos, enquanto o odor, o sabor e a textura obtiveram 3,80, 3,25 e 2,95 pontos, respectivamente. As observações apontadas pelos avaliadores sugerem modificações quanto à textura do produto, uma vez que consideram a textura quebradiça e mais densa para um brigadeiro, sendo o critério que obteve uma média menor.

Figura 2 - Gráfico dos resultados da avaliação sensorial

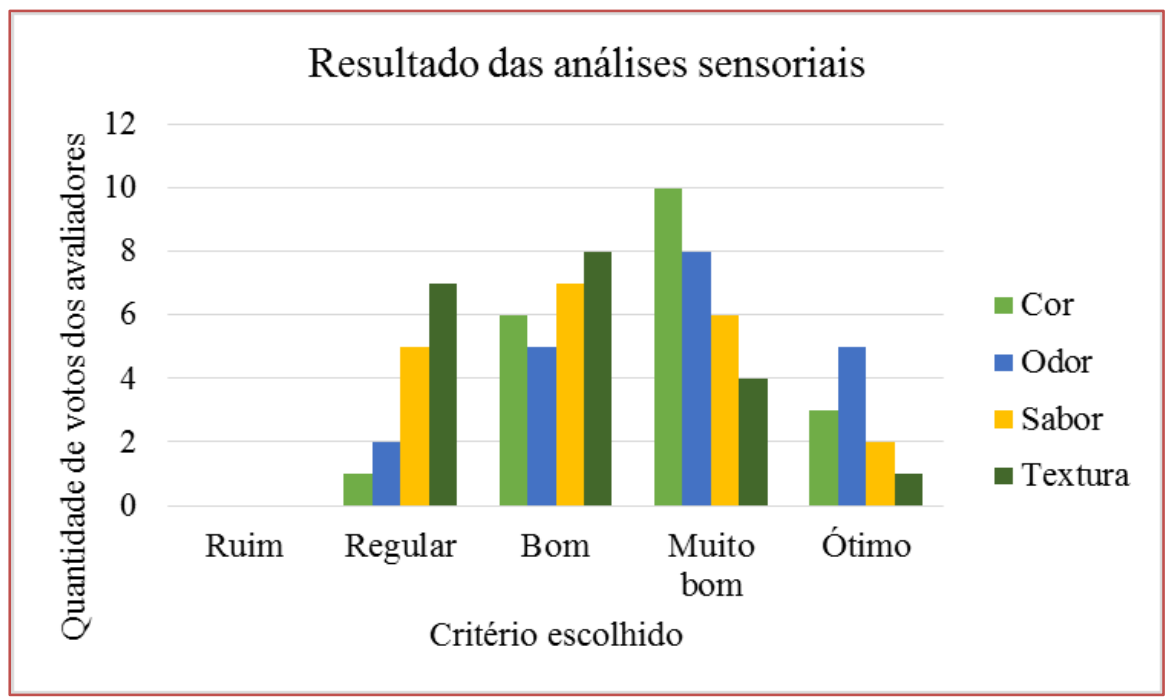

Fonte: elaborada pela autora

Os resultados da pesquisa de mercado estão expressos através das Figuras 3 e 4, onde 13,8\% dos entrevistados apresentaram algum tipo de intolerância alimentar, sendo a restrição ao leite a principal delas. Outra informação relevante foi que apenas $9 \%$ dos entrevistados não gostaria de experimentar o 
produto, um percentual extremamente baixo. Conforme Dutcosky (1996), o percentual de aceitação acima de $70 \%$ indica que o produto tem potencial mercadológico.

Figura 3 - Pesquisa de mercado: restrição alimentar e interesse no consumo
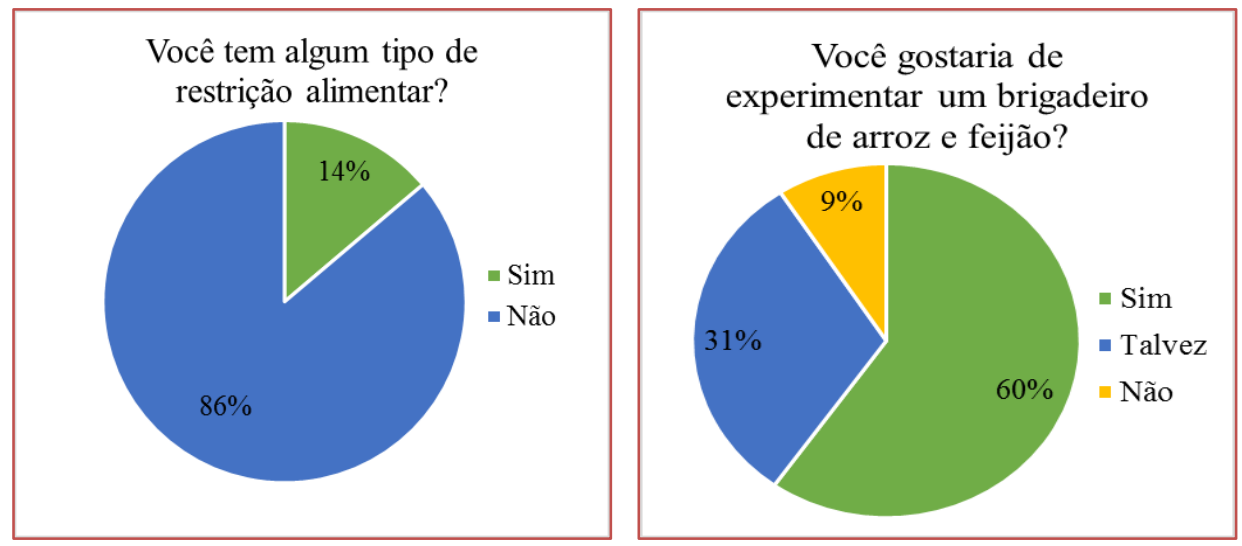

Fonte: elaborada pela autora

Figura 4 - Gráfico dos resultados da pesquisa de mercado

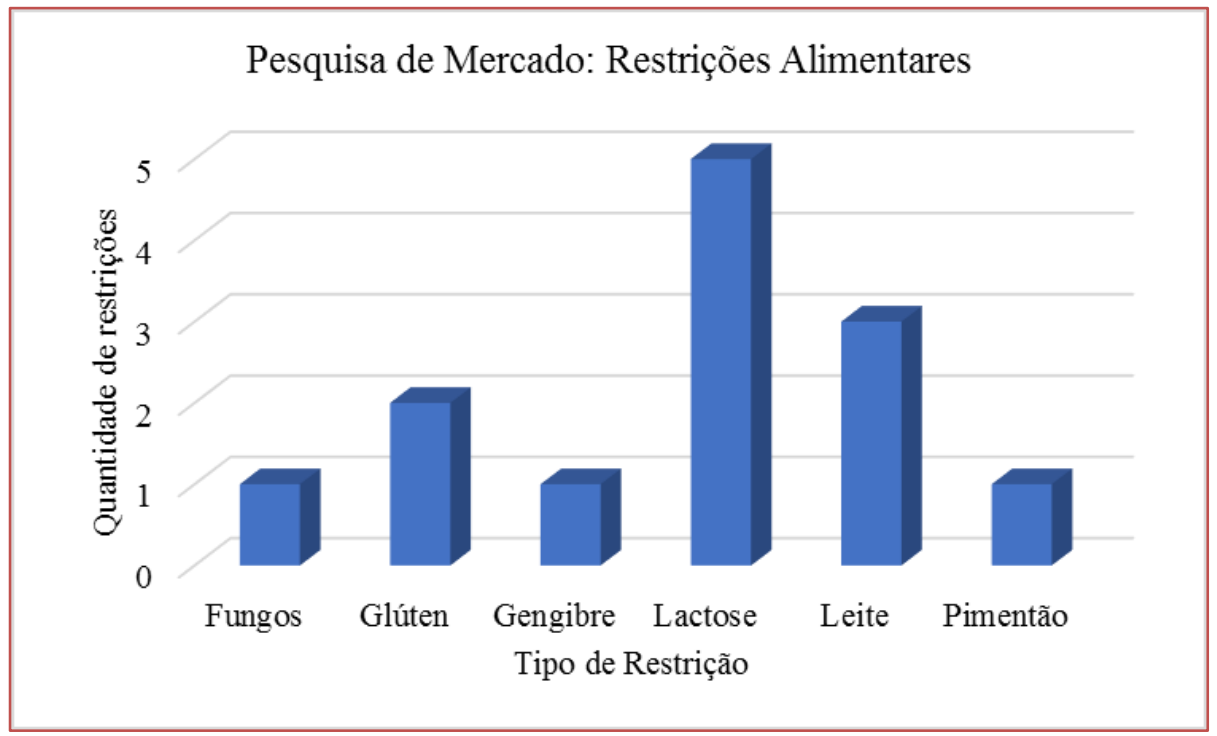

Fonte: elaborada pela autora

Com o propósito de oferecer o brigadeiro de arroz e feijão ao mercado consumidor, cumprindo com as exigências pré-estabelecidas para os rótulos de alimentos, desenvolveu-se a tabela nutricional teórica tendo como base as informações fornecidas pela Tabela Brasileira de Composição de Alimentos (TACO, 2011), para cada insumo utilizado na formulação do brigadeiro desenvolvido. Comparando o brigadeiro desenvolvido com um brigadeiro encontrado no mercado, como pode ser observado na Figura 5, este apresenta valor energético menor, além de menores quantidades de carboidratos, gorduras totais e sódio. Em contrapartida, o brigadeiro desenvolvido apresenta mais fibras em sua composição. 
Figura 5 - Comparação Informação Nutricional do brigadeiro de arroz e feijão e concorrente

\begin{tabular}{|c|c|c|}
\hline \multicolumn{3}{|c|}{ INFORMAÇÁO NUTRICIONAL } \\
\hline \multirow{2}{*}{ Porção de } & $20 \mathrm{~g}$ (colher/so & \\
\hline & Quantidade por porção & $\% \mathrm{VD}\left({ }^{*}\right)$ \\
\hline Valor Energético & $54 \mathrm{kcal}=227 \mathrm{~kJ}$ & $3 \%$ \\
\hline Carboidratos & $13 \mathrm{~g}$ & $4 \%$ \\
\hline Proteínas & $0,3 \mathrm{~g}$ & $0 \%$ \\
\hline Gorduras Totais & $0,1 \mathrm{~g}$ & $0 \%$ \\
\hline Gorduras Saturadas & $0 \mathrm{~g}$ & $0 \%$ \\
\hline Gorduras Trans & $0 \mathrm{~g}$ & $0 \%$ \\
\hline Fibra Alimentar & $0,4 \mathrm{~g}$ & $2 \%$ \\
\hline Sódio & $1,5 \mathrm{mg}$ & $0 \%$ \\
\hline
\end{tabular}

Fonte: Elaborada pela autora

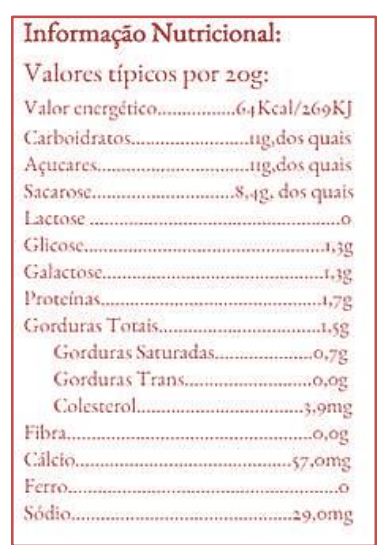

Fonte: Doces São Lourenço

\section{CONCLUSÕES}

Ao final do desenvolvimento da pesquisa obteve-se sucesso quanto à elaboração do produto, uma vez que o brigadeiro de arroz e feijão apresentou maiores vantagens nutricionais se comparado a um brigadeiro convencional - menor valor energético, menor taxa de carboidratos, gordura e de sódio e maior percentual de fibras - e pode ser consumido por pessoas que tenham uma dieta com restrição a lactose. Além disso, teve excelente aceitabilidade na avaliação sensorial, embora, sua textura possa ser melhorada para que fique mais úmido e macio, segundo sugestões registradas pelos painelistas, e despertou o interesse de mais de $90 \%$ dos entrevistados na pesquisa de mercado.

\section{REFERÊNCIAS}

[1] AOAC (1995). Association of Official Analystical Chemists. Official Methods of Analysis of the AOAC International. 16th ed. Washington: AOAC.

[2] DUTCOSKY, S.D. Análise sensorial de alimentos. Curitiba: Champagnat, 1996, 123.

[3] FREITAS, Karina. Intolerância à lactose - causas e consequências. Disponível em:

[4] http://vitalitecentromedico.com.br/intolerancia-lactose/

[5] GAVA, A. J.; SILVA, C. A. B.; FRIAS, J. R. G. Tecnologia de alimentos: princípios e aplicações.

[6] São Paulo: Nobel, 2008.

[7] JENNRICH, Jênifer. Elaboração, aceitabilidade e valor nutricional de massas de brigadeiro isentas de lactose, produzidas a partir de vegetais. Disponível em:

[8] https://univates.br/bdu/bitstream/10737/1662/1/2017JeniferJennrich.PDF.

[9] Resolução - CNNPA no 12, de 1978. Disponível em:

[10] http://www.anvisa.gov.br/anvisalegis/resol/12_78.pdf. Acesso em 07 set. 2017.

[11] Tabela brasileira de composição de alimentos / NEPA - UNICAMP. - 4. ed. rev. e ampl.. -- Campinas: NEPAUNICAMP, 2011.

[12] TÉO, Carla R. P. A. Intolerância à lactose: uma breve revisão para o cuidado nutricional. Arquivos de Ciências da Saúde da Unipar, Umuarama - PR, v. 6, n. 3, p. 135 - 140, set. - dez. 2002. VANESSA, Jéssica. Conheça os nutrientes do Feijão e seus benefícios para a saúde. Disponível em: https://www.remedio-caseiro.com/conheca-os-nutrientesdo-feijao-e-seus-beneficios-para-saude/. WEBER, Jéssica Muniz. Arroz: características químicas, culinárias e nutricionais das diferentes variedades consumidas no Brasil. Disponível em: http://bdm.unb.br/bitstream/10483/6333/1/2012_JessicaMunizWeber.pdf. 


\section{Capítulo 18}

Avaliação da rotulagem de bebidas não alcoólicas de uva comercializados em Imperatriz-MA

\section{Helen Costa Silva}

Leonardo Hunaldo Santos

Andresa Sousa Carvalho

Victor Veríssimo Cardoso Lima

Lara Lima Seccádio

Vitória Virgínia Soares Azevedo

Virlane Kelly Lima Hunaldo

Resumo: No Brasil, há diferentes tipos de bebidas de frutas, podendo citar o suco e o néctar, que, de acordo com a legislação brasileira diferem entre si na quantidade de polpa de fruta. $\mathrm{O}$ objetivo do presente trabalho foi analisar diferentes marcas comerciais de bebidas não alcoólicas de uva. 0 estudo foi realizado com vinte e uma amostras de bebida de uva de diferentes marcas, sendo onze "suco integral", três "concentrado líquido" e seis "néctar, as quais foram obtidas em supermercados da cidade de Imperatriz, Maranhão. Foram realizadas análises da rotulagem com base nas legislações vigentes. Apesar de 14\% das amostras não apresentarem a denominação de venda do produto, 19\% não declararem a adição dos aditivos e 29\% não conter a declaração da quantidade de polpa, pode-se afirmar que de um modo geral, os parâmetros analisados estão de acordo com o exigido pela legislação brasileira quanto à rotulagem, principalmente rotulagem nutricional.

Palavras-Chave: rótulo; legislação; suco. 


\section{INTRODUÇÃO}

Segundo Suss (2015) apesar da crise economia Brasileira, o mercado de alimentação saudável apresenta um movimento inverso em um período de prosperidade. As vendas dos produtos com apelo saudável tiveram um crescimento de $98 \%$ no Brasil entre 2009 e 2014, sendo que $28 \%$ dos Brasileiros consideram o valor nutricional o mais importante na hora de consumir um produto, enquanto $22 \%$ dá preferência a alimentos naturais e sem conservantes.

Os derivados não alcoólicos da uva são muito antigos, e só passou a ser conservado sob a forma integral, após os estudos de Louis Pasteur, que identificou a natureza biológica das fermentações (Marzarotto, 2010). No Brasil, há diferentes tipos de bebidas de frutas, dentre elas pode-se citar o suco e o néctar, que, de acordo com a legislação brasileira diferem entre si na quantidade de polpa de fruta que é adicionada em cada formulação, sendo o néctar a bebida com menor proporção de polpa de fruta. Segundo o Decreto no 6.871, de 4 de junho de 2009, suco é a bebida não fermentada, não concentrada, e não diluída, destinada ao consumo, obtida da fruta madura e sã. E néctar é a bebida não fermentada, obtida da diluição em água potável da parte comestível ou extrato do vegetal, adicionado de açúcares, destinada ao consumo direto.

Os rótulos são elementos essenciais de comunicação entre produtos e consumidores, devem declarar informações de forma clara e verdadeira a fim de evitar decisões ou conclusões equivocadas. Os elementos descritos precisam ser confiáveis, atualizados e mais completo possível, conforme a regulamentação vigente, possibilitando comparações entre os diferentes produtos.

Dessa forma, o presente trabalho teve como objetivo analisar diferentes marcas comerciais de bebidas não alcoólicas de uva comercializados na cidade de Imperatriz, Maranhão quanto às características de rotulagem.

\section{MATERIAL E MÉTODOS}

Foram analisadas vinte e uma amostras de bebida não fermentada de uva de diferentes marcas, sendo onze "suco integral" (Marcas comerciais numeradas de 1 a 12), três "concentrado líquido para refresco" (Marcas comerciais numeradas de 13 e 15) e seis "néctar" (Marcas comerciais numeradas de 16 a 21), envasadas em embalagens de vidro (13 marcas), cartonadas ( 7 marcas) e plástico (1 marca) de diferentes volumes e armazenadas à temperatura ambiente $\left(22^{\circ} \mathrm{C}\right)$. Todas as amostras analisadas foram obtidas em supermercados da cidade de Imperatriz, Maranhão. Foi realizada a verificação da rotulagem. Para a análise elaborou-se tabelas a fim de facilitar a comparação das informações contidas nos rótulos dos produtos com as estabelecidas pelas legislações vigentes: Portaria no 157/2002 (Brasil, 2002) do INMETRO sobre metrologia para produtos pré medidos; Instrução Normativa no 12/2003 (Brasil, 2003) que estabelece o regulamento técnico para Fixação dos Padrões de Identidade e Qualidade Gerais para Suco Tropical e Instrução Normativa no 55/2002 (BRASIL, 2002), que fixa os critérios para indicação da denominação do produto na rotulagem de bebidas, vinhos, derivados da uva e do vinho e vinagres do Ministério da Agricultura Pecuária e Abastecimento do Ministério da Agricultura Pecuária e Abastecimento - MAPA; RDC no 259/2002 (Brasil, 2002), que regulamenta a rotulagem de alimentos embalados; RDC no 360/2003 (Brasil, 2003) (regulamenta a rotulagem nutricional de alimentos embalados); RDC no 359/2003 (Brasil, 2003), que regulamenta as porções de alimentos embalados para fins de rotulagem nutricional; e Portaria no 540/1997 (Brasil, 1997), que regulamenta a classificação e emprego dos aditivos alimentares ambos da Secretária de Vigilância Sanitária do Ministério da Saúde.

\section{RESULTADOS E DISCUSSÃO}

Na Tabela 1 encontram-se os resultados referentes à apresentação e distribuição das informaç̧ões obrigatórias: denominação de venda do alimento, lista de ingredientes, conteúdo líquido, identificação da origem, identificação do lote, data de validade e instruções para o preparo e uso do alimento, quando apropriado. 
Tabela 1 - Identificação das amostras e itens obrigatórios da rotulagem segundo a RDC n²59/2002, Portaria $n^{\circ}$ 540/ 1997 da ANVISA e Portaria $n^{\circ}$ 157/2002 do INMETRO.

\begin{tabular}{|c|c|c|c|c|c|c|c|c|c|c|c|}
\hline 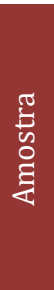 & 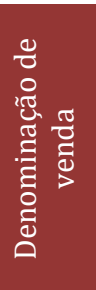 & 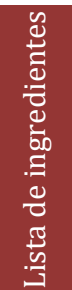 & 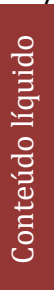 & 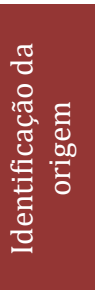 & 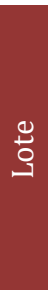 & 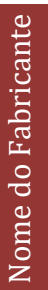 & 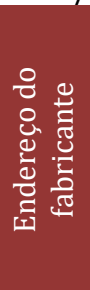 & \begin{tabular}{l}
0 \\
$\frac{0}{\pi}$ \\
$\frac{\pi}{0}$ \\
$\frac{0}{0}$ \\
0 \\
0 \\
0 \\
0 \\
\multirow{0}{0}{} \\
0
\end{tabular} & 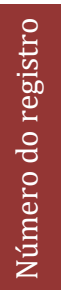 & 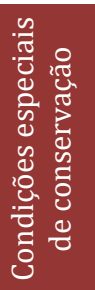 & 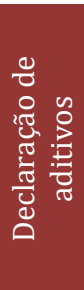 \\
\hline 1 & $\mathrm{C}$ & $\mathrm{C}$ & $\mathrm{C}$ & $\mathrm{C}$ & $\mathrm{C}$ & $\mathrm{C}$ & C & $\mathrm{C}$ & $\mathrm{C}$ & C & $\mathrm{C}$ \\
\hline 2 & $\mathrm{C}$ & $\mathrm{C}$ & $\mathrm{C}$ & $\mathrm{C}$ & $\mathrm{C}$ & $\mathrm{C}$ & C & $\mathrm{C}$ & $\mathrm{C}$ & $\mathrm{C}$ & $\mathrm{C}$ \\
\hline 3 & $\mathrm{C}$ & $\mathrm{C}$ & $\mathrm{C}$ & $\mathrm{C}$ & $\mathrm{C}$ & $\mathrm{C}$ & $\mathrm{C}$ & $\mathrm{C}$ & $\mathrm{C}$ & $\mathrm{C}$ & $\mathrm{NC}$ \\
\hline 4 & $\mathrm{C}$ & $\mathrm{C}$ & $\mathrm{C}$ & $\mathrm{C}$ & $\mathrm{C}$ & $\mathrm{C}$ & $\mathrm{C}$ & $\mathrm{C}$ & $\mathrm{C}$ & $\mathrm{C}$ & $\mathrm{NC}$ \\
\hline 5 & $\mathrm{C}$ & $\mathrm{C}$ & $\mathrm{C}$ & $\mathrm{C}$ & $\mathrm{C}$ & $\mathrm{C}$ & C & $\mathrm{C}$ & $\mathrm{C}$ & $\mathrm{C}$ & $\mathrm{NC}$ \\
\hline 6 & C & C & C & $\mathrm{C}$ & $\mathrm{C}$ & $\mathrm{C}$ & $\mathrm{C}$ & $\mathrm{C}$ & $\mathrm{C}$ & $\mathrm{C}$ & $\mathrm{C}$ \\
\hline 7 & $\mathrm{C}$ & $\mathrm{C}$ & $\mathrm{C}$ & $\mathrm{C}$ & $\mathrm{C}$ & $\mathrm{C}$ & $\mathrm{C}$ & $\mathrm{C}$ & $\mathrm{C}$ & $\mathrm{C}$ & $\mathrm{C}$ \\
\hline 8 & $\mathrm{C}$ & $\mathrm{C}$ & $\mathrm{C}$ & $\mathrm{C}$ & $\mathrm{C}$ & $\mathrm{C}$ & $\mathrm{C}$ & $\mathrm{C}$ & $\mathrm{C}$ & $\mathrm{C}$ & $\mathrm{C}$ \\
\hline 9 & C & C & C & C & C & C & C & C & $\mathrm{C}$ & C & C \\
\hline 10 & C & $\mathrm{C}$ & $\mathrm{C}$ & $\mathrm{C}$ & $\mathrm{C}$ & $\mathrm{C}$ & $\mathrm{C}$ & $\mathrm{C}$ & $\mathrm{NC}$ & $\mathrm{C}$ & $\mathrm{C}$ \\
\hline 11 & $\mathrm{C}$ & NC & $\mathrm{C}$ & $\mathrm{C}$ & $\mathrm{C}$ & $\mathrm{C}$ & $\mathrm{C}$ & $\mathrm{C}$ & $\mathrm{C}$ & $\mathrm{C}$ & $\mathrm{C}$ \\
\hline 12 & $\mathrm{NC}$ & $\mathrm{C}$ & C & $\mathrm{C}$ & $\mathrm{C}$ & C & C & C & $\mathrm{C}$ & $\mathrm{C}$ & $\mathrm{C}$ \\
\hline 13 & $\mathrm{NC}$ & $\mathrm{C}$ & $\mathrm{C}$ & $\mathrm{C}$ & $\mathrm{C}$ & $\mathrm{C}$ & $\mathrm{C}$ & $\mathrm{C}$ & $\mathrm{C}$ & $\mathrm{C}$ & $\mathrm{C}$ \\
\hline 14 & NC & $\mathrm{C}$ & $\mathrm{C}$ & $\mathrm{C}$ & $\mathrm{C}$ & $\mathrm{C}$ & $\mathrm{C}$ & $\mathrm{C}$ & $\mathrm{C}$ & $\mathrm{C}$ & $\mathrm{C}$ \\
\hline 15 & $\mathrm{C}$ & C & C & C & C & $\mathrm{C}$ & C & C & C & $\mathrm{C}$ & $\mathrm{C}$ \\
\hline 16 & $\mathrm{C}$ & $\mathrm{C}$ & $\mathrm{C}$ & $\mathrm{C}$ & $\mathrm{C}$ & $\mathrm{C}$ & $\mathrm{C}$ & $\mathrm{C}$ & $\mathrm{C}$ & $\mathrm{C}$ & $\mathrm{C}$ \\
\hline 17 & $\mathrm{C}$ & $\mathrm{C}$ & $\mathrm{C}$ & $\mathrm{C}$ & $\mathrm{C}$ & $\mathrm{C}$ & $\mathrm{C}$ & $\mathrm{C}$ & $\mathrm{C}$ & $\mathrm{C}$ & $\mathrm{C}$ \\
\hline 18 & C & $\mathrm{C}$ & $\mathrm{C}$ & $\mathrm{C}$ & $\mathrm{C}$ & $\mathrm{C}$ & $\mathrm{C}$ & $\mathrm{C}$ & $\mathrm{C}$ & $\mathrm{C}$ & $\mathrm{C}$ \\
\hline 19 & $\mathrm{C}$ & $\mathrm{C}$ & $\mathrm{C}$ & $\mathrm{C}$ & $\mathrm{C}$ & $\mathrm{C}$ & $\mathrm{C}$ & $\mathrm{C}$ & $\mathrm{C}$ & $\mathrm{C}$ & $\mathrm{C}$ \\
\hline 20 & $\mathrm{C}$ & $\mathrm{C}$ & $\mathrm{C}$ & $\mathrm{C}$ & $\mathrm{C}$ & C & $\mathrm{C}$ & $\mathrm{C}$ & $\mathrm{C}$ & $\mathrm{C}$ & $\mathrm{C}$ \\
\hline 21 & $\mathrm{C}$ & $\mathrm{C}$ & $\mathrm{C}$ & $\mathrm{C}$ & $\mathrm{C}$ & $\mathrm{C}$ & $\mathrm{C}$ & $\mathrm{C}$ & $\mathrm{C}$ & $\mathrm{C}$ & $\mathrm{C}$ \\
\hline
\end{tabular}

Fonte: Autores, 2016. Legenda: C - conforme; NC - não conforme; NA - não se aplica.

Observa-se que $14 \%$ das amostras não apresentaram a denominação de venda correta, estando em desacordo com a RDC no 259/2002 (Brasil, 2002), 5\% das amostras analisadas apresentaram inconformidade em relação a lista de ingredientes e número de registro do produto, no que se refere a adição de aditivos 19\% estão em discordância. Todas as amostras apresentaram as demais informações obrigatórias.

A denominação de venda refere-se ao nome específico e não genérico que indica a verdadeira natureza e as características do alimento e, quando é estabelecido por regulamento técnico com uma ou mais denominações para um alimento, deve ser utilizada uma dessas denominações. A legislação permite o uso de palavras ou frases adicionais, juntamente à denominação, que facilite a compreensão do consumidor quanto à natureza e as condições físicas próprias do alimento. 0 lote compreende o conjunto de produtos que foram processados em um espaço de tempo determinado, sob condições essencialmente iguais e por um mesmo fabricante ou fracionador. 0 mesmo deve ser informado por meio de código chave, precedido da letra "L" e facilita o rastreamento de produtos evitando danos ao consumidor (Brasil, 2002).

De acordo com a Portaria do INMETRO no 157/2002 (Brasil, 2002) os produtos pré-medidos, comercializados em unidades legais de volume, deve expressar o conteúdo líquido no seguinte formato gráfico: "CONTEÚDO" ou "Conteúdo" ou "Volume Líquido", com dimensões dos caracteres alfanuméricos com altura de $4 \mathrm{~mm}$ para embalagens envasadas com $200 \mathrm{~mL}$ até $1000 \mathrm{~mL}$. Tal informação é relevante para que o consumidor tenha o conhecimento de quanto está pagando por aquela quantidade.

Quanto às informações sobre conservação do produto verificou-se que todas as amostras estão em conformidade com a RDC nº 259/2002 (Brasil, 2002), mostrando os cuidados de temperatura e tempo, redigidos de forma legível. Esta informação garante a segurança do uso e/ou consumo do produto. 
A avaliação dos itens conforme as Instruções Normativas no 12/2003 (Brasil, 2003) e no 55/2002 (Brasil, 2002) para as bebidas não fermentadas de uva estão apresentadas na Tabela 2. Observa-se que $29 \%$ das amostras não possuem a declaração obrigatória quanto ao percentual mínimo, em peso, da polpa da respectiva fruta utilizada na elaboração do produto.

Tabela 2 - Avaliação de outras informações contida nos rótulos de néctar de uva conforme a Instrução Normativa ${ }^{\circ} 12 / 2003$ e Instrução Normativa $n^{\circ} 55 / 2002$.

\begin{tabular}{|c|c|c|c|}
\hline Amostra & $\begin{array}{c}\text { Declaração do } \\
\text { percentual mínimo } \\
\text { de polpa }\end{array}$ & $\begin{array}{l}\text { Tamanho da } \\
\text { fonte }\end{array}$ & $\begin{array}{c}\text { Declaração do } \\
\text { termo "adoçado" } \\
\text { / "pronto para } \\
\text { beber" }\end{array}$ \\
\hline 1 & $\mathrm{C}$ & $\mathrm{C}$ & NA \\
\hline 2 & $\mathrm{C}$ & $\mathrm{C}$ & NA \\
\hline 3 & $\mathrm{C}$ & $\mathrm{C}$ & NA \\
\hline 4 & $\mathrm{C}$ & $\mathrm{C}$ & NA \\
\hline 5 & $\mathrm{C}$ & $\mathrm{C}$ & $\mathrm{C}$ \\
\hline 6 & $\mathrm{C}$ & $\mathrm{C}$ & NA \\
\hline 7 & $\mathrm{C}$ & C & $\mathrm{C}$ \\
\hline 8 & $\mathrm{C}$ & $\mathrm{C}$ & NA \\
\hline 9 & $\mathrm{C}$ & $\mathrm{C}$ & NA \\
\hline 10 & $\mathrm{C}$ & $\mathrm{C}$ & $\mathrm{C}$ \\
\hline 11 & $\mathrm{C}$ & $\mathrm{C}$ & NA \\
\hline 12 & $\mathrm{C}$ & $\mathrm{C}$ & NA \\
\hline 13 & $\mathrm{NC}$ & $\mathrm{C}$ & NA \\
\hline 14 & $\mathrm{NC}$ & $\mathrm{C}$ & $\mathrm{C}$ \\
\hline 15 & $\mathrm{NC}$ & $\mathrm{C}$ & NA \\
\hline 16 & $\mathrm{NC}$ & $\mathrm{C}$ & $\mathrm{C}$ \\
\hline 17 & $\mathrm{NC}$ & $\mathrm{C}$ & $\mathrm{NC}$ \\
\hline 18 & $\mathrm{NC}$ & $\mathrm{C}$ & $\mathrm{NC}$ \\
\hline 19 & $\mathrm{C}$ & $\mathrm{C}$ & $\mathrm{NC}$ \\
\hline 20 & $\mathrm{C}$ & $\mathrm{C}$ & $\mathrm{C}$ \\
\hline 21 & $\mathrm{C}$ & $\mathrm{C}$ & $\mathrm{NC}$ \\
\hline
\end{tabular}

Fonte: Autores, 2016. Legenda: C - conforme; NC - não conforme; NA - não se aplica.

O néctar, por ser uma preparação adicionada de açúcar, pode alegar na sua rotulagem, a expressão "suco pronto para beber" ou expressões semelhantes. No presente trabalho, apenas 33\% dos néctares apresentaram esta expressão declarada no rótulo. Todas as amostras apresentaram-se em conformidade para o tamanho da letra da denominação do produto, no painel principal do rótulo, acima e ou no mínimo de $2 \mathrm{~mm}$.

Em todas as amostras a rotulagem nutricional, conforme mostra na Tabela 3, atendeu as exigências da legislação vigente, RDC no 360/2003 (Brasil, 2003), estando os nutrientes e respectivos valores apresentados nos modelos propostos pela mesma, prevalecendo o tipo "vertical B", exceto a amostra 4 que apresentou a tabela nutricional em uma conformação distinta dos modelos apresentados pela legislação. Poucos fabricantes dos sucos informaram valores referentes às vitaminas e aos minerais, sendo essa uma informação optativa. A informação "rico em vitamina C" foi observada em 83\% dos néctares (marcas 16 a 21). Os valores nutricionais estavam declarados em porção do alimento e em medida caseira definida pela RDC no 359/2003 da ANVISA (Brasil, 2003), comumente: “200 mL/ 1 copo”. 
Tabela 3 - Análise da rotulagem nutricional conforme a RDC nº 359/2003 e Portaria n³60/1997.

\begin{tabular}{|c|c|c|c|c|c|c|c|c|}
\hline Amostra & $\begin{array}{c}\text { Valor } \\
\text { energético } \\
\text { (kcal) }\end{array}$ & $\begin{array}{c}\text { Carboidratos } \\
\text { (g) }\end{array}$ & $\begin{array}{l}\text { Proteínas } \\
\text { (g) }\end{array}$ & $\begin{array}{l}\text { Gorduras } \\
\text { totais }(\mathrm{g})\end{array}$ & $\begin{array}{l}\text { Gordura } \\
\text { trans } \\
\text { (g) }\end{array}$ & $\begin{array}{c}\text { Forma } \\
\text { da } \\
\text { tabela }\end{array}$ & $\begin{array}{c}\text { Informação } \\
\text { da medida } \\
\text { caseira }\end{array}$ & $\begin{array}{c}\text { Informação } \\
\text { nutricional } \\
\text { complementar }\end{array}$ \\
\hline 1 & $\mathrm{C}$ & $\mathrm{C}$ & $\mathrm{C}$ & C & $\mathrm{C}$ & $\mathrm{C}$ & $\mathrm{C}$ & $\mathrm{C}$ \\
\hline 2 & $\mathrm{C}$ & $\mathrm{C}$ & $\mathrm{C}$ & $\mathrm{C}$ & $\mathrm{C}$ & $\mathrm{C}$ & $\mathrm{C}$ & $\mathrm{C}$ \\
\hline 3 & $\mathrm{C}$ & $\mathrm{C}$ & $\mathrm{C}$ & $\mathrm{C}$ & $\mathrm{C}$ & $\mathrm{C}$ & $\mathrm{C}$ & $\mathrm{C}$ \\
\hline 4 & $\mathrm{C}$ & $\mathrm{C}$ & $\mathrm{C}$ & $\mathrm{C}$ & $\mathrm{C}$ & $\mathrm{C}$ & $\mathrm{NC}$ & $\mathrm{C}$ \\
\hline 5 & $\mathrm{C}$ & $\mathrm{C}$ & $\mathrm{C}$ & $\mathrm{C}$ & $\mathrm{C}$ & $\mathrm{C}$ & $\mathrm{C}$ & $\mathrm{C}$ \\
\hline 6 & $\mathrm{C}$ & $\mathrm{C}$ & $\mathrm{C}$ & $\mathrm{C}$ & $\mathrm{C}$ & $\mathrm{C}$ & $\mathrm{C}$ & $\mathrm{C}$ \\
\hline 7 & $\mathrm{C}$ & $\mathrm{C}$ & $\mathrm{C}$ & $\mathrm{C}$ & $\mathrm{C}$ & $\mathrm{C}$ & $\mathrm{C}$ & $\mathrm{C}$ \\
\hline 8 & $\mathrm{C}$ & $\mathrm{C}$ & $\mathrm{C}$ & $\mathrm{C}$ & $\mathrm{C}$ & $\mathrm{C}$ & $\mathrm{C}$ & $\mathrm{C}$ \\
\hline 9 & $\mathrm{C}$ & $\mathrm{C}$ & $\mathrm{C}$ & $\mathrm{C}$ & $\mathrm{C}$ & $\mathrm{C}$ & $\mathrm{C}$ & $\mathrm{C}$ \\
\hline 10 & $\mathrm{C}$ & $\mathrm{C}$ & $\mathrm{C}$ & $\mathrm{C}$ & $\mathrm{C}$ & $\mathrm{C}$ & $\mathrm{C}$ & $\mathrm{C}$ \\
\hline 11 & $\mathrm{C}$ & $\mathrm{C}$ & $\mathrm{C}$ & $\mathrm{C}$ & $\mathrm{C}$ & $\mathrm{C}$ & $\mathrm{C}$ & $\mathrm{C}$ \\
\hline 12 & $\mathrm{C}$ & $\mathrm{C}$ & $\mathrm{C}$ & $\mathrm{C}$ & $\mathrm{C}$ & $\mathrm{C}$ & $\mathrm{C}$ & $\mathrm{C}$ \\
\hline 13 & $\mathrm{C}$ & $\mathrm{C}$ & $\mathrm{C}$ & $\mathrm{C}$ & $\mathrm{C}$ & $\mathrm{C}$ & $\mathrm{C}$ & $\mathrm{C}$ \\
\hline 14 & $\mathrm{C}$ & $\mathrm{C}$ & $\mathrm{C}$ & $\mathrm{C}$ & $\mathrm{C}$ & C & $\mathrm{C}$ & $\mathrm{C}$ \\
\hline 15 & $\mathrm{C}$ & $\mathrm{C}$ & $\mathrm{C}$ & $\mathrm{C}$ & $\mathrm{C}$ & $\mathrm{C}$ & $\mathrm{C}$ & C \\
\hline 16 & $\mathrm{C}$ & $\mathrm{C}$ & $\mathrm{C}$ & $\mathrm{C}$ & $\mathrm{C}$ & $\mathrm{C}$ & $\mathrm{C}$ & $\mathrm{C}$ \\
\hline 17 & $\mathrm{C}$ & $\mathrm{C}$ & $\mathrm{C}$ & $\mathrm{C}$ & $\mathrm{C}$ & $\mathrm{C}$ & $\mathrm{C}$ & $\mathrm{C}$ \\
\hline 18 & $\mathrm{C}$ & $\mathrm{C}$ & $\mathrm{C}$ & $\mathrm{C}$ & $\mathrm{C}$ & $\mathrm{C}$ & $\mathrm{C}$ & $\mathrm{C}$ \\
\hline 19 & C & $\mathrm{C}$ & $\mathrm{C}$ & C & $\mathrm{C}$ & C & C & C \\
\hline 20 & $\mathrm{C}$ & $\mathrm{C}$ & $\mathrm{C}$ & C & $\mathrm{C}$ & C & C & C \\
\hline 21 & $\mathrm{C}$ & $\mathrm{C}$ & $\mathrm{C}$ & $\mathrm{C}$ & $\mathrm{C}$ & $\mathrm{C}$ & $\mathrm{C}$ & $\mathrm{C}$ \\
\hline
\end{tabular}

Fonte: Autores, 2016. Legenda: C - conforme; NC - não conforme

Em todos os sucos (100\% polpa) foi observada a adição do termo "sem adição de açúcar", e apenas um fez menção ao fato da obrigatoriedade para todo suco integral. A maioria das amostras fez menção ao método de tratamento acrescentando o termo "pasteurizado" a embalagem, uma pequena quantidade não acrescentou o tratamento nem a adição de aditivos. Apesar da maioria dos néctares mistos fazem a correta denominação de venda do alimento a embalagem causa confusão por apresentar apenas a figura e o destaque do nome da fruta uva induzindo o consumidor ao erro.

\section{CONCLUSÃO}

De maneira geral, as amostras analisadas estão de acordo com as exigências das legislações vigentes quanto às características de rotulagem. Precisando se adequarem principalmente no que se refere a declaração da quantidade de polpa, denominação de venda e declaração de aditivos.

\section{REFERÊNCIAS}

[1] Brasil, Instituto Nacional de Metrologia, Normalização e Qualidade Industrial (2002). Aprova o regulamento técnico metrológico, em anexo, estabelecendo a forma de expressar o conteúdo líquido a ser utilizado nos produtos pré-medidos (Portaria INMETRO n 157, de 19 de agosto de 2002). Diário Oficial da República Federativa do Brasil.

[2] Brasil, Ministério da Agricultura, Pecuária e Abastecimento (2003). Aprova o Regulamento Técnico para Fixação dos Padrões de Identidade e Qualidade Gerais para Suco Tropical; os Padrões de Identidade e Qualidade dos Sucos Tropicais de Abacaxi, Acerola, Cajá, Caju, Goiaba, Graviola, Mamão, Manga, Mangaba, Maracujá e Pitanga; e os Padrões de Identidade e Qualidade dos Néctares de Abacaxi, Acerola, Cajá, Caju, Goiaba, Graviola, Mamão, Manga, Maracujá, Pêssego e Pitanga (Instrução Normativa $n^{\circ}$ 12, de 04 de setembro de 2003). Diário Oficial da República Federativa do Brasil. 
[3] Brasil, Ministério da Agricultura, Pecuária e Abastecimento (2002). Aprova o regulamento técnico para fixação de critérios para indicação da denominação do produto na rotulagem de bebidas, vinhos, derivados da uva e do vinho e vinagres (Instrução Normativa $n^{\circ}$ 55, de 18 de outubro de 2002). Diário Oficial da República Federativa do Brasil.

[4] Brasil, Ministério da Saúde (1997). Aprova o regulamento técnico: aditivos alimentares - definições, classificação e emprego (Portaria ${ }^{\circ}$ 540, de 27 de outubro de 1997). Diário Oficial da República Federativa do Brasil.

[5] Brasil, Ministério da Saúde (2002). Aprova o regulamento técnico sobre rotulagem de alimentos embalados (Resolução RDC n² 259, de 20 de setembro de 2002). Diário Oficial da República Federativa do Brasil.

[6] Brasil, Ministério da Saúde (2003). Aprova o regulamento técnico de porções de alimentos embalados para fins de rotulagem nutricional (Resolução RDC nํ 359, de 23 de dezembro de 2003). Diário Oficial da República Federativa do Brasil.

[7] Brasil, Ministério da Saúde (2003). Aprova o regulamento técnico sobre rotulagem nutricional de alimentos embalados, tornando obrigatória a rotulagem nutricional (Resolução RDC n 360, de 23 de dezembro de 2003). Diário Oficial da República Federativa do Brasil.

[8] Brasil, Presidência da República (2009). Regulamenta a Lei no 8.918, de 14 de julho de 1994, que dispõe sobre a padronização, a classificação, o registro, a inspeção, a produção e a fiscalização de bebidas (Decreto no 6.871, de 4 de junho de 2009). Diário Oficial da República Federativa do Brasil. Marzarotto, V.

[9] Suss, L. (2015). Mercado saudável movimenta US\$ 35 bilhões por ano no Brasil. Gazeta do Povo. Disponível em http://www.gazetadopovo.com.br/economia/mercado-saudavel-movimenta-us-35-bilhoes-por-ano-no-Brasila2w7of1gwktt7ghup5wfo6z01 


\section{Capítulo 19}

Sistemas de reuso do efluente proveniente do destilador do laboratório de engenharia de alimentos da Universidade Estadual de Maringá

\section{Danielle Cristine Silveira \\ Lais Cristina de Lima Silva \\ Gisele Cristina dos Santos Bazanella}

Resumo: A água é um bem de grande relevância tanto no contexto social, econômico e ambiental, sendo fundamental para o desenvolvimento de qualquer sociedade. Estimase que, apenas, cerca de $0,5 \%$ da água disponível no mundo está apta ao consumo humano e ainda observa-se um aumento no desperdício de água, o que evidencia a necessidade de se buscar alternativas de reutilização. 0 presente trabalho teve como objetivos estudar a geração de efluente do equipamento de destilação do laboratório do curso de Engenharia de Alimentos da Universidade Estadual de Maringá, caracterizar parâmetros físico-químicos e microbiológicos deste efluente, quantificar a demanda de água potável do laboratório e propor sistemas de reuso. Os resultados mostraram um alto consumo de água no processo de destilação, alta geração de efluente e uma água residual de boa qualidade. Concluiu-se que o sistema 2 mostrou-se mais indicado, uma vez que exige menor recurso de investimento e apresenta maior facilidade de instalação.

Palavras-chave: Água, Desperdício, Gestão de água, Água residual, Sustentabilidade. 


\section{INTRODUÇÃO}

A água é um recurso essencial e de uso imperativo. É necessário na vida cotidiana e afeta o bem-estar de cada indivíduo (QIAN, 2018). 0 crescimento populacional, a urbanização e as mudanças climáticas, bem como o aumento dos padrões de vida, têm impactos muito semelhantes na disponibilidade e no acesso à água e à energia (SCHAUM; LENSCH e CORNEL, 2015).

Por vários anos, os Relatórios de Risco Global do Fórum Econômico Mundial identificaram a água como um dos três desafios mais importantes em todo o mundo. Em 2015, a água foi movida para o topo como o maior risco social e econômico para o mundo pelos próximos 10 anos. Enquanto o mundo como um todo possui abundantes recursos hídricos, disparidades espaciais e sazonalidade da água doce, agravada pela mudança climática, está emergindo como uma ameaça séria em muitas partes do mundo (ZHANG, 2016).

Estima-se que aproximadamente $0,5 \%$ da água disponível no mundo está apta para o consumo humano, sendo sua maior parte utilizada na agricultura (ANA et al., 2009). Além disso, independente do uso, ocorre um aumento no desperdício da água, o que evidencia a necessidade de se buscar alternativas de reutilização (PEIXINHO, 2010). Recursos através da reutilização de águas residuais é uma possível alternativa de disponibilidade de água. No entanto, a possibilidade de reutilização destas águas também implica em uma série de problemas de ordem técnica, econômica e aspectos sanitários que devem ser considerados adequadamente (MAIOLO e PANTUSA, 2018).

Neste sentido, a gestão sustentável da água é cada vez mais essencial em uma época caracterizada pelo rápido crescimento populacional, desenvolvimento urbano e industrial e mudanças climáticas (LIU; GIURCO; MUKHEIBIR, 2016). A gestão sustentável dos recursos hídricos requer a identificação de soluções para racionalizar e otimizar o uso dos recursos disponíveis, melhorando o nível de satisfação da demanda e reduzindo o impacto no meio ambiente (MAIOLO e PANTUSA, 2018).

Quando se fala em sustentabilidade, espera-se que as universidades sejam exemplos neste assunto, não somente no que diz respeito à educação, mas também na utilização de práticas que minimizem o desperdício, seja ele qual for (SOUSA; OLIVEIRA; COELHO, 2016).

A água destilada ou desmineralizada é essencial em laboratórios de práticas químicas e derivados e, em sua grande maioria, é obtida mediante o uso de destiladores contidos nos próprios laboratórios das instituições de ensino (MAIA, 2013).

Todo o sistema de destilação é alimentado por água proveniente do próprio sistema de abastecimento do laboratório e o equipamento é composto basicamente de uma cuba e uma resistência elétrica. A água é encaminhada até a cuba e aquecida pela resistência até sua temperatura de ebulição, em seguida é condensada e recolhida em um recipiente estéril externo ao equipamento. A água utilizada no sistema para condensar o vapor e resfriar o destilador é descartada no sistema de esgoto comum. 0 sistema é operado de forma manual, desde a vazão de alimentação até o acionamento da resistência, que só deve ser feito quando a cuba estiver completamente cheia, para não danificar o equipamento. De modo geral, cerca de $95,5 \%$ da água de alimentação é descartada no esgoto, ou seja, apenas 4,5 \% da água é desmineralizada (PINTO, CAPRI e NETO, 2015).

Dentro deste contexto, o objetivo do presente trabalho foi estudar a geração de efluente do equipamento de destilação e apresentar um sistema de reuso.

\section{MATERIAIS E MÉTODOS}

A pesquisa foi desenvolvida no laboratório de Engenharia de Alimentos da Universidade Estadual de Maringá, localizado no bloco 0-27. 0 equipamento analisado foi um destilador da marca Fisaton, modelo 670 , como mostra a figura 1. 
Figura 1 Destilador de água do laboratório de Engenharia de Alimentos

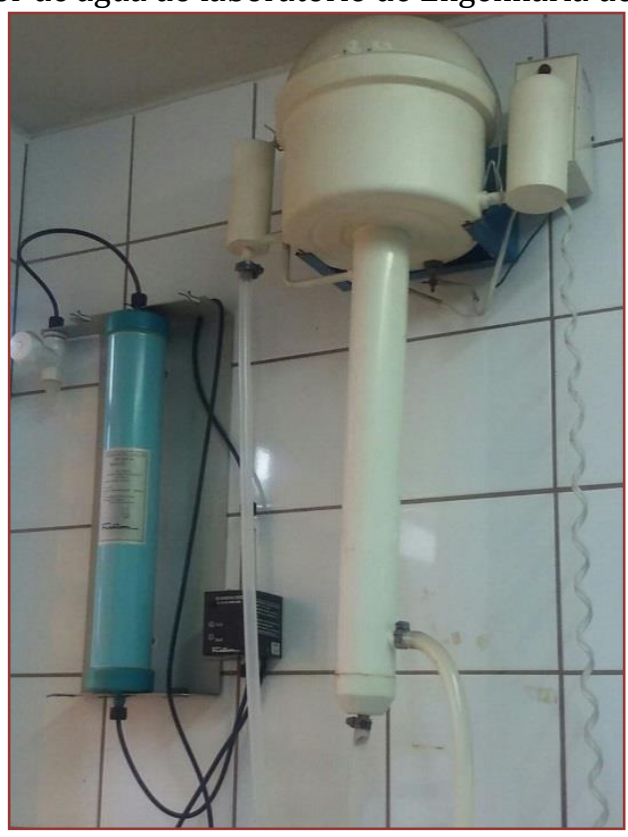

Foi feita a caracterização do destilador, a demanda de água potável do laboratório em um mês e a verificação da qualidade do efluente gerado durante o processo de destilação da água, através de análises físico-químicas e microbiológicas do mesmo.

\subsection{DADOS DE PROJETO}

\subsubsection{ESTIMATIVA DA GERAÇÃO DE EFLUENTE}

Foi determinado o volume de efluente gerado durante o processo de destilação da água, bem como, do volume de água destilada produzida e a frequência de utilização em um mês. Foram realizadas quatro coletas, com intervalos de 15 dias entre elas.

\subsubsection{ESTIMATIVA DO CONSUMO DE ÁGUA POTÁVEL}

Foi quantificado o consumo de água potável do laboratório durante seis dias, a fim de estimar o consumo de água potável do laboratório em um mês, no que diz respeito às descargas dos sanitários, bebedouros e torneiras do laboratório para uso geral, tais como, lavagens de vidrarias, utensílios e limpeza. Além disso, foi verificado o número de agentes consumidores das referidas instalações laboratoriais.

\subsection{3 ÍNDICE DE CONSUMO}

O índice de consumo diário de água foi calculado segundo Oliveira (1999) através da equação (1):

$$
I C=\frac{1000 C_{m}}{N A \cdot D_{m}}
$$

Em que, IC é o indicador de consumo (litros/agente consumidor*dia); $\mathrm{C}_{\mathrm{m}}$ é o consumo mensal $\left(\mathrm{m}^{3} / \mathrm{mês}\right.$ ); NA é o número de agentes consumidores e $\mathrm{D}_{\mathrm{m}}$ é a quantidade de dias úteis no referido mês. 


\subsubsection{SISTEMA HIDRÁULICO}

Foi feito um estudo das instalações hidráulicas do referido laboratório, a fim de propor uma adaptação do projeto para que o efluente gerado no processo de destilação da água passe a ser reaproveitado.

\subsubsection{DIMENSIONAMENTO DA BOMBA}

O dimensionamento da bomba foi feito segundo Soares (2010) e Çengel (2015).

\subsection{ANÁLISES MICROBIOLÓGICAS}

As avaliações microbiológicas foram realizadas através do método descrito pelo Standard Methods for de Examination of Water and Wastewater (APHA, 1998).

\subsubsection{DETERMINAÇÃO DO NÚMERO MAIS PROVÁVEL DE COLIFORMES TOTAIS}

O número mais provável de Coliformes totais foi determinado utilizando a técnica dos tubos múltiplos. Inoculou-se 1,0 mL de cada diluição em uma série de três tubos de caldo lauril sulfatotriptose e incubou-se a $35^{\circ} \mathrm{C}$ por $48 \mathrm{~h}$. A partir dos tubos com produção de gás transferiu-se, com bastão estéril, para tubos de caldo verde brilhante bile, reencubou-se por $24 \mathrm{~h}$.

\subsubsection{DETERMINAÇÃO DO NÚMERO MAIS PROVÁVEL DE COLIFORMES TERMOTOLERANTES}

0 número mais provável de Coliformes termotolerantes foi determinado utilizando a técnica dos tubos múltiplos. A partir dos tubos de lauril com produção de gás transferiu-se, com bastão estéril, para tubos contendo caldo EC (Escherichia coli), com incubação a $44,5^{\circ} \mathrm{C}$ durante $24 \mathrm{~h}$. A determinação do número mais provável de coliformes totais e termotolerantes foi realizada empregando-se a Tabela de Hoskins (ICMSF, 1978).

\subsubsection{PESQUISA DE ESCHERICHIA COLI}

A partir dos tubos contendo caldo EC que foram usados na quantificação de coliformes termotolerantes que apresentaram turvação, com ou sem gás no interior do tubo de Durham, semeou-se em placas de Petri contendo ágar eosina azul de metileno (teague). Os resultados foram avaliados observando o desenvolvimento de colônias típicas.

\subsection{ANÁLISES FÍSICO-QUÍMICAS}

$0 \mathrm{pH}$ e a condutividade foram determinados por pHmetro digital, da marca Analion, modelo PM 608. A temperatura foi determinada por bulbo seco. A massa de sólidos totais foi determinada através do método descrito pelo Instituto Adolfo Lutz (IAL, 2008). O cloro residual livre foi determinado através do método descrito pelo Standard Methods for the Examination of Water and Wastewater (APHA, 1998).

\section{RESULTADOS E DISCUSSÃO}

\subsection{DADOS DO PROJETO}

\subsubsection{ESTIMATIVA DA GERAÇÃO DE EFLUENTE}

A tabela 1 apresenta os dados coletados durante o processo de destilação da água, sendo eles o tempo de

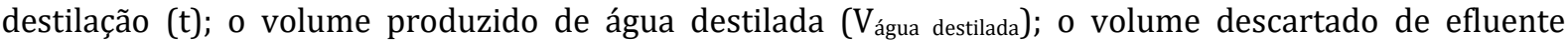
( $\left.V_{\text {efluente}}\right)$; a temperatura de descarte de efluente $\left(\mathrm{T}_{\text {efluente }}\right)$ e a razão de efluente descartado por litro de água destilada produzida (efluente/L(água_destilada)). 
Tabela 1 Dados coletados durante a operação de destilação de água

\begin{tabular}{|c|c|c|c|c|c|}
\hline Coleta & \multicolumn{1}{c}{$\mathrm{t}(\mathrm{h})$} & $\begin{array}{c}\text { Vágua } \\
\text { destilada } \\
\text { (L) }\end{array}$ & $\begin{array}{c}\text { Vefluente } \\
\text { (L) }\end{array}$ & $\begin{array}{c}\text { Tefluente } \\
\text { (0C) }\end{array}$ & \begin{tabular}{c} 
efluente \\
\hline 1
\end{tabular} \\
\hline 7,5 & 29 & 1514 & 35 & 52 \\
\hline 2 & 4,3 & 15 & 801 & 30 & 53 \\
\hline 3 & 8,0 & 30 & 1640 & 35 & 55 \\
\hline 4 & 6,5 & 25 & 1298 & 32 & 52 \\
\hline
\end{tabular}

Observa-se pela tabela 1 que para cada litro de água destilada produzida descarta-se cerca de $53 \mathrm{~L}$ de efluente, ou seja, despreza-se 53 vezes mais volume de efluente do que produz-se de água destilada. Neste caso, cerca de $98 \%$ da água de alimentação é descartada no esgoto. Ainda, nota-se que a temperatura de descarte do efluente está abaixo de $40{ }^{\circ} \mathrm{C}$, dentro do limite permitido pela Portaria no 2914/11 do Ministério da Saúde.

Marsaro e Guimarães (2007) quantificaram o desperdício de água, durante a produção de 1 L de água destilada, de dois destiladores, e obtiveram, respectivamente, $17 \mathrm{~L}$ e $21 \mathrm{~L}$ de água descartada para cada litro de água produzida. Comparado aos referidos autores, o destilador estudado gera maior volume de efluente por litro de água destilada.

\subsubsection{ESTIMATIVA DO CONSUMO DE ÁGUA POTÁVEL}

Os dados referentes ao consumo de água potável no laboratório em estudo estão dispostos na tabela 2.

Tabela 2 - Consumo de água do laboratório

\begin{tabular}{|c|c|c|c|c|}
\hline \multirow{2}{*}{ Coleta } & \multirow{2}{*}{$\begin{array}{c}\text { Agente } \\
\text { consumidor }\end{array}$} & \multicolumn{3}{|c|}{ Quantidade de água utilizada (L) } \\
\hline & & Banheiros & Bebedouros & Torneiras \\
\hline 1 & 5 & 30 & 0,28 & 78 \\
\hline 2 & 17 & 36 & 0,13 & 2131 \\
\hline 3 & 6 & 60 & 0,27 & 116 \\
\hline 4 & 4 & 30 & 0,27 & 124 \\
\hline 5 & 5 & 45 & 0,21 & 1750 \\
\hline 6 & 7 & 25 & 0,26 & 82 \\
\hline
\end{tabular}

Partindo-se dos dados apresentados na tabela 2 determinou-se o índice de consumo (IC) através da equação 1. Vale mencionar que o alto consumo de água nas torneiras, nos dias 2 e 5, se deu porque foi produzido água destilada nesses dias.

\subsection{3 ÍNDICE DE CONSUMO}

O IC foi calculado adotando-se a média semanal de consumo de água no laboratório, e posteriormente estimando-se o consumo mensal no período de Junho de 2017 a Julho de 2017. Assim, o IC foi de 2,34 L/agente consumidor*dia. Soares, Nunes e Silva (2017) apresentam um estudo do IC em várias regiões do Brasil e de outros países e obtiveram valores entre 4,5 e $134 \mathrm{~L} /$ agente consumidor*dia. 0 que indica que o consumo de água do laboratório pesquisado está abaixo destas regiões. 
Comparando o resultado do IC e a estimativa de geração de efluente no destilador; considerando que normalmente 4 vezes por mês ocorre a destilação da água, a fim de suprir a demanda de 120 L do laboratório, pode-se afirmar que o volume de efluente gerado é suficiente para suprir a demanda mensal de água do laboratório.

\subsubsection{SISTEMAS PROPOSTOS}

Foram estudadas duas propostas de projeto. Uma proposta é coletar o efluente, encaminhá-lo a uma cisterna de reaproveitamento, por gravidade, e depois, bombear essa água captada até um reservatório superior, de onde será distribuída aos pontos de consumo. A água de reuso deverá alimentar uma torneira (para ser utilizada em limpezas gerais) e dois vasos sanitários localizados no bloco. A figura 2 apresenta o esboço do projeto hidráulico.

Figura 2 Sistema 1

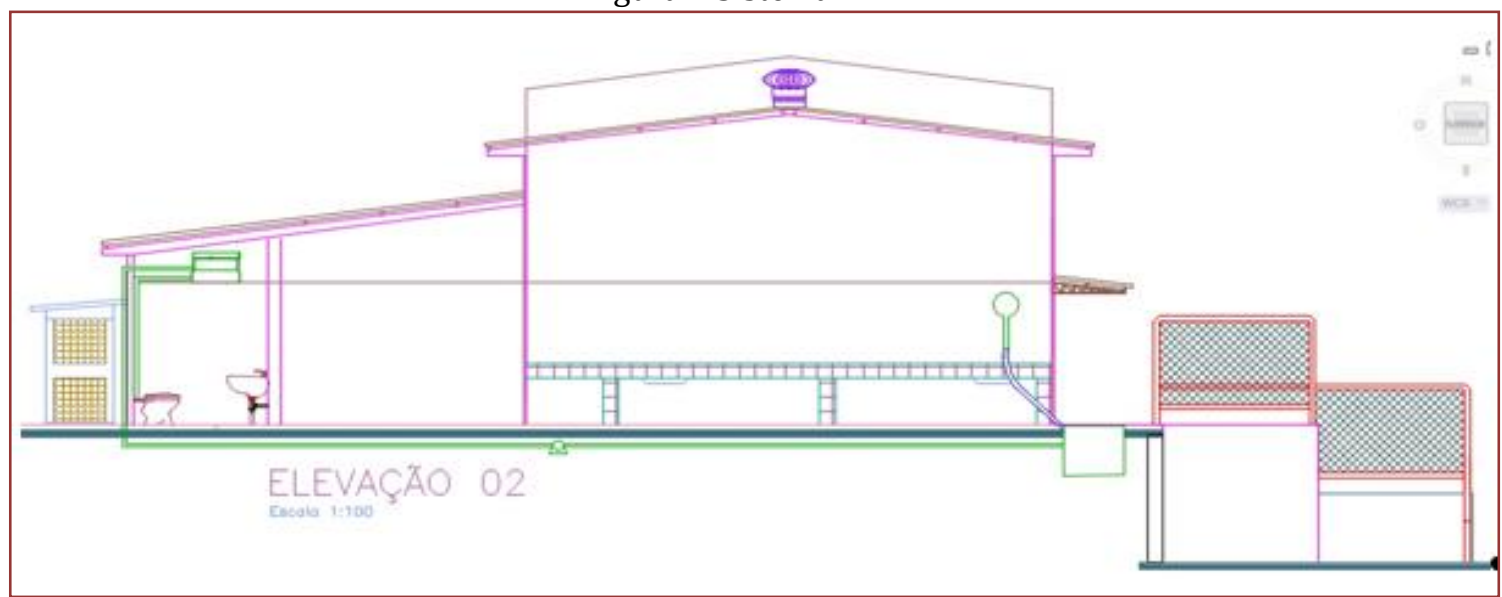

A segunda proposta é coletar o efluente em um reservatório por gravidade, e depois bombear essa água captada até um reservatório superior, de onde será enviada ao destilador. Neste sentido, a água captada será utilizada no processo de destilação. Vale mencionar que o tempo de transporte entre um reservatório e outro é suficiente para resfriar a água de reuso, antes de retornar ao processo. A figura 3 mostra o esboço do projeto hidráulico 2.

Figura 3 Sistema 2

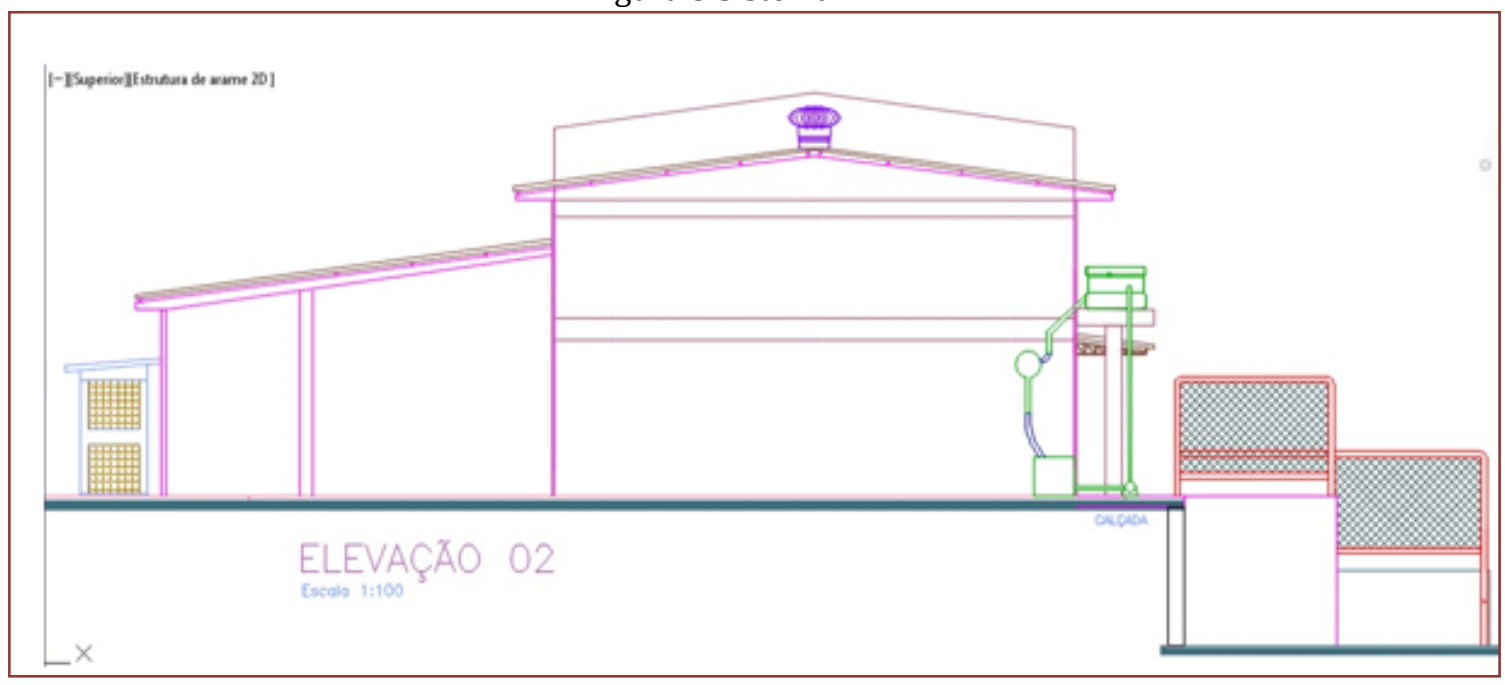




\subsubsection{DIMENSIONAMENTO DA BOMBA}

Para os dois sistemas foi escolhido a turbobomba tipo centrífuga. Para se determinar o tamanho da bomba e confirmar a escolha do tipo entrou-se com os valores da altura manométrica e vazão no catálogo de seleção fornecido pelo fabricante.

As especificações para confirmar a escolha da bomba para o sistema 1 estão dispostas na tabelas 3.

Tabela 3 Especificações para escolha da bomba para o sistema 1

\begin{tabular}{|l|c|}
\hline Vazão (m³/h) & 0,30 \\
\hline Altura de recalque (m) & 2,83 \\
\hline Altura de sucção (m) & 1,20 \\
\hline Comprimento da tubulação (m) & 20,05 \\
\hline Diâmetro da tubulação (mm) & 25,00 \\
\hline Altura manométrica (m.c.a.) & 4,10 \\
\hline
\end{tabular}

As especificações para confirmar a escolha da bomba para o sistema 2 estão dispostas na tabelas 4 .

Tabela 4 Especificações para escolha da bomba para o sistema 2

\begin{tabular}{|l|c|}
\hline Vazão (m³/h) & 0,3 \\
\hline Altura de recalque (m) & 2,0 \\
\hline Altura de sucção (m) & 0,0 \\
\hline Comprimento da tubulação (m) & 4,2 \\
\hline Diâmetro da tubulação (mm) & 25,0 \\
\hline Altura manométrica (m.c.a.) & 2,0 \\
\hline
\end{tabular}

Utilizando-se as especificações apresentadas nas tabelas 3 e 4 no catálogo do fabricante, pode-se enquadrar a turbobomba ao modelo BCR-2000 e motor WEG IP-00 com capa de proteção, proteção térmica e capacitor permanente, 2 polos, $60 \mathrm{~Hz}$ de $1 / 4 \mathrm{cV}$ de potência para os dois sistemas. Após a seleção do tipo, modelo e tamanho da bomba fez-se um levantamento aproximado dos custos de investimento para ambos os sistemas, levando-se em consideração os materiais necessários e a mão-de-obra. Os resultados estimados para o sistema 1 estão dispostos na tabela 5. 
Tabela 5 Levantamento de custos para o sistema 1

\begin{tabular}{|c|c|}
\hline Material & Valor $(\mathrm{R} \$)$ \\
\hline Cano PVC - 25 mm (21,55 m) & 42,42 \\
\hline Cotovelos (4) & 2,40 \\
\hline Caixa d'água (2000 L) & 791,91 \\
\hline Cisterna (5000 L) & $3.856,05$ \\
\hline Cimento (3 sacos) & 62,70 \\
\hline Turbobomba modelo BCR-2000 & 464,50 \\
\hline Torneira (Uso geral) & 82,33 \\
\hline Mão-de-obra & 500,00 \\
\hline Total & $5.802,31$ \\
\hline
\end{tabular}

Os resultados estimados para o sistema 2 estão apresentados na tabela 6.

Tabela 6 Levantamento de custos para o sistema 2

\begin{tabular}{|c|c|}
\hline Material & Valor $(\mathrm{R} \$)$ \\
\hline Cano PVC - 25 mm (4,2 m) & 8,27 \\
\hline Cotovelos (2) & 1,20 \\
\hline Reservatório de água (50 L) & 150,00 \\
\hline Cisterna (500 L) & 175,91 \\
\hline Cimento (10 sacos) & 209,00 \\
\hline Tijolos & 670,00 \\
\hline Areia $\left(1 \mathrm{~m}^{3}\right)$ & 95,00 \\
\hline Pedras $\left(1 \mathrm{~m}^{3}\right)$ & 85,00 \\
\hline Turbobomba modelo BCR-2000 & 464,50 \\
\hline Mão-de-obra & 200,00 \\
\hline Total & $2.2848,88$ \\
\hline
\end{tabular}

Pode-se observar pelas tabelas 5 e 6 que o custo de investimento para implementar o sistema 1 é maior comparado ao custo de investimento para o sistema 2. Isso se deve ao fato de que o sistema 1 demandaria de uma maior área de reforma, maior tempo de duração da obra, quebra de pisos, reservatórios de maiores capacidades, maior quantidade de materiais auxiliares, entre outros.

\subsection{ANÁLISES MICROBIOLÓGICAS}

Os resultados das análises microbiológicas estão dispostos na tabela 7. 
Tabela 7 Resultados obtidos a partir das análises microbiológicas

\begin{tabular}{|l|c|}
\hline \multicolumn{2}{|c|}{ Resultado } \\
\hline Coliformes Totais ${ }^{1,3}$ & Ausente \\
\hline Escherichia coli2 & Ausente \\
\hline
\end{tabular}

(1) Indicador de eficiência de tratamento; (2) Indicador de contagem fecal; (3) Indicador de integridade do sistema de abastecimento (reservatório e rede).

Pela Tabela 7 observa-se que o efluente gerado é livre de contaminação e está de acordo com a Portaria no 2914/11 do Ministério da Saúde, que indica os valores máximos permitidos de Coliformes Totais e Escherichia coli como ausentes em $100 \mathrm{~mL}$.

\subsection{ANÁLISES FÍSICO-QUÍMICAS}

Os resultados das análises de $\mathrm{pH}$, condutividade, sólidos totais presentes e cloro residual livre estão dispostos na tabela 8.

Tabela 8 Análises de pH, condutividade, sólidos totais e cloro residual livre

\begin{tabular}{|l|c|}
\multicolumn{1}{|c|}{ Parâmetro } & Resultados \\
\hline $\mathrm{pH}$ & $6,52 \pm 0,32$ \\
\hline Condutividade $(\mu \mathrm{S} / \mathrm{cm})$ & $133,9 \pm 0,1$ \\
\hline Sólidos totais $(\mathrm{mg} / \mathrm{L})$ & $0,0625 \pm 0,032$ \\
\hline Cloro residual livre $(\mathrm{mg} / \mathrm{L})$ & $1,05 \pm 0,416$ \\
\hline
\end{tabular}

A Portaria no 2914/11 do Ministério da Saúde afirma que é obrigatória a manutenção de no mínimo 0,2 $\mathrm{mg} / \mathrm{L}$ e no máximo $2,0 \mathrm{mg} / \mathrm{L}$ de cloro residual livre, para garantia da potabilidade. A mesma Portaria também indica um valor máximo de $1000 \mathrm{mg} / \mathrm{L}$ para sólidos totais, e $\mathrm{pH}$ entre 6,0 a 9,5. Para condutividade não há um valor máximo exigido pela legislação, porém adota-se como potável a água com condutividade inferior a $200 \mu \mathrm{S} / \mathrm{cm}$ (FUNASA, 2014). Portanto, pelos resultados apresentados na tabela 8 pode-se afirmar que o efluente analisado está dentro dos padrões de potabilidade exigidos pela legislação.

\section{CONSIDERAÇÕES FINAIS}

Os resultados das análises físico-químicas e microbiológicas mostraram que o efluente gerado está dentro dos padrões de potabilidade exigidos pela legislação, todavia, como não há manutenção periódica do equipamento, nem controle de contaminação, não foi proposto um sistema de reuso para fins potáveis. Conclui-se que o sistema 2 mostrou-se mais indicado, uma vez que exige menor recurso de investimento e apresenta maior facilidade de instalação.

\section{REFERÊNCIAS}

[1] Apha. Standard Methods for the examination of water and wastewater - American Public Health Association, American Water Works Association, Water Environmental Federation, 20th ed. Washington, 1998.

[2] Brasil. Ministério da Saúde. Portaria no. 2914 de 12 de dezembro de 2011. Disponível em: <http://www.saude.mg.gov.br/images/documentos/Portaria\%20No\%202.914,\%20DE\%2012\%20DE\%20dezembro\%20DE\%202011.pdf>.

[3] Çengel, Y. A.; Cimbala, J. M. Mecânica dos Fluidos - Fundamentos e Aplicações. Amgh Editora Ltda, 3aㅡ edição, 2015.

[4] IAL - Métodos físico-químicos para análise de alimentos - Edição IV - Instituto Adolfo Lutz, 2008. 
[5] Liu, Ariane; Giurco, Damien; Mukheibir, Pierre. Advancing household water-use feedback to inform customer behaviour for sustainable urban water. Water Supply, 17(1): 198-205, 2016.

[6] Maia, S. R. R. et al. Manual de Aulas Práticas de um laboratório de Química com Materiais Alternativos. Subprojeto PIBID/Química/FAEC-UECE, 2013.

[7] Maiolo, Mario; Pantusa, Daniela. A proposal for multiple reuse of urban wastewater. Journal of Water Reuse and Desalination, 8(4): 468-478, 2018.

[8] Marsaro, C. S. G.; Guimarães, P. C.. Avaliação da viabilidade de reutilização da água de refrigeração dos destiladores para lavagem de pipetas. I Simpósio de Recursos Hídricos do Norte e Centro-Oeste. Cuiabá, MS, 2007.

[9] Oliveira, L. H. Metodologia para a implantação de programa de uso racional de água em edifícios. Tese (Doutorado) - Escola Politécnica, Universidade de São Paulo, São Paulo, 1999.

[10] Peixinho, F. C. Gestão Sustentável de Recursos Hídricos. In: XVI Congresso Brasileiro de Águas Subterrâneas e XVII Encontro Nacional de Perfuradores de Poços, 2010.

[11] Pinto, A. C.; Capri, M. R.; Neto, A. C. Gestão de Água no Laboratório: Recuperação da água descartada dos destiladores. $2^{\circ}$ Congresso Internacional RESAG - Gestão da Água e Monitoramento Ambiental, 2015.

[12] Qian, Neng. Bottled Water or Tap Water? A Comparative Study of Drinking Water Choices on University Campuses. Water, 10(1), 59, 2018.

[13] Schaum, C; Lensch, D; Cornel, P. Water reuse and reclamation: a contribution to energy efficiency in the water cycle. Journal of Water Reuse and Desalination 5(2):83-94, 2015.

[14] Soares, A. E. P.; Nunes, L. G. C. F.; Silva, S. R. Diagnóstico dos Indicadores de Consumo de Água em Escolas Públicas de Recife - PE. Fórum Ambiental da Alta Paulista, Volume 13, número 1, 2017.

[15] Soares, A. M. M. Análise dos Consumos de Água em Edifícios Não Habitacionais. Faculdade de Engenharia da Universidade do Porto, Portugal, 2010.

[16] Sousa, W. D.; Oliveira, A. M. B. M.; Coelho, L. F. O. Aproveitamento do Potencial Hídrico de Fontes Alternativas em Benefício da Sustentabilidade de Campus Universitário da Cidade de pombal (PB). VII Congresso Brasileiro de Gestão Ambiental Campina Grande/PB, 2016.

[17] Zhang, Hongzhou. Sino-Indian water disputes: the coming water wars? Water, 3:155-166, 2016. 


\title{
Capítulo 20
}

Composição química de sementes de Sorgo (Sorghum bicolor L. Moench)

\author{
Antonio Daniel Buriti de Macedo \\ Ana Paula Moises de Sousa \\ Aline Priscila de França Silva \\ Alison Silva Oliveira \\ Jaciara Dantas Costa \\ Ana Regina Nascimento Campos
}

Resumo: O sorgo (Sorghum bicolor L. Moench) apresenta grande versatilidade no que diz respeito a seu uso e aproveitamento, podendo ser empregadas na alimentação humana e animal. Atualmente, a produção de sorgo assim como a área plantada vem aumentando progressivamente e, nessa perspectiva de crescimento da cultura, vem o aumento da demanda por sementes de alta qualidade. A composição química das sementes pode variar em função de diversos fatores, tais como fatores genéticos, condições ambientais, bem como os tratos culturais. Desta maneira, este trabalho teve como objetivo avaliar a composição físico-química de sementes de sorgo comercializadas para semeadura. Os experimentos foram conduzidos no Laboratório de Bioquímica e Biotecnologia de Alimentos da Universidade Federal de Campina Grande. As sementes de sorgo utilizadas foram adquiridas de lotes comercializados no município Campina Grande-PB e foram submetidas à caracterização físico-química, em triplicata, de acordo com a metodologia definida pelo Instituto Adolf Lutz. As sementes apresentam tratamento químico a fim de eliminar, controlar ou repelir microrganismo e pragas, sendo destinadas unicamente à semeadura. As sementes apresentaram teor de água de $11,73 \%$, ideal para 0 armazenamento, garantindo assim a qualidade para o plantio, teor de proteína bruta de $11,23 \%$, além de 1,46\% de resíduo mineral fixo e pH 6,63, valores semelhantes aos citados na literatura. As sementes analisadas apresentaram percentual de minerais superiores às sementes sem tratamento, destacando-se os teores de fósforo, potássio, magnésio e cálcio.

Palavras-chave: produção de sorgo, semeadura, armazenamento. 


\section{INTRODUÇÃO}

O sorgo, conhecido cientificamente como Sorghum bicolor L. Moench é originário da África e da Ásia. Apesar de ser uma cultura antiga, apenas a partir do final do século XIX a cultura começou a se expandir para várias regiões do mundo. No Brasil, o seu desenvolvimento se deu a partir da década de 70, especialmente nos estados de Rio Grande do Sul, São Paulo, Bahia e Paraná (ROSA, 2012).

Estudos apontam que este cereal passou a ser consumido por humanos e animais na África, entre $3.000 \mathrm{e}$ 5.000 anos atrás e, em seguida, se expandiu para a Índia e a China. Nos dias atuais, aproximadamente 35 $\%$ é cultivado diretamente para consumo humano e os outros $65 \%$ é destinado, sobretudo, para a alimentação animal (AWIKA; ROONEY, 2004).

O sorgo ocupa a quinta posição entre os cereais mais importantes no mundo, sendo antecedido pelo trigo, arroz, milho e cevada (TARDIN; RODRIGUES, 2008). No Brasil, o consumo do sorgo como alimento pela população é praticamente zero, sendo assim, o cultivo deste cereal é visando a produção de grãos, para abastecer a indústria de ração animal ou para a produção de forragem para alimentação de ruminantes. (QUEIROZ et al., 2014).

O sorgo apresenta grande versatilidade no que diz respeito a seu uso e aproveitamento. Seus grãos podem ser empregados na alimentação humana e animal, usados como matéria-prima para a produção de álcool, bebidas alcoólicas, colas, tintas, extração de açúcar de seus colmos e aplicação como forragens. Pode substituir em parte o milho na ração de aves e suínos e completamente para ruminantes, apresentando ainda vantagem quanto ao custo de produção (SILVA, 2010).

Segundo o Instituto Brasileiro de Geografia e Estatística - IBGE (2015), a avaliação da produção do sorgo no Brasil em 2015 foi de 2,1 milhões de toneladas com uma área plantada de 738.000 ha. Goiás é o maior produtor, com participação de $42,3 \%$ do total nacional a ser colhido.

Nos últimos anos a produção de sorgo assim como a área plantada vem aumentando progressivamente. Sendo assim, com essa perspectiva de crescimento da cultura, vem o aumento da demanda por sementes de alta qualidade. Segundo Nascimento; Dias e Silva, (2011) a qualidade das sementes utilizadas na semeadura influenciará diretamente no resultado final, desde o nascimento e crescimento até a produtividade.

A composição química das sementes pode variar em função de diversos fatores, como por exemplo; fatores genéticos, condições ambientais durante a formação da semente, bem como os tratos culturais (NUNES, 2016). Desta maneira, este trabalho teve como objetivo avaliar a composição química de sementes de sorgo (Sorghum bicolor L.) comercializadas para semeadura.

\section{METODOLOGIA}

Os experimentos foram conduzidos no Laboratório de Bioquímica e Biotecnologia de Alimentos da Universidade Federal de Campina Grande, Centro de Educação e Saúde (UFCG/CES). As sementes de sorgo (Sorghum bicolor L.) utilizadas foram adquiridas de lotes comercializados no município Campina Grande, Paraíba, Brasil.

As sementes empregadas nessa pesquisa são sementes tratadas destinadas unicamente à semeadura, não podendo ser usada na alimentação humana ou animal. 0 tratamento consiste na aplicação de substâncias químicas e/ou organismos biológicos nas sementes, a fim de eliminar, controlar ou repelir microrganismo e pragas. As sementes apresentavam, de acordo com o fabricante, $98 \%$ de pureza, germinação mínima de $80 \%$ e os produtos químicos utilizados foram pirimifos-mentil $(50 \%)$, bifenthrin $(2,5 \%)$, fludioxonil $(2,5 \%)$, matalaxil-M $(1,0 \%)$ e vermelho resin.

As sementes foram submetidas à caracterização físico-química, em triplicata, nos seguintes parâmetros:

- $\quad$ Teor de água

$\mathrm{O}$ teor de água das amostras foi determinado após secagem em estufa a $105^{\circ} \mathrm{C}$, até massa constante, de acordo com metodologia descrita em IAL (2008).

- $\mathrm{pH}$

A determinação do $\mathrm{pH}$ foi realizada através de medidas potenciométricas do líquido sobrenadante, em peagâmetro conforme metodologia descrita em IAL (2008). 


\section{- Resíduos minerais}

Para a determinação do resíduo mineral foi realizada uma incineração em mufla a $550{ }^{\circ} \mathrm{C}$, por 6 h, de acordo com a metodologia descrita em IAL (2008).

\section{- Proteína bruta}

0 método Kjeldahl, (Tedesco et al., 1995) foi utilizado para determinação de proteína bruta (PB). A determinação de proteína por esse método compreende por três etapas: digestão, destilação e titulação.

\section{- Determinação de Minerais}

Os minerais foram quantificados por Espectrômetro de Fluorescência de Raios-X por Energia Dispersiva; o equipamento utilizado foi o Shimadzu EDX-720.

\section{RESULTADOS}

As sementes de sorgo apresentaram teor de água médio de 11,73\% e massa seca de 88,27 \%, resultados próximos ao encontrados por Antunes et al. (2007) ao estudarem a composição bromatológica e parâmetros físicos de grãos de sorgo. De acordo com Silva et al. (2001) o teor de água alto pode causar prejuízo mecânico latente às sementes, no período da colheita, acarretando perda na qualidade. Segundo Fonseca (2008) o teor de umidade dos grãos pode reduzir sua atividade metabólica e a probabilidade de ataque de insetos, além de garantir melhor germinação e vigor da semente. Ainda ressalta que a umidade em grãos de sorgo não pode ultrapassar 15\%.

0 valor médio encontrado para o pH nas sementes de sorgo foi de 6,63. Com relação ao teor de proteína bruta, as sementes apresentaram valor médio de 11,23\%. 0 resultado encontrado para o percentual de proteína bruta foi inferior aos encontrados por Antunes et al. (2007) e por Antunes et al. (2008) ao determinarem composição bromatológica de diferentes genótipos de sorgo. No entanto, o valor de proteína bruta de grãos de sorgo encontrado na base de dados USDA, 10,62\%, é próximo ao encontrado nesse estudo.

0 resíduo mineral fixo estima a quantidade de minerais presentes na amostra. A amostra de sementes de sorgo apresentou 1,46\%. Quanto aos minerais presentes, destaca-se o fósforo, potássio, magnésio e cálcio, 566,2, 469,5, 396,3 e 69,8 mg/100g, respectivamente. Esses valores se apresentaram superiores aos mencionados por USDA (2017), que cita valores de $289 \mathrm{mg} / 100 \mathrm{~g}$ para fósforo, $363 \mathrm{mg} / 100 \mathrm{~g}$ para potássio, $165 \mathrm{mg} / 100 \mathrm{~g}$ para magnésio e 13,0 mg/100g para o cálcio. A diferença encontrada nos valores dos teores de minerais pode ser justificada pelo tratamento com agentes químico que as sementes analisadas sofreram antes de sua comercialização.

\section{CONCLUSÃO}

As sementes de sorgo comercializadas destinadas à semeadura e analisadas apresentaram teor de água $(11,73 \%$,) ideal para o armazenamento, garantindo assim a qualidade para o plantio. Apresentou teor de proteína bruta, além de resíduo mineral fixo e $\mathrm{pH}$ semelhantes a literatura. As sementes analisadas apresentaram percentual de minerais superior as sementes sem tratamento, destacando-se os teores de fósforo, potássio, magnésio e cálcio.

\section{REFERÊNCIAS}

[1] Awika, J. M.; Rooney, L. W. Sorghum phytochemicals and their potential aspects on human health. Phytochemistry, Elmsford, v. 65, p. 1199-1221, 2004.

[2] Antunes, R. C. et al. Composição bromatológica e parâmetros físicos de grãos de sorgo com diferentes texturas do endosperma. Arq. Bras. Med. Vet. Zootec., v.59, n.5, p.1351- 1354, 2007.

[3] Antunes, R. C. et al. Valor nutritivo de grãos de sorgo com diferentes texturas do endosperma para leitões. Arq. Bras. Med. Vet. Zootec., v.60, n.3, p.713-718, 2008.

[4] Instituto Brasileiro de geografia e Estatística - IBGE. Levantamento Sistemático da Produção Agrícola. IBGE, v. 29, n. 10, p. 1-97, 2015.

[5] Instituto Adolfo Lutz (São Paulo). Métodos físico-químicos para análises de alimentos. Coordenadores: Odair Zenebon; Neus Sadoco Pascuet \& Pablo Tigea. São Paulo, Ed. 4, 1a Edição Digital, 2008. 
[6] Nascimento, W. M.; Dias, D. C. F. S.; Silva, P. P. Qualidade fisiológica da semente e estabelecimento de plantas de hortaliças no campo. XI Curso sobre Tecnologia de Produção de Sementes de Hortaliças, p. 16, 2011.

[7] Nunes, J. L. S. Tecnologia de sementes - Conceitos, 2016. Disponível em: < https://www.agrolink.com.br/sementes/tecnologia-sementes/conceitos_361334.html Acesso em: 05 jun. 2017.

[8] Queiroz, V. A. V. et al. Potencial do sorgo para uso no alimentação humano. Informe Agropecuário, v. 35, n. 278, p. 7-12, 2014.

[9] Rosa, W. J. Cultura do Sorgo. Emater-MG, p. 6, 2012.

[10] Silva, T. T. A. Qualidade de sementes de sorgo (Sorghum bicolor L.) durante a maturação, secagem e armazenamento. [s.l.] Universidade Federal de Lavras, 2010.

[11] Silva, J. N.; Sobrinho, J. C.; Carvalho, J. A.; Dias, D. C. F. S.; Reis, F. P. Qualidade fisiológica de sementes de sorgo coletadas em diferentes pontos de um secador. Revista Brasileira de Engenharia Agrícola, Campina Grande, v. 5, p. 487-491, 2001.

[12] Tedesco, J. M. et al. Análise de solo, plantas e outros materiais, Porto Alegre, 1995.

[13] Tardin, F. D.; Rodrigues, J. A. S. Embrapa. Embrapa Milho e Sorgo. Versão Eletrônica, 4플. 2008.

[14] Usda - National Nutrient Database for Standard Reference. Disponível em: https://ndb.nal.usda.gov/ndb/search/list. Acesso em: 02 de jun. 2010. 


\section{Capítulo 21}

\section{Tratamentos para superação da dormência em sementes de palmito Juçara}

\section{Bruno Vinicius Daquila \\ Marcia Regina Royer}

Resumo: 0 Brasil é o país que mais produz, consome e exporta palmito, sendo aquele comercializado, extraído de forma extrativista, podendo levar a espécie à extinção. Desse modo, sendo necessária, a busca de tratamentos que aumentem a taxa de germinação da espécie Euterpe edulis (palmito Juçara), em consequência da quebra de dormência, agilizando um processo natural, o qual foi o objetivo desse trabalho. As sementes sofreram cinco tratamentos, além do controle, sendo: Testemunha; imersão em H2SO4 por 3 min.; imersão em HNO3 por 3 min.; imersão em HCl por 3 min.; imersão em H2SO4 por 5 min. e; imersão em H2SO4 por 7 min. 0 teste de germinação foi conduzido em câmara de germinação tipo Biochemical Oxigen Demand, com temperatura de $23{ }^{\circ} \mathrm{C}$ e fotoperíodo alternado de 5 horas luz / 19 horas escuro. Foram avaliados, o índice de velocidade de germinação (IVG), e a germinação (\%). Os dados do foram coletados diariamente pelo período total de 100 dias. Os dados coletados foram submetidos à análise de variância, e a comparação entre as médias, utilizando para isso, o teste de agrupamento Scott-Knott a 5\% de probabilidade. Os resultados revelaram que para quebra da dormência em sementes de E. edulis, os tratamentos utilizados não foram efetivos quando objetivados (\%) de germinação e IVG. Pelo contrário, alguns tratamentos prejudicaram a germinação natural da espécie. Esses resultados revelam a necessidade de novos testes em busca do aumento da \% germinação do palmito juçara.

Palavras-chave: Extinção. Espécie-florestal. Germinação. Euterpe-edulis. 


\section{INTRODUÇÃO}

Várias espécies de palmeiras produzem palmito comestível no Brasil, a mais conhecida em nosso país é a Euterpe edulis Mart; popularmente conhecida como palmito Juçara. Sua ocorrência desempenha um papel importante para a manutenção do ecossistema. Muito mais abundante durante o ano, é a mais saborosa e possui maior riqueza de nutrientes que as outras espécies, seus frutos e sementes servem de alimento para várias espécies de aves, roedores e mamiferos.

O Brasil é o maior produtor, consumidor e exportador de palmito do mundo, dentre as espécies, as palmeiras açaí (E. oleracea) e juçara (E. edulis), sendo $97 \%$ do palmito comercializado de origem extrativista, causando, desse modo, uma preocupação na sustentabilidade biológica e econômica (MORSBACH et al., 1998).

Intensamente derrubadas a partir do século 20 para delas ser aproveitado somente um vigésimo de sua imponente estrutura, o palmiteiro ocorrência no estrato médio da Floresta Ombrófila Densa, desde o sul da Bahia (15오) até o norte do Rio Grande do Sul (30S), com distribuição preferencial ao longo do litoral brasileiro, no domínio Florestal Tropical Atlântica, ocorrendo também na maior parte das formações Estacional Decidual e Semidecidual (REIS; REIS, 2000).

Atualmente a grande floresta que se estende ao longo do litoral, tem menos de $8 \%$ de área que tinha no ano de 1.500. Devido à sua qualidade superior, ainda é intensamente explorada de forma ilegal e predatória, deixando a espécie ameaçada de extinção na área do Rio Grande do Sul ao Espírito Santo. Considerado um dos produtos mais explorados na Floresta Tropical Atlântica, tem alto valor econômico como alimento, e sofre, em virtude disto, intenso extrativismo. Essa exploração contribui para a degradação do meio ambiente e tornou-se um fator de preocupação para a preservação da espécie, uma vez que não há rebrota após o corte para a extração do palmito (MORTARA; VALERIANO, 2001).

A exploração predatória deste produto além de uma atividade criminosa, também traz graves riscos à saúde do consumidor. A partir dos anos 90 , as leis ambientais, tornaram a exploração desta espécie restrita a um manejo florestal, sendo este o processo mais adequado para a exploração do palmiteiro. Dessa forma, além de evitar o risco de extinção da espécie, em seu estado natural, protege-se a fonte de renda de famílias inteiras que se dedicam a extração de produtos da floresta (PEREIRA, 2000).

A indiscriminada exploração do palmiteiro (E. edulis Mart.) em florestas nativas remanescentes, visando a extração do palmito, alcançou, nas últimas décadas níveis bastante críticos, reduzindo drasticamente a regeneração natural (NODARI; GUERRA, 1986). Levando em consideração o grande risco de extinção do palmiteiro existe a grande necessidade da preservação da espécie, bem como de plantio de reflorestamentos, este tem despertado maior interesse pela cultura e por seu estudo por parte de técnicos e pesquisadores da área (FIGLIORIA et al., 1987).

O desenvolvimento da semente é a resultante do processo de polinização, assim o embrião inicia seu desenvolvimento, sendo este controlado, ao atingir um determinado estágio, o embrião deixa de se desenvolver e entra em estado de dormência, ou seja, torna-se inerte, aguardando o momento biológico mais favorável para a continuidade de seu desenvolvimento. 0 impedimento estabelecido pela dormência se constitui numa estratégia benéfica, pela distribuição da germinação ao longo do tempo, aumentando a probabilidade de sobrevivência da espécie.

A germinação de sementes viáveis é definida pelos tecnologistas como a emergência e o desenvolvimento das estruturas essenciais do embrião, resultando na formação de uma plântula normal, sob condições ambientais favoráveis, é um fenômeno biológico cuja ocorrência é determinada por um conjunto de condições ambientais específicas (FILHO et al., 1986). As sementes de cerca de um terço das espécies germinam imediatamente em condições favoráveis, mas as demais apresentam algum grau de dormência (KRAMER e KLOZLOWSKI, 1972).

Segundo Kerbauy (2004) a dormência em sementes é um processo caracterizado pelo atraso da germinação, isso ocorre porque mesmo em condições favoráveis (umidade, temperatura, luz e oxigênio) não germinam.

O fenômeno de dormência em sementes vem de uma adaptação da espécie a condições ambientais para que ela germine, podendo ser muita ou pouca umidade, incidência de luz, baixa temperatura, entre outras. Este recurso é utilizado pelas plantas para germinarem na estação mais propicia ao seu desenvolvimento, buscando através disto a perpetuação da espécie (garantia de que alguns indivíduos se estabeleçam). Portanto, quando nos deparamos com este fenômeno há necessidade de conhecermos como cada espécie 
supera seu estado de dormência em condições naturais, para que através dele possamos buscar novas alternativas para uma germinação rápida e homogênea, este processo é chamado de quebra de dormência.

A padronização de métodos deve ser constantemente reavaliada, mediante a aplicação de testes de referência, alternativos e da determinação de novas metodologias (FORMOSO; ANDRADE, 1988).

É indiscutível a necessidade de tratamentos pré-germinativos. A germinação de suas sementes é do tipo hipógea, muito variada, dependendo de fatores internos e externos. 0 período da variação vai de 60 a 120 dias. A desigualdade na germinação pode ser atribuída, em parte, ao fato de que o processo de perda d'água, que não se manifesta uniformemente nas sementes individuais, que apresentam acentuadas variações em termos de peso, forma e volume (CARVALHO e MULLER, 1998, citados por LEDO et al, 2002). Para reduzir o período de formação das mudas, têm sido realizados estudos que contribuem no processo de aceleração da germinação.

Esta pesquisa teve como objetivo identificar técnicas que sejam viáveis para a produção de mudas de reflorestamento, assim como para os produtores do manejo florestal do palmiteiro, técnicas estas que apresentem um melhor resultado na quebra da dormência de sementes de E. edulis Mart; aumentando sua taxa de germinação e diminuindo sua perda pelo ataque de agentes biológicos do meio externo ao embrião.

\section{METOdOLOGIA}

Os tratamentos para quebra da dormência das sementes foram desenvolvidos no laboratório de química da Universidade Estadual do Paraná, campus Paranavaí - PR, no período de Setembro de 2015 a Abril de 2016. Paranavaí está localizado entre as coordenadas geográficas $23^{\circ} 04^{\prime} 36.48^{\prime \prime}$ de latitude sul e

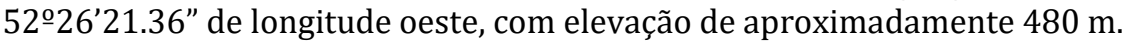

As sementes de E. edulis Mart; utilizadas para estes testes foram obtidas em Planalto- PR, em propriedade particular da pesquisadora. Após sua obtenção estas sementes foram mantidas sobre refrigeração para evitar o estresse com a alteração de temperatura até o início dos testes.

As amostras foram divididas em três repetições. Cada repetição foi composta de cinco tratamentos mais uma testemunha, sendo que cada parcela experimental constituída de 23 sementes. As sementes passaram pelos seguintes tratamentos:

- T1: testemunha;

- T2: imersão em H2SO4 - ácido sulfúrico por 3 min;

- T3: imersão em HNO3 - ácido nítrico por 3 min;

- T4: imersão em $\mathrm{HCl}$ - ácido clorídrico por 3 min;

- T5: imersão em H2SO4 - ácido sulfúrico por 5 min;

- T6: imersão em H2SO4 - ácido sulfúrico por 7 min.

Foram realizadas três repetições para minimizar o índice de erros da pesquisa. As sementes que foram imersas, após término do tempo estipulado, foram lavadas em água corrente com o auxílio de uma peneira metálica e acondicionadas sobre papel absorvente por um período de uma hora para absorção da maior parte da umidade, evitando assim a germinação de esporos de possíveis fungos presentes no laboratório. As amostras T1 não passaram por tratamento. Esta teve finalidade comparativa a fim de identificar possíveis melhorias na germinação do palmito.

Os tratamentos foram esquematizados em delineamento inteiramente casualizado. 0 plantio das amostras foi realizado em bandejas de isopor, específicas para germinação, tendo substrato comercial e, as sementes foram plantadas em uma profundidade de três centímetros.

0 teste de germinação foi conduzido em câmera de germinação tipo Biochemical Oxigen Demand (B.O.D.), regulado para a temperatura constante de $23^{\circ} \mathrm{C}$, e, com fotoperíodo de alternado 5 horas luz/ 19 horas escuro, utilizando lâmpadas fluorescentes tipo luz do dia $(4 \times 20 \mathrm{~W})$. Sua observação foi realizada diariamente pelo período de 100 dias, tomando-se nota de todas as observações efetuadas neste período 
de tempo. Foi avaliado o número de sementes germinadas, diariamente, tornando possível o cálculo do índice de velocidade de germinação (IVG), segundo Ferreira e Borghetti (2004), sendo:

$$
\mathrm{IVG}=(\mathrm{x} 1 / \mathrm{n} 1+\mathrm{x} 2 / \mathrm{n} 2+\ldots . .+\mathrm{xn} / \mathrm{nn})
$$

onde:

IVG: índice de velocidade da germinação/ emergência;

x: número de plantas contadas no dia n;

n: número dos dias de contagem após a semeadura.

Com base nos resultados finais foi obtida a taxa de germinação (\% G), representando a porcentagem de sementes germinadas em relação ao número de sementes dispostas a germinar sob determinadas condições experimentais.

Os dados serão submetidos à análise de variância e a comparação entre as médias serão realizadas através do teste de agrupamento do Scott-Knott a 5\% de probabilidade.

Após a avaliação dos parâmetros da germinação, as mudas foram transplantadas para saquinhos plástico preto contendo substrato comercial e terra, posteriormente foram mantidas em casa de vegetação, coberta com sombrite e regadas em dias intercalados. Essas mudas sofrerão os devidos tratos culturais, quando apresentarem $30 \mathrm{~cm}$ de altura serão plantadas no campus da universidade, fazendo parte do projeto do paisagismo.

\section{RESULTADOS E DISCUSSÃO}

Os resultados revelaram que para quebra de dormência das sementes de palmito juçara os tratamentos não se diferenciaram estatisticamente entre si para índice de velocidade de germinação (IVG), apesar dos valores variarem de 1,24 a 2,38, conforme se visualiza na tabela 1 . Esse resultado indica que os tratamentos utilizados, não melhoram a velocidade germinação, quando comparado as sementes controles. Segundo Maguire (1962), quanto maior o índice, maior será a velocidade de germinação das sementes.

Para a variável porcentagem de germinação ocorreu diferença estatística entre ele. As porcentagens de germinação variam de 5,55\% a 59,79\%. As sementes tratadas com ácido nítrico e ácido clorídrico, apresentaram germinação inferior estatisticamente quando comparada as sementes que não foram tratadas, ou seja, as sementes controle. Isso mostra que esses ácidos ou o tempo que foram utilizados, prejudicaram o embrião. Por outro lado, o tratamento em ácido sulfúrico, por 7 minutos, apresentou porcentagem de 59,79\%, mas esse valor estatisticamente é semelhante aos tratamentos T5, T2 e ao controle.

A dormência das sementes para ser efetiva como mecanismo de sobrevivência, deve variar entre os indivíduos e principalmente entre espécies (BIANCHETTI, 1989). Entretanto, na prática silvicultural o ideal é que sementes de uma espécie tenham germinação rápida e homogênea para produção de mudas (TORRES e SANTOS, 1994). Deste modo, a dormência das sementes torna-se um problema para o manejo florestal e métodos para sua superação devem ser utilizados. Neste estudo, foram observadas taxas germinativas e velocidade de germinação, semelhante ao controle. Desse modo, os testes utilizados, não contribuíram para um aumento de produção de mudas, sendo necessários novos testes, ou então, mudanças na temperatura da germinadora e na regulagem do fotoperíodo para a espécie estudada. 
Tabela 1. Porcentagem média dos valores totais de germinação e Índice de Velocidade da Germinação (IVG) de sementes de Palmito Juçara, submetidas a diferentes tratamentos para superação da dormência. Paranavaí, 2016.

\begin{tabular}{|c|c|c|}
\hline Tratamentos & Germinação (\%) & Vigor (IVG) \\
\hline Testemunha (T1) & $32,83^{\mathrm{a}}$ & $2,033^{\underline{a}}$ \\
\hline Imersão em H2SO4 - ácido sulfúrico por 3 min. (T2) & $46,95 a$ & $1,74^{\mathrm{a}}$ \\
\hline Imersão em HNO3 - ácido nítrico por 3 min. (T3) & $5,55 b$ & $1,24^{\mathrm{a}}$ \\
\hline Imersão em $\mathrm{HCl}$ - ácido clorídrico por 3 min. (T4) & $5,55 b$ & $1,29 \underline{a}$ \\
\hline Imersão em H2SO4 - ácido sulfúrico por 5 min. (T5) & $44,44^{\underline{a}}$ & $1,68^{\underline{a}}$ \\
\hline Imersão em H2SO4 - ácido sulfúrico por 7 min. (T6) & $59,79 \underline{a}$ & $2,38^{a}$ \\
\hline Média Geral & 32,52 & 1,72 \\
\hline $\mathrm{CV}(\%)$ & 30,00 & 27,90 \\
\hline
\end{tabular}

*Médias seguidas pela mesma letra, na coluna, não diferem significantemente entre si a 5\% de probabilidade pelo teste de agrupamento Scott- knott (1974)

\section{CONCLUSÃO}

Os resultados revelaram que para quebra de dormência das sementes de palmito Juçara os tratamentos não demostraram efeitos significativos para taxa de germinação e índice de velocidade de germinação (IVG). Pelo contrário, teve tratamento que prejudicou a germinação natural.Esses resultados revelam a necessidade de novos testes em busca de aumento da germinação do palmito juçara.

Apesar da existência de diversos trabalhos sobre germinação de sementes de espécies nativas, este número é, ainda, muito pequeno em relação a grande diversidade de espécies vegetais dos diferentes ambientes tropicais. Portanto, estudos sobre o potencial germinativo de espécies nativas, tornam-se essenciais para o desenvolvimento de técnicas de conservação, manejo e restauração dos ambientes naturais, bem como para o fornecimento de novos produtos para o setor agroindustrial.

\section{REFERÊNCIAS}

[1] BIANCHETTI, A. Tratamentos pré-germinativos para sementes florestais. $2^{\circ}$ Simpósio Brasileiro Sobre Tecnologia de Sementes Florestais. Anais...Atibaia, p. 237-274, 1989.

[2] FERREIRA, G., BORGHETTI, F. Germinação: do básico ao aplicado. Porto Alegre: Artmed, 2004. p. 3-30.

[3] FIGLIORIA, M.B.; OLIVEIRA, E.C.; YAMANZOE, G.; SIQUEIRA, A.C.M.F. Conservação de sementes de Euterpe edulis Mart., em diferentes embalagens e ambientes de armazenamento. Boletim técnico do Instituto Florestal, v.41, p.355-368, 1987.

[4] FILHO, J.M. Germinação de sementes. In: CÍCERO, S.M.; FILHO, J.M.; SILVA, W.S. Atualização em produção de sementes. Piracicaba: Fundação Cargill, 1986. p.11-39.

[5] FLEIG, F.D.; RIGO, S.M. Influência do Tamanho dos Frutos do Palmiteiro Euterpe edulis Mart. Na germinação das sementes e crescimento das mudas. Ciência Florestal, Santa Maria, v.8, n.1, p.35- 41, 1998,

[6] FORMOSO, A.M.T.; ANDRADE, R.N. Qualidade de sementes de hortaliças da região sul, 1988, Santa Maria, Anais... Santa Maria: Universidade Federal de Santa Maria, 1988. p.73-90.

[7] KERBAUY, G.B. Fisiologia Vegetal. 1aㅡ ed., Rio de Janeiro-RJ. Guanabara Koogan S.A., p. 404- 407. 2004.

[8] KRAMER, P.J.; KOZLOWSKI, T. Fisiologia das árvores. Lisboa: Fundação Calouste Gulbenkian, 1972.745 p.

[9] LEDO, A.S. MEDEIROS FILHO, S.; LEDO, F.J.S.; ARAÚJO, E.C. Efeito do tamanho da semente, do substrato e prétratamento na germinação de sementes de pupunha. Ciência Agronômica, v. 33, n. 1, p. 29-32, 2002.

[10] MORSBACH, N.; RODRIGUES, A.S.; CHAIMSOHN, F.P.; TREITNY, M.R. Pupunha para palmito: cultivo no Paraná. Londrina: IAPAR, 1998. 56 p. (IAPAR. Circular, 103).

[11] MORTARA, M.O.; VALERIANO, D.M. Modelagem da distribuição potencial do palmiteiro (Euterpe edulis Martius) a partir de variáveis topográficas. Anais...X SBSR, Foz do Iguaçu, 21-26 abril 2001, INPE, p. 459-471, Sessão Técnica Oral. 
[12] NODARI, R.O.; GUERRA, M.P. O palmiteiro no sul do Brasil: Situação e perspectivas. Useful palms of Tropical America, v.2, p.9-10, 1986.

[13] PEREIRA, L.B. A economicidade do palmiteiro (Euterpe edulis Martius) sob manejo em regime de rendimento sustentado. Sellowia, n.49/52, p.225-244, 2000.

[14] REIS, M.S.; REIS, A. Manejo sustentável do palmiteiro. In: REIS, M.S; REIS, A. Euterpe edulis Martius (Palmiteiro): biologia, conservação e manejo. Itajaí. Herbário Barbosa Rodrigues, 2000.

[15] TORRES, S.B.; SANTOS, D.S.B. Superação de dormência em sementes de Acacia senegal (L.) Willd. e Parkinsonia aculeata (L.). Revista Brasileira de Sementes, v.16, n.1, p. 54-57, 1994. 


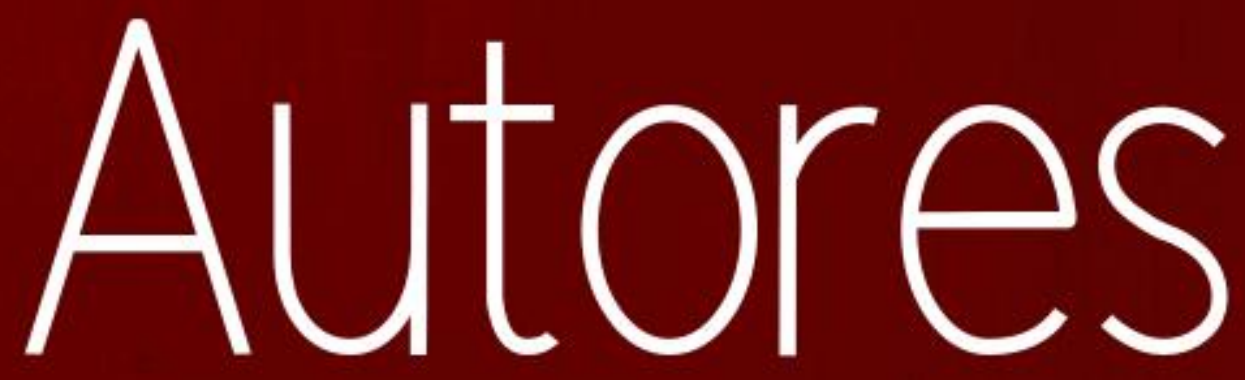




\section{ÁDINA LIMA DE SANTANA}

Engenheira de Alimentos (fevereiro de 2011), mestra em Engenharia Química (dezembro de 2012) pela Universidade Federal do Pará e doutora em Engenharia de Alimentos pela Universidade Estadual de Campinas (junho de 2017). Possui conhecimento nos ramos de pesquisa que envolvem tecnologia de fluidos supercríticos e líquidos pressurizados, aproveitamento de rejeitos, separação/caracterização/biotransformação de extratos e óleos vegetais, reologia de alimentos, análise da qualidade e segurança de alimentos processados, estudos de mercado de produtos alimentícios. Atualmente é pesquisadora de pós doutorado com bolsa Capes (Processo Seletivo PNPD) na Universidade Estadual de Campinas, UNICAMP.

\section{ADNA QUESIA COSTA DE OLIVEIRA}

Possui graduação em Engenharia de Alimentos pelo Instituto Federal de Educação, Ciência e Tecnologia de Mato Grosso - Campus Cuiabá - Bela Vista (IFMT). Acadêmico do curso de Zootecnia da Universidade Federal de Mato Grosso - UFMT.

\section{ALANA DE ALMEIDA OLIVEIRA}

Graduada em Engenharia de Alimentos (2017) pela Universidade Estadual de Maringá (UEM). Possui experiência industrial na área de Engenharia e Tecnologia de Alimentos, com ênfase em controle de qualidade no ramo de laticínios e atuou como auxiliar de laboratório no Laticínio Simionato (VidaAtiva), Terra Boa - PR. Atualmente exerce a função de analista de laboratório, com ênfase no controle de qualidade, nos Entrepostos Laticínios Latco na cidade de Cruzeiro do Oeste PR.

\section{ALEXSANDRA IARLEN CABRAL CRUZ}

Mestre em Microbiologia Agrícola pela Universidade Federal do Recôncavo da Bahia-UFRB. Tecnóloga em Alimentos pelo Instituto Federal de Educação, Ciência e Tecnologia do Maranhão IFMA. Técnica em Agroindústria pelo IFMA. Atuação no controle higiênico sanitário e qualidade físico-química de alimentos. Conhecimentos básicos em informática. Língua estrangeira: Inglês.

\section{ALINE PRISCILA DE FRANÇA SILVA}

Graduada em Licenciatura em Química Universidade Federal e Campina Grande centro de Educação e Saúde

\section{ALISON SILVA OLIVEIRA}

Possui Graduação em Licenciatura Plena em Química pela Universidade Federal de Campina Grande (UFCG), Centro de Educação e Saúde (CES). Linhas de estudo: Eletrodeposição de ligas metálicas, Corrosão, Difração de raios-X e caracterização de ligas metálicas.

\section{AMANDA CORREIA GARDENAL}

Estudante do curso de engenharia de alimentos na Universidade Tecnológica Federal do ParanáCampus Campo Mourão, participa do projeto de Extensão "Comendo Bem" e através da iniciação científica, estudou extratos brutos pra inibição do fungo Botrytis Cinerea.

\section{AMAURI GERALDO DE SOUZA}

Professor adjunto da Universidade Federal de São João Del Rei - Campus Sete Lagoas, doutor em Química Analítica pela (UFMG), com ênfase em análise de pesticidas e degradação (2011). Mestrado Multidisciplinar em Física, Química e Neurociência pela Universidade Federal de São João del Rei (2006). Licenciatura Plena em Química pela Universidade Federal de São João Del-Rei (2004). Tem experiência na área de Química Analítica, atuando principalmente nos seguintes 
temas: amostras ambientais, amostras comerciais, pesticidas, biodegradação e análise de hidrocarbonetos policíclicos aromáticos (HPAs), por cromatografia gasosa com detector de espectrometria de massas. Pesquisas em Ensino e Extensão na área de materiais e amostras ambientais, Sete Lagoas-MG.

\section{ANA LUIZA ALVES FARIA}

Mestranda em Engenharia Química pela Universidade Federal de São Carlos. Graduada em Engenharia Química pela Universidade Federal de Alfenas (2019) e graduada em Ciência e Tecnologia pela Universidade Federal de Alfenas (2016).

\section{ANA PAULA MOISES DE SOUSA}

Graduação em Licenciatura em Ciências Biológicas pela Universidade Federal de Campina Grande (2013) e mestrado em Ciências Naturais e Biotecnologia pela Universidade Federal de Campina Grande (2016). Atualmente, é aluna de doutorado no Programa de Pós-Graduação em Engenharia Agrícola. Tem experiência em iniciação à docência como monitora bolsista em genética geral. Participou de projetos de pesquisa na área de Biologia Molecular e Biotecnologia atuando nos seguintes temas: bioprospecção de genes, interação molecular planta-patógeno, fermentação semissólida, enriquecimento proteico e tecnologia de alimentos.

\section{ANA REGINA NASCIMENTO CAMPOS}

Possui graduação em Química Industrial pela Universidade Estadual da Paraíba (2000), mestrado em Engenharia Química pela Universidade Federal de Campina Grande (2003) e doutorado em Engenharia de Processos pela Universidade Federal de Campina Grande (2008). Professora Associada I da Universidade Federal de Campina Grande (UFCG/CCT/UAEQ). Tem experiência na área de Engenharia Química, com ênfase em Fermentação Semi Sólida e Eletrodeposição de ligas metálicas, atuando principalmente nos seguintes temas: fermentação semi-sólida, enriquecimento protéico, produtos farináceos, corrosão e eletrodeposição.

\section{ANA RITA ZULIM LEITE}

Graduanda no curso de Engenharia de alimentos pela Universidade Tecnológica Federal do Paraná- Campus Campo Mourão e participa do projeto de Extensão "Comendo Bem". Concluiu a iniciação científica na área de microbiologia de alimentos, em que foi analisado a ação de extratos brutos de plantas contra as cepas do fungo Botrytis cinerea.

\section{ANDRESA SOUSA CARVALHO}

Técnica em Alimentos, pelo Instituto Federal de Educação, Ciência e Tecnologia do Maranhão (IFMA) e Engenharia de Alimentos pela Universidade Federal do Maranhão (UFMA).

\section{ANTONIO DANIEL BURITI DE MACEDO}

Graduação em Licenciatura em Química pela Universidade Federal de Campina Grande (2016) e mestrado em Ciências Naturais e Biotecnologia pela Universidade Federal de Campina Grande (2018). Atualmente, é aluno de doutorado no Programa de Pós-Graduação em Engenharia de Processos pela Universidade Federal de Campina Grande. Tem experiência em iniciação à docência como monitor em Química Geral I. Participou de projetos de pesquisa na área de Química e Biotecnologia atuando nos seguintes temas: fermentação semissólida, enriquecimento proteico e tecnologia de alimentos. 


\section{ASTRÉA FILOMENA DE SOUZA SILVA}

Profa . Associada I no Departamento de Química da UFV - Viçosa - MG, trabalha com química de soluções, desenvolvimento, otimização e validação de métodos de separação, métodos espectrofotométricos, potenciométricos e voltamétricos aplicados a compostos de interesse agrícola e farmacológicos. Bel. Química (UFSCar), e MSc Q. Inorgânica (UFSCar); Drª Q. Q. Analítica (UNESP-Araraquara).

\section{BRUNA DEMARCHI}

Graduada em Gastronomia pela Universidade do Vale do Rio dos Sinos - UNISINOS, período 2017/02., com monitorias realizadas nas áreas de confeitaria e panificação. Atualmente atua como auxiliar de cozinha e microempreendedora na área de confeitaria.

\section{BRUNO VINICIUS DAQUILA}

Doutorando em Biotecnologia Ambiental, pela Universidade estadual de Maringá - UEM (2019 atual), Possuí título de mestre em Biotecnologia Ambiental, concedido pela Universidade Estadual de Maringá - UEM (2017-2019), especialização em Educação do Campo, concedido pela Faculdade de Educação, Ciências, Administração e Letras - FACEL (2017-2018) e Graduação em Ciências Biológicas - Licenciatura Plena, pela Universidade Estadual do Paraná - UNESPAR (2013-2017). Atualmente desenvolve estudos na área de Controle Biológico de organismos pragas, com ênfase em Diatraea saccharalis Fabricius, 1794 (Lepidoptera: Crambidae) e do entomopatógeno Bacillus thuringiensis (Bacillales: Bacillaceae), observando alterações na morfologia dos ovos, larvas, pupas, adultos e respostas celulares oriundas dos tratamentos.

\section{CAMILA MIKA SASSAI SATO}

Graduada em Engenharia de Alimentos pela Universidade Estadual de Maringá (2019). Atuação em projetos voluntários na área da educação pública (2018-2019). Experiência na área da qualidade microbiológica em processo cervejeiro no estágio obrigatório (2018-2019). Na Empresa Júnior de Projetos em Engenharia de Alimentos atividades na área de Gestão de Pessoas, capacidade em recrutamento e planejamento estratégico (2013-2016).

\section{CARLA ROSANE BARBOZA MENDONÇA}

Doutor em Química

\section{CARLA WEBER SCHEEREN}

Possui graduação em Química Industrial pela Universidade Federal de Santa Maria (2000), Mestrado em Química pela Universidade Federal de Santa Maria (2002), Doutorado em Química pela Universidade Federal do Rio Grande do Sul (2006), Pós-doutorado pela Université Louis Pasteur de Strasbourg França(2007) e Pós-doutorado pela Petrobras (2010). Atualmente é Professor Adjunto IV na Escola de química e alimentos da Universidade Federal do Rio GrandeCampus Santo Antônio da Patrulha e desenvolve pesquisas na área de Química, com ênfase em Nanomateriais, Suportes Sólidos, Biossensores, Catálise e Química Verde.

\section{CAROLINE DELLINGHAUSEN BORGES}

Doutor em Biotecnologia Agrícola

\section{CLEYTTON LUIZ BEZERRA DE PAULA}

Possui graduação em Engenharia de Alimentos pelo Instituto Federal de Educação, Ciência e Tecnologia de Mato Grosso - Campus Cuiabá - Bela Vista (IFMT). 


\section{DANIELLE CRISTINE SILVEIRA}

Engenheira de Alimentos, graduada pela Universidade Estadual de Maringá (2018). Atua como Gestora de Processos em uma indústria do ramo de corantes naturais.

\section{DANIELLI MATOS SANTIAGO}

Possui graduação em Engenharia de Alimentos Instituto Federal de Educação, Ciência e Tecnologia de Mato Grosso - Campus Cuiabá (2017),Pós-graduanda em Gestão de Negócios.

\section{DEYDYANE DOS SANTOS MOREIRA}

Tecnóloga em Alimentos pelo Instituto Federal de Ciência e Tecnologia do Maranhão IFMA. Conhecimentos básicos em informática, língua estrangeira: Inglês. Conhecimento em boas práticas de manipulação de alimentos.

\section{DORIVAL PEREIRA BORGES DA COSTA}

Possui graduação em Zootecnia pela Universidade Federal Rural do Rio de Janeiro (2005), mestrado em Zootecnia pela Universidade Federal Rural do Rio de Janeiro (2006) e doutorado em Zootecnia pela Universidade Estadual Paulista Júlio de Mesquita Filho (2009). Atualmente é docente da Universidade Federal de Mato Grosso e docente do Instituto Federal de Educação, Ciência e Tecnologia do Mato Grosso. Tem experiência na área de Zootecnia, com ênfase na Ciência e Tecnologia da Carne. Atua também na área de Gestão e Liderança Universitária.

\section{EDIMAR APARECIDA FILOMENO FONTES}

Possui graduação em Engenharia de Alimentos pela Universidade Federal de Viçosa (1994), mestrado (1997) e doutorado (2002) em Ciência e Tecnologia de Alimentos pela mesma universidade. Atuou como professora no Centro Federal de Educação Tecnológica de Rio Pomba e atualmente é professora do Departamento de Tecnologia de Alimentos da Universidade Federal de Viçosa. Tem experiência na área de Ciência e Tecnologia de Alimentos, com ênfase em Ciência e Tecnologia de Alimentos, atuando principalmente nos seguintes temas: Processamento de Alimentos, Conservação de Alimentos, Cinética de processos, Análise de Alimentos, Química de Alimentos e Estatística Experimental.

\section{EDIVALDO SAMPAIO DE ALMEIDA FILHO}

Possui graduação em Medicina Veterinária pela Universidade Federal Rural da Amazônia (1994), especialização em Inspeção de Alimentos pela UNESP (1996), mestrado em Medicina Veterinária Preventiva, pela UNESP (1998) e doutorado em Medicina Veterinária (Higiene Veterinária e Processamento Tecnológico de Produtos de Origem Animal) pela Universidade Federal Fluminense (2006). Atualmente é professor na Faculdade de Medicina Veterinária e Zootecnia (FAMEV) da Universidade Federal de Mato Grosso. Tem experiência na área de Medicina Veterinária, com ênfase em Higiene e Tecnologia de Pescado. Participa do Núcleo de Estudos em Pescado (NEPES) e orienta no Programa de Pós-Graduação em Ciência Animal (4 Capes) PPGCA.

\section{EDNA MARIA SILVA SANTOS}

Tecnóloga em Alimentos pelo Instituto Federal de Ciência e Tecnologia do Maranhão IFMA. Conhecimentos básicos em informática, língua estrangeira: Inglês, francês e espanhol. Conhecimento em boas práticas de manipulação de alimentos e rotinas administrativas.

\section{ELIEZER AVILA GANDRA}

Doutor em Ciência e Tecnologia Agroindustrial 


\section{ERIC MARSALHA GARCIA}

Doutor em Físico-Química pela Universidade Federal de Minas Gerais (UFMG) com bolsa do CNPq, atua nas áreas de eletroquímica, materiais semicondutores, anodos e catodos para a produção de hidrogênio além de reciclagem de pilhas íon-Li. Atua na área de química ambiental e descontaminação de poluentes orgânicos. Também atua na área de química analítica e atualmente é professor adjunto na Universidade Federal de São-João Del Rei.

\section{FÁBIA COSTA}

Possui graduação em ENGENHARIA DE ALIMENTOS pela Universidade Federal do Ceará (2012). Tem experiência na área de Ciência e Tecnologia de Alimentos, com ênfase em Supervisor de produção, consultoria em controle de qualidade e treinamentos. Com especialização de Gestão de Recursos Hídricos, Ambientais e Energéticos na UNILAB e Aperfeiçoamento em Docência na Educação Profissional pelo IFCE. Atualmente é coordenadora e professora do Curso Técnico em Agroindústria pelo CENTEC e é mestre em Tecnologia de Alimentos no IFCE- Campus Limoeiro do Norte.

\section{FABIANA DE MELO CALDEREIRO}

Graduada em Engenharia de Alimentos pela Universidade Estadual de Maringá (2015), Auditora Interna em APPCC pela Certifee (2018), Atualmente é Pós-Graduanda em MBA em Gestão da Produção pela Universidade Estadual de Maringá. Tem experiência nas áreas de garantia e controle de qualidade, planejamento e controle de produção e desenvolvimento de novos produtos. Supervisora de qualidade em indústria alimentícia desde 2017.

\section{FLÁVIA DE ABREU PINHEIRO}

Possui graduação em Engenharia de Alimentos pela Universidade Federal de Viçosa (2006), mestrado (2007) e doutorado (2018) em Ciência e Tecnologia de Alimentos pela mesma universidade. Atualmente é professora do Instituto Federal de Educação, Ciência e Tecnologia do Espírito Santo - Campus Venda Nova do Imigrante. Tem experiência na área de Ciência e Tecnologia de Alimentos, com ênfase em Análises Químicas de Alimentos, Gestão da Qualidade e Legislação de Alimentos.

\section{GABRIELA ALVES MACEDO}

Engenheira de Alimentos pela Unicamp, com Mestrado e Doutorado em Ciência de Alimentos pela Universidade Estadual de Campinas, pos doutorado na Universidade da Califorinia UC-Davis 20172018. Após o doutoramento, trabalhou na indústria como pesquisadora em multinacionais como a Degussa (SKW) e Rhodia na área de ingredientes de alimentos. Retornou para a Unicamp como docente em 2002 e atualmente é professora Livre Docente em Bioquímica dos Alimentos, na Faculdade de Engenharia de Alimentos. Profa. Macedo se dedica à pesquisa da produção de ingredientes e alimentos funcionais de alto valor agregado a partir de co-produtos e resíduos da agroindústria. $O$ foco é a prevenção de doenças e promoção da saúde; ingredientes e conservantes naturais; mecanismos celulares e moleculares de compostos bioativos ; bioquímica de alimentos e enzimologia. Foi ganhadora do grande prêmio Capes de Teses na area de Ciência de Alimentos em 2009 e já orientou mais de 30 alunos de mestrado e doutorado. Tem 5 patentes registradas e mais de 90 artigos publicados em revistas internacionais indexadas. Em 2013 foi agraciada com o Prêmio de reconhecimento acadêmico "Zeferino Vaz"pela Unicamp. Atualmente é coordenadora do lab de bioprocessos no departamento de alimentos e nutrição, dedicando ao desenvolvimento de extratos bioativos e testes de bioatividade in vivo e ex vivo com ênfase em alimentos funcionais e nutracêuticos. 


\section{GEODRIANE ZATTA CASSOL}

Possui graduação em Ciência e Tecnologia de Alimentos pela Universidade Federal de Mato Grosso (2017). Tem experiência na área de Ciência e Tecnologia de Alimentos, com ênfase em Tecnologia de Pescado. Atualmente é mestranda do Programa de Pós-Graduação em Nutrição, Alimentos e Metabolismo da Faculdade de Nutrição, Universidade Federal de Mato Grosso.

\section{GILMAR FREIRE DA COSTA}

Possui graduação em Agroindústria pela universidade Federal da Paraíba, Campus III, Bananeiras PB. Atualmente e estudante de pós-graduação em Tecnologia Agroalimentar pela Universidade Federal da Paraíba, Campus III, Bananeiras - PB. Trabalhou como bolsista de iniciação científica no período compreendido entre 2014-2015 pesquisando a viabilidade do uso de biopolímeros comestíveis a base de fécula de mandioca e amido de milho na conservação de queijo de coalho armazenado em refrigeração. Continuou como Bolsista de Iniciação Científica no período entre 2015-2016 pesquisando, "Produtos cárneos formulado com teores reduzido de sal com aplicação de substâncias bioativas como óleos essenciais de orégano (origanum vulgare l.) e alecrim (rosmarinus oficinalis)".

\section{GISELE CRISTINA DOS SANTOS BAZANELLA}

Graduada em Engenharia de Alimentos pela Universidade Estadual de Maringá (2007), Mestre em Engenharia Química pela Universidade Estadual de Maringá (2010) e Doutora em Ciência de Alimentos pela mesma Universidade (2013). Tem experiência na área de Engenharia de Alimentos e Engenharia Química. Docente de ensino superior desde 2010. Atua principalmente nos seguintes temas: operações unitárias, produção de enzimas, reaproveitamento de resíduos, separação com membranas, secagem e adsorção.

\section{HELEN COSTA SILVA-RODRIGUES}

Possui curso Técnico em Alimentos pelo Instituto Federal do Maranhão (2012), graduação em Engenheira de Alimentos pela Universidade Federal do Maranhão (2017), na qual durante a trajetória acadêmica participou de monitorias, representou a Instituição de Ensino participando de trabalhos e projetos de pesquisa e publicações, juntamente ao CNPq. Participou da Empresa Júnior de Engenharia de Alimentos no departamento de Marketing. Além de atuar na representação estudantil, fazendo parte do Centro Acadêmico. Atualmente, é discente do mestrado em Engenharia de Alimentos da Universidade Federal do Paraná, pesquisando sobre filmes biodegradáveis.

\section{HOSANE APARECIDA TARÔCO}

Professora adjunta na Universidade Federal de São João del Rei- Campus de Sete Lagoas. Possui doutorado em Química, área de concentração: Físico Química, pela Universidade Federal de Minas Gerais (UFMG), com ênfase em materiais cerâmicos (2009). Possui mestrado em Ciências, área de concentração Física: Teoria Quântica de Campos, pela UFSJ (2002). É licenciada em Química pela Universidade Federal de São João del-Rei , UFSJ, (2000). Tem experiência na área de Química de Materiais com ênfase em pilhas a combustível de óxido sólido (SOFC), atuando nos seguintes temas: síntese de materiais cerâmicos e eletroquímica.

\section{IASMIM PEREIRA DE MORAES}

Estagiária do almoxarifado químico, UTFPR-CM. Estudante de Engenharia de Alimentos UTFPR CM. Técnico em alimentos (2015). 


\section{IOLANDA CRISTINA CEREZA ZAGO}

Graduada em Engenharia de alimentos pela Universidade Estadual de Maringá (2016), Mestranda em Ciência de alimentos pela Universidade Estadual de Londrina. Possui experiência na indústria alimentícia nos setores de controle e gestão de qualidade, produção e pesquisa e desenvolvimento. Atualmente é supervisora da Garantia da Qualidade e Pesquisa e Desenvolvimento de uma fábrica de ração de aves, farinhas, óleos e unidade cerealista.

\section{JACIARA DANTAS COSTA}

Possui graduação em Engenharia de Alimentos pela Universidade Federal de Campina Grande (2015), Mestrado em Ciências Naturais e Biotecnologia pela Universidade Federal de Campina Grande (2018), Doutorado em Engenharia de Processos (UFCG) em andamento. Tem experiência na área de Engenharia de Alimentos, com ênfase em elaboração de novos produtos e fermentação semissólida, com as seguintes linhas de pesquisa: físico-química, microbiológica e analise sensorial de alimentos.

\section{JÉSSICA MARIA FERREIRA DE ALMEIDA DO COUTO}

Graduada em Engenharia de Alimentos (2015), Engenheira de Segurança do Trabalho (2019) e Mestre em Engenharia Química (2019) pela Universidade Estadual de Maringá. Atualmente está cursando doutorado em Engenharia Química pela mesma Universidade. Atua sobre os temas: Café, produtos cárneos, embalagens ativas, compostos ativos, reaproveitamento de resíduos, tecnologias de extração de óleos vegetais, materiais acústicos e segurança do trabalho.

\section{JOÃO CARLOS PALAZZO DE MELLO}

Professor Titular na Universidade Estadual de Maringá - UEM, e Coordenador do Laboratório de Biologia Farmacêutica - PALAFITO desde 1986. Realizou Mestrado em Ciências Farmacêuticas na Faculdade de Farmácia de Universidade Federal do Rio Grande do Sul e Doutorado em Ciências Naturais na Universidade de Münster, Alemanha. Professor Mello trabalha com taninos de espécies vegetais da Biodiversidade Brasileira.

\section{JORDÂNIA DE SOUSA GOMES}

Estudante de Administração pela Universidade Federal do Ceará (UFC). Atua como bolsista do Programa de Estímulo a Cooperação à Escola - PRECE / EIDEIA - UFC. Atua como monitora voluntária da disciplina da Teoria Geral da Administração - TGA. Técnica em Agroindústria. Membra do grupo de pesquisa em Finanças Comportamentais. Tem experiência na área de Ciência e Tecnologia de Alimentos, com ênfase em Ciência e Tecnologia de Alimentos. Seus últimos trabalhos tem destacado a Elaboração de biscoitos, tipo Cookies, efetuando a substituição de farinha de Trigo por farinha de Quinoa e Linhaça, sendo a linha de pesquisa voltada para a dieta de Celíacos. Foi estagiária no Hospital e Maternidade Regional Vale do Curu, durante 6 meses. Atuou como supervisora na preparação das refeições dos pacientes, além de realizar juntamente com a equipe responsável pela alimentação, treinamentos de Boas Práticas de Manipulação em ambiente Hospitalar, visando a segurança alimentar e o bem-estar dos pacientes internados.

\section{JORGE ANTÔNIO FERREIRA DE LARA}

Veterinário pela Universidade Estadual Paulista (Unesp Araçatuba, 1997), mestre e doutor em Ciência de Alimentos pela Universidade Estadual de Londrina (UEL, 2000 e 2003) e pós-doutorado em Biotecnologia Animal na Universidade de São Paulo (Esalq,/USP, 2004) Desde 2004 é pesquisador da Empresa Brasileira de Pesquisa Agropecuária (Embrapa) realizando pesquisas com foco em ciência da carne e bioquímica muscular. Atualmente é Chefe Geral da Embrapa Pantanal

\section{JOSELAINE DE SOUZA TEIXEIRA}

Graduada em Ciência e Tecnologia de Alimentos pela Universidade Federal de Mato Grosso. 


\section{JÚLIA AZEVEDO ZANINI}

Estudante de graduação do curso de Engenharia de Alimentos da Universidade Estadual de Campinas (Unicamp).

\section{JULIANA SCANAVACCA}

Mestrado em Microbiologia pela Universidade Estadual de Londrina (1998). Atualmente é Professora Assistente - D TIDE da Universidade Estadual de Maringá - UEM - Departamento de Tecnologia (DTC). Tem experiência na área de microbiologia, higiene dos alimentos, implantação em Sistema da Qualidade (ISO 9001) em Laboratórios, Boas Práticas de Manipulação em Serviços de Alimentação e Gestão da Segurança em Alimentos. Atua principalmente nos seguintes temas: análise microbiológica da água, análise microbiológica de ambientes, análise microbiológica de alimentos. Experiência em docência do Ensino superior nas áreas de microbiologia da água e alimentos, microbiologia geral, microbiologia aplicada e Higiene e Legislação em Alimentos

\section{JULIO ONÉSIO FERREIRA MELO}

Graduado em Farmácia pela Universidade Federal de Minas Gerais, doutorado em Ciências pela Universidade Federal de Minas Gerais. Professor e pesquisador Associado III da Universidade Federal de São João del Rei. Atua nas áreas de Fitoquímica, Química Farmacêutica e Farmacognosia e Química Orgânica. Coordenador dos Programas de Extensão de Ensino de Química. Coordenador de Projetos de Pesquisa nas áreas de Estudo de compostos voláteis de frutos por CG/MS; Estudo da composição química de frutos por ESI/MS e Paper Spray/MS; Estudo metabolômico de plantas por DESI/MS; Estudo da qualidade das águas. Professor colaborador e orientador no Programa de PósGraduação em Ciência de Alimentos(UFMG).

\section{JÚNIO GONÇALVES DA SILVA}

Possui formação de bacharel em Química (2017) e mestrado em Agroquímica com ênfase em sínteses orgânicas (2019) pela Universidade Federal de Viçosa - UFV. Atualmente é aluno de doutorado do programa de pós-graduação em Química na Universidade Federal de Minas Gerais UFMG. Possui experiência em análises voltamétricas, espectrométricas e espectroscópicas. Tem como principal linha de trabalho a síntese de compostos orgânicos com potencias atividades biológicas. Trabalha com reações de Diels-Alder, e síntese total de produtos naturais.

\section{KARINE ALMEIDA PAULA}

Técnica em Agroindústria, atuou no controle de qualidade de supermercados.

\section{LAIS CRISTINA DE LIMA SILVA}

Graduada em Engenharia de Alimentos pela Universidade Estadual de Maringá (2018). Mestranda não regular no programa de mestrado de ciência de alimentos- Universidade Estadual de Maringá cursando as seguintes disciplinas: Bioquímica de alimentos, Método de separação por membranas e Biofilmes em alimentos, pós- graduação em andamento em gestão da qualidade: Unifamma-EAD.

\section{LARA LIMA SECCÁDIO}

Graduação em Engenharia de Alimentos (2010) e Mestrado em Ciência e Tecnlogia de Alimentos (2013), pela Universidade Federal do Pará. Possui experiência na área de Ciência e Tecnologia de Alimentos, atuando com ênfase em tecnologia de produtos de origem vegetal, pós-colheita, alimentos funcionais, tecnologia de extrusão, transmissão oral da Doença de Chagas pelo açaí, e processos de fermentação espontânea. Atualmente, é professora EBTT do Instituto Federal de Ciência e Tecnologia do Pará, Campus Marabá Rural, onde atua também como coordenadora do Curso Técnico em Agroindústria - Subsequente - PRONERA, e Diretora de Pesquisa, Pós-graduação e Inovação Substituta. 


\section{LARISSA FERREIRA MORGANA SCOPEL}

Aluna do curso de Licenciatura em Ciências Exatas, com ênfase em Química na Universidade Federal do Rio Grande. Participou como monitora na disciplina de Química Geral Experimental I e II com dedicação exclusiva e atuou como bolsista de Iniciação Científica pelo Conselho Nacional de Desenvolvimento Científico e Tecnológico- CNPq no projeto de pesquisa; Membranas Biopoliméricas Contendo Nanopartículas de Platina Aplicada na Eliminação de Compostos Aromáticos de Combustíveis; e também atuou como bolsista de iniciação Científica pela Fundação de Amparo à Pesquisa do Estado do Rio Grande do Sul - FAPERGS no projeto; Difusão de nanocatalizadores em multicamadas de filmes finos poliméricos; sob a orientação da professora Dr.(a) Carla Weber Scheeren

\section{LEIDIANA DE SOUSA LIMA}

Mestre em Química Analítica pela Universidade Federal do Maranhão, Especialista em Ciência dos alimentos- UFPel. Química licenciada pela Universidade Cruzeiro do Sul. Química Industrial -UFMA. Técnica em Agroindústria- EAS-SL (IFMA). Técnica em Agroindústria do IFMA, lotada no campus Maracanã, desenvolvendo atividades de responsabilidades técnicas no departamento de produtos de origem animal e vegetal.

\section{LEILA LARISA MEDEIROS MARQUES}

Possui graduação em Farmácia - Habilitação em Indústria pela Universidade Federal do Paraná (2001), mestrado em Biotecnologia pela Universidade Estadual de Londrina (2004) e doutorado no Programa de Pós-graduação em Ciências Farmacêuticas da Universidade Estadual de Maringá (2016), na área de concentração em Produtos Naturais e Sintéticos Biologicamente Ativos. Atualmente é professora do Ensino Básico, Técnico e Tecnológico da Universidade Tecnológica Federal do Paraná, ministrando as disciplinas de Biotecnologia, Bioquímica Aplicada e Microbiologia de Alimentos para o curso de Engenharia e Tecnologia em Alimentos. Tem experiência na área de Bioquímica, Microbiologia e Fitoquímica. Chefe de Departamento de Alimentos da UTFPR, Campus Campo Mourão, desde Agosto/2019.

\section{LEONARDO HUNALDO DOS SANTOS}

Professor Adjunto III do curso de Licenciatura em Ciências Naturais com ênfase em Biologia da Universidade Federal do Maranhão, Campus de Imperatriz, onde também faz parte do Programa de Mestrado em Saúde e Tecnologia, além de coordenar o Projeto do Programa Institucional de Bolsas de Iniciação à Docência (PIBID). Atuou como Professor convidado do Programa de Pós-Graduação em Enfermagem da UFMA (São Luís-MA). Licenciado em Ciências Biológicas pela Universidade Estadual do Sudoeste da Bahia, Mestre e Doutor em Zootecnia com ênfase em Melhoramento Genético Animal pela Universidade Federal do Ceará. Possui experiência em Metodologia da Pesquisa Científica e Análise Estatística Aplicada. Atua em projetos de pesquisa nos seguintes temas: Genética, Melhoramento Genético, Estatística, Epidemiologia, Planejamento Experimental, Educação, Engenharia de Alimentos. Possui experiência em Ensino, tendo atuado nos níveis Fundamental, Pré-Vestibular, Técnico e Superior.

\section{LEONARDO LUIZ OKUMURA}

Possui formação de bacharel em Química pelo Instituto de Química da UNESP (2000), com mestrado (2003) e doutorado (2008) em Química Analítica pela mesma universidade. Atualmente é professor Associado II do departamento de Química da Universidade Federal de Viçosa e tem experiência na área de Química Analítica, com ênfase na análise de agroquímicos em diversas matrizes alimentícias, no desenvolvimento e aplicação de novos sensores e métodos voltamétricos e no desenvolvimento de novos protocolos experimentais para a determinação da capacidade antioxidante de algumas substâncias. 


\section{LIZIANE DANTAS LACERDA}

Química, especialista em Ciência e Tecnologia de Alimentos, mestre em Físico Química e doutora em Ciência dos Materiais pela UFRGS. Profissional com mais de 15 anos de experiência em indústria química e alimentícia. Atualmente atua como consultora nas áreas de desenvolvimento de produto e controle de qualidade, pesquisadora associada do Instituto Tecnológico em Ensaios e Segurança Funcional (itt Fuse) e professora dos cursos de Graduação em Engenharia de Alimentos e Química, Gastronomia e Nutrição da Universidade do Vale do Rio dos Sinos - UNISINOS.

\section{LUCIANA KIMIE SAVAY-DA-SILVA}

Possui graduação em Ciências dos Alimentos (2006), mestrado em Ciência e Tecnologia de Alimentos (2009) pela Escola Superior de Agricultura Luiz de Queiroz (ESALQ/USP) e doutorado em Química na Agricultura e no Ambiente, pelo Centro de Energia Nuclear na Agricultura (CENA/USP). Tem experiência na área de Ciência e Tecnologia de Alimentos, com ênfase em avaliação e controle de qualidade de pescado e seus coprodutos; análises físico-químicas, microbiológicas e sensoriais. Trabalhou de 2006 a 2013 no Laboratório de Pescado da Universidade de São Paulo e atualmente é professora Adjunta do curso de Ciência e Tecnologia de Alimentos, da Universidade Federal do Mato Grosso e orienta nos programas de pós-graduação em Ciência Animal e Nutrição, Alimentos e Metabolismo.

\section{MAICON ROLDÃO BORGES}

Aluno de graduação da Universidade Federal do Rio Grande no curso: Engenharia AgroindustrialAgroquímica, trabalhando com o projeto de pesquisa Difusão de Nanocatalisadores em Multicamadas de Filmes finos Poliméricos iniciado em 2015 sendo orientado pela Prof. Dra Carla Weber Scheeren com o apoio da Fundação de Amparo à Pesquisa do Estado do Rio Grande do SulFAPERGS, na mesma instituição foi bolsista de iniciação cientifica, no projeto de pesquisa \&quot;Menbranas Biopoliméricas contendo Nanopartículas de Platina Aplicada na Eliminaç̧ão de Compostos Aromáticos de Combustíveis; sendo bolsista do Conselho Nacional de Desenvolvimento Científico e Tecnológico- CNPq.

\section{MÁRCIA REGINA FERREIRA GERALDO PERDONCINI}

Doutorado (2009) e Mestrado (2004) em Ciências Biológicas (Biologia Celular) na área de Química e Fisiologia de Microrganismos pela Universidade Estadual de Maringá. Especialização em Farmácia de Dispensação (1996) e Graduação em Farmácia Bioquímica pela Universidade Estadual de Ponta Grossa (1995). Professora das disciplinas de Microbiologia I, Microbiologia de Alimentos e Microscopia do curso superior de Tecnologia em Alimentos e as disciplinas de Microbiologia Geral e Microbiologia de Alimentos do curso superior de Engenharia de Alimentos da Universidade Tecnológica Federal do Paraná.

\section{MARCIA REGINA ROYER}

Possui graduação em Ciências Biológicas pela Universidade Estadual de Maringá (1996), mestrado em Agronomia (Melhoramento Genético Vegetal) pela Universidade Estadual de Maringá (1999) e doutorado em Agronomia (Melhoramento Genético Vegetal) pela Universidade Estadual de Maringá (2004). Professora Associada A, da Universidade Estadual do Paraná -Campus Paranavaí (UNESPAR), Colegiado de Ciências Biológicas. Atua na área de genética e ensino, orientando PIBIC, PIBID e Mestrado. Coordenadora do subprojeto de Ciências/ Biologia do Programa Institucional de Bolsa de Iniciação a Docência (PIBID). Professora e orientadora do Mestrado em Ensino: Formação Docente Interdisciplinar, UNESPAR - Campus Paranavaí. 


\section{MARINA CORRÊA DA COSTA ABREU}

Bacharel em Ciência e Tecnologia de Alimentos e Mestre em Ciência Animal pela Universidade Federal de Mato Grosso (UFMT). Atualmente atua como professora substituta da Faculdade de Nutrição da Universidade Federal de Mato Grosso, lecionando as disciplinas de Análise Microbiológica de Alimentos, Alimentos Transgênicos, Avaliação Biológica de Alimentos e Tecnologia de cana de açúcar e mel.

\section{MAURIELEN GUTERRES DALCIN}

Possui graduação em Engenharia Química pela Universidade Federal de Santa Maria (2006), mestrado em Engenharia Química pela Universidade Federal de Uberlândia (2009) e doutorado em Engenharia Química pela Universidade Federal de Uberlândia (2013) . Atualmente é professora de Engenharia Química na Universidade Federal de Alfenas/Campus Poços de Caldas.

\section{NUBERLENE FERREIRA CARVALHO}

Tecnóloga em Alimentos pelo Instituto Federal de Ciência e Tecnologia do Maranhão IFMA. Conhecimentos básicos em informática, língua estrangeira: Inglês. Conhecimento e experiência em análises físico-químicas de alimentos.

\section{OTÁVIO BUGONI}

Estudante de Engenharia Agroindustrial - Agroquímica na Universidade Federal do Rio Grande FURG. Atuou como bolsista de pesquisa no projeto; Difusão de Nanocatalisadores em multicamadas de filmes finos poliméricos\&quot; sob a orientação da Prof. ${ }^{\text {a }}$ Dr. ${ }^{\text {a }}$ Carla Weber Scheeren entre os anos de 2015 e 2016

\section{PAULA ANDRE BORBA}

Graduada em ciência e tecnologia (2016) e Engenharia Química (2018) pela Universidade Federal de Alfenas (UNIFAL-MG). Atualmente trabalha no setor de qualidade em uma empresa de cereais.

\section{PEDRO BITENCOURT}

Graduado em Engenharia de Alimentos pela Universidade Estadual de Maringá (2019). Experiência como monitor nas matérias de Estatística (2014-2015) e Refrigeração (2017). Estágio obrigatório em Cervejaria Artesanal durante 5 meses (2018) na área do processo cervejeiro e suas etapas. Iniciou o atual emprego de Analista da Qualidade na empresa Alltech do Brasil, em São Pedro do Ivaí em Agosto de 2019.

\section{PÉRSIA BARCELLOS CARRASCO}

Mestre em Nutrição e Alimentos

\section{RAFAEL RESENDE ASSIS SILVA}

Graduado em Engenharia de Alimentos pela Universidade Federal de São João Del Rei - UFSJ (2018). Atualmente é estudante de mestrado em Ciência e Tecnologia de Alimentos pela Universidade Federal de Viçosa - UFV. Tem experiência na área de embalagens de alimentos com ênfase em embalagens ativas, filmes antimicrobianos, microencapsulação por Freeze-Drying e Kneading, caracterização de materiais, impressão molecular polimérica, quimiossensores e toxicidade de plantas por meio do bioensaio com Artêmia Salina. 


\section{RITA DE CÁSSIA BERGAMASCO}

Possui graduação em engenharia química pela Universidade Estadual de Maringá(2000), mestrado em Engenharia Química pela Universidade Estadual de Maringá(2002) e doutorado em Engenharia Química pela Universidade Estadual de Maringá(2006). É professora adjunta do Depto de Eng. de Alimentos da Universidade Estadual de Maringá. Tem experiência na área de Engenharia Química e Engenharia de Alimentos, atuando principalmente nos seguintes temas: ciclodextrina, microencapsulação, extração de mucilagens de plantas.

\section{ROBSON ROGÉRIO PESSOA COELHO}

Possui graduação em Engenharia de Alimentos pela Universidade Federal da Paraíba (1994), mestrado em Engenharia Agrícola pela Universidade Federal da Paraíba (2000) e doutorado em Agronomia pela Universidade Federal da Paraíba (2006). Atualmente é professor do ensino básico, técnico e tecnológico da Escola Agrícola de Jundiaí / Universidade Federal do Rio Grande do Norte. Tem experiência na área de Ciência e Tecnologia de Alimentos, com ênfase em Ciência e Tecnologia de Alimentos, atuando principalmente nos seguintes temas: frutas, produção, pós-colheita, processamento, sementes (germinação e vigor).

\section{RONI ANTONIO MENDES}

Graduado em Farmácia-Bioquímica pela UNIFAL-MG (1997). Mestre em Química Analítica pela UNESP-Araraquara (1999). Doutor em Química pela UNESP-Araraquara (2004). Especialista em Farmácia Clínica pela UNIRP - São José do Rio Preto (2005). Cursando MBA em Finanças e Banking na FMU - SP. 21 anos de experiência docente no Ensino Superior. Autor do livro Fundos de Investimento Imobiliário- Aspectos Gerais e Princípios de Análise (2018).

\section{SAMUEL DE OLIVEIRA SANTOS}

Técnico em Agroindústria. Graduando em Agronomia pela Universidade da Integração Internacional da Lusofonia Afro-Brasileira (UNILAB). Possui experiência na área de educação ambiental e agroecologia em comunidades carentes de Redenção - CE.

\section{SHANISE LISIE MELLO EL HALAL}

Doutora em Ciência e Tecnologia Agroindustrial

\section{SOLANGE DE SOUSA}

Possui graduação em Engenharia de Alimentos pela Universidade Federal da Paraíba, mestrado em Ciência e Tecnologia de Alimentos pela Universidade Federal da Paraíba e Doutorado em Ciência de Alimentos pela Universidade Federal de Viçosa-MG. Atualmente é Professora Adjunta do Departamento de Gestão e Tecnologia Agroindustrial, do Centro de Ciências Humanas, Sociais e Agrárias, da Universidade Federal da Paraíba. Tem experiência na área de Ciência e Tecnologia de Alimentos, com ênfase em Embalagem de Alimentos, Microbiologia de Alimentos, Higiene e Sanitização de Alimentos, atuando principalmente nos seguintes temas: tecnologia de panificação, pesquisa de micro-organismos, desenvolvimento e utilização de embalagens comestíveis. Atualmente é Coordenadora do Programa de Pós-Graduação em Tecnologia Agroalimentar (PPGTA), do CCHSA/UFPB. Professora permanente do Programa de Pós-Graduação em Ciências Agrárias/Agroecologia (PPGCAG)/CCHSA/UFPB.

\section{SUELEN PEREIRA RUIZ HERRIG}

Graduada em Tecnologia em Alimentos pela Universidade Estadual de Maringá (2009). Mestrado em Ciência de Alimentos pela Universidade Estadual de Maringá (2012) e Doutorado em Ciência de Alimentos pela Universidade Estadual de Maringá (2016). Possui experiência na área de Ciência e Tecnologia de Alimentos, atuando principalmente sobre os seguintes temas: Microbiologia de Alimentos, e Biotecnologia de alimentos e aproveitamento de subprodutos agroindustriais. 
Atualmente é professora adjunta dos cursos de Engenharia de Alimentos e Tecnologia em Alimentos da Universidade Estadual de Maringá.

\section{TAYZA FERREIRA ROSENO}

Possui graduação em Ciência e Tecnologia de Alimentos pela Universidade Federal de Mato-Grosso (UFMT). Tem experiência na área de Ciência e Tecnologia de Alimentos, com ênfase em análises físico-químicas, microbiológicas e sensoriais; desenvolvimento de produtos a base de pescado. Trabalhou de 2013 a 2016 no Laboratório de Bromatologia (Ciência dos Alimentos) da Universidade de Cuiabá (UNIC). Mestranda no Programa de Pós-Graduação em Ciência e Tecnologia de Alimentos pelo Instituto Federal de Mato Grosso (IFMT)

\section{VALERIA SOUSA MOTA}

Tecnóloga em Alimentos pelo Instituto Federal de Ciência e Tecnologia do Maranhão IFMA. Conhecimentos básicos em informática, língua estrangeira: Inglês. Conhecimento em boas práticas de manipulação de alimentos

\section{VICTOR VERÍSSIMO CARDOSO LIMA}

Doutorando em Engenharia Química pela Universidade Federal do Rio Grande do Sul, Mestre em Engenharia Química (2019) pela Universidade Federal de Santa Maria, Engenheiro de Alimentos (2017) pela Universidade Federal do Maranhão e Técnico em Alimentos (2011) pelo Instituto Federal de Educação, Ciência e Tecnologia do Maranhão. Atuou em pesquisas nas áreas de Ciência e Tecnologia de Alimentos, com ênfase em Tecnologia e Qualidade de Produtos de Origem Animal e Vegetal, e Química Orgânica, com ênfase em Química de Produtos Naturais. Atualmente atua em pesquisas relacionadas ao tratamento de efluentes líquidos e processos de separação, adsorção, biossorção.

\section{VIRLANE KELLY LIMA HUNALDO}

Possui graduação em Engenharia de Alimentos pela Universidade Federal do Ceará (2005), mestrado em Ciência e Tecnologia de Alimentos pela Universidade Federal do Ceará (2008) e doutorado em Ciência e Tecnologia de Alimentos pela Universidade Federal do Ceará (2013). Atualmente é professor adjunto da Universidade Federal do Maranhão. Tem experiência na área de Ciência e Tecnologia de Alimentos, com ênfase em Tecnologia de Alimentos, atuando principalmente nos seguintes temas: Processamento de frutas, aproveitamento integral de alimentos.

\section{WILLIAN PINHEIRO SOARES}

Possui graduação em Engenharia de Alimentos Instituto Federal de Educação, Ciência e Tecnologia de Mato Grosso - Campus Cuiabá (2016), mestrado em Engenharia de Alimentos Instituto Federal de Educação, Ciência e Tecnologia de Mato Grosso - Campus Cuiabá . 
